\title{
Pyrazolbasierte zweikernige Zink(II)-Komplexe als Modellsysteme zum Verständnis der Rolle des Zinks in enzymatischen Reaktionen
}

\author{
Dissertation \\ Zur Erlangung des Doktorgrades \\ der Mathematisch-Naturwissenschaftlichen Fakultäten \\ der Georg-August-Universität zu Göttingen \\ vorgelegt von \\ Diplom-Chemiker \\ Miguel Alvariño Gil \\ aus Viveiro (Lugo) \\ (Spanien)
}

Göttingen 2006 
D 7

Referent: Prof. Dr. Franc Meyer

Korreferent: Prof. Dr. Jörg Magull

Tag der mündlichen Prüfung: Mittwoch, 1. November 2006 
Ich erkläre hiermit an Eides statt, dass ich diese Arbeit selbständig und ohne unerlaubte Hilfsmittel angefertigt habe. 
Die vorliegende Arbeit entstand im Zeitraum von November 2002 bis Juni 2006 unter Anleitung von Herrn Professor Dr. Franc Meyer am AnorganischChemischen Institut der Georg-August-Universität Göttingen. 


\section{Inhaltsverzeichnis}

1 Einleitung 1

2 Kenntnisstand _ 6

2.1 Zinkhaltige Enzyme __ 6

2.2 Metallhydrolasen _ 7

2.2.1 Zink, ein Baustein für Hydrolasen ___ 8

2.2.2 Carboxypeptidasen __ 9

2.2.2.1 Carboxypeptidase A _ 10

2.2.2.2 AHL-Lactonase___ 11

2.2.3 Aminopeptidasen__ 14

2.3 Ligandsysteme für dinukleare und tetranukleare Komplexe:

Brückenliganden

2.4 Pyrazol als Brückenligand für dinukleare und tetranukleare Metallkomplexe

3 Ligandsynthese__ 24

3.1 Eigenschaften der Pyrazolat-Liganden __ 24

3.2 Synthese der 3,5-Bis(aminomethyl)pyrazol-Liganden__ 26

3.2.1 Mehrstufensynthese der 3,5-difunktionellen Pyrazol-Schlüsselsubstanz ___ 26

3.2.2 Darstellung der Amine für die Pyrazol-Seitenarme ___ 27

3.2.3 Synthese der Liganden ___ 31

\section{Pyrazolatodizinkkomplexe (Darstellung, Strukturen und} spektroskopische Daten) __ 33

4.1 Allgemeine Komplexsynthese und Festkörperstrukturen _ 33

4.2 Zink(II)-Pyrazolatokomplexe _ 35

4.2.1 Coligand: Acetat _ـ 35

4.2.1.1 Zink(II)-Komplex des Liganden $L^{1}$ - Synthese von $\left[\mathrm{L}^{1}{ }_{-\mathrm{H}}\left(\mu-\mathrm{CH}_{3} \mathrm{COO}\right) \mathrm{Zn}_{2}\right]\left(\mathrm{ClO}_{4}\right)_{2}(\mathbf{1 a})$ und (1b)

4.2.1.2 Zink(II)-Komplex des Liganden $\mathrm{L}^{4}$ - Synthese von $\left[\mathrm{L}^{4}{ }_{-\mathrm{H}}\left(\mu-\mathrm{CH}_{3} \mathrm{COO}\right) \mathrm{Zn}_{2}\right]\left(\mathrm{ClO}_{4}\right)_{2}(2)$ 35

4.2.1.3 Zink(II)-Komplex des Liganden $\mathrm{L}^{3}$ - Synthese von $\left[\mathrm{L}^{3}{ }_{-\mathrm{H}}\left(\mu-\mathrm{CH}_{3} \mathrm{COO}\right) \mathrm{Zn}_{2}\right]\left(\mathrm{ClO}_{4}\right)_{2}(3) \_42$

4.2.1.4 Zink(II)-Komplex des Liganden $\mathrm{L}^{7}$-Synthese von $\left[\mathrm{L}^{7}{ }_{-\mathrm{H}}\left(\mu-\mathrm{CH}_{3} \mathrm{COO}\right) \mathrm{Zn}_{2}\right]\left(\mathrm{ClO}_{4}\right)_{2}(4) \ldots 46$

4.2.1.5 Zink(II)-Komplex des Liganden $\mathrm{L}^{6}$ - Synthese von $\left[\mathrm{L}^{6}{ }_{-\mathrm{H}}\left(\mu-\mathrm{CH}_{3} \mathrm{COO}\right) \mathrm{Zn}_{2}\right]\left(\mathrm{ClO}_{4}\right)_{2}(5) \_49$

4.2.2 Schwingungen der Carbonylgruppe der Komplexe 1 bis $5 \ldots 52$

4.3 Spektroskopische Untersuchungen _ـ 53

4.3.1 Aktivität der Pyrazolatodizinkkomplexe in der Esterhydrolyse___ 53 
4.3.1.1 Metallverbindungen als Modelle für Esterhydrolasen___ 53

4.3.1.2 Modellsubstrate für die Spaltung aktiver Ester___ 55

4.3.1.3 Kinetische Untersuchung der Hydrolyse von p-Nitrophenylacetat____ 56

4.3.1.4 Abhängigkeit der p-Nitrophenylacetat-Hydrolyse von der Komplexkonzentration ___ 58

4.3.1.5 Abhängigkeit der $p$-Nitrophenylacetat-Hydrolyse von der Substratkonzentration und dem

$\mathrm{pH}$-Wert 60

4.3.1.6 Untersuchungen mit Glycin- $p$-nitrophenylanilid __ 60

4.3.2 Massenspektrometrische Messungen __ 60

4.3.2.1 Reaktion des Komplexes $\left[\mathrm{L}^{6}{ }_{-\mathrm{H}}(\mathrm{MeOH})(\mathrm{OH}) \mathrm{Zn}_{2}\right]\left(\mathrm{ClO}_{4}\right)_{2} \mathrm{Zu} 5$

4.3.2.2 Reaktion des Komplexes $\left[\mathrm{L}^{7}{ }_{-\mathrm{H}}(\mathrm{MeOH})(\mathrm{OH}) \mathrm{Zn}_{2}\right]\left(\mathrm{ClO}_{4}\right)_{2} \mathrm{Zu} 4$

4.3.2.3 Reaktion von anderen Komplexen des Typs $\left[\mathrm{L}^{\mathrm{n}}{ }_{-\mathrm{H}}(\mathrm{ROH})(\mathrm{OR}) \mathrm{Zn}_{2}\right]\left(\mathrm{ClO}_{4}\right)_{2}$ mit $p$ -

Nitrophenylacetat

\subsection{Zinkkomplexe mit anderen Zweitbrücken __ 66}

4.4.1 Zink(II)-Komplex des Liganden $\mathrm{L}^{6}$ - Synthese von $\left[\mathrm{L}^{6}{ }_{-\mathrm{H}}(\mu-\mathrm{HCOO}) \mathrm{Zn}_{2}\right]\left(\mathrm{ClO}_{4}\right)_{2}(6) \ldots 66$

4.4.2 Zink(II)-Komplex des Liganden $\mathrm{L}^{1}$ - Synthese von $\left[\left(\mathrm{L}^{1}{ }_{-\mathrm{H}}\right)_{2} \mathrm{Zn}_{2}\right]\left(\mathrm{CF}_{3} \mathrm{SO}_{3}\right)_{2}(7) \ldots 8$

4.4.3 Zink(II)-Komplex des Liganden $\mathrm{L}^{6}$ - Synthese von $\left[\left(\mathrm{L}^{6}{ }_{-\mathrm{H}}\right)_{2}\left(\mu_{3}-\mathrm{CO}_{3}\right)\left(\mathrm{H}_{2} \mathrm{O}\right) \mathrm{Zn}_{4}\right]\left(\mathrm{ClO}_{4}\right)_{4}$

(8) 71

4.4.4 Zink(II)-Komplex des Liganden $\mathrm{L}^{1}$ - Synthese von $\left[\left(\mathrm{L}_{-}^{1}\right)_{2}\left(\mu_{4}-\mathrm{CO}_{3}\right) \mathrm{Zn}_{4}\right]\left(\mathrm{BPh}_{4}\right)_{4}(\mathbf{9})_{-} 76$

4.5 Hydrolyse von $\gamma$-Butyrolacton durch einen Dizinkkomplex $\quad 79$

4.5.1 Lactonhydrolyse __ 79

4.5.2 Nachweis der $\gamma$-Butyrolacton-Spaltung durch ${ }^{1} \mathrm{H}$-NMR __ 80

4.5.3 Zink(II)-Komplex des Liganden $\mathrm{L}^{6}-$

Synthese von $\left[\mathrm{L}^{6}{ }_{-\mathrm{H}}\left(\mu-\mathrm{HOCH}_{2} \mathrm{CH}_{2} \mathrm{CH}_{2} \mathrm{COO}\right) \mathrm{Zn}_{2}\right]\left(\mathrm{ClO}_{4}\right)_{2}(\mathbf{1 0})$

4.6 Komplexe mit weiteren Übergangsmetallen

4.6.1 Nickel(II)-Komplex des Liganden $\mathrm{L}^{2}$ - Synthese von $\left[\mathrm{L}^{2}{ }_{-\mathrm{H}}\left(\mathrm{NO}_{3}\right)_{2} \mathrm{Ni}_{2}\right] \mathrm{NO}_{3}(11) \ldots$

4.6.2 Nickel(II)-Komplex des Liganden $\mathrm{L}^{4}-$ Synthese von $\left[\mathrm{L}^{4}{ }_{-\mathrm{H}}\left(\mu-\mathrm{CH}_{3} \mathrm{COO}\right) \mathrm{Ni}_{2}\right]\left(\mathrm{ClO}_{4}\right)_{2}(12)$ 90

4.6.3 Kupfer(II)-Komplex eines Restes des Liganden $L^{4}-$

Synthese von $\left[\mathrm{DMelmDEtEtA}\left(\mathrm{NO}_{3}\right) \mathrm{Cu}\right]\left(\mathrm{NO}_{3}\right)(\mathbf{1 3})$ 93

\section{Zusammenfassung}

6.2 Synthese von Ligandvorstufen 108

6.2.1 Synthese von Bis[2-(1-Methylimidazolyl)methyl]amin 108

6.2.2 Synthese von (1-Methyl-imidazol-2-ylmethyl)(2-pyridin-2-ylethyl)amin 109

6.2.3 Synthese von N,N-Diethyl-N'-(Pyridin-2-ylmethyl)ethylendiamin 110

6.2.4 Synthese von N,N-Diethyl-N'-(1-methylimidazol-2-ylmethyl)ethylendiamin 111

6.2.5 Synthese von Methyl-(1-methylimidazol-2-ylmethyl)amin 113

6.2.6 Synthese von N,N,N'-Trimethylethylendiamin 114 
6.3 Synthese der Liganden 115

6.3.1 Synthese von $L^{1}$ 115

6.3.2 Synthese von $L^{2}$ 116

6.3.3 Synthese von $L^{3}$ 118

6.3.4 Synthese von $L^{4}$ 119

6.4 Komplexsynthese 121

6.4.1 Synthese von $\left[\mathrm{L}^{1}{ }_{-\mathrm{H}}\left(\mu-\mathrm{CH}_{3} \mathrm{COO}\right) \mathrm{Zn}_{2}\right]\left(\mathrm{ClO}_{4}\right)_{2}(\mathbf{1})$ 122

6.4.2 Synthese von $\left[\mathrm{L}^{4}{ }_{-\mathrm{H}}\left(\mu-\mathrm{CH}_{3} \mathrm{COO}\right) \mathrm{Zn}_{2}\right]\left(\mathrm{ClO}_{4}\right)_{2}(2)$ 123

6.4.3 Synthese von $\left[\mathrm{L}^{3}{ }_{\mathrm{H}}\left(\mu-\mathrm{CH}_{3} \mathrm{COO}\right) \mathrm{Zn}_{2}\right]\left(\mathrm{ClO}_{4}\right)_{2}(3)$ 124

6.4.4 Synthese von $\left[\mathrm{L}^{7}{ }_{-\mathrm{H}}\left(\mu-\mathrm{CH}_{3} \mathrm{COO}\right) \mathrm{Zn}_{2}\right]\left(\mathrm{ClO}_{4}\right)_{2}(4)$ 125

6.4.5 Synthese von $\left[\mathrm{L}^{6}{ }_{-\mathrm{H}}\left(\mu-\mathrm{CH}_{3} \mathrm{COO}\right) \mathrm{Zn}_{2}\right]\left(\mathrm{ClO}_{4}\right)_{2}(5)$ 126

6.4.6 Synthese von $\left[\mathrm{L}^{6}{ }_{-\mathrm{H}}(\mu-\mathrm{HCOO}) \mathrm{Zn}_{2}\right]\left(\mathrm{ClO}_{4}\right)_{2}(6)$ 127

6.4.7 Synthese von $\left[\left(\mathrm{L}^{1}{ }_{-H}\right)_{2} \mathrm{Zn}_{2}\right]\left(\mathrm{CF}_{3} \mathrm{SO}_{3}\right)_{2}(7)$ 128

6.4.8 Synthese von $\left[\left(\mathrm{L}^{6}{ }_{-H}\right)_{2}\left(\mathrm{OH}_{2}\right)\left(\mu_{3}-\mathrm{CO}_{3}\right) \mathrm{Zn}_{4}\right]\left(\mathrm{ClO}_{4}\right)_{4}(8) \ldots 129$

6.4.9 Synthese von $\left[\mathrm{L}^{1}{ }_{-\mathrm{H}}\left(\mu_{4}-\mathrm{CO}_{3}\right) \mathrm{Zn}_{4}\right]\left(\mathrm{BPh}_{4}\right)_{4}(9)$ 130

6.4.10 Synthese von $\left[\mathrm{L}^{6}{ }_{-\mathrm{H}}\left(\mu-\mathrm{HOCH}_{2} \mathrm{CH}_{2} \mathrm{CH}_{2} \mathrm{COO}\right) \mathrm{Zn}_{2}\right]\left(\mathrm{ClO}_{4}\right)_{2}(10)$ 131

6.4.11 Synthese von $\left[\mathrm{L}^{2}{ }_{-} \mathrm{Ni}_{2}\left(\mathrm{NO}_{3}\right)_{2}\right]\left(\mathrm{NO}_{3}\right)(\mathbf{1 1})$ 133

6.4.12 Synthese von $\left[\mathrm{L}^{4}{ }_{-\mathrm{H}}\left(\mu-\mathrm{CH}_{3} \mathrm{COO}\right) \mathrm{Ni}_{2}\right]\left(\mathrm{ClO}_{4}\right)_{2}(12)$ 134

6.4.13 Synthese von [DMelmDEtEtA $\left.\left(\mathrm{NO}_{3}\right) \mathrm{Cu}\right]\left(\mathrm{NO}_{3}\right)(\mathbf{1 3})$ 135

6.5 Untersuchungen mit $\boldsymbol{p}$-Nitrophenylacetat 136

6.5.1 Kinetische Messungen der $p$-Nitrophenylacetathydrolyse mittels UV/Vis-

Spektroskopie 136

6.5.2 ESI-MS Untersuchungen 137

$6.6{ }^{1} \mathrm{H}-N M R$ Untersuchungen 137

6.7 Röntgenstrukturanalyse 137

6.7.1 Allgemeines 137

6.7.2 Röntgenographischer Anhang 139 


\section{Verzeichnis der verwendeten Abkürzungen}

\begin{tabular}{|c|c|}
\hline$\AA$ & Ångstrøm $\left(10^{-10} \mathrm{~m}\right)$ \\
\hline Abb. & Abbildung \\
\hline Ac & Acetat \\
\hline Äq & Äquivalente \\
\hline Asp & Asparagin \\
\hline ber. & berechnet \\
\hline BIS-TRIS & bis[Hydroxyethyl]imino-tris[hydroxymethyl]methan \\
\hline BPEA & Bis[2-(2-pyridyl)ethyl]amin \\
\hline BPEMA & (2-Pyridylmethyl)[2-(2-pyridyl)ethyl]amin \\
\hline BPMA & Bis(2-pyridylmethyl)amin \\
\hline${ }^{\circ} \mathrm{C}$ & Grad Celsius \\
\hline $\mathrm{CH}_{2} \mathrm{Cl}_{2}$ & Dichlormethan \\
\hline$d$ & Abstand \\
\hline DMelmDEtEtA & $\begin{array}{l}\mathrm{N}, \mathrm{N}-\text { Diethyl-N',N'-bis-(1-methyl-1H-imidazol-2-yl-methyl)- } \\
\text { ethylen-1,2-diamin }\end{array}$ \\
\hline$\delta$ & Chemische Verschiebung \\
\hline DMF & Dimethylformamid \\
\hline DMSO & Dimethylsulfoxid \\
\hline$\varepsilon$ & Extinktionskoeffizient $\left[\mathrm{mol} \cdot \mathrm{I}^{-1} \cdot \mathrm{cm}^{-1}\right]$ \\
\hline EA & Elementaranalyse \\
\hline El & Electron Impact \\
\hline ESI & Electron Spray lonisation \\
\hline Et & Ethyl \\
\hline $\mathrm{EtOH}$ & Ethanol \\
\hline $\mathrm{Et}_{2} \mathrm{O}$ & Diethylether \\
\hline exp. & experimentell \\
\hline Glu & Glutamat \\
\hline His & Histidin \\
\hline HEPES & Hydroxyethylpiperazinethansulfonsäure \\
\hline $\mathrm{Hz}$ & Hertz \\
\hline IR & Infrarot \\
\hline$J$ & Kopplungskonstante \\
\hline
\end{tabular}




\begin{tabular}{|c|c|}
\hline$k$ & Geschwindigkeitskonstante \\
\hline Kat. & Katalysator \\
\hline [Kat] & Konzentration des Katalysators \\
\hline$K_{\mathrm{M}}$ & Michaelis-Konstante \\
\hline Konz. & Konzentration \\
\hline $\mathrm{KOtBu}$ & Kalium-tert-butylat \\
\hline $\mathrm{L}$ & Ligand \\
\hline Lys & Lysin \\
\hline M & molar \\
\hline $\max$ & Maximum \\
\hline $\mathrm{Me}$ & Methyl \\
\hline $\mathrm{MeCN}$ & Acetonitril \\
\hline Melm & Methylimidazol \\
\hline MS & Massenspektrometrie \\
\hline n-BuLi & $n$-Butyllithium \\
\hline NMR & Nuclear Magnetic Resonance \\
\hline OAc & Acetat \\
\hline Py & Pyridyl \\
\hline $\mathrm{Pz}$ & Pyrazolyl \\
\hline $\mathrm{R}$ & Rest \\
\hline $\mathrm{T}$ & Temperatur \\
\hline Tyr & Tyroxin \\
\hline$\tilde{v}$ & Wellenzahl \\
\hline $\mathrm{v}$ & Geschwindigkeit \\
\hline
\end{tabular}


Legende für die abgebildeten Kristallstrukturen

$\begin{array}{ll}\text { hellgrau } & \text { Wasserstoff } \\ \text { grau } & \text { Kohlenstoff } \\ \text { blau } & \text { Stickstoff } \\ \text { rot } & \text { Sauerstoff } \\ \text { türkis } & \text { Zink } \\ \text { lila } & \text { Kupfer } \\ \text { grün } & \text { Nickel }\end{array}$




\section{Einleitung}

Zink ist mit 76 ppm eines der häufigsten Metalle der Erdkruste (24. Platz in der Häufigkeitsreihe der Elemente). Deren Gehalt an Zink in den obersten $16 \mathrm{~km}$ wird auf $0.012 \%$ geschätzt. Seine Häufigkeit entspricht somit jener von $\mathrm{Sr}, \mathrm{V}$ oder $\mathrm{Cu}$. Die Verhüttung von Zinkerzen ist nicht ganz einfach. Deshalb konnte annähernd reines Zink in Europa erst im 18. Jahrhundert in größerem Umfang gewonnen werden. Seine erste zuverlässige Beschreibung stammt aus dem Jahr 1721 von Henkel. Margraf erhielt Zink, indem er im Jahre 1746 Zinkoxid mit Kohle unter Luftausschluß erhitzte.

Einige industrielle Anwendungen sind von besonderem Interesse. Die Hauptmenge von Zink wird zum Verzinken von Stahl (Galvanisierung, Feuerverzinkung) eingesetzt. Daneben ist es auch als Bestandteil von Legierungen wichtig. Dazu zählen Messing ( $\mathrm{Zn}-\mathrm{Cu}$ ), Neusilber ( $\mathrm{Zn}, \mathrm{Cu}, \mathrm{Ni}$ ) oder Legierungen für Lagerwerkstoffe (Zn-Al-Cu). Hinzu kommt seine Bedeutung in der Batterieindustrie. Außerdem werden Zinkderivate für zahlreiche Prozesse verwendet.

Zink ist, wie z.B. auch $\mathrm{Cu}, \mathrm{Fe}$ und $\mathrm{Ni}$, ein physiologisch verträgliches, essentielles Spurenelement. Bei dessen Fehlen kann beim Menschen eine Mangelsymptomatik ausgelöst werden, weil für den Ablauf von Stoffwechselvorgängen Zinkproteine wichtig sind. Die nötige Zn-Menge von $10 \mathrm{mg} / \mathrm{Tag}$ wird mit der Nahrung aufgenommen. Zu einem Zinkmangel kann es durch Verdauungsstörungen kommen. Eine Zn-Mangelsymptomatik äußert sich bei Kindern durch verzögertes Wachstum. Zink ist aber auch in der Gentranskription und in der Neurotransmission sehr wichtig. ${ }^{[1]}$

In der Forschung und Industrie spielen Zinkverbindungen, wie z.B. Zinkenolate, seit vielen Jahren eine wichtige Rolle in organischen Synthesereaktionen. Sie wurden dann aber teilweise durch Grignard-Reagentien verdrängt. Hauptsächlich werden Organozinkverbindungen eingesetzt, wenn die Elektrophilie der Reaktandten abgeschwächt werden soll und keine Änderungen in der Oxidationsstufe nötig sind. Sie bieten aber auch die Möglichkeit zum Einsatz funktioneller Gruppen, die bei anderen elektrophilen Reagentien Störungen bei Reaktionsabläufen zur Folge hätten. Für spezielle 
Reaktionen (z.B. die Reformatsky-Reaktion) wurden Organozinkreagentien entwickelt. Dazu gehören vor allem das Lombardos-Reagens $\left(\mathrm{Zn} / \mathrm{CH}_{2} \mathrm{Br}_{2} / \mathrm{TiCl}_{4}\right)$ und das Reformatsky-Reagens (Abb. 1). ${ }^{[2-4]}$

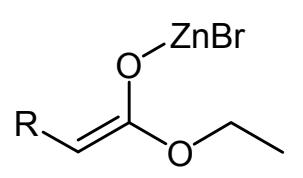

Abb. 1: Reformatsky-Reagens.

In der Koordinationschemie spielt der recht kleine Radius von Zink(II) (0.69 $\AA)$ eine wichtige Rolle. Zink bevorzugt die Koordinationszahlen 4, 5 und 6. Da die d-Schale komplett ist, hat Zink keine bevorzugte Stereochemie. Wegen seines amphoteren Verhaltens sind sowohl harte als auch schwache Donoratome bevorzugt. Desweiteren zeichnen sich Zink(II)-Komplexe durch das Fehlen von Redoxvorgängen aus. Die Summe dieser Eigenschaften ermöglicht es, dass das Zink ein unumgängliches Element für Lebewesen ist.

Die bioanorganische Chemie versucht die Wirkung wichtiger chemischer Elemente in biologischen Systemen zu verstehen. Zink ist eines der Elemente, die besonders wichtig sind, da es eine Vielzahl von Funktionen in biologischen Organismen hat. Zum Verständnis der Rolle dieses Elements in den Metalloproteinen sind einfache synthetische Modellsysteme entwickelt worden. Solche Modellsysteme sollen so genau wie möglich strukturell und elektronisch die Reaktionszentren der Metalloproteine reproduzieren und eine ähnliche Funktion erfüllen. Die Entwicklung und Feineinstellung der Modellsysteme ermöglicht die Optimierung der Prozesse, die die Metalloproteine katalysieren. Enzyme sind Biokatalysatoren, die durch Beeinflussung der Aktivierungsprozesse die Reaktionsgeschwindigkeit chemischer Prozesse erhöhen können und somit den Stoffwechsel katalytisch steuern. Diese Prozesse verlaufen über mehrere Zwischenstufen. Durch die Enzymkatalyse wird die Aktivierungsenergie der gesamten Reaktion herabgesetzt.

Die Vielzahl der Enzyme wird mit Blick auf die Art ihrer Wirkung in sechs Gruppen eingeteilt: 
- Oxidoreduktasen: katalysieren Redox-Prozesse

- Transferasen: katalysieren den Austausch einer funktionellen Gruppe zwischen zwei Substraten

- Hydrolasen: katalysieren Hydrolysereaktionen

- Lyasen: katalysieren die Spaltung eines Substrats

- Isomerasen: katalysieren die Umwandlung von Isomeren

- Ligasen: katalysieren die Bindung zweier Substrate

Selbständiges Leben ohne Enzyme ist selbst in den einfachsten pflanzlichen und tierischen Zellen nicht möglich. Die enzymatischen Reaktionen sind daher äußerst vielfältig. Stoffwechselprozesse, welche durch die Biochemie beschrieben werden, bedürfen zu ihrem Ablauf in vielen Fällen der Mitwirkung von Metallen in aktiven Zentren der Enzyme.

Oft laufen diese katalytischen Prozesse nach einem allgemeinen Mechanismus ab, der die Beziehungen zwischen Enzym (E), Substrat $(S)$ und Produkt $(P)$ erklärt, dem Michaelis-Menten Mechanismus (Schema 1).

$$
\begin{aligned}
& v=\frac{v_{\mathrm{Max}}[\mathrm{S}]}{K_{\mathrm{M}}+[\mathrm{S}]} \\
& \mathrm{E}+\mathrm{S} \stackrel{k_{1}}{\underset{k_{-1}}{\longrightarrow}} \mathrm{ES} \stackrel{k_{2}}{\longrightarrow} \mathrm{E}+\mathrm{P} \quad \begin{array}{l}
\mathrm{v}=\text { Geschwindigkeit } \\
K_{\mathrm{M}}=\text { Michaelis Konstante }
\end{array} \\
& k_{\mathrm{x}}=\text { Geschwindigkeitskonstante }
\end{aligned}
$$

Schema 1: Allgemeine Darstellung des Michaelis-Menten Mechanismus.

Auch technisch sind Enzyme wichtig in der Biotechnologie. Amylasen werden zur Verzuckerung von Stärke eingesetzt, Proteasen bei der Käseherstellung etc. Der Zusatz von Proteasen zu Waschmitteln ermöglicht beim Waschprozeß die Entfernung von eiweißhaltigen Flecken aus textilem Gewebe.

Von einigen Zinkproteinen ist bekannt, dass sich zwei Zinkzentren in enger Nachbarschaft zueinander befinden und so bei der Vermittlung der Hydrolyse miteinander kooperieren können. ${ }^{[5]}$ Vorbild sind hier Zinkpeptidasen (Carboxypeptidasen und Aminopeptidasen) wie die Aminopeptidase von Aeromonas proteolytica (Abb. 2), die eine Spaltung peptidischer Bindungen bewirkt (Schema 2). 


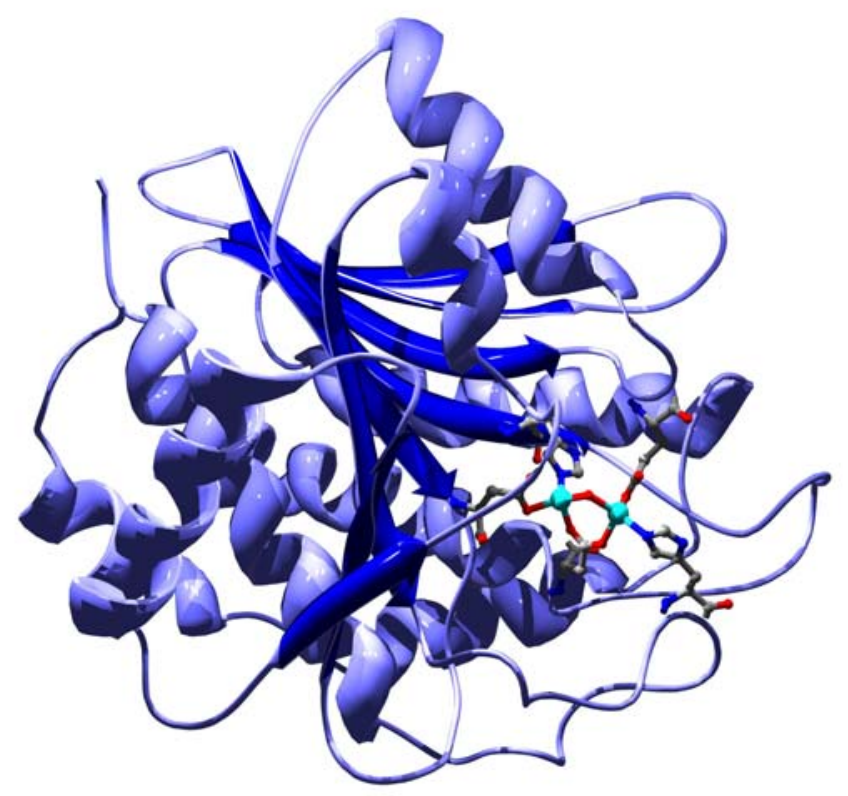

Abb. 2: Struktur der Aminopeptidase von Aeromonas proteolytica. ${ }^{[6]}$

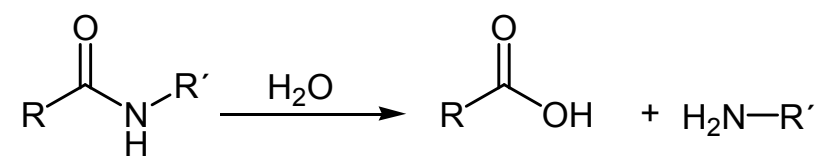

Schema 2: Hydrolyse von Peptiden. 
In Abb. 3 ist das aktive Zentrum einer Aminopeptidase dargestellt.

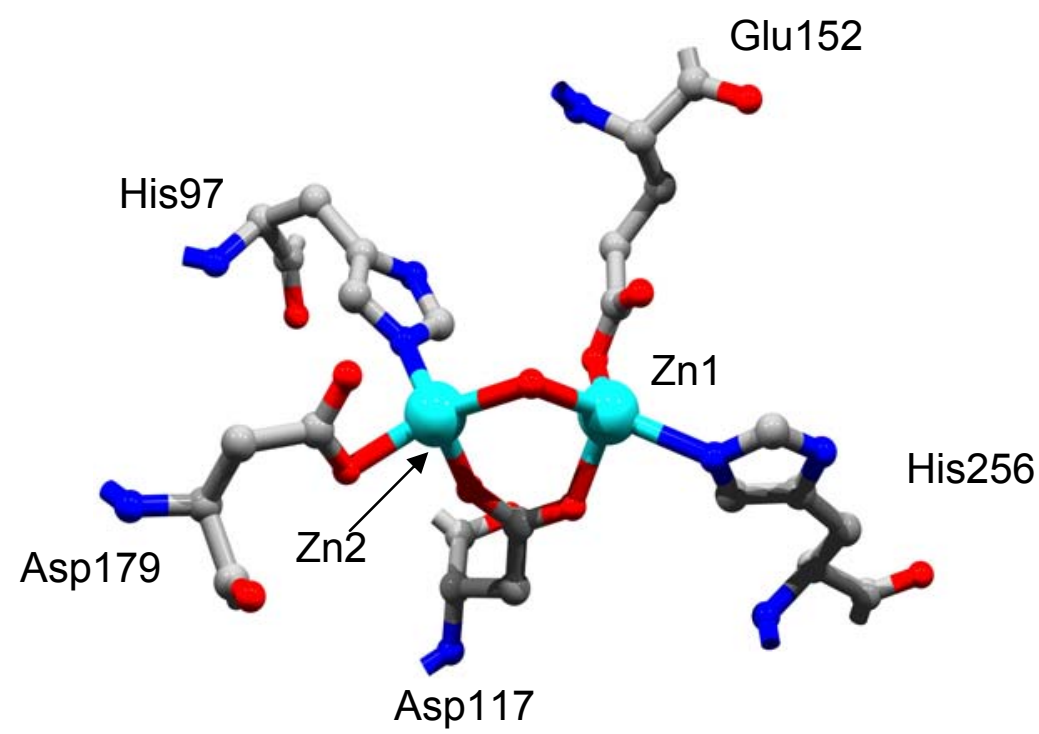

Abb. 3: Aktives Zentrum der Aminopeptidase von Aeromonas proteolytica.

Wie bereits erwähnt, versucht die bioanorganische Chemie Modellsysteme zu entwickeln, die zum Verständnis der Rolle der Metalle in enzymatischen Reaktionen beitragen sollen. Darauf baut nun die vorliegende Arbeit auf. In Zinkproteinen stehen den Zink(II)-lonen u.a. N-Donoratome zur Verfügung. Dieses Strukturmotiv sollte sich in den Modellverbindungen wiederfinden. Darüber hinaus soll in dem Modell auch der Abstand der beiden Zink(II)-Ionen jenem in den Zinkproteinen nahekommen. Dafür bieten sich Kompartimentliganden auf Pyrazolbasis an. Diese besitzen zwei „Taschen“, in welchen die zwei Zink(II)-lonen durch N-Donoratome wie in den Zn-haltigen Proteinen koordinativ gebunden werden können (Abb. 4).

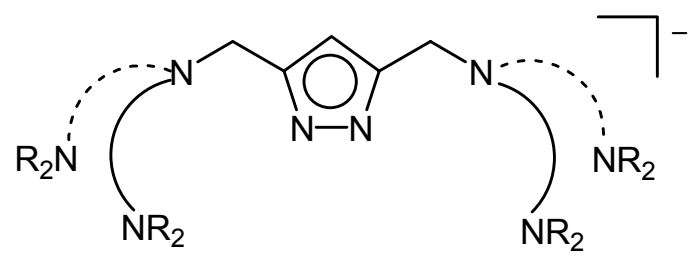

Abb. 4: Schematische Darstellung verwendeter pyrazolbasierter Kompartimentliganden. 


\section{Kenntnisstand}

\subsection{Zinkhaltige Enzyme}

Die Anwesenheit von Zink ist für alle Lebewesen essentiell. Sein Einfluss stammt von seiner Rolle in Metallenzymen, in welchen das Zink sowohl katalytischen als auch strukturellen Einfluss haben kann. Es gibt viele Hunderte Enzyme, welche Zink als Metallzentrum enthalten, mit Vertretern in allen wichtigen Klassen von Enzymen (Oxidoreduktasen, Transferasen, Hydrolasen, Lyasen, Isomerasen und Ligasen). ${ }^{[7,8]}$

Die häufigste Umgebung der Zinkatome in Enzymen (Abb. 5) ist jene mit drei Aminosäuren des entsprechenden Proteins. Eine vierte Bindung wird durch Wasser oder einen Hydroxidliganden besetzt. Wasser oder Liganden mit Hydroxidgruppen spielen eine große Rolle bei der katalytischen Aktivität der zinkhaltigen Enzyme.

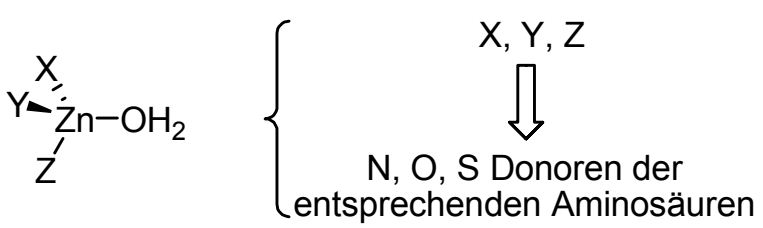

Abb. 5: Koordination des Zinkions in Metalloenzymen.

Tetraedrische Zinkzentren wie die in Abb. 5 können einen wichtigen Einfluss auf die Proteinstruktur haben und damit die Stabilität und Konformation der Enzyme steuern. Insbesondere in Zn-haltigen Enzymen mit Cysteinresten in der Koordinationsschale besitzt das Zink sehr häufig strukturelle Funktion. Ein anderes Beispiel für strukturell wirkendes Zink in Proteinen sind die Zinkfinger. ${ }^{[9]}$ Nicht nur die Donoratome bestimmen die katalytischen Eigenschaften, sondern auch die verschiedenen Aminosäuren, die als Abstandshalter zwischen den Donorgruppen wirken. Sie können die Reaktivität des aktiven Zentrums modulieren. Zwei der Donorgruppen sind in solchen Zentren durch ein bis drei 
Reste getrennt, die dritte Donorgruppe kann durch eine lange Kette getrennt sein (5-196 Reste). ${ }^{[10]}$

Häufig findet man zwei kooperierende Zinkkerne in derselben Baueinheit. Hier wirken die Metallzentren cokatalytisch. Beide Zinkionen sind notwendig zur Erreichung der vollen Aktivität. Die Entfernung des Metalls im aktiven Zentrum führt zu einem Abfall der Aktivität oder einer Deaktivierung des Enzymes. In manchen zinkhaltigen Enzymen ist die Funktion des Metalls noch immer unklar. Studien der Rolle der Zink(II)-lonen der Zinkenzyme werden häufig durch die hohe Geschwindigkeit der enzymatischen Reaktionen und durch den silenten Charakter des Zinkkerns gegen manche spektroskopische Techniken erschwert.

\subsection{Metallhydrolasen}

Die hydrolytische Spaltung von Peptid-, Phosphat- oder Esterbindungen in metabolischen Prozessen läuft in vielen Stufen ab. Unterschiedliche Stufen können geschwindigkeitsbestimmend für die gesamte Hydrolyse sein.

Hydrolasen wurden von der Natur entwickelt, um solche Bindungen unter physiologischen Bedingungen $z u$ spalten. Um diese Spaltung $z u$ beschleunigen, benutzen die Hydrolasen unterschiedliche Strukturen, funktionelle Gruppen oder chemische Mechanismen.

Metallionen sind für viele Hydrolasen wesentliche Cofaktoren, die in der Hydrolyse direkt beteiligt sind. Eine gute katalytische Kooperation der Metallionen mit einer oder mehreren funktionellen organischen Gruppen (z.B. Carbonyl- oder Aminfunktion) ermöglicht eine größere Effektivität.

Funktionelle organische Gruppen oder Metallionen können nach folgendem Mechanismus die hydrolytische Abspaltung fördern: ${ }^{[11]}$

- Elektrostatische Aktivierung des Substrates im Grundzustand oder Stabilisierung des Übergangszustandes durch Koordination an das Metall, Wasserstoffbrückenbindung oder Protonenübertragung

- Stabilisierung der Abgangsgruppe durch Koordination an das Metall, Wasserstoffbrückenbindung oder Protonenübertragung 
- Nukleophiler Angriff auf das Substrat durch eine funktionelle Gruppe oder eine Hydroxidgruppe, die an das Metall koordiniert ist

- Erzeugung der Nukleophilie durch Abspaltung eines Protons.

Zwei der wichtigsten Hydrolaseenzyme sind die Nukleasen und die Peptidasen. In Schema 3 ist der Angriff der Peptidasen auf die drei unterschiedlichen Peptidgruppen einer peptidischen Kette, der zur Zerlegung des Peptidmoleküls in seine molekularen Bausteine führt, dargestellt.

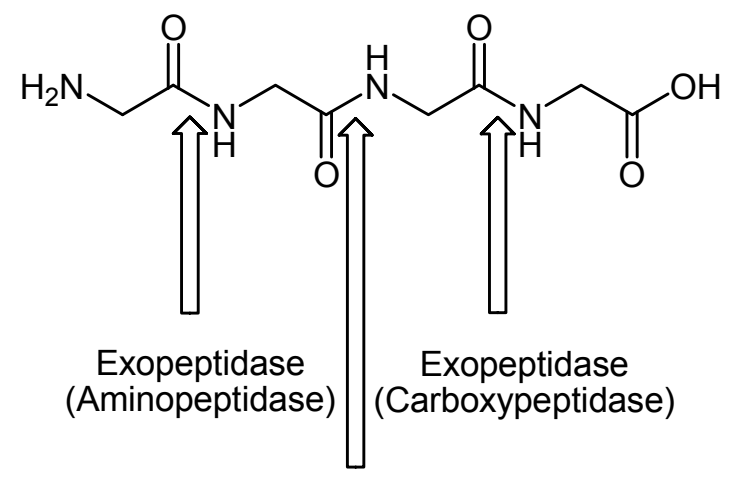

Endopeptidase

Schema 3: Angriffspunkte der Peptidasen.

\subsubsection{Zink, ein Baustein für Hydrolasen}

An Stelle von Zink wären auch andere Metallionen $\left(\mathrm{Mg}^{2+}, \mathrm{Ca}^{2+}, \mathrm{Mn}^{2+}, \mathrm{Co}^{2+}, \mathrm{Ni}^{2+}\right.$ und $\mathrm{Cu}^{2+}$ ) wegen ihrer chemischen Eigenschaften bei einem Einsatz in enzymkatalysierten Hydrolysereaktionen vorstellbar. Viele Studien zeigen, dass sich Zink als Zentralatom bei vielen dieser enzymatischen Prozesse am besten eignet. $^{[12]}$ Dafür gibt es sehr vielfältige Ursachen, wie zum Beispiel:

- flexible Koordinationsgeometrie

- Lewis-Säure-Charakter

- seine mittlere Polarisierbarkeit (hart-weich Charakter)

- fehlende Redox-Aktivität

- starke Bindungsmöglichkeiten an geeignete Stellen

- Bildung von $\mathrm{OH}^{-}$-Ionen bei neutralen $\mathrm{pH}-$ Werten 
- große Verfügbarkeit

- sehr schnelle Ligandenaustauschreaktionen.

Alle zusammen ermöglichen, dass Zink als Metallion bei vielen Hydrolasen tätig ist.

Zink ist aber oft durch manche der o.g. Metallionen, z.B. Cobalt(II)-Ionen, ersetzbar, ohne dass sich die Aktivität des Metalloproteins in größerem Ausmaß ändern würde. Es ist sogar gelungen, durch einen solchen Austausch hyperaktive Enzyme herzustellen. ${ }^{[13]}$ Eine mögliche Erklärung dafür könnte an der Eigenschaft von Cobalt(II)-Ionen liegen, Komplexe mit den Koordinationszahlen 4, 5 und 6 zu bilden. ${ }^{[14]}$ Trotzdem wird Zink anstatt Cobalt von der Natur gewählt.

Besonders wichtige Enzyme, welche Zink(II)-Ionen enthalten, sind die Hydrolasen mit ihren Vertretern, wie z.B. die Aminopeptidasen und Carboxypeptidasen. In allen Fällen handelt es sich dabei um Enzyme, welche Proteine unter Bildung ihrer molekularen Bestandteile zerstören können. Über jedes dieser Enzyme und seine Funktion wird im Folgenden kurz berichtet.

\subsubsection{Carboxypeptidasen}

Carboxypeptidasen sind Exopeptidasen, die selektiv die Hydrolyse C-endständiger Aminosäurereste katalysieren. Die meisten von innen sind mononukleare Zinkenzyme und stehen in enger Beziehung $\mathrm{zu}$ anderen Zinkproteasen wie Thermolysin und Neutralprotease.

Die Zinkzentren sind an das Protein durch zwei Histidin- und einen Glutamatrest gebunden. Wie in Abb. 6 dargestellt ist, wird die vierte Koordinationsstelle von einem Wassermolekül besetzt. Die Carboxylgruppe des Glutamatrests kann sowohl als ein- als auch als zweizähniger Ligand fungieren.

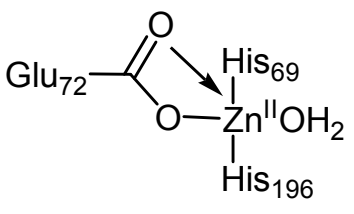

Carboxypeptidase A

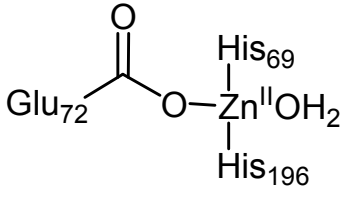

Carboxypeptidase B 
Abb. 6: Aktives Zentrum der Carboxypeptidasen A und B.

Der Mechanismus der Carboxypeptidasen wird kontrovers diskutiert. Es gibt zwei Hypothesen, die sich darin unterscheiden, ob die Hydrolyse der Peptide über einen Angriff ein Zink-gebundenen Hydroxids oder über einen Angriff eines nicht koordinierten Wassermoleküls der Umgebung abläuft.

Bei der ersten Hypothese hat der Zinkkern zwei Aufgaben: ${ }^{[15,16]}$

- Aktivierung eines Wassermoleküls

- Aktivierung der Carbonylgruppe der Peptide

Bei der zweiten Hypothese ist Zink nur für die Aktivierung der Carbonylgruppe verantwortlich. Das Wassermolekül wird durch eine Base, wie z.B. eine Aminogruppe einer Aminosäure, aktiviert. ${ }^{[17]}$

Eine Ausnahme bei den Carboxypeptidasen stellt die Carboxypeptidase $\mathrm{G}_{2}$ dar. Sie besitzt wie die Aminopeptidasen zwei Zinkkerne an ihrer aktiven Seite. ${ }^{[18]}$ Die Topologie am aktiven Zentrum wird durch unterschiedliche Gruppen beeinflusst. Das erklärt die Tatsache, dass zwei ähnliche Metalloproteine unterschiedliche Substratspezifität entwickelt haben. ${ }^{[19]}$

\subsubsection{Carboxypeptidase A}

Die Carboxypeptidase $A$ ist die am meisten erforschte Carboxypeptidase. Diese Carboxypeptidase enthält im aktiven Zentrum ein Zink(II)-lon, das an zwei Histidine, ein Glutamat und ein Wassermolekül, welches Wasserstoffbrückenbindungen zu einem anderen Glutamat bilden kann, gebunden ist (Abb. 7). Durch diese zusätzlichen Wasserstoffbrückenbindungen kann der $\mathrm{pK}_{\mathrm{a}}$ dieses Wassermoleküls bis zu einem Wert nahe sechs sinken. Dieses Wassermolekül kann durch einen zweizähnigen Liganden, wie z.B. Glycyltyrosin, entfernt werden. ${ }^{[15]}$ 


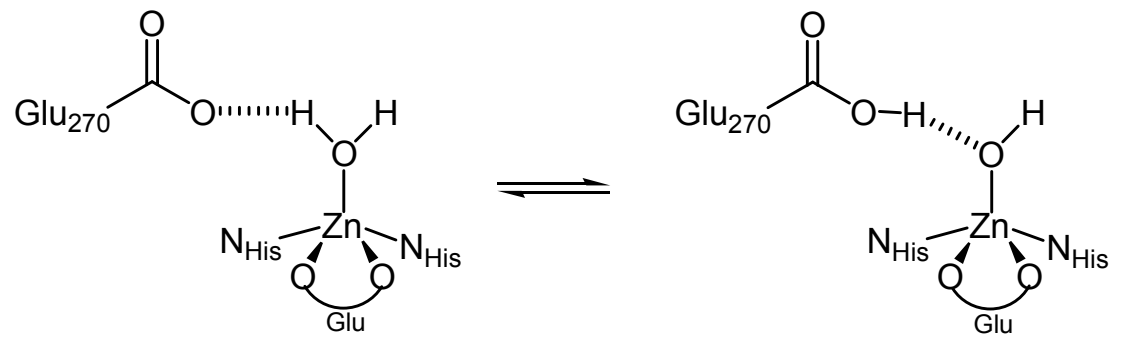

Abb. 7: Einfluss des Glutamatrests auf den $p K_{a}$-Wert des gebundenen Wassermoleküls.

Diese Metalloenzyme können nicht nur terminale peptidische Bindungen spalten, sondern auch Esterbindungen. Das Enzym kann auch mit Thioestern reagieren, aber mit einer deutlich kleineren Reaktivität. Die Peptidase- und Esteraseaktivitäten sind kinetisch nicht äquivalent und laufen wahrscheinlich nach unterschiedlichen Mechanismen ab. ${ }^{[20]}$ In Schema 4 sind die unterschiedlichen Enzymaktivitäten der Carboxypeptidase A dargestellt.

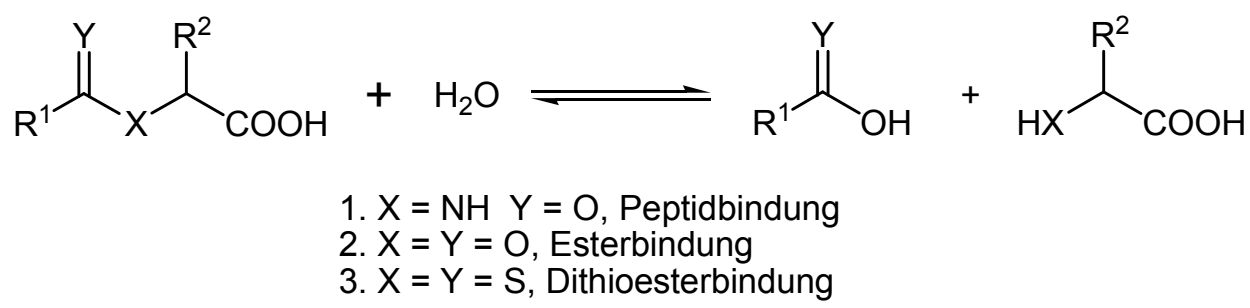

Schema 4: Unterschiedliche Enzymaktivitäten der Carboxypeptidase A.

In allen Aktivitäten dieser Metalloenzyme ist der Metallkern direkt beteiligt. Der Austausch des Metalls im aktiven Zentrum beeinflusst geringfügig die Stabilität der Metalloproteine. Die vom Enzym abhängige Konstante $\left(k_{\mathrm{cat}}\right)$ kann damit stark erniedrigt werden. Auch der Austausch der Metallzentren verursacht eine weitere Senkung des $p K_{\mathrm{a}}$-Wertes des gebundenen Wassermoleküls, wie z.B. bis $p K_{a}=5.3$ für die Enzyme mit Cobalt(II)-Ionen im aktiven Zentrum.

\subsubsection{AHL-Lactonase}

Die AiiA („autoinducer inactivation“) Metalloenzyme hydrolysieren die Esterbindung des Fünfrings von Homoserin Lacton (AHL) und verhindern damit 
die Bindung dieser Moleküle an ihre Transkriptoren. Auf diese Art und Weise wird die Kommunikation zwischen den Zellen in Bakterien, die durch diese kleinen Moleküle vermittelt wird, blockiert. Das Wachstum der Bakterien wird durch diese Hydrolyse verhindert. ${ }^{[21,22]}$ Die aus Bakterien gewinnbare AHL-Lactonase kann medizinisch zur Heilung und Kontrolle gewisser Infektionen verwendet werden. ${ }^{[23]}$ In Abb. 8 ist die Struktur der AHL-Lactonase aus Bacillus thuringensis dargestellt.

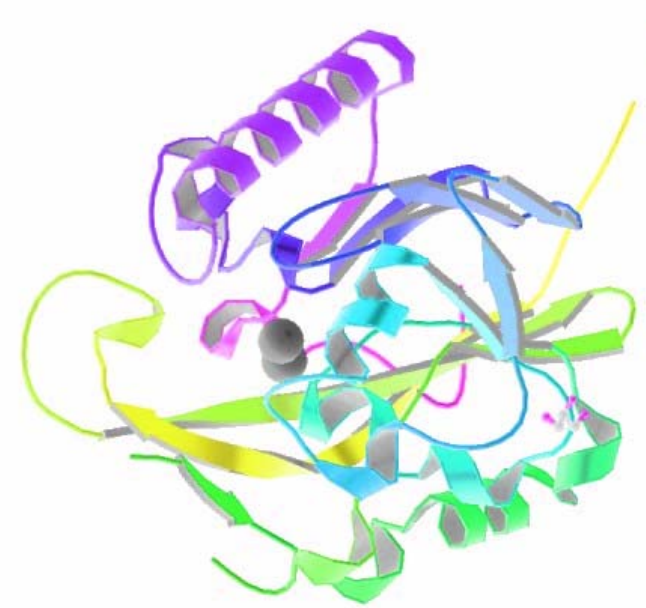

Abb. 8: Struktur der AHL-Lactonase aus Bacillus thuringensis (BTK-AiiA). ${ }^{[24]}$

Die BTK-AiiA besitzt 250 Aminosäuren und ihre Struktur ist gleichartig zu den Strukturen anderer Hydrolasen, wie z.B. den Metallo- $\beta$-lactamasen, der menschlichen Glyoxalase II oder den Phosphodiesterasen von Bakterien. ${ }^{[25,26]}$ Die Struktur zeigt eine $\alpha \beta / \beta \alpha$ gefaltete Form mit einem dinuklearen Zinkzentrum. ${ }^{[24]}$ Wie in vielen anderen Hydrolasen sind die beiden Zinkionen über eine Hydroxidgruppe oder ein Wassermolekül verbrückt und liegen relativ nah zueinander $(\mathrm{d}(\mathrm{Zn} \cdots \mathrm{Zn})=3.4 \AA)$. Untersuchungen mit diesen Metalloenzymen zeigten, dass beide Zinkkerne wesentlich für die Aktivität der Enzyme sind. Das aktive Zentrum der BTK-AiiA ist in Abb. 9 dargestellt. 


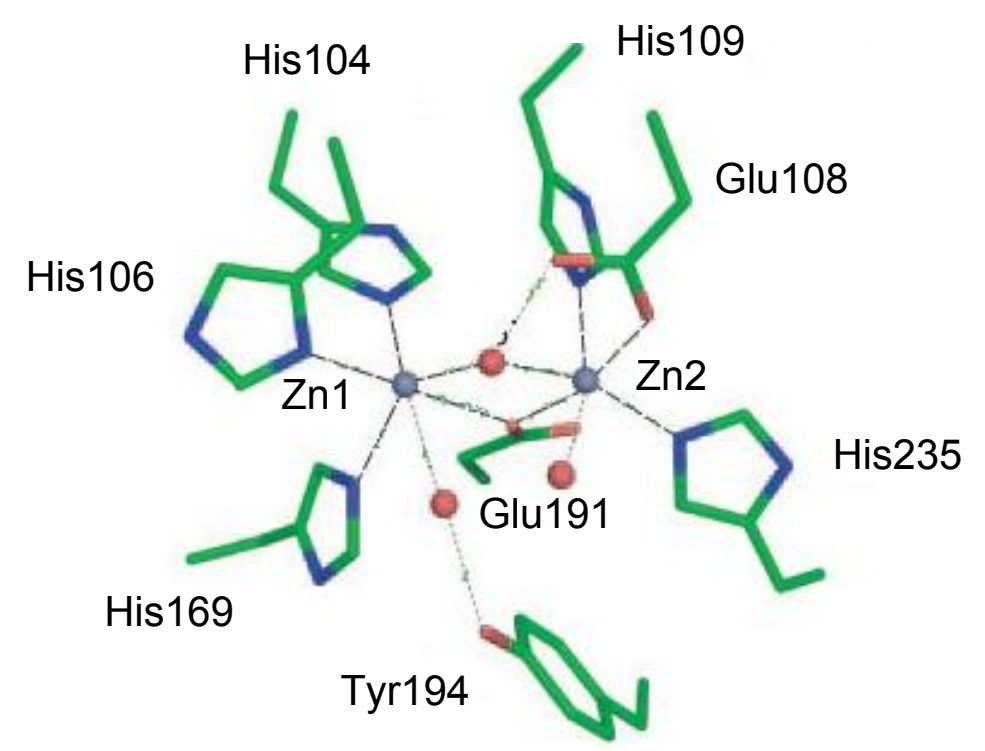

Abb. 9: Aktives Zentrum der BTK-AiiA.

Um den Wirkungsmechanismus dieser Enzyme zu verstehen, wurden Untersuchungen mit der BTK-AiiA und verwandten Enzymen oder Inhibitoren der AHL durchgeführt. ${ }^{[24]}$ Diese Untersuchungen zeigen, dass die Amidbindung sehr wichtig für die korrekte Erkennung durch die AHL-Lactonase ist. Hierbei wurde ein möglicher Mechanismus für die Reaktion der AHL-Lactonase postuliert (Schema 5). Das Wasser oder die Hydroxidgruppe, die an die Zinkatome gebunden ist, greift den Kohlenstoff der Carbonylverbindung nukleophil an. Die Carbonylverbindung wird durch Interaktionen mit beiden Zinkkernen polarisiert, damit ist der nukleophile Angriff begünstigt. Durch die Interaktion von Tyr-194, welches als Protonendonator arbeitet, wird das Zwischenprodukt stabilisiert. 


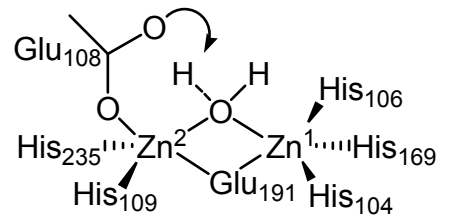

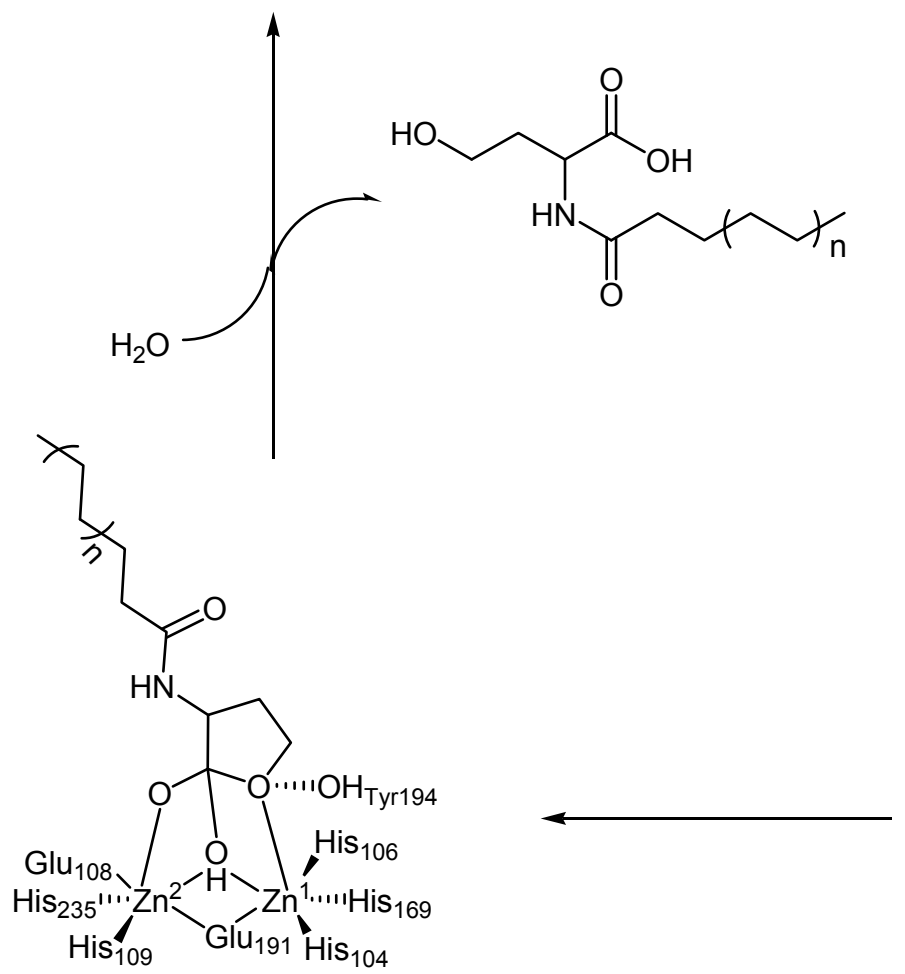

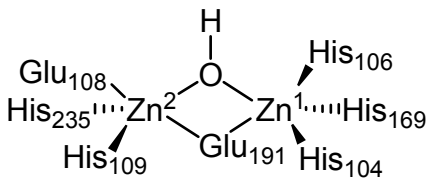<smiles>CCCCCCC(=O)NC1CCOC1=O</smiles>

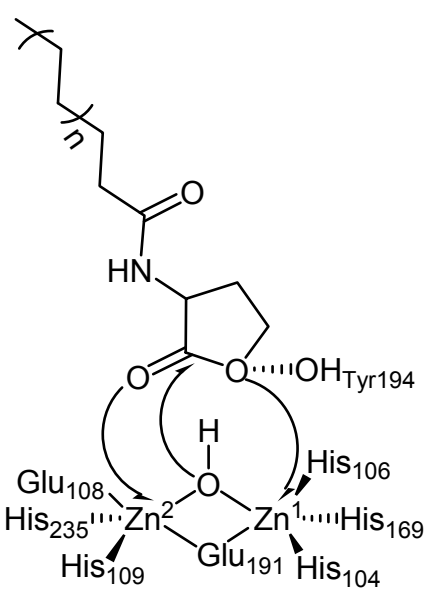

Schema 5: Postulierter Mechanismus der BTK-AiiA. ${ }^{[24]}$

\subsubsection{Aminopeptidasen}

Aminopeptidasen sind Exopeptidasen, die eine wichtige Rolle u.a. beim Abbau von Proteinen, im Stoffwechsel der Aminosäuren und in Regulationsprozessen spielen. Sie sind zuständig für die Abspaltung N-terminaler Reste in polypeptidischen Ketten (Schema 6). Diese Spaltung tritt sowohl in körpereigenen aber auch in pathophysiologischen Prozessen auf. 


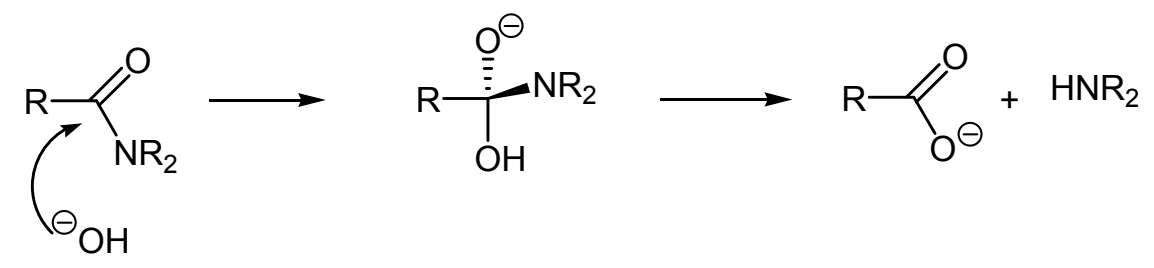

Schema 6: Hydrolysereaktion einer Peptidbindung.

Viele Enzyme brauchen Metallionen im aktiven Zentrum, um katalytisch wirksam zu sein. Im Gegensatz zu anderen Hydrolasen, in welchen man häufiger Mangan(II)-lonen oder Magnesium(II)-lonen als Metallzentren in Metalloenzymen findet, haben Hydrolasen, welche peptidische Bindungen spalten, fast ausschließlich Zink im aktiven Zentrum. ${ }^{[15,27]}$

Metalloaminopeptidasen können mono- oder binukleare aktive Zentren haben. Bei den binuklearen Metalloaminopeptidasen wurde cokatalytische Aktivität beobachtet, wenn beide metallische Stellen belegt sind. ${ }^{[28]}$ Eines der Metalle ist für die Katalyse verantwortlich, das zweite moduliert positiv oder negativ die katalytische Aktivität. ${ }^{[29]}$ Durch die Analyse der Festkörperstrukturen von Metalloaminopeptidasen wurde festgestellt, dass das Metall die katalytische Aktivität bewirkt und sich nahe am Eingang zur aktiven Seite befindet. Das strukturelle Metall ist verdeckt und nahe an der Bindungsstelle des entsprechenden $\mathrm{N}$-Terminus.

Alle röntgenographisch charakterisierten Strukturen der bimetallischen Metalloaminopeptidasen besitzen eine überbrückende Carboxylat- sowie eine überbrückende Hydroxyleinheit. Die Festkörperstrukturen zeigen fast immer dieselbe Koordination, obwohl die Reihenfolge der Aminosäuren nur zu etwa $30 \%$ gleich ist. Zwei Beispiele röntgenographisch charakterisierter Metalloaminopeptidasen sind in Abb. 10 dargestellt. 


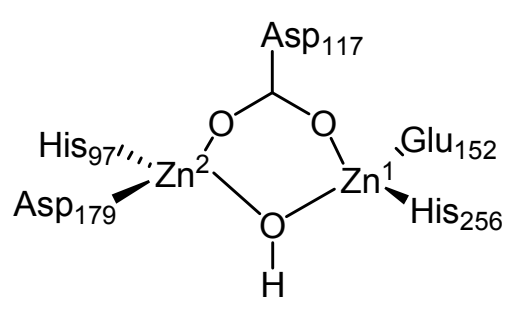

ApAP

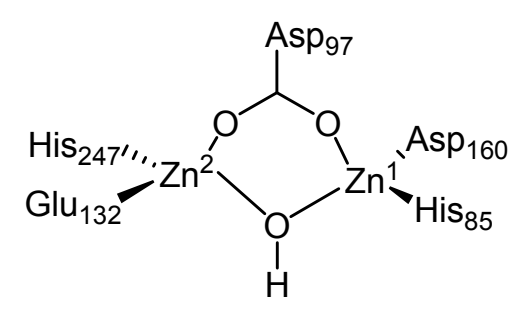

SGAP

Abb. 10: Aktive Zentren der Aminopeptidasen ApAP und SGAP. ${ }^{[29,30]}$

Ein Beispiel von Aminopeptidasen sind die Leucin Aminopeptidasen (LeuAPs). LeuAPs sind ubiquitäre Enzyme, die zu den Metalloaminopeptidasen gehören. ${ }^{[31]}$ Sie wirken auch in pathophysiologischen Prozessen. Ursprünglich gehörten zu dieser Familie nur Enzyme, die einen Leucinrest als letzten Rest am N-Terminus hatten. ${ }^{[32]}$ LeuAPs können nicht alle Aminosäuren am $\mathrm{N}$-Terminus abspalten. Manche Baureihen von Aminosäuren werden bevorzugt. Aminosäuren mit D-Konfiguration können diese Enzyme blockieren. ${ }^{[33]}$ In Abb. 11 ist die Struktur einer LeuAP dargestellt. Das aktive Zentrum ist in Abb. 12 dargestellt.

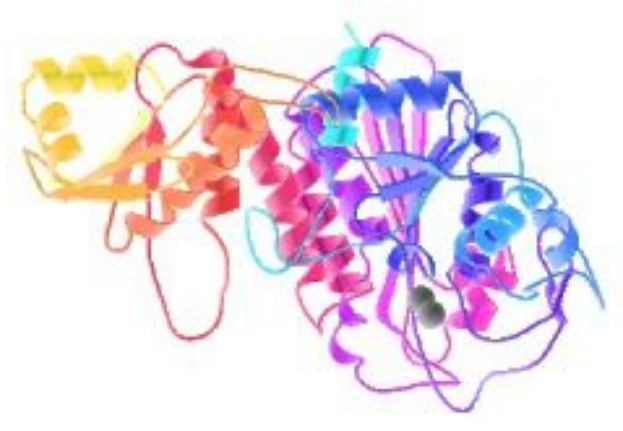

Abb. 11: Struktur der bLeuAP. ${ }^{[34]}$ 


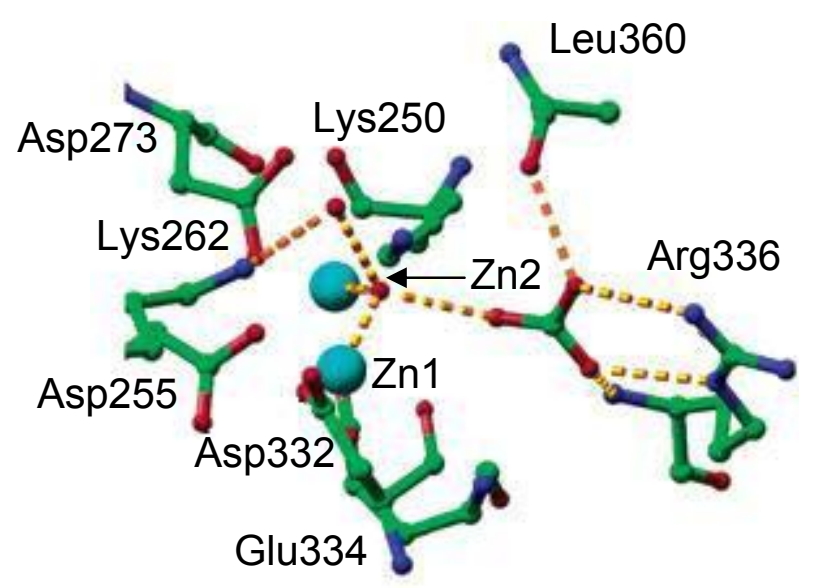

Abb. 12: Aktives Zentrum der bLeuAP.

Die Zinkionen, die in diesen Metalloproteinen enthalten sind, haben eine trigonal bipyramidale Koordination. Der Metall-Metall-Abstand zwischen beiden Metallkernen beträgt ungefähr 3.0 $\AA^{\left[{ }^{[35]}\right.}$ Die Unterschiede in der Umgebung der Zinkkerne spiegeln sich in deren Reaktionsverhalten wieder. Ein Wassermolekül oder eine Hydroxidgruppe verbrückt beide Metallzentren. Die Notwendigkeit zweier Metallionen für die Aufgabe des Enzyms wurde bestätigt, aber es ist nicht nur das aktive Zentrum mit den Zinkionen beteiligt. ${ }^{[36-38]}$ Neue Studien ermöglichen ein besseres Verständnis des Mechanismus dieser Enzyme. ${ }^{[39]}$ In einem der postulierten Mechanismen läuft die Hydrolyse über einen Anhydridmechanismus mit einem kovalenten Übergangszustand. Eine leichte Modifizierung dieser Postulate ist in Abb. 13, Fig. A dargestellt. Die Intermediate $B$ und $C$ der $A b b .13$ wurden aufgrund der Bindungsweise von Inhibitoren an das Metalloprotein postuliert. Der größte Unterschied zwischen diesen drei Zwischenstufen ist der Ursprung des nukleophilen Angriffs. Ein vollständiger Mechanismus wurde nicht postuliert. Kürzliche Arbeiten haben durch strukturelle, kinetische und biologische Daten einen einleuchtenden Mechanismus begründet. ${ }^{[11]}$ 


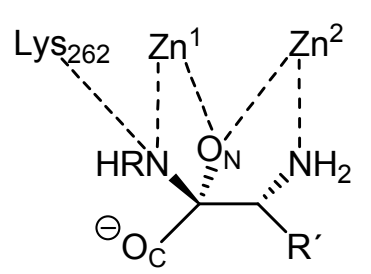

A

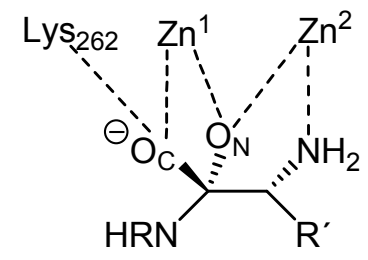

B

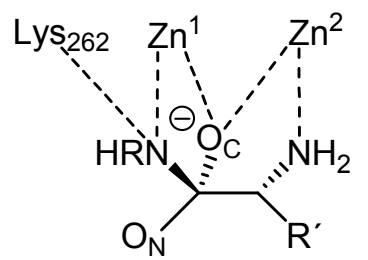

C

$\mathrm{O}_{\mathrm{N}}=$ nukleophiler Sauerstoff

$\mathrm{O}_{\mathrm{C}}=$ Sauerstoff der Carbonylgruppe

Abb. 13: Denkbare Bindungsmöglichkeiten im Übergangszustand von bLeuAP.

\subsection{Ligandsysteme für dinukleare und tetranukleare Komplexe: Brückenliganden}

Für den Aufbau dinuklearer Komplexe sollte ein Ligandsystem als zentrales Element zwischen zwei Metallionen geeignete Bindungsstellen bieten. Liganden für dinukleare Komplexe können die Metalle fixieren, ohne dass Veränderungen an der Peripherie einen großen Einfluß an der Bindung haben.

Hier bieten sich besonders gut Liganden an, die diese zwei Metallionen verbrücken können. Ein gemeinsames Ligandgerüst kann durch koordinierende Donoratome, die in den entsprechenden Seitenarmen eingebunden sind, an die Metallionen binden. Durch Bildung von Chelaten steigt die Stabilität solcher Komplexe. Ein allgemeines Beispiel verbrückter Bimetallkomplexe zeigt Abb. 14.

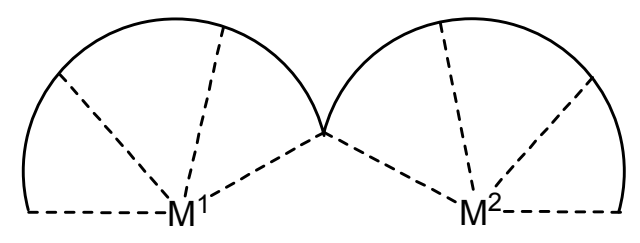

Abb. 14: Aufbau verbrückter Bimetallkomplexe.

Als koordinierende Brückenliganden können Heterozyklen eingesetzt werden, die vicinale Donoratome, wie z.B. Stickstoff, enthalten. Pyrazol-, Pyridazin- oder 
Triazolhaltige Liganden bieten sich als Brückenliganden für dinukleare Komplexe an (Abb. 15).

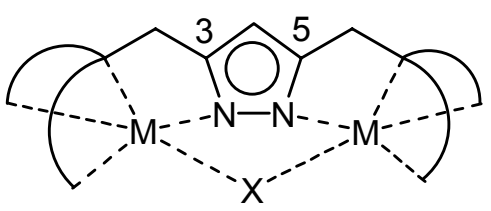

Abb. 15: Pyrazolbasierte verbrückte bimetallische Komplexe.

Der Ligand sollte die zwei Metallionen in einem Komplex in einem Abstand voneinander halten, der den zu untersuchenden Enzymen entspricht. Oft liegt dieser Bereich zwischen 3.0 und $4.6 \AA^{[40]}$ So wird eine realistische Modellierung aktiver Zentren ermöglicht. Durch Variation des Brückenliganden kann der Metall-Metall-Abstand in einem zweikernigen Komplex eingestellt bzw. beeinflusst werden. Eine weitere Eigenschaft solcher Ligandsysteme soll sein, dass die Änderungen der Koordinationsumgebung der Metallionen zu einer unterschiedlichen Reaktivität führen können. Damit können Zusammenhänge zwischen Struktur und Reaktivität gefunden werden. Desweiteren ist für realistische Untersuchungen von Enzymaktivitäten eine ausreichende Stabilität der Modellkomplexe gegen Wasser notwendig.

\subsection{Pyrazol als Brückenligand für dinukleare und tetranukleare Metallkomplexe}

Das Pyrazol ist hierfür als aromatischer Stickstoff-Heterozyklus besonders gut geeignet. Der anionische Charakter der Pyrazolate und die gute Donoreigenschaft der Stickstoffatome wird bevorzugt durch positiv geladene Metallionen stabilisiert. ${ }^{[41,42]}$ Der Metall-Metall-Abstand lässt sich durch Variation der Struktur des Liganden steuern und kann recht unterschiedlich in seiner Größe sein. In Abb. 16 sind zwei Komplexe dargestellt, in welchen die Metall-Metall-Abstände um fast $0.88 \AA$ variieren. Im Nickelkomplex beträgt der Abstand 4.46 $\AA$, im Cobaltkomplex $3.58 \AA$. 


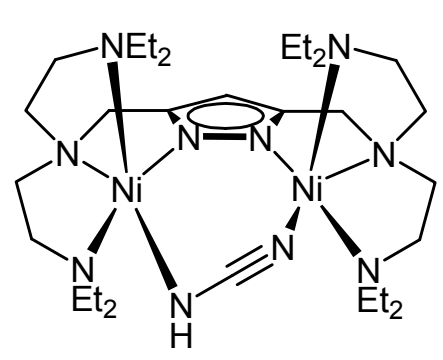

I

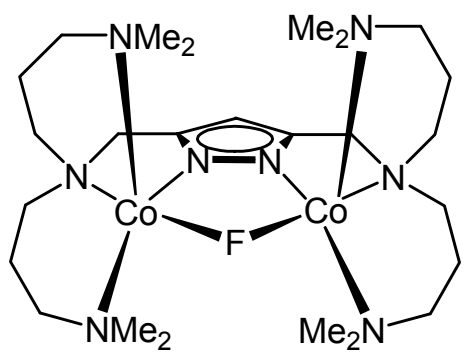

II

Abb. 16: Pyrazolatverbrückter Nickelkomplex ${ }^{[45]}$ und Cobaltkomplex. ${ }^{[46]}$

Die Anzahl der charakterisierten zweikernigen Pyrazolatkomplexe ist relativ groß. ${ }^{[41-43]}$ Auf der Basis von Pyrazolat-Grundbausteinen wurde eine Vielzahl von Ligandsystemen entwickelt. ${ }^{[4]}$ In den letzten Jahren konnten Pyrazolatliganden synthetisiert werden, die in Position 3 und 5 mit chelatisierenden Seitenarmen funktionalisiert sind. Die Chelatfunktion wurde bislang überwiegend mit Stickstoffatomen ausgestattet, aber über Beispiele mit Sauerstoff ${ }^{[47-49]}$, Phosphor ${ }^{[50,51]}$ und Schwefe ${ }^{[52]}$ als koordinierende Heteroatome wurde ebenfalls berichtet. Unsymmetrische Liganden mit unterschiedlichen Donoratomen wurden auch in letzter Zeit dargestellt. ${ }^{[53,54]}$ Pyrazolliganden, die eine metallorganische Bindung ermöglichen, sind ebenso bekannt. ${ }^{[5]}$ In Abb. 17 sind zwei Pyrazolatkomplexe mit unterschiedlich chelatisierenden Seitenarmen dargestellt.

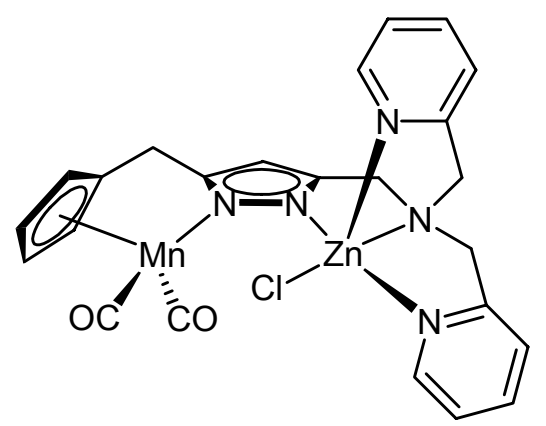

III

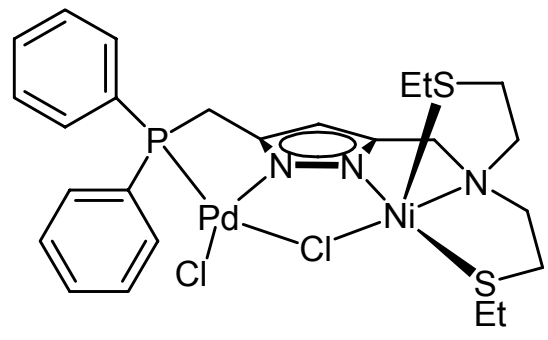

IV

Abb. 17: Pyrazolatkomplexe mit unterschiedlichen Chelatfunktionen. ${ }^{[53,56]}$ 
Durch die besonderen Eigenschaften des Pyrazols als Brückenligand und die Variation der Seitenarme können unterschiedliche Typen von Metallkomplexen, wie z.B. $L M_{2}$ oder $L_{2} M_{2}$ synthetisiert werden. Für Typ $L_{2}$ wird das Ligandmolekül mit der Metallverbindung im stöchiometrischen Molverhältnis von 1:2 umgesetzt. Um die Koordination einer zweiten Pyrazoleinheit zu verhindern, ist der Einbau eines zweiten Brückenliganden nötig. Für den Typ $L_{2} M_{2}$ braucht man Substituenten an den Pyrazolseitenarmen, die nicht allzu sperrig sind. Als Zweitbrücke kann ebenfalls eine zweite Pyrazoleinheit wirken. ${ }^{[44,57]}$ Auch über Metallkomplexe des Typs $\mathrm{L}_{2} \mathrm{M}_{4}$ wurde berichtet. ${ }^{[58,59]}$ Diese Art von Komplexen enthält die Metallionen in zwei unterschiedlichen Subeinheiten. Die beiden Subeinheiten werden durch einen Coligand, der an zwei oder mehrere Metallionen gebunden ist, zusammengehalten. In Abb. 18 sind einige ausgewählte Beispiele für $L_{2} M_{2}$ und $L_{2} M_{4}$ dargestellt.

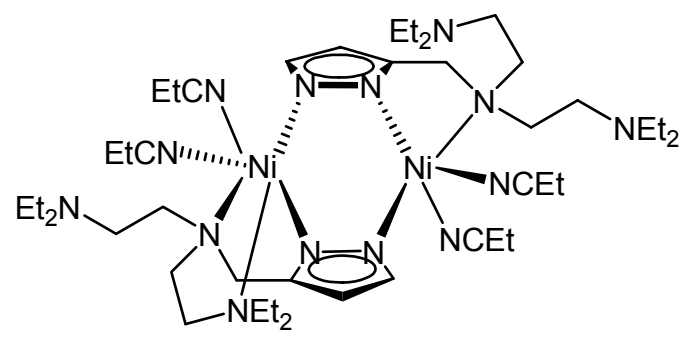

V

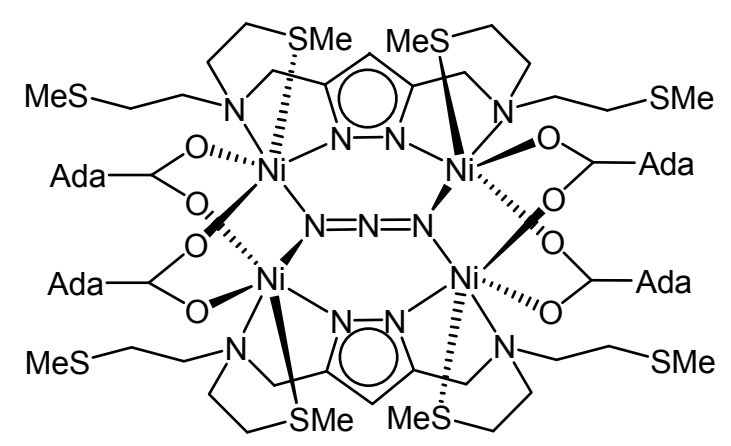

VI

Abb. 18: Beispiele für Komplexe des Typs $L_{2} M_{2}$ und $L_{2} M_{4}{ }^{[57,59]}$

In vorangegangenen Arbeiten über neuartige bimetallische Pyrazolatokomplexe (mit Nickel, Kupfer oder Zink als Metallionen) zeigte sich, dass Variationen in den Seitenarmen des Liganden und eine Veränderung der Zahl und Art der Donoratome zu Komplexen mit unterschiedlichen Eigenschaften führen können. ${ }^{[51-63]}$ Der Metall-Metall-Abstand in den zweikernigen Komplexen beeinflusst deren Reaktivität. Lange Seitenarme in den Positionen 3 und 5 des Pyrazolrings (z.B. Propylentriamin) ergeben mit $3.61 \AA$ in VIII einen kurzen Abstand zwischen den beiden Metallionen und bieten so nur einer monoatomaren Zweitbrücke ausreichend Platz. Im Gegensatz dazu ist bei kurzen Seitenarmen (z.B. Ethylendiamin) am Pyrazol durch den großen 
Abstand zwischen beiden Metallionen von 4.37 $\AA$ (Verbindung VII) auch eine größere, z.B. dreiatomige, Zweitbrücke möglich (Abb. 19).

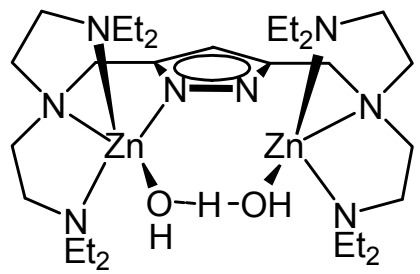

VII

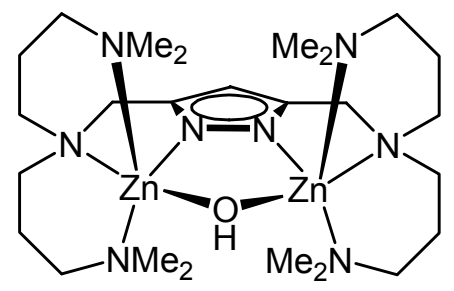

VIII

Abb. 19: Pyrazolatodizinkkomplexe mit verbrückendem und terminalem Hydroxid. ${ }^{[64]}$

\subsection{Zielsetzung}

In einem dinuklearen Metallkomplex kann der Abstand zwischen den beiden Metallionen durch dafür geeignete Ligandstrukturen beeinflusst werden. Dabei kommt es bei einem System auf Pyrazolbasis vor allem auf die Länge der chelatisierenden Ketten in Position 3 und 5 an.

Für den Fall eines Dizinkkomplexes soll eine Reihe von bereits in der Literatur bekannten sowie erstmals darzustellenden Liganden die Kenntnisse über deren Eignung als Modellsubstanzen für enzymatische Reaktionen erweitern. Das Ziel dabei ist die Möglichkeit des Einbaus einer zweiten Brücke, welche anionischer Natur ist und aus drei Atomen besteht. Eine zusätzliche Pyrazolatbrücke als Zweitbrücke soll durch Wahl eines geeigneter Substituenten in Position 3 und 5 des Pyrazols umgangen werden. Für den Einbau einer dreiatomigen Brücke muss der Abstand zwischen den beiden Zink(II)-Ionen in einem geeigneten Bereich liegen.

Erfolg versprechen dabei besonders Liganden mit N-Methyl-imidazolylaminound Pyridinylaminosubstituenten an den Seitenarmen des Pyrazols. Die Positionen 3 und 5 des Pyrazols sollen durch $-\mathrm{CH}_{2} \mathrm{~N}\left(\mathrm{R}_{1} \mathrm{R}_{2}\right)$ Gruppen substituiert sein, wobei $R_{1}=R_{2}$, aber auch $R_{1} \neq R_{2}$ sein kann. $R_{1}$ und $R_{2}$ können dabei sowohl aromatischer wie auch aliphatischer Natur sein. Es soll dabei 
auch festgestellt werden, welche Ligandmoleküle einen besonders günstigen chelatisierenden Effekt haben und somit die Dizinkkomplexe stabilisieren.

Um Zusammenhänge zwischen Struktur und Reaktivität zu verfolgen, sollen verschiedene Dizinkkomplexe mit unterschiedlicher Koordinationsumgebung synthetisiert werden. Die in den Modellkomplexen eingesetzte Zweitbrücke soll den in der Natur vorkommenden Verbrückungen ähneln. Nur so kann ein guter Vergleich der Reaktivität erhalten werden. Enzyme, die unter physiologischen Bedingungen wirken, gehen Wechselwirkungen mit dem Substrat (z.B. Peptidketten) ein und bauen dieses in mehreren Schritten in seine molekularen Bestandteile ab. Die Modellkomplexe sollen sich diesem Muster aus der Natur anpassen und somit auch bereits unter physiologischen Bedingungen eine gewisse Aktivität aufweisen. Die Aktivität soll quantitativ durch Wechselwirkung eines Komplexes mit geeigneten Substraten (z.B. p-Nitrophenolacetat) bestimmt werden. Diese Umsetzung kann spektroskopisch (z.B. UV-Vis Spektroskopie) verfolgt werden. Darüber hinaus kommen für qualitative Befunde für die Aktivität eines Komplexes auch andere spektroskopische Methoden, z.B. ${ }^{1} \mathrm{H}-\mathrm{NMR}-S p e k t r o s k o p i e$ und Massenspektrometrie in Frage.

Ziel der vorliegenden Arbeit ist es, Ligandmoleküle zu entwickeln, mit welchen die Darstellung von Dizinkkomplexen mit den beschriebenen Eigenschaften ermöglicht wird. Die dargestellten Komplexe sollen dann vollständig charakterisiert werden. 


\section{Ligandsynthese}

\subsection{Eigenschaften der Pyrazolat-Liganden}

In Rahmen dieser Arbeit wurden die Liganden $L^{1}$ bis $L^{12}$ verwendet (Abb. 21). Sie erlauben ein Studium der Koordinationseigenschaften mit zweifach geladenen Metallionen, insbesondere mit Zink. Wie bei vielen dieser Liganden in anderen Arbeiten gefunden wurde, erlauben diese Liganden unterschiedliche Metall-Metall-Abstände durch die wechselnde Länge der Seitenarme. ${ }^{[51,65]} \mathrm{Je}$ nach Länge der Seitenarme werden Chelatringe aus fünf oder sechs Atomen gebildet. Diese möglichen unterschiedlichen Chelate sollen Auswirkung auf die Koordination der Donoratome mit dem Metall haben und die Eigenschaften der Komplexe modifizieren. Sonderfälle in dieser Arbeit sind die Liganden $L^{3}$ und $L^{9}$, die zwei unterschiedliche Chelatringe bilden können, einen mit fünf Atomen und einen anderen mit sechs. Das führt zu vier unterschiedlichen N-Donoratomen an jedem Seitenarm. Die Nutzung von asymmetrischen Aminen an den Seitenarmen des Liganden $\left(L^{2}, L^{3}\right.$ und $\left.L^{4}\right)$ führt ebenfalls $z u$ vier unterschiedlichen N-Donoratomen (Abb. 20).<smiles>[R]N([R])Cc1cc(CN([R])[R])[nH]n1</smiles><smiles>[R]N([R])Cc1cc(CN([R])[R])[nH]n1</smiles>

Abb. 20: Allgemeine Darstellung von in dieser Arbeit verwendeten 3,5-Bis(aminomethyl)pyrazol Liganden.

Die verschiedenen Donoratome der Seitenarme können zu einer unterschiedlichen Koordinationssphäre führen. Bei Liganden mit $\mathrm{sp}^{2}$ hybridisierten N-Atomen bietet sich die Möglichkeit zur Metall-DonoratomRückbindung. Dies kann bei vielen Metallen zur Modifizierung der Redoxpotentiale führen. ${ }^{[66]}$ Seitenarme mit aliphatischen Resten ermöglichen diese Rückbindung nicht. 
<smiles>Cn1ccnc1CN(Cc1cc(CN(Cc2nccn2C)Cc2nccn2C)[nH]n1)Cc1nccn1C</smiles>

$\mathrm{L}^{1}$<smiles>Cn1ccnc1CN(CCc1ccccn1)Cc1cc(CN(CCc2ccccn2)Cc2nccn2C)[nH]n1</smiles>

$\mathbf{L}^{3}$<smiles>Cc1cccc(CN(Cc2cc(CN(Cc3cccc(C)n3)Cc3cccc(C)n3)[nH]n2)Cc2cccc(C)n2)n1</smiles>

$\mathbf{L}^{5}$<smiles>CCNCCN(CCNCC)Cc1cc(CN(CCNCC)CCNCC)[nH]n1</smiles>

$\mathbf{L}^{7}$<smiles>c1ccc(CCN(CCc2ccccn2)Cc2cc(CN(CCc3ccccn3)Cc3ccccn3)[nH]n2)nc1</smiles>

$L^{9}$<smiles>CNCCN(C)Cc1cc(CN(C)CCN(C)C)[nH]n1</smiles>

$\mathrm{L}^{11}$<smiles>CCNCCN(Cc1ccccn1)Cc1cc(CN(CCNCC)Cc2ccccn2)[nH]n1</smiles>

$L^{2}$<smiles>CCNCCN(Cc1cc(CN(CCNCC)Cc2nccn2C)[nH]n1)Cc1nccn1C</smiles>

$L^{4}$<smiles>c1ccc(CN(Cc2ccccn2)Cc2cc(CN(Cc3ccccn3)Cc3ccccn3)[nH]n2)nc1</smiles>

$\mathrm{L}^{6}$<smiles>c1ccc(CCN(CCc2ccccn2)Cc2cc(CN(CCc3ccccn3)CCc3ccccn3)[nH]n2)nc1</smiles><smiles>CNCCCN(CCCNC)Cc1cc(CN(CCCNC)CCCN(C)C)[nH]n1</smiles>

$\mathrm{L}^{10}$<smiles>CNCCCN(C)Cc1cc(CN(C)CCCN(C)C)[nH]n1</smiles>

$L^{12}$

Abb. 21: Verwendete Pyrazolliganden. 


\subsection{Synthese der 3,5-Bis(aminomethyl)pyrazol-Liganden}

\subsubsection{Mehrstufensynthese der 3,5-difunktionellen Pyrazol- Schlüsselsubstanz}

Als Grundbausteine für die Synthese symmetrischer und asymmetrischer Pyrazolatliganden mit chelatisierenden Aminomethylseitenarmen stehen das $N$-THP-geschützte 3,5-Bis(chloromethyl)pyrazol XIII sowie das ungeschützte 3,5-Bis(chloromethyl)-pyrazol Hydrochlorid XII zur Verfügung (Schema 7). Im Gegensatz zu früheren Arbeiten mit Pyrazolatliganden wurde hier das Pyrazol-3,5-dicarbonsäuredichlorid für die Reaktion mit sekundären aliphatischen Aminen wegen Problemen bei der Aufreinigung nicht benutzt. Diese Probleme entstehen zum Teil auch aufgrund einer partiellen Spaltung der Amidbindung durch das Lithiumaluminiumhydrid $\left(\mathrm{LiAlH}_{4}\right)$ bei der nachfolgenden Reduktion der Amide.

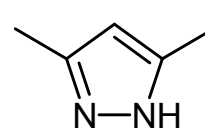

VIII

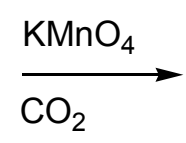

$\mathrm{CO}_{2}$<smiles></smiles>

$\mathrm{X}$<smiles>CC(=O)OC(=O)c1cc(C(=O)O)n[nH]1</smiles>

IX

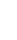

\section{$\mathrm{MeOH} / \mathrm{HCl}$}

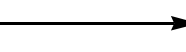<smiles>C[C+](Cl)Cl</smiles>

XI

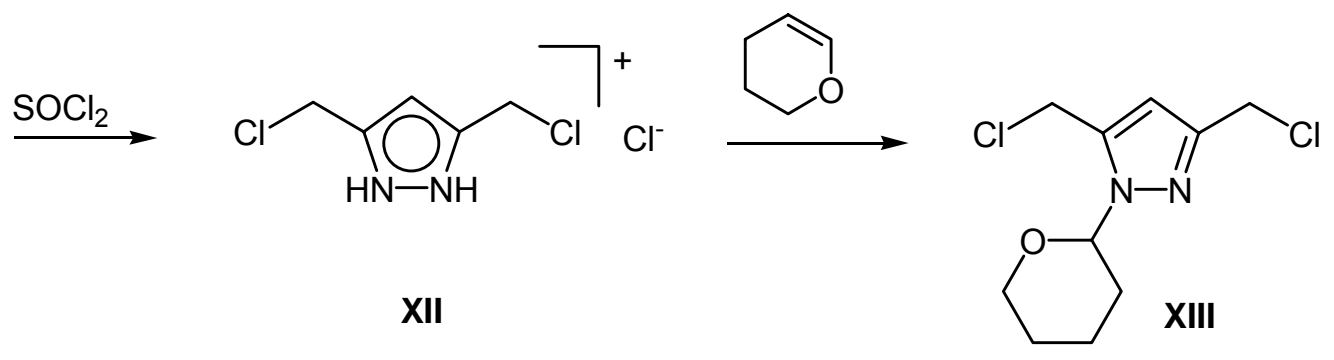

Schema 7: Route der Synthese von 3,5-Bis(chloromethyl)-1-(tetrahydropyran-2-yl)pyrazol.

Der Grundbaustein 3,5-Bis(chloromethyl)-1-(tetrahydropyran-2-yl)pyrazol wurde nach Literaturvorschriften hergestellt. ${ }^{[50,67,68]}$ Die erste Stufe ist die Oxidation des 3,5-Dimethylpyrazols VIII durch Kaliumpermanganat $\left(\mathrm{KMnO}_{4}\right)$ zum 
Pyrazol-3,5-dicarbonsäuremonokaliumsalz IX. Dieses Salz wird durch Säurekatalyse mit Methanol verestert. Durch die Reaktion des Esterhydrochlorids $\mathbf{X}$ mit $\mathrm{LiAlH}_{4}$ findet die Reduktion zum Alkohol XI statt. Die Menge $\mathrm{LiAlH}_{4}$ für die Reduktion zum Alkohol konnte gegenüber den Angaben in der Literatur deutlich gesenkt werden. Um ein Mol des Esterhydrochlorids zum Alkohol XI zu reduzieren, werden theoretisch $1.25 \mathrm{Mol} \mathrm{LiAlH}_{4}$ benötigt. Die Reduktion wurde mit einem Überschuss von etwa $20 \% \mathrm{LiAlH}_{4}$ durchgeführt. Die Chlorierung des Alkohols XI wird durch Umsetzung mit $\mathrm{SOCl}_{2}$ durchgeführt. Das erhaltene 3,5-Bis(chloromethyl)pyrazol Hydrochlorid XII wird mit 3,4Dihydropyran in Dichlormethan zum THP-geschützten 3,5-Bis(chloromethyl)-1(tetrahydropyran-2-yl)pyrazol XIII umgesetzt.

\subsubsection{Darstellung der Amine für die Pyrazol-Seitenarme}

Die verschiedenen ausgewählten Amine für die Bindung der Seitenarme wurden in den meisten Fällen nach Literaturvorschriften hergestellt. Im Einzelnen sind das die folgenden Amine:

Bis[2-(2-pyridyl)ethyl]amin (BPEA) $\mathbf{X X}^{\left[{ }^{[71,72]}\right.}$

Bis[2-(2-pyridyl)methyl]amin (BPMA) $\mathbf{X X I}^{[71,72]}$

(2-Pyridylmethyl)[2-(2-pyridyl)ethyl]amin (BPEMA) XXII ${ }^{[71,72]}$

$\mathrm{N}, \mathrm{N}, \mathrm{N}^{\prime}, \mathrm{N}^{\prime}$-Tetraethyldiethylentriamin $\mathbf{X X V}^{[73]}$

$\mathrm{N}, \mathrm{N}, \mathrm{N}^{\prime}$-Trimethyl-1,2-ethylendiamin $\mathbf{X V} \mathbf{I}^{[69,70]}$

$\mathrm{N}, \mathrm{N}, \mathrm{N}^{\prime}$-Trimethyl-1,3-propylendiamin $\mathrm{XVII}^{[69,70]}$

Bis[2-(1-methylimidazolyl)methyl]amin $\mathbf{X X I X}^{[75,76]}$

Bis[(6-methyl-2-pyridyl)methyl]amin XXXII

$\mathrm{N}$-(Pyridyl-2-methyl)-(2-diethylaminoethyl)amin XXXIV

$\mathrm{N}, \mathrm{N}$-Diethyl-N-(1-methyl-1H-imidazol-2-yl-methyl)ethylen-1,2-diamin XXXV (1-Methyl-1H-imidazol-2-yl-methyl)-(2-pyridin-2-yl-ethyl)amin XXXVI $\mathrm{N}, \mathrm{N}, \mathrm{N}^{\prime}$-Trimethylpropylentriamin ist im Handel erhältlich

Ausgangsstoffe für die Synthese von N,N,N'-Trimethyl-1,3-propylendiamin XVII und $\mathrm{N}, \mathrm{N}, \mathrm{N}^{\prime}$-Trimethyl-1,2-ethylendiamin $\mathrm{XVI}$ sind die Hydrochloride von 
3-Chlorpropyl-N,N-dimethylamin XV und von 2-Chlorethyl-N,N-dimethylamin XIV, welche mit einer 40 \%-igen wäßrigen Lösung von Methylamin umgesetzt werden (Schema 8). ${ }^{[69,70]}$

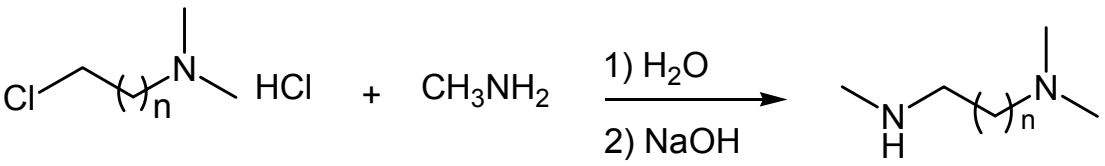

$$
\begin{aligned}
& \mathrm{n}=1:(\mathbf{X I V}) \\
& \mathrm{n}=2:(\mathbf{X V}) \\
& \begin{array}{l}
\mathrm{n}=1:(\mathbf{X V I}) \\
\mathrm{n}=2:(\mathbf{X V I I})
\end{array}
\end{aligned}
$$

Schema 8: Synthese aliphatischer Diamine.

Bis[2-(2-pyridyl)ethyl]amin (BPEA) XX kann aus 2-Vinylpyridin XVIII und Ammoniumchlorid in Methanol gewonnen werden. Bis(2-pyridylmethyl)amin (BPMA) XXI und (2-Pyridylmethyl)[2-(2-pyridyl)ethyl]amin (BPEMA) XXII werden aus Pyridin-2-aldehyd $\mathrm{XIX}$ und dem entsprechenden (2-Pyridylalkyl)amin in absolutem Ethanol hergestellt (Schema 9). ${ }^{[71,72]}$
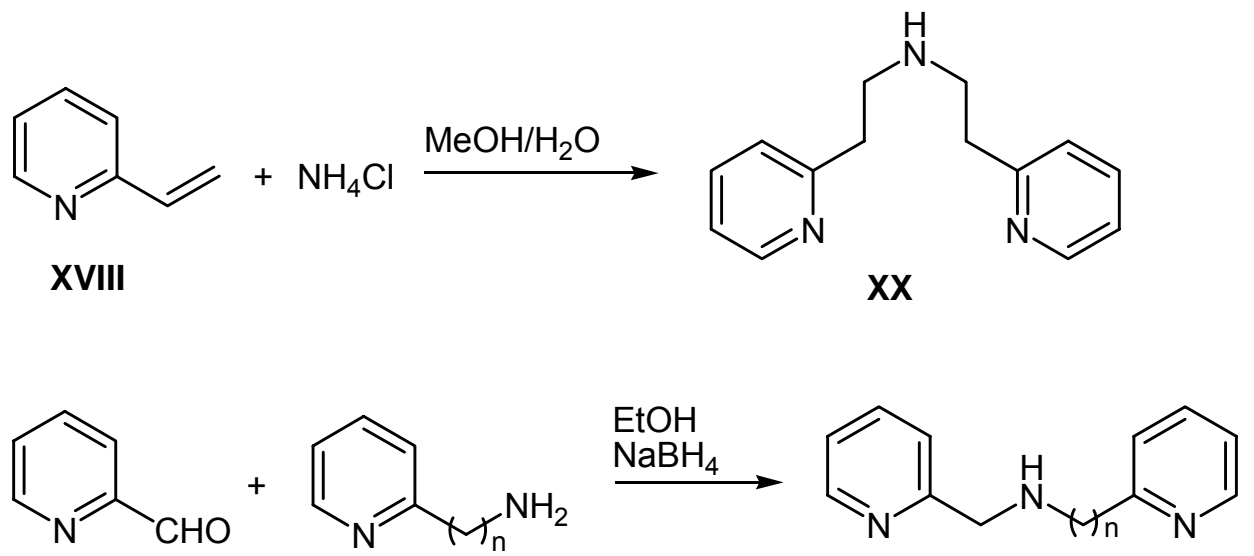

XIX

$$
\begin{aligned}
& n=1: \text { BPMA }(\mathbf{X X I}) \\
& n=2: \text { BPEMA (XXII) }
\end{aligned}
$$

Schema 9: Synthese der Pyridylamine XX, XXI und XXII.

$\mathrm{N}, \mathrm{N}, \mathrm{N}^{\prime}, \mathrm{N}^{\prime}$-Tetraethyldiethylentriamin XXV wurde, wie in der Literaturvorschrift durch die Umsetzung des Hydrochlorids von 2-Chloroethyldiethylamin XXIII mit $\mathrm{N}, \mathrm{N}$-Diethylethylendiamin XXIV nach Schema 10 dargestellt. ${ }^{[73]}$ 
<smiles>CCNCCNCCNCCCN(CC)CCN</smiles>

Schema 10: Synthese von $N, N, N^{\prime}, N^{\prime}-$ Tetraethyldiethylentriamin.

Für Bis[(1-methylimidazol-2-yl)methyl]amin XXIX wurde das Darstellungsverfahren, welches in der Literatur beschrieben ist, leicht modifiziert. ${ }^{[75,76]}$ N-Methylimidazol XXVI wurde mit $n$-BuLi deprotoniert, dann mit Dimethylformamid zum N-Methylimidazolyl-2-aldehyd XXVII umgesetzt, welches mit Hydroxylaminhydrochlorid in das N-Methylimidazol-2-yl-oxim XXVIII überführt wurde. Aus diesem wurde schließlich durch Hydrierung an einem $\mathrm{Pd} / \mathrm{C}$-Katalysator XXIX erhalten (Schema 11).

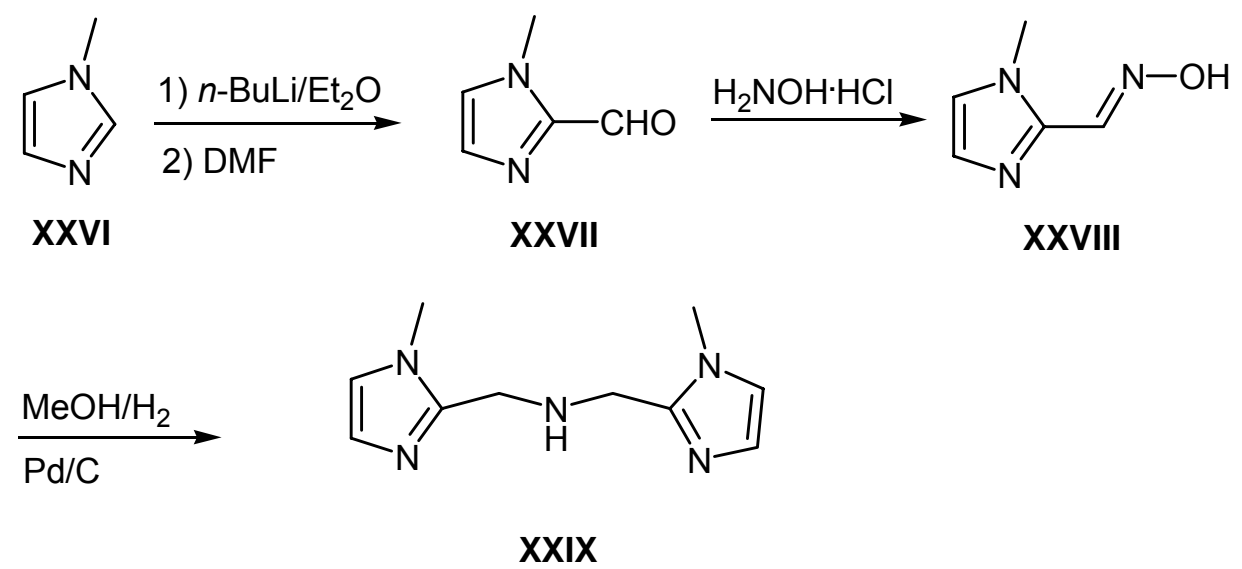

Schema 11: Synthese von Bis[(1-methylimidazol-2-yl)methyl]amin.

Nach Angaben in der Literatur beträgt die Dauer der Hydrierung bei Raumtemperatur etwa 7 Tage. Durch Erhöhung der Temperatur auf $65{ }^{\circ} \mathrm{C}$ konnte die Reaktionszeit auf 2-3 Tage verkürzt werden. Als Nebenprodukt der Reaktion fällt eine geringe Menge an N-Methyl-2-aminomethylimidazol an.

Für Bis[(6-methyl-2-pyridyl)methyl]amin XXXII wurde ähnlich zu XXIX aus 6-Methylpyridin-2-aldehyd und Hydroxylaminhydrochlorid zunächst das 6-Methylpyridin-2-oxim hergestellt. Das Oxim wurde an einem Pd/C-Katalysator in einer Methanol/Wasser-Mischung hydriert (Schema 12). Der Unterschied in 
den Synthesebedingungen zur Darstellung von XXIX und XXXII besteht darin, dass für XXXII die Oxim-Zwischenstufe XXXI nicht isoliert wurde, sondern sich sofort die Hydrierung angeschlossen hat.

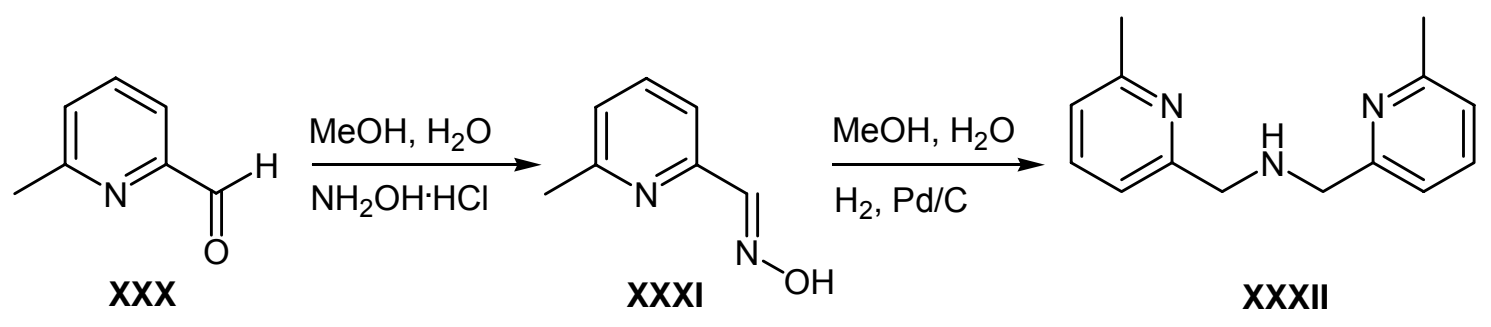

Schema 12: Synthese von Bis[(6-methyl-2-pyridyl)methyl]amin.

Für die Synthese von Pyrazolliganden mit bislang nicht verwendeten Seitenarmen war auch die Herstellung neuartiger Amine notwendig. Sie erfolgt im Prinzip nach Hinweisen aus ähnlichen Verbindungen. ${ }^{[72,74,75]}$ Dabei wurden die Darstellungsverfahren allerdings zwecks Optimierung der Ausbeute und der Reaktionsbedingungen etwas abgewandelt. Bei diesen selten verwendeten Aminen handelt es sich um N,N-Diethyl- $\mathrm{N}^{\prime}$-2-pyridylmethylethylendiamin XXXIV, N,N-Diethyl-N'-(1-methylimidazol-2-ylmethyl)ethylendiamin XXXV, (1-Methylimidazol-2-ylmethyl)-(2-pyridin-2-ylethyl)amin XXXVI und Methyl-(1methylimidazol-2-ylmethyl)amin XXXVII. Sie wurden durch Umsetzung von Pyridin-2-aldehyd XIX bzw. N-Methylimidazol-2-aldehyd XXVII mit $\mathrm{N}, \mathrm{N}$-Diethylethylendiamin XXIV, 2-Aminoethylpyridin XXXIII bzw. Methylamin zu den entsprechenden Iminen und durch nachfolgende Reduktion der Imine mit Natriumborhydrid erhalten (Schema 13). Die vier Amine XXXIV, XXXV, XXXVI und XXXVII sind insofern von besonderem Interesse, als die N-Atome der 3,5ständigen Aminomethylgruppen des Pyrazols ungleiche Substituenten tragen, so dass an jedes dieser beiden Stickstoffatome zwei verschiedene Seitenarme gebunden sind. 
<smiles>O=Cc1ccccn1</smiles>
XIX<smiles>Cn1ccnc1C=O</smiles>
XXVI<smiles>Cn1ccnc1C=O</smiles>
XXVI<smiles>CCN(CC)Cc1nccn1C</smiles>
1) $\mathrm{EtOH}$
2) $\mathrm{NaBH}_{4}$

XXIV

1) $\mathrm{EtOH}$

2) $\mathrm{NaBH}_{4}$

XXIV<smiles>CCNCCNCc1ccccn1</smiles><smiles>CCNCCNCc1nccn1C</smiles>

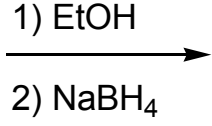<smiles>Cn1ccnc1CNCCc1ccccn1</smiles><smiles>CNCc1nccn1C</smiles>

Schema 13: Allgemeine Synthese asymmetrischer Amine.

\subsubsection{Synthese der Liganden}

Die Synthese bekannter Liganden erfolgt nach Literaturangaben. ${ }^{[49,77,78]}$ Neue Liganden wurden in abgewandelter Form aus der geschützten Pyrazolverbindung XIII, dem jeweiligen Amin und $\mathrm{Na}_{2} \mathrm{CO}_{3}$ in Acetonitril durch 24-stündiges Erhitzen unter Rückfluss dargestellt. Das verwendete Molverhältnis XIII:Amin: $\mathrm{Na}_{2} \mathrm{CO}_{3}$ war etwa 1:2:10. $\mathrm{Na}_{2} \mathrm{CO}_{3}$ wurde vor dem Einsatz $3 \mathrm{~h}$ bei $120^{\circ} \mathrm{C}$ und $10^{-3}$ mbar getrocknet.

Nach Abkühlen der Reaktionslösung auf Raumtemperatur erfolgte die Abtrennung von $\mathrm{Na}_{2} \mathrm{CO}_{3}$ und $\mathrm{NaCl}$ durch Filtration. Das vom Lösungsmittel befreite Filtrat wurde zur Abspaltung der THP-Schutzgruppe mit ethanolischer $\mathrm{HCl}$ behandelt. Das dabei erhaltene Hydrochlorid des Liganden wurde mit wässriger $\mathrm{NaOH}$ deprotoniert und die alkalische Lösung mit Dichlormethan extrahiert. Nach Trocknung des Dichlormethan-Extrakts über $\mathrm{MgSO}_{4}$ und 
Entfernen des Lösungsmittels im Vakuum wurde der Ligand erhalten (Schema 14).

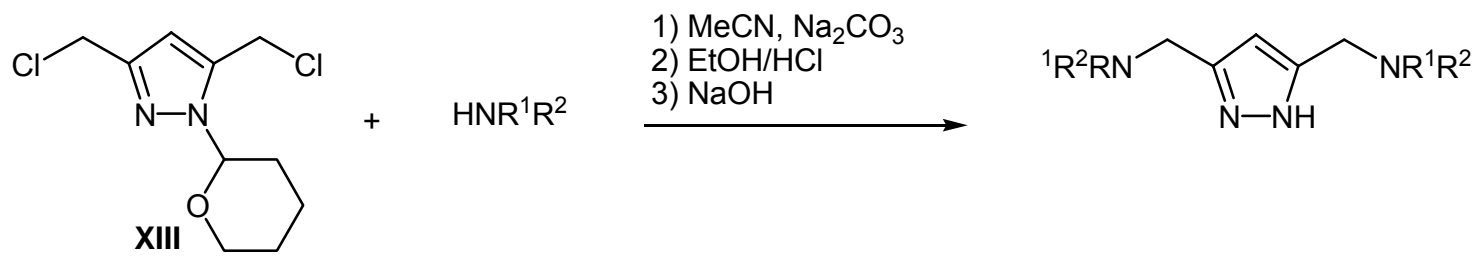

Schema 14: Synthese der Pyrazolliganden.

Letzte Lösungsmittelspuren wurden den Liganden durch Temperierung auf $60{ }^{\circ} \mathrm{C}$ im Vakuum bei etwa $10^{-5}-10^{-6}$ mbar entzogen. Auf Einhaltung der Temperatur wurde dabei besonders geachtet, da derartige Pyrazolliganden erfahrungsgemäß bei höheren Temperaturen zu Zersetzung neigen.

Mit der Verbindung XII, bei der die Spaltung der THP-Schutzgruppe entfällt, wurden auch Liganden dargestellt. Die verwendeten Bedingungen sind dieselben wie bei den Reaktionen, bei denen die Verbindung XIII als Grundbaustein benutzt wurde.

Die Synthese von Komplexen mit asymmetrischen Pyrazolderivaten kann zur Bildung von Isomeren führen (Abb. 22). Ist die Symmetrie solcher Komplexe durch eine Spiegelebene bestimmt, spricht man von der meso Form. Wenn die Symmetrie durch eine $\mathrm{C}_{2}$-Achse definiert ist, liest die die rac Form vor, bei der zwei Enantiomere möglich sind.<smiles>SN(S)Cc1n[nH]c(CN(S)S)c1I</smiles>

meso<smiles>SN(S)Cc1cc(CN(S)S)[nH]n1</smiles>

rac

Abb. 22: Mögliche Raumorientierungen asymmetrischer deprotonierter Pyrazolliganden (bezüglich der Symmetrie dinuklearer Komplexe). 


\section{Pyrazolatodizinkkomplexe (Darstellung, Strukturen und spektroskopische Daten)}

\subsection{Allgemeine Komplexsynthese und Festkörperstrukturen}

In dieser Arbeit wurde eine Vielzahl von neuen Pyrazolliganden dargestellt, die mit unterschiedlichen Metallsalzen zur Herstellung von dinuklearen Metallkomplexen eingesetzt wurden. Wie in der Literatur bereits bekannt ist, können ähnliche Pyrazolliganden und deren Komplexe mit Zink(II)-, Kupfer(II)-, Cobalt(II), Mangan(II)- bzw. Nickel(II)-lonen sinnvoll zur Anwendung als Modellverbindungen für Metallenzyme benutzt werden. ${ }^{[51,60,61,79-81]}$

Um Dizink(II)-Komplexe der Liganden zu erhalten, wurde ein Äquivalent des Liganden mit einer Base und zwei Äquivalenten eines Zink(II)-Salzes umgesetzt. Eine Base wird zur Deprotonierung der $\mathrm{NH}$-Bindung des Pyrazolrings benötigt, um eine verbrückende Pyrazolateinheit zu schaffen.

Um eine zweite Brücke zwischen beiden Metallkernen aufzubauen, wird ein zweites Äquivalent Base verwendet. Je nachdem, welchen Abstand die beiden Metallionen zueinander haben sollen, sind unterschiedliche Brückenarten möglich. Für kleinere Abstände bieten sich sehr gut Hydroxid- oder Methanolatbrücken an. Für größere Abstände werden diese Brücken von halbterminalem Wasser bzw. Hydroxid oder Methanol bzw. Methanolat aufgebaut (Abb. 23). Eine zweite Möglichkeit ist die Nutzung verbrückender, koordinierender, anionischer Coliganden. Hier bieten sich Anionen wie Nitrat oder Acetat an, die auch als nicht verbrückende Coliganden dienen.
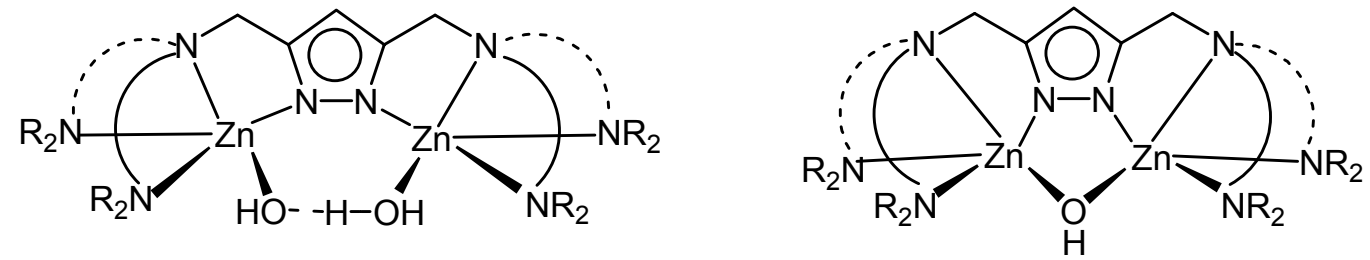

Abb. 23: Möglichkeiten für die Zweitbrücke zwischen den Metallionen. 
Als Base wurde üblicherweise Lithiumhydroxid oder Kalium-tert-butylat verwendet. Als Gegenion bietet sich insbesondere das nicht koordinierende Perchloration an. Komplexe mit Nitrat (koordinierend), Triflat und Tetraphenylborat wurden ebenso dargestellt.

Die Synthese der Metallkomplexe wurde immer auf ähnliche Art durchgeführt. ${ }^{[64]}$ Die Liganden wurden in Methanol, Aceton oder einer Mischung von Acetonitril und Wasser gelöst und mit einem oder zwei Äquivalenten Kalium-tert-butylat deprotoniert. Nach 10 Minuten wurde das entsprechende Metallsalz zugegeben und die Reaktionsmischung bei Raumtemperatur 12 Stunden gerührt. Die erhaltenen Metallkomplexe wurden zur Reinigung aus verschiedenen organischen Lösungsmitteln kristallisiert. Der unterschiedliche Aufbau der Ligandenseitenarme hat Auswirkungen auf die Koordinationschemie und bestimmt somit die Struktur der erhaltenen Komplexe.

Dinukleare Zink(II)-Komplexe vieler Liganden wurden nach der oben beschriebenen Methode isoliert und strukturell charakterisiert. Die Zinkkerne befinden sich in allen Fällen innerhalb der durch die Seitenarme am Pyrazol gebildeten Tasche. Durch geeignete Wahl von Ligand und Coligand kann der Metall-Metall-Abstand gesteuert werden.

Um die trigonal bipyramidale und die pyramidal tetragonale Koordination eindeutiger zu unterscheiden, wurde der strukturelle Parameter $\tau$ verwendet (Abb. 24). ${ }^{[82]} \tau$ ist ein Mass für die Trigonalität fünffach koordinierter Strukturen und ist wie folgt definiert: $\tau=(\beta-\alpha) / 60$. $\alpha$ und $\beta$ sind die zwei basalen Winkel, wobei $\beta$ der größere von beiden ist. $\alpha$ ist der größte Winkel zwischen den drei übrigen Bindungen. Für eine ideal tetragonale Symmetrie ist $\tau=0$ ( $\alpha=\beta=$ $\left.180^{\circ}\right)$, für ideal trigonal bipyramidale Symmetrie ist $\tau=1\left(\alpha=120^{\circ}\right.$ und $\beta=$ $180^{\circ}$ ). Bei vielen tetragonalen Strukturen ist das Metallatom außerhalb der äquatorialen Ebene in Richtung des axialen Donoratoms verschoben, was größere Werte als 1 verursachen kann. 

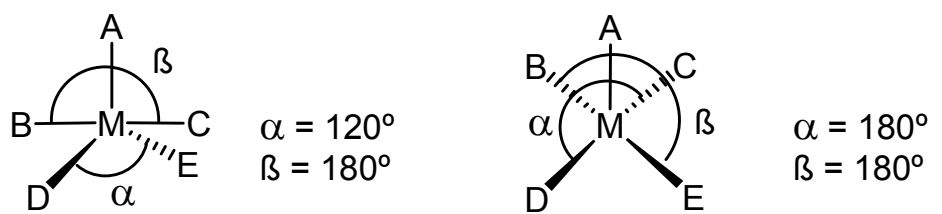

Abb. 24: Schematische Darstellung des Parameters $\tau$.

\subsection{Zink(II)-Pyrazolatokomplexe}

\subsubsection{Coligand: Acetat}

\subsubsection{Zink(II)-Komplex des Liganden $\mathrm{L}^{1}-$ Synthese von $\left[\mathrm{L}^{1}{ }_{\mathrm{H}}\left(\mu-\mathrm{CH}_{3} \mathrm{COO}\right) \mathrm{Zn}_{2}\right]\left(\mathrm{ClO}_{4}\right)_{2}$ (1a) und (1b)}

Durch die Umsetzung des deprotonierten Liganden $\mathrm{L}^{1}$ mit Zink(II)-Perchlorat Hexahydrat und Natriumacetat konnte der Komplex $\left[\mathrm{L}^{1}{ }_{-\mathrm{H}}\left(\mu-\mathrm{CH}_{3} \mathrm{COO}\right) \mathrm{Zn}_{2}\right]\left(\mathrm{ClO}_{4}\right)_{2}$ (1a) erhalten werden (Abb. 25). Durch langsame Diffusion von Petrolether in eine konzentrierte Acetonlösung des Komplexes wurden farblose Kristalle von 1a erhalten.

Der Komplex kristallisiert in der Raumgruppe $P$-1, mit zwei Komplexmolekülen in der triklinen Zelle. Die Molekülstruktur einer dinuklearen Einheit $\left[\mathrm{L}^{1}{ }_{-\mathrm{H}}\left(\mu-\mathrm{CH}_{3} \mathrm{COO}\right) \mathrm{Zn}_{2}\right]\left(\mathrm{ClO}_{4}\right)_{2}$ (1a) sowie einige wichtige strukturelle Parameter sind in Abb. 26 und Tab. 1 und 2 aufgeführt.

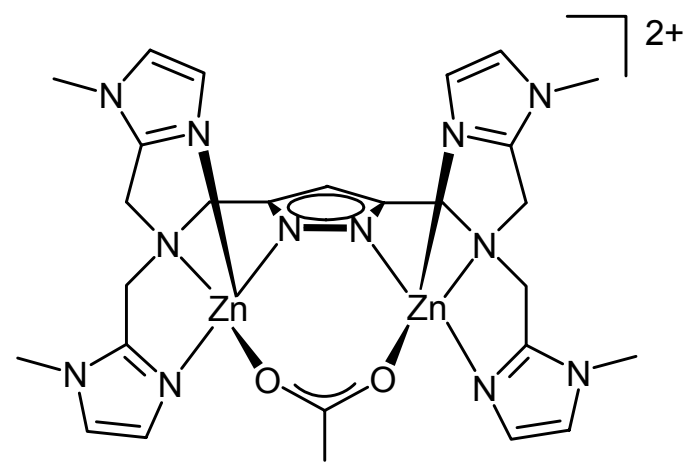

1a und $1 \mathbf{b}$ 
Abb. 25: Strukturformel der erhaltenen Isomere der Kationen 1a und $\mathbf{1 b .}$

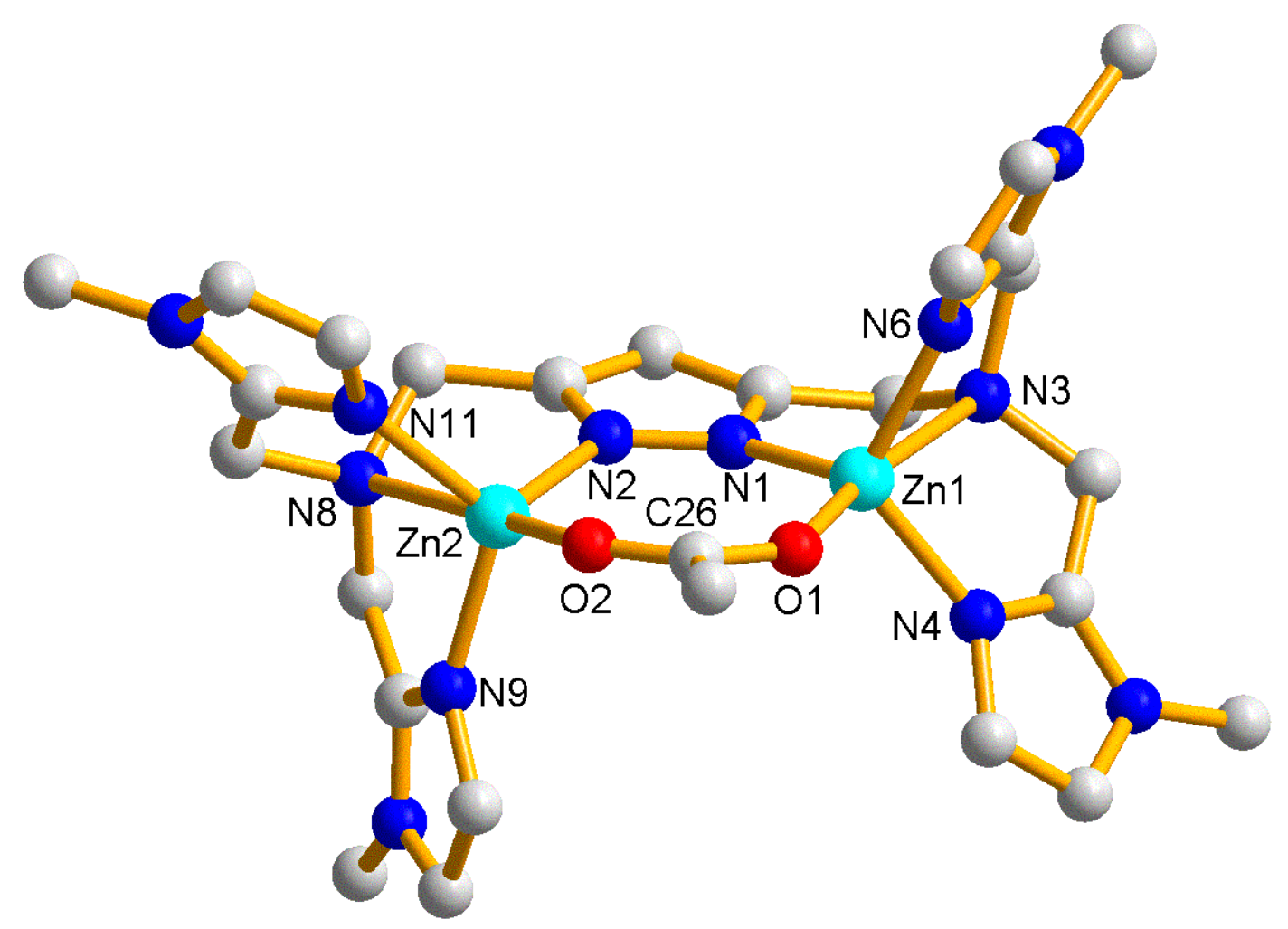

Abb. 26: Festkörperstruktur des Kations von 1a.

Tab. 1: Ausgewählte Atomabstände $[\AA]]$ von 1a.

\begin{tabular}{|l|l|l|l|}
\hline $\mathrm{Zn}(1)-\mathrm{N}(1)$ & $1.974(3)$ & $\mathrm{Zn}(2)-\mathrm{N}(11)$ & $2.006(4)$ \\
\hline $\mathrm{Zn}(1)-\mathrm{N}(4)$ & $1.984(4)$ & $\mathrm{Zn}(2)-\mathrm{N}(9)$ & $2.009(3)$ \\
\hline $\mathrm{Zn}(1)-\mathrm{N}(6)$ & $2.025(3)$ & $\mathrm{Zn}(2)-\mathrm{N}(8)$ & $2.460(3)$ \\
\hline $\mathrm{Zn}(1)-\mathrm{N}(3)$ & $2.462(4)$ & $\mathrm{Zn}(2)-\mathrm{O}(2)$ & $1.980(3)$ \\
\hline $\mathrm{Zn}(1)-\mathrm{O}(1)$ & $1.978(3)$ & $\mathrm{N}(1)-\mathrm{N}(2)$ & $1.368(4)$ \\
\hline $\mathrm{Zn}(1) \cdots \mathrm{Zn}(2)$ & $3.922(6)$ & $\mathrm{O}(1)-\mathrm{C}(26)$ & $1.231(6)$ \\
\hline $\mathrm{Zn}(2)-\mathrm{N}(2)$ & $1.994(3)$ & $\mathrm{O}(2)-\mathrm{C}(26)$ & $1.249(5)$ \\
\hline
\end{tabular}

Tab. 2: Ausgewählte Bindungswinkel ( $\left.{ }^{\circ}\right)$ von 1a.

\begin{tabular}{|l|l|l|l|}
\hline $\mathrm{N}(1)-\mathrm{Zn}(1)-\mathrm{O}(1)$ & $114.14(13)$ & $\mathrm{O}(2)-\mathrm{Zn}(2)-\mathrm{N}(2)$ & $111.66(13)$ \\
\hline $\mathrm{N}(1)-\mathrm{Zn}(1)-\mathrm{N}(4)$ & $114.42(13)$ & $\mathrm{O}(2)-\mathrm{Zn}(2)-\mathrm{N}(11)$ & $98.79(16)$ \\
\hline $\mathrm{N}(1)-\mathrm{Zn}(1)-\mathrm{N}(3)$ & $76.46(12)$ & $\mathrm{O}(2)-\mathrm{Zn}(2)-\mathrm{N}(9)$ & $105.04(15)$ \\
\hline
\end{tabular}




\begin{tabular}{|l|l|l|l|}
\hline $\mathrm{N}(1)-\mathrm{Zn}(1)-\mathrm{N}(6)$ & $113.81(13)$ & $\mathrm{O}(2)-\mathrm{Zn}(2)-\mathrm{N}(8)$ & $172.81(13)$ \\
\hline $\mathrm{O}(1)-\mathrm{Zn}(1)-\mathrm{N}(6)$ & $98.73(17)$ & $\mathrm{N}(2)-\mathrm{Zn}(2)-\mathrm{N}(9)$ & $108.90(14)$ \\
\hline $\mathrm{O}(1)-\mathrm{Zn}(1)-\mathrm{N}(4)$ & $98.76(16)$ & $\mathrm{N}(2)-\mathrm{Zn}(2)-\mathrm{N}(8)$ & $74.63(12)$ \\
\hline $\mathrm{O}(1)-\mathrm{Zn}(1)-\mathrm{N}(3)$ & $169.39(12)$ & $\mathrm{N}(2)-\mathrm{Zn}(2)-\mathrm{N}(11)$ & $114.92(15)$ \\
\hline $\mathrm{N}(4)-\mathrm{Zn}(1)-\mathrm{N}(6)$ & $114.93(13)$ & $\mathrm{N}(11)-\mathrm{Zn}(2)-\mathrm{N}(9)$ & $116.66(14)$ \\
\hline $\mathrm{N}(6)-\mathrm{Zn}(1)-\mathrm{N}(3)$ & $76.01(14)$ & $\mathrm{N}(11)-\mathrm{Zn}(2)-\mathrm{N}(8)$ & $74.95(13)$ \\
\hline $\mathrm{N}(4)-\mathrm{Zn}(1)-\mathrm{N}(3)$ & $75.70(14)$ & $\mathrm{N}(9)-\mathrm{Zn}(2)-\mathrm{N}(8)$ & $75.29(12)$ \\
\hline $\mathrm{O}(1)-\mathrm{C}(26)-\mathrm{O}(2)$ & $125.8(5)$ & $\mathrm{C}(26)-\mathrm{O}(1)-\mathrm{Zn}(1)$ & $141.0(3)$ \\
\hline $\mathrm{C}(26)-\mathrm{O}(2)-\mathrm{Zn}(2)$ & $142.5(4)$ & & \\
\hline
\end{tabular}

Im ESI-Massenspektrum der Methanollösung des Produkts beobachtet man mit einer Intensität von $100 \%$ die Spezies $\left[\mathrm{L}^{1}{ }_{-\mathrm{H}}\left(\mu-\mathrm{CH}_{3} \mathrm{COO}\right) \mathrm{Zn}_{2}\left(\mathrm{ClO}_{4}\right)\right]^{+}$, sowie mit einer Intensität von $5 \%$ die Spezies $\left[\mathrm{L}^{1}{ }_{-\mathrm{H}}\left(\mu-\mathrm{CH}_{3} \mathrm{COO}\right) \mathrm{Zn}_{2}\right]^{2+}$. Daraus kann man schliessen, dass das Kation in Lösung seine Konfiguration beibehält und somit die Acetatbrücke in der Koordinationsschale der Zink(II)-lonen bleibt.

Bei der Komplexierung kommt es zur Bildung von drei sehr stabilen fünfgliedrigen Chelatringen. Die Koordination der zwei Zink(II)-Ionen entspricht einer verzerrt trigonal-bipyramidalen Struktur (Zn1: $\tau=0.94 ; \mathrm{Zn} 2: \tau=0.91)$, in welcher die beiden Zink(II)-lonen einen gegenseitigen Abstand von $3.92 \AA$ einnehmen. Ähnliche Abstände wurden für andere durch Pyrazol, Phtalazin oder Oxadiazol verbrückte Bimetallkomplexe mit einer Acetateinheit als Zweitbrücke gemessen. ${ }^{[83-85]}$ Die Abstände zwischen den Zink(II)-lonen und den Sauerstoffatomen der Acetatbrücke und jene zwischen Zink und dem Stickstoffatom der Pyrazolatbrücke sind in etwa gleich groß. Die Stabilität des Moleküls kommt durch die beiden Brücken zwischen den beiden Zink(II)-lonen, der Acetatbrücke und der Pyrazolatbrücke, zustande.

An den Bindungsabständen zwischen den Zink(II)-lonen und den Stickstoffatomen, welche zwischen 1.97 und $2.46 \AA$ liegen, wird die unterschiedliche Art der N-Donoratome deutlich. Die Bindung der Zink(II)-lonen zum Stickstoffatom des N-Methylimidazols ist mit etwa $2.0 \AA$ kürzer als jene zum $\mathrm{sp}^{3}$-hybridisierten N-Atom der $-\mathrm{N}\left(\mathrm{CH}_{2}-\right)_{3}$ Gruppierung mit $2.46 \AA$. Beide Zink(II)-Ionen befinden sich deutlich außerhalb der Ebene, die der Pyrazolring bildet (Zn1: $0.26 \AA ;$ Zn2: $0.35 \AA$ ). Obwohl dieses Phänomen nicht so typisch in 
der Koordinationschemie des Pyrazols ist, wurde es schon bei anderen Pyrazolatokomplexen beobachtet. ${ }^{[86]}$

Im IR-Spektrum sind zwei starke Banden bei 1584 bzw. $1440 \mathrm{~cm}^{-1}$ zu beobachten. Diese Werte sind typisch für verbrückende Carboxylateinheiten. $\Delta=\left[\mathrm{V}_{\text {as }}\left(\mathrm{CH}_{3} \mathrm{COO}^{-}\right)-\mathrm{v}_{\mathrm{s}}\left(\mathrm{CH}_{3} \mathrm{COO}^{-}\right)\right]$liegt zwischen den Werten von ionischen und chelatisierenden Carboxylatgruppen. ${ }^{[65,87,88]}$

Durch Änderungen der Kristallisationsbedingungen konnte die Verbindung $\mathbf{1 b}$ erhalten werden. Kristalle dieser Verbindung entstanden durch Diffusion aus Diethylether und einer konzentrierten Lösung des Komplexes in Acetonitril. Der Komplex kristallisiert in der Raumgruppe $C 2_{1} / \mathrm{c}$, wobei sich vier Komplexmoleküle in der monoklinen Zelle befinden. Die Molekülstruktur einer dinuklearen Einheit $\left[\mathrm{L}_{-}^{1}\left(\mu-\mathrm{CH}_{3} \mathrm{COO}\right) \mathrm{Zn}_{2}\right]\left(\mathrm{ClO}_{4}\right)_{2}$ (1) $)$ sowie einige wichtige strukturelle Parameter sind in Abb. 27 und Tab. 3 und 4 aufgeführt.

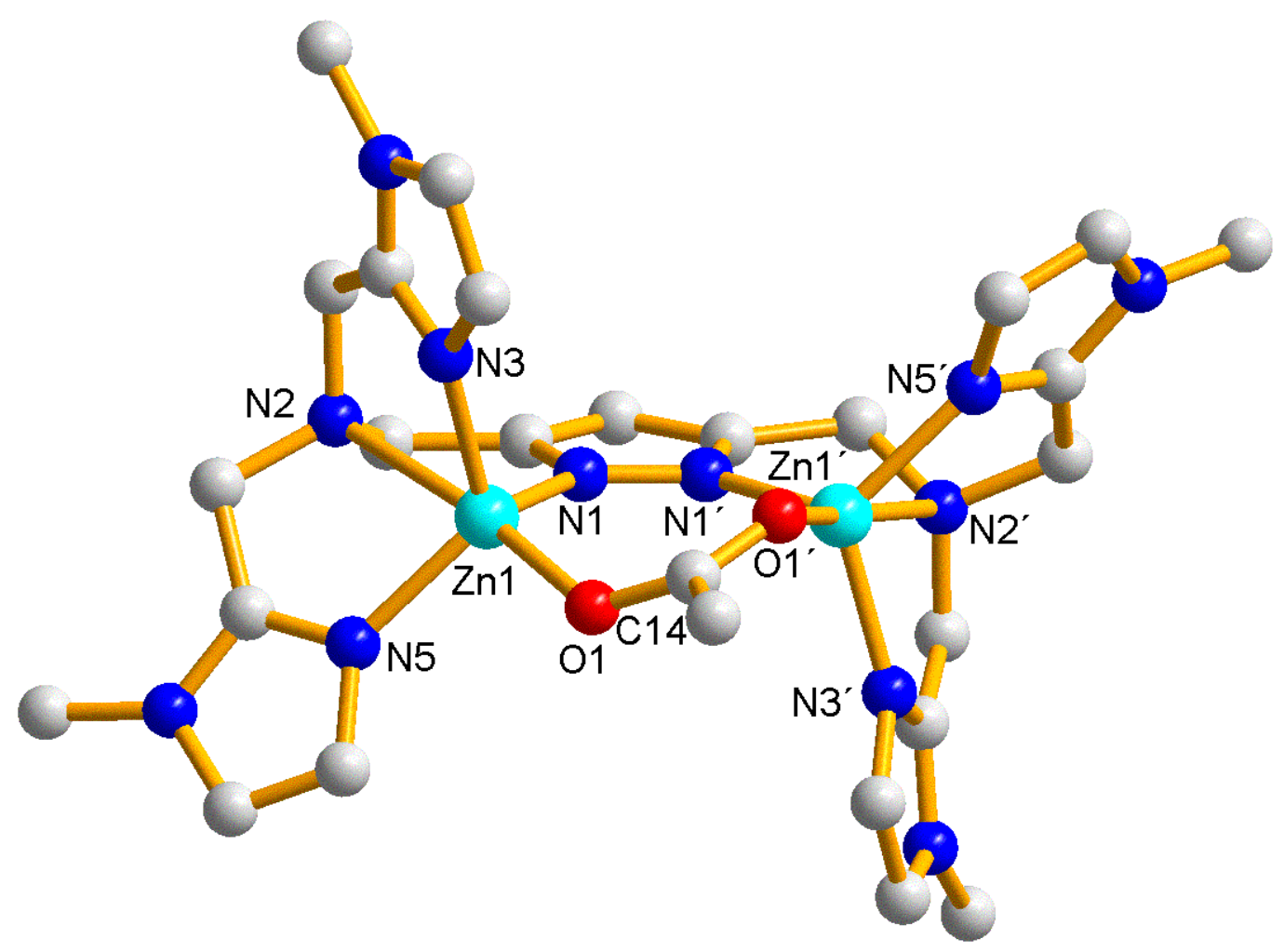

Abb. 27: Festkörperstruktur des Kations von $\mathbf{1 b .}$ 
Tab. 3: Ausgewählte Atomabstände $[\AA]$ von $\mathbf{1 b}$.

\begin{tabular}{|l|l|l|l|}
\hline $\mathrm{Zn}(1)-\mathrm{N}(1)$ & $1.992(4)$ & $\mathrm{Zn}(1)-\mathrm{N}(2)$ & $2.468(4)$ \\
\hline $\mathrm{Zn}(1)-\mathrm{N}(5)$ & $2.004(5)$ & $\mathrm{Zn}(1) \cdots \mathrm{Zn}\left(1^{\prime}\right)$ & $3.863(1)$ \\
\hline $\mathrm{Zn}(1)-\mathrm{O}(1)$ & $2.004(4)$ & $\mathrm{O}(1)-\mathrm{C}(14)$ & $1.269(6)$ \\
\hline $\mathrm{Zn}(1)-\mathrm{N}(3)$ & $2.014(4)$ & & \\
\hline
\end{tabular}

Tab. 4: Ausgewählte Bindungswinkel $\left(^{\circ}\right)$ von $\mathbf{1 b}$.

\begin{tabular}{|l|l|l|l|}
\hline $\mathrm{N}(1)-\mathrm{Zn}(1)-\mathrm{N}(5)$ & $115.68(17)$ & $\mathrm{N}(5)-\mathrm{Zn}(1)-\mathrm{N}(2)$ & $75.20(17)$ \\
\hline $\mathrm{N}(1)-\mathrm{Zn}(1)-\mathrm{N}(2)$ & $74.44(16)$ & $\mathrm{O}(1)-\mathrm{Zn}(1)-\mathrm{N}(3)$ & $104.46(18)$ \\
\hline $\mathrm{N}(1)-\mathrm{Zn}(1)-\mathrm{N}(3)$ & $106.69(17)$ & $\mathrm{O}(1)-\mathrm{Zn}(1)-\mathrm{N}(2)$ & $172.94(16)$ \\
\hline $\mathrm{N}(1)-\mathrm{Zn}(1)-\mathrm{O}(1)$ & $111.75(18)$ & $\mathrm{N}(3)-\mathrm{Zn}(1)-\mathrm{N}(2)$ & $76.21(16)$ \\
\hline $\mathrm{N}(5)-\mathrm{Zn}(1)-\mathrm{N}(3)$ & $118.84(19)$ & $\mathrm{O}(1)-\mathrm{C}(14)-\mathrm{O}\left(1^{\prime}\right)$ & $125.0(8)$ \\
\hline $\mathrm{N}(5)-\mathrm{Zn}(1)-\mathrm{O}(1)$ & $98.60(19)$ & $\mathrm{C}(14)-\mathrm{O}(1)-\mathrm{Zn}(1)$ & $130.9(4)$ \\
\hline
\end{tabular}

Die Koordinationsumgebung ist für beide Zink(II)-Ionen die gleiche wie im Kation 1a. Beide Metallionen sind wieder verzerrt trigonal bipyramidal $(\tau=0.9)$. Die Pyrazolat- und die $\mu$-Acetatbrücke befinden sich in diesem Fall nicht in derselben Ebene wie in 1a. Durch den Torsionswinkel zwischen beiden Ebenen $\left(18^{\circ}\right)$ ist die neue Struktur $\mathbf{1 b} \mathrm{C}_{2}$-symmetrisch geworden. Der Abstand zwischen beiden Metallkernen hat sich geringfügig verkleinert, beide befinden sich in der Ebene des Pyrazolrings.

\subsubsection{Zink(II)-Komplex des Liganden $\mathrm{L}^{4}$ - Synthese von $\left[\mathrm{L}^{4}{ }_{\mathrm{H}}\left(\mu-\mathrm{CH}_{3} \mathrm{COO}\right) \mathrm{Zn}_{2}\right]\left(\mathrm{ClO}_{4}\right)_{2}(2)$}

Durch die Reaktion des deprotonierten Liganden $\mathrm{L}^{4}$ mit $\mathrm{Zn}\left(\mathrm{ClO}_{4}\right)_{2} \cdot 6 \mathrm{H}_{2} \mathrm{O}$ und $\mathrm{CH}_{3} \mathrm{COONa}$ in Aceton und anschließende langsame Diffusion von Petrolether konnten farblose Kristalle von $\left[\mathrm{L}^{4}{ }_{-\mathrm{H}}\left(\mu-\mathrm{CH}_{3} \mathrm{COO}\right) \mathrm{Zn}_{2}\right]\left(\mathrm{ClO}_{4}\right)_{2}$ isoliert werden (Abb. 28).

Die Röntgenstrukturanalyse eines geeigneten Einkristalls zeigt wieder, dass 
beide Zink(II)-Ionen zweifach verbrückt sind: $\mu$-Pyrazolat und $\mu$-Acetat, die leicht gegenseitig verkippt sind. Der Komplex kristallisiert in der Raumgruppe $C 2_{1} / \mathrm{c}$. Es befinden sich acht Moleküle in der monoklinen Zelle. Die Molekülstruktur des Kations einer dinuklearen Einheit $\left[\mathrm{L}^{4}-\mathrm{H}\left(\mu-\mathrm{CH}_{3} \mathrm{COO}\right) \mathrm{Zn}_{2}\right]\left(\mathrm{ClO}_{4}\right)_{2}$ (2) sowie einige wichtige strukturelle Parameter sind in Abb. 29 und Tab. 5 und 6 aufgeführt.

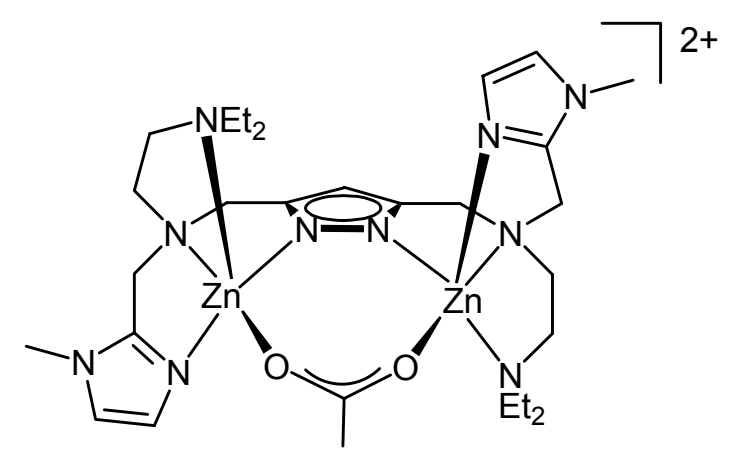

Abb. 28: Strukturformel des Kations von 2.

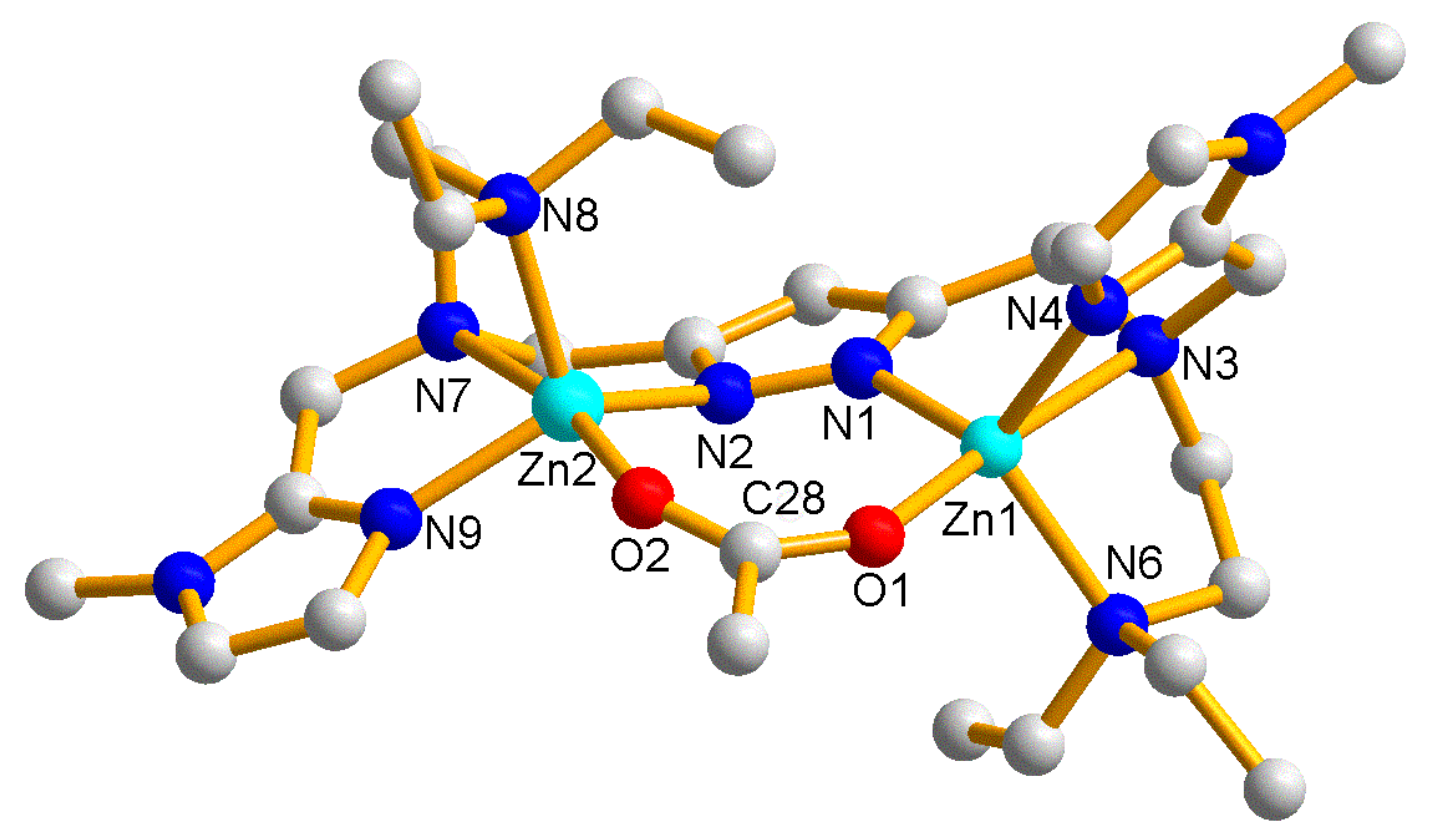

Abb. 29: Festkörperstruktur des Kations von 2. 
Tab. 5: Ausgewählte Atomabstände $[\AA]$ von 2.

\begin{tabular}{|l|l|l|l|}
\hline $\mathrm{Zn}(1)-\mathrm{O}(1)$ & $1.978(5)$ & $\mathrm{Zn}(2)-\mathrm{N}(9)$ & $1.999(6)$ \\
\hline $\mathrm{Zn}(1)-\mathrm{N}(1)$ & $1.992(6)$ & $\mathrm{Zn}(2)-\mathrm{N}(8)$ & $2.112(6)$ \\
\hline $\mathrm{Zn}(1)-\mathrm{N}(4)$ & $1.993(7)$ & $\mathrm{Zn}(2)-\mathrm{N}(7)$ & $2.390(5)$ \\
\hline $\mathrm{Zn}(1)-\mathrm{N}(6)$ & $2.110(6)$ & $\mathrm{Zn}(2)-\mathrm{N}(2)$ & $1.999(6)$ \\
\hline $\mathrm{Zn}(1)-\mathrm{N}(3)$ & $2.410(5)$ & $\mathrm{N}(1)-\mathrm{N}(2)$ & $1.373(8)$ \\
\hline $\mathrm{Zn}(1) \cdots \mathrm{Zn}(2)$ & $4.003(1)$ & $\mathrm{O}(1)-\mathrm{C}(28)$ & $1.256(10)$ \\
\hline $\mathrm{Zn}(2)-\mathrm{O}(2)$ & $2.013(5)$ & $\mathrm{O}(2)-\mathrm{C}(28)$ & $1.273(9)$ \\
\hline
\end{tabular}

Tab. 6: Ausgewählte Bindungswinkel ( ${ }^{\circ}$ ) von 2.

\begin{tabular}{|l|l|l|l|}
\hline $\mathrm{O}(1)-\mathrm{Zn}(1)-\mathrm{N}(1)$ & $110.5(2)$ & $\mathrm{N}(2)-\mathrm{Zn}(2)-\mathrm{N}(9)$ & $127.3(2)$ \\
\hline $\mathrm{O}(1)-\mathrm{Zn}(1)-\mathrm{N}(4)$ & $99.3(3)$ & $\mathrm{N}(2)-\mathrm{Zn}(2)-\mathrm{O}(2)$ & $109.5(2)$ \\
\hline $\mathrm{O}(1)-\mathrm{Zn}(1)-\mathrm{N}(6)$ & $94.8(2)$ & $\mathrm{N}(2)-\mathrm{Zn}(2)-\mathrm{N}(8)$ & $109.2(2)$ \\
\hline $\mathrm{O}(1)-\mathrm{Zn}(1)-\mathrm{N}(3)$ & $172.7(2)$ & $\mathrm{N}(2)-\mathrm{Zn}(2)-\mathrm{N}(7)$ & $77.33(19)$ \\
\hline $\mathrm{N}(1)-\mathrm{Zn}(1)-\mathrm{N}(6)$ & $114.7(2)$ & $\mathrm{N}(9)-\mathrm{Zn}(2)-\mathrm{O}(2)$ & $92.3(2)$ \\
\hline $\mathrm{N}(1)-\mathrm{Zn}(1)-\mathrm{N}(4)$ & $121.0(2)$ & $\mathrm{N}(9)-\mathrm{Zn}(2)-\mathrm{N}(8)$ & $110.5(2)$ \\
\hline $\mathrm{N}(1)-\mathrm{Zn}(1)-\mathrm{N}(3)$ & $76.8(2)$ & $\mathrm{N}(9)-\mathrm{Zn}(2)-\mathrm{N}(7)$ & $75.7(2)$ \\
\hline $\mathrm{N}(4)-\mathrm{Zn}(1)-\mathrm{N}(6)$ & $111.9(2)$ & $\mathrm{O}(2)-\mathrm{Zn}(2)-\mathrm{N}(8)$ & $104.7(2)$ \\
\hline $\mathrm{N}(4)-\mathrm{Zn}(1)-\mathrm{N}(3)$ & $76.9(2)$ & $\mathrm{O}(2)-\mathrm{Zn}(2)-\mathrm{N}(7)$ & $167.9(2)$ \\
\hline $\mathrm{N}(6)-\mathrm{Zn}(1)-\mathrm{N}(3)$ & $81.0(2)$ & $\mathrm{N}(8)-\mathrm{Zn}(2)-\mathrm{N}(7)$ & $81.63(18)$ \\
\hline $\mathrm{O}(1)-\mathrm{C}(28)-\mathrm{O}(2)$ & $124.7(6)$ & & \\
\hline
\end{tabular}

Aus einer methanolischen Komplexlösung von 2 wurde ein ESI-Spektrum gemessen. Bei $\mathrm{m} / \mathrm{z}=801$ mit einer Intensität von $30 \%$ beobachtet man die Spezies $\left[\mathrm{L}^{4}{ }_{\mathrm{H}}\left(\mu-\mathrm{CH}_{3} \mathrm{COO}\right) \mathrm{Zn}_{2}\left(\mathrm{ClO}_{4}\right)\right]^{+}$. Bei $\mathrm{m} / \mathrm{z}=351$ und mit einer Intensität von $100 \%$ kann man die Spezies $\left[\mathrm{L}^{4}{ }_{-} \mathrm{H}\left(\mu-\mathrm{CH}_{3} \mathrm{COO}\right) \mathrm{Zn}_{2}\right]^{2+}$ beobachten. Das Kation behält in Lösung das verbrückende $\mu$-Acetat in seiner Konfiguration bei.

Im IR-Spektrum eines Kristalls von 2 sind zwei intensive Banden bei 1584 bzw. $1444 \mathrm{~cm}^{-1} \mathrm{zu}$ sehen. Diese Banden entsprechen typischen symmetrischen und asymmetrischen Banden des verbrückenden Acetations. 
Die Zink(II)-lonen sind verzerrt trigonal bipyramidal (Zn1: $\tau=0.88$; $\mathrm{Zn2}: \tau=0.63$ ) angeordnet, wobei der Metallkern Zn2 eine starke Verzerrung aufweist, und sind durch einen Abstand von $4.00 \AA$ voneinander getrennt. Wie bei $\mathbf{1 a}$ und $\mathbf{1 b}$ sind die Abstände $\mathrm{Zn}-\mathrm{N}^{\mathrm{Pz}}$ und $\mathrm{Zn}-\mathrm{O}^{\mathrm{Ac}}$ in etwa gleich. Es ist auch zu sehen, dass die Abstände zwischen den Metallkernen und den beiden aliphatischen N-Donoratomen deutlich unterschiedlich sind (2.11 und $2.41 \AA)$. Durch die größere Beweglichkeit der Enden des Seitenarms ist dieser Unterschied der Abstände zu erklären. Die Pyrazolat- und die Acetateinheit sind deutlich gegeneinander geneigt (Torsionswinkel $14.69^{\circ}$ ), aber nicht so stark wie bei der Struktur 1a. Auch in dieser Struktur sind die Zink(II)-lonen stark von der Ebene des Pyrazolrings verschoben (Zn1: $0.46 \AA$; Zn2: $0.72 \AA$ ). Im Fall von Zn2 ist dieser Abstand sehr groß für diese Art von Komplexen. Die Struktur wurde nur in der rac Form erhalten.

\subsubsection{Zink(II)-Komplex des Liganden $\mathrm{L}^{3}$ - Synthese von $\left[\mathrm{L}^{3} \cdot \mathrm{H}\left(\mu-\mathrm{CH}_{3} \mathrm{COO}\right) \mathrm{Zn}_{2}\right]\left(\mathrm{ClO}_{4}\right)_{2}$ (3)}

Die Umsetzung des deprotonierten Liganden $L^{3}$ mit Zink(II)perchlorat Hexahydrat und Natriumacetat in Aceton führte zum Komplex $\left[\mathrm{L}^{3}{ }_{\mathrm{H}}\left(\mu-\mathrm{CH}_{3} \mathrm{COO}\right)\right]\left(\mathrm{ClO}_{4}\right)_{2}$ (3) (Abb. 30$)$. Farblose Kristalle von 3 wurden nach langsamer Diffusion von Petrolether in eine konzentrierte Acetonlösung erhalten. Der Komplex kristallisiert in der Raumgruppe $P 2_{1} / \mathrm{c}$, wobei sich vier Moleküle in der monoklinen Zelle befinden.

In Abb. 31 sowie in Tab. 7 und 8 sind einige wichtige strukturelle Parameter des Kations von 3 zusammengefasst.

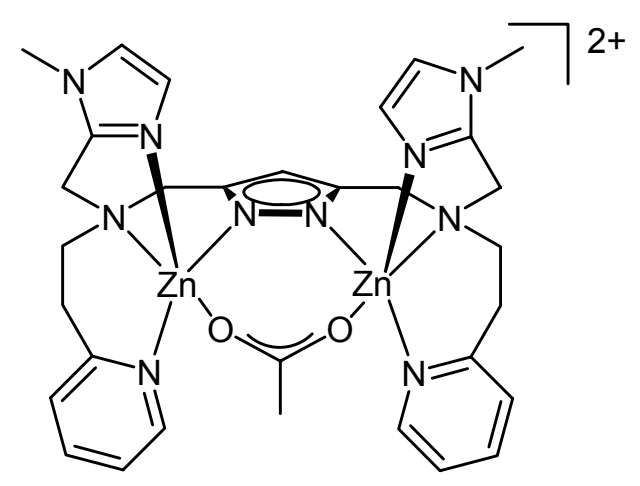


Abb. 30: Strukturformel des Kations von 3.

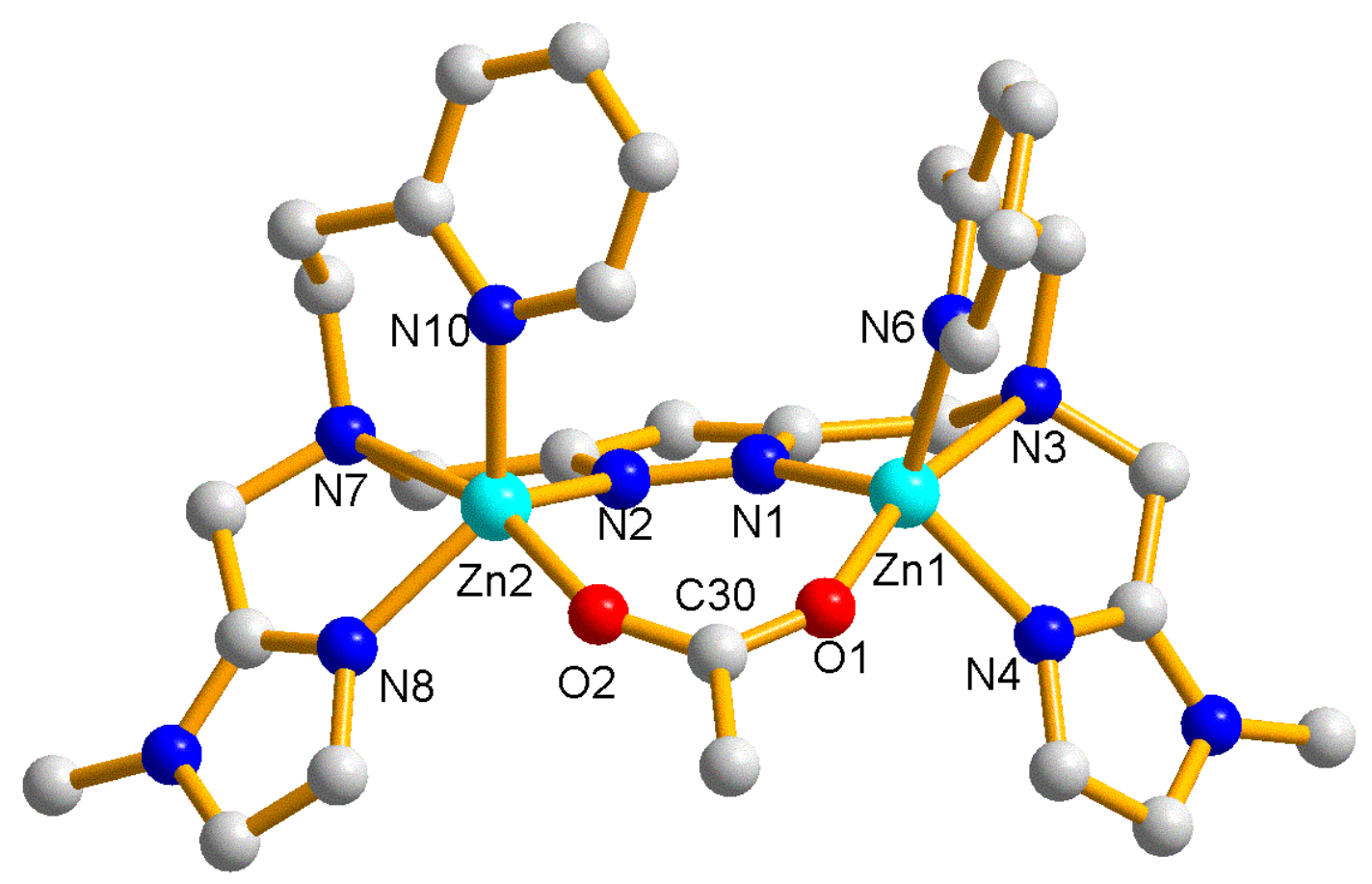

Abb. 31: Festkörperstruktur des Kations von 3.

Tab. 7: Ausgewählte Atomabstände $[\AA]]$ von 3.

\begin{tabular}{|l|l|l|l|}
\hline $\mathrm{Zn}(1)-\mathrm{O}(1)$ & $2.012(3)$ & $\mathrm{Zn}(2)-\mathrm{N}(2)$ & $2.013(3)$ \\
\hline $\mathrm{Zn}(1)-\mathrm{N}(1)$ & $1.980(3)$ & $\mathrm{Zn}(2)-\mathrm{N}(8)$ & $2.011(3)$ \\
\hline $\mathrm{Zn}(1)-\mathrm{N}(4)$ & $2.015(3)$ & $\mathrm{Zn}(2)-\mathrm{N}(10)$ & $2.048(3)$ \\
\hline $\mathrm{Zn}(1)-\mathrm{N}(6)$ & $2.047(3)$ & $\mathrm{Zn}(2)-\mathrm{N}(7)$ & $2.424(3)$ \\
\hline $\mathrm{Zn}(1)-\mathrm{N}(3)$ & $2.463(3)$ & $\mathrm{N}(1)-\mathrm{N}(2)$ & $1.375(4)$ \\
\hline $\mathrm{Zn}(1) \cdots \mathrm{Zn}(2)$ & $4.0151(6)$ & $\mathrm{O}(1)-\mathrm{C}(30)$ & $1.252(5)$ \\
\hline $\mathrm{Zn}(2)-\mathrm{O}(2)$ & $2.013(3)$ & $\mathrm{O}(2)-\mathrm{C}(30)$ & $1.262(5)$ \\
\hline
\end{tabular}

Tab. 8: Ausgewählte Bindungswinkel ( $\left.{ }^{\circ}\right)$ von 3.

\begin{tabular}{|l|l|l|l|}
\hline $\mathrm{N}(1)-\mathrm{Zn}(1)-\mathrm{O}(1)$ & $107.84(12)$ & $\mathrm{N}(8)-\mathrm{Zn}(2)-\mathrm{O}(2)$ & $90.07(12)$ \\
\hline $\mathrm{N}(1)-\mathrm{Zn}(1)-\mathrm{N}(4)$ & $114.62(13)$ & $\mathrm{N}(8)-\mathrm{Zn}(2)-\mathrm{N}(2)$ & $121.45(13)$ \\
\hline $\mathrm{N}(1)-\mathrm{Zn}(1)-\mathrm{N}(6)$ & $115.19(13)$ & $\mathrm{N}(8)-\mathrm{Zn}(2)-\mathrm{N}(10)$ & $129.22(13)$ \\
\hline
\end{tabular}




\begin{tabular}{|l|l|l|l|}
\hline $\mathrm{N}(1)-\mathrm{Zn}(1)-\mathrm{N}(3)$ & $77.13(12)$ & $\mathrm{N}(8)-\mathrm{Zn}(2)-\mathrm{N}(7)$ & $75.47(12)$ \\
\hline $\mathrm{O}(1)-\mathrm{Zn}(1)-\mathrm{N}(4)$ & $92.97(13)$ & $\mathrm{O}(2)-\mathrm{Zn}(2)-\mathrm{N}(2)$ & $107.62(12)$ \\
\hline $\mathrm{O}(1)-\mathrm{Zn}(1)-\mathrm{N}(6)$ & $97.97(13)$ & $\mathrm{O}(2)-\mathrm{Zn}(2)-\mathrm{N}(10)$ & $101.31(12)$ \\
\hline $\mathrm{O}(1)-\mathrm{Zn}(1)-\mathrm{N}(3)$ & $167.97(11)$ & $\mathrm{O}(2)-\mathrm{Zn}(2)-\mathrm{N}(7)$ & $164.23(11)$ \\
\hline $\mathrm{N}(4)-\mathrm{Zn}(1)-\mathrm{N}(6)$ & $122.28(13)$ & $\mathrm{N}(2)-\mathrm{Zn}(2)-\mathrm{N}(10)$ & $101.99(13)$ \\
\hline $\mathrm{N}(4)-\mathrm{Zn}(1)-\mathrm{N}(3)$ & $75.04(12)$ & $\mathrm{N}(2)-\mathrm{Zn}(2)-\mathrm{N}(7)$ & $75.71(11)$ \\
\hline $\mathrm{N}(6)-\mathrm{Zn}(1)-\mathrm{N}(3)$ & $89.42(12)$ & $\mathrm{N}(10)-\mathrm{Zn}(2)-\mathrm{N}(7)$ & $92.85(12)$ \\
\hline $\mathrm{O}(1)-\mathrm{C}(30)-\mathrm{O}(2)$ & $125.3(4)$ & & \\
\hline
\end{tabular}

Im ESI-Massenspektrum einer Lösung von $\mathbf{3}$ in Aceton findet man bei $\mathrm{m} / \mathrm{z}=813$ mit einer Intensität von $15 \%$ ein Fragment mit der Zusammensetzung $\left[\mathrm{L}^{3}{ }_{\mathrm{H}}\left(\mu-\mathrm{CH}_{3} \mathrm{COO}\right) \mathrm{Zn}_{2}\left(\mathrm{ClO}_{4}\right)\right]^{+}$, das eine Perchloratgruppe weniger als das Gesamtmolekül 3 enthält. Die größte Intensität (Basispeak $=100 \%$ ) bildet bei $m / z=771$ ein Peak, welcher einem Komplex entspricht, bei dem die Acetatgruppe durch eine Hydroxidgruppe ersetzt ist. Die Bildung solcher Spezies mit einer Hydroxidbrücke wurde in Lösung bei den anderen Komplexen mit einer Acetatbrücke nicht beobachtet. Abb. 32 zeigt das ESIMassenspektrum. 


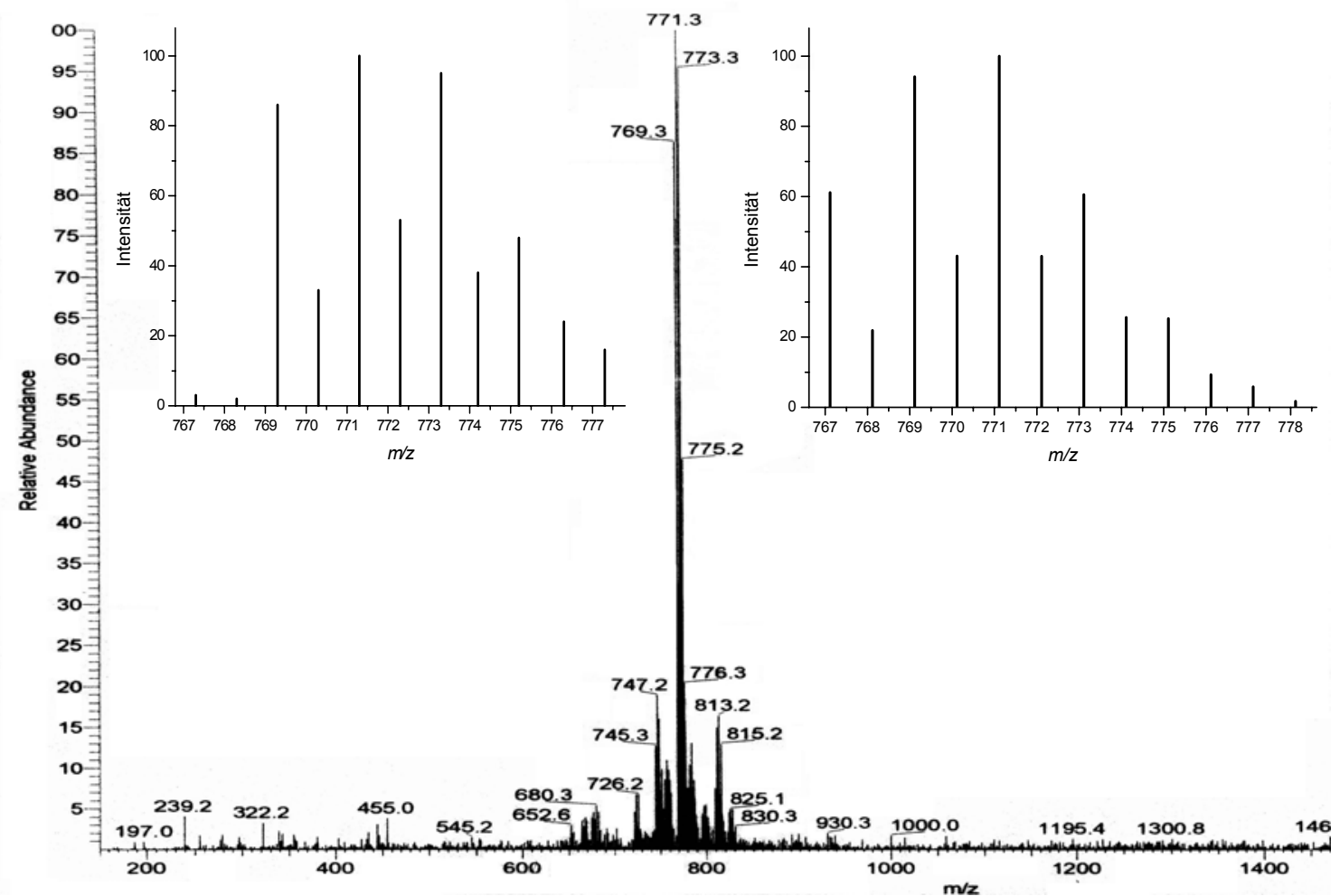

Abb. 32: ESI-Massenspektrum des Komplexes 3 mit der berechneten Isotopenverteilung (rechts) für $\left[\mathrm{L}^{3}{ }_{-H}(\mathrm{OH}) \mathrm{Zn} n_{2}\right]\left(\mathrm{ClO}_{4}\right)$. Links ist der Hauptpeak vergrösert dargestellt.

Beide Zink(II)-Ionen sind verzerrt trigonal bipyramidal $(Z n 1: \tau=0.76$; Zn2: $\tau=0.58)$ koordiniert. Der Abstand zwischen beiden metallischen Zentren beträgt $4.01 \AA$. Hier ist die Abweichung einer der Koordinationssphären (Zn2) vom Idealfall groß und liegt fast zwischen beiden Fällen (trigonal bipyramidal und pyramidal tetragonal). Es befinden sich beide Zink(II)-lonen nur geringfügig außerhalb der Ebene des Pyrazolrings (Zn1: $0.13 \AA$; Zn2: $0.17 \AA$ ). Obwohl verschiedene Heteroaromaten mit $\mathrm{sp}^{2}$-hybridisierten Stickstoffatomen enthalten sind, sind die Abstände zum zugehörigen Zinkkern mit etwa 2 A gleich groß. Die Ausrichtung der Pyridin- und N-Methylimidazolseitenarme in 3- und 5Position des Pyrazols ist an beiden Zink(II)-lonen dieselbe. Die Pyridinreste stehen senkrecht zueinander und so ist eine mögliche Symmetrie des Moleküls im Festkörper ausgeschlossen. Die Acetatbrücke ist leicht in Richtung der beiden Melm-Einheiten orientiert. Im Gegensatz zu den anderen asymmetrischen Liganden verursacht $\mathrm{L}^{3}$ in diesem Fall die einzige meso 
Struktur, die während dieser Arbeit erhalten wurde.

Im IR-Spektrum treten zwei starke Banden bei 1583 bzw. $1442 \mathrm{~cm}^{-1}$ auf, welche den symmetrischen und asymmetrischen Banden eines verbrückenden Acetations zugeordnet werden können.

\subsubsection{Zink(II)-Komplex des Liganden $\mathrm{L}^{7}-$ Synthese von $\left[\mathrm{L}^{7}{ }_{-\mathrm{H}}\left(\mu-\mathrm{CH}_{3} \mathrm{COO}\right) \mathrm{Zn}_{2}\right]\left(\mathrm{ClO}_{4}\right)_{2}(4)$}

Durch die Reaktion des deprotonierten Liganden $\mathrm{L}^{7}$ mit Zinkperchlorat Hexahydrat und Natriumacetat in Methanol konnte der Komplex $\left[\mathrm{L}^{7}{ }_{-}\left(\mu-\mathrm{CH}_{3} \mathrm{COO}\right)\right]\left(\mathrm{ClO}_{4}\right)_{2}$ (4) erhalten werden (Abb. 33). Durch langsame Diffusion zwischen Diethylether und einer Lösung des Komplexes in Methanol/Acetonitril wurden farblose Kristalle von 4 erhalten, die für die Röntgenstrukturanalyse geeignet waren.

Der Komplex 4 kristallisiert in der Raumgruppe $P 2_{1} / \mathrm{c}$ mit vier Molekülen in der monoklinen Zelle. In Abb. 34 sowie in Tab. 9 und 10 sind einige wichtige strukturelle Parameter des Kations des Komplexes $\left[\mathrm{L}^{7}{ }_{-\mathrm{H}}\left(\mu-\mathrm{CH}_{3} \mathrm{COO}\right) \mathrm{Zn}_{2}\right]\left(\mathrm{ClO}_{4}\right)_{2}$ 4 zusammengefasst.

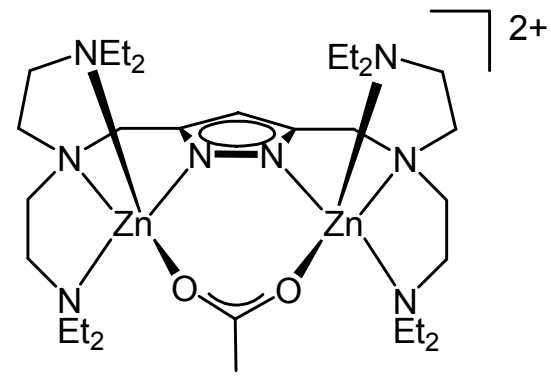

Abb. 33: Strukturformel des Kations von 4. 


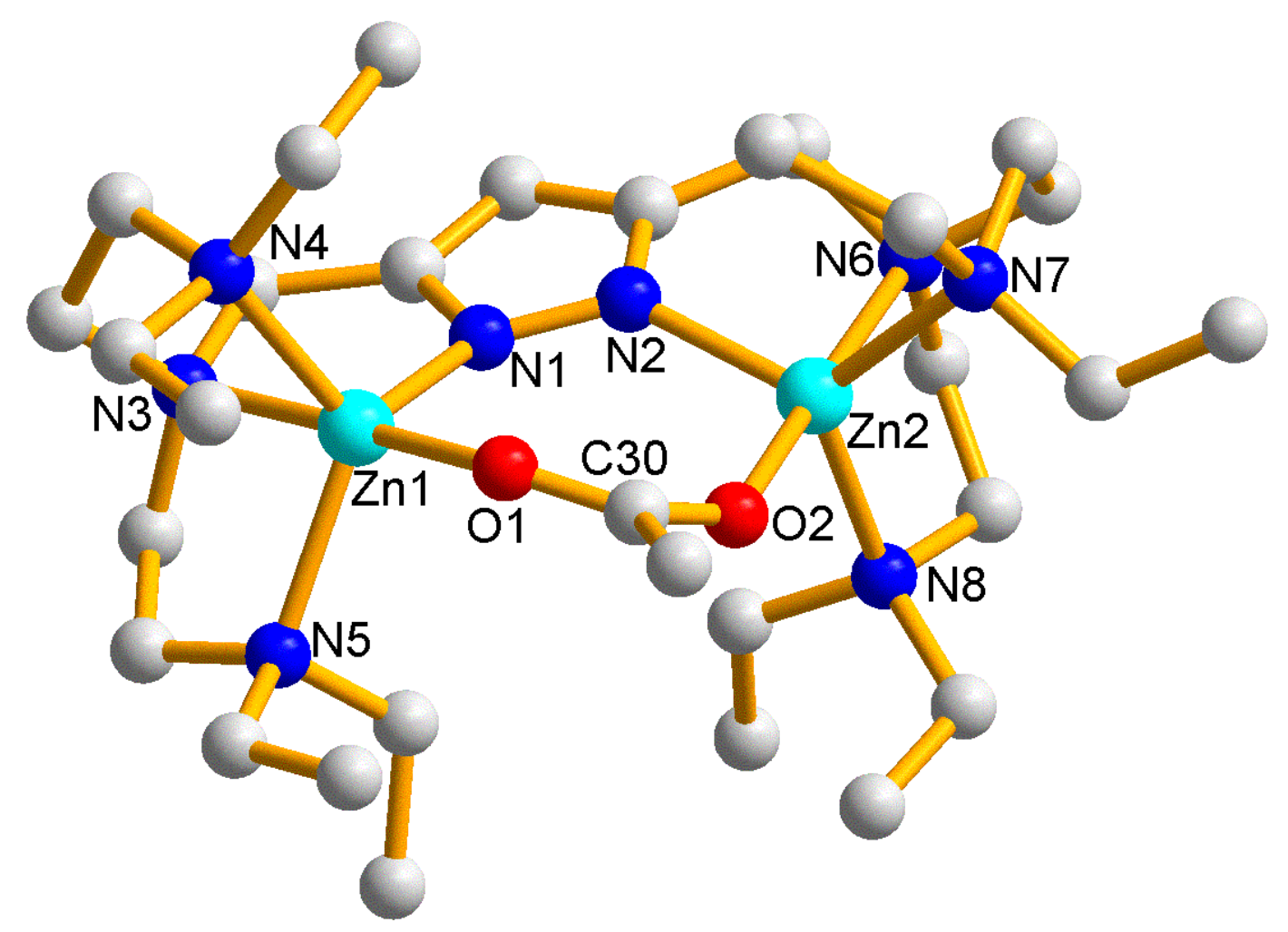

Abb. 34: Festkörperstruktur des Kations von 4.

Tab. 9: Ausgewählte Atomabstände [Å] von 4.

\begin{tabular}{|l|l|l|l|}
\hline $\mathrm{Zn}(1)-\mathrm{O}(1)$ & $2.017(2)$ & $\mathrm{Zn}(2)-\mathrm{N}(2)$ & $2.015(3)$ \\
\hline $\mathrm{Zn}(1)-\mathrm{N}(1)$ & $2.010(3)$ & $\mathrm{Zn}(2)-\mathrm{N}(7)$ & $2.127(3)$ \\
\hline $\mathrm{Zn}(1)-\mathrm{N}(4)$ & $2.139(3)$ & $\mathrm{Zn}(2)-\mathrm{N}(8)$ & $2.161(3)$ \\
\hline $\mathrm{Zn}(1)-\mathrm{N}(5)$ & $2.180(3)$ & $\mathrm{Zn}(2)-\mathrm{N}(6)$ & $2.244(2)$ \\
\hline $\mathrm{Zn}(1)-\mathrm{N}(3)$ & $2.262(3)$ & $\mathrm{N}(1)-\mathrm{N}(2)$ & $1.373(4)$ \\
\hline $\mathrm{Zn}(1) \cdots \mathrm{Zn}(2)$ & $4.220(5)$ & $\mathrm{O}(1)-\mathrm{C}(30)$ & $1.262(4)$ \\
\hline $\mathrm{Zn}(2)-\mathrm{O}(2)$ & $2.018(2)$ & $\mathrm{O}(2)-\mathrm{C}(30)$ & $1.245(4)$ \\
\hline
\end{tabular}

Tab. 10: Ausgewählte Bindungswinkel () von 4.

\begin{tabular}{|l|l|l|l|}
\hline $\mathrm{N}(1)-\mathrm{Zn}(1)-\mathrm{O}(1)$ & $102.67(10)$ & $\mathrm{N}(2)-\mathrm{Zn}(2)-\mathrm{O}(2)$ & $101.89(10)$ \\
\hline $\mathrm{N}(1)-\mathrm{Zn}(1)-\mathrm{N}(4)$ & $114.09(12)$ & $\mathrm{N}(2)-\mathrm{Zn}(2)-\mathrm{N}(7)$ & $122.81(11)$ \\
\hline $\mathrm{N}(1)-\mathrm{Zn}(1)-\mathrm{N}(5)$ & $118.91(11)$ & $\mathrm{N}(2)-\mathrm{Zn}(2)-\mathrm{N}(8)$ & $111.10(10)$ \\
\hline
\end{tabular}




\begin{tabular}{|l|l|l|l|}
\hline $\mathrm{N}(1)-\mathrm{Zn}(1)-\mathrm{N}(3)$ & $78.74(10)$ & $\mathrm{N}(2)-\mathrm{Zn}(2)-\mathrm{N}(6)$ & $79.90(10)$ \\
\hline $\mathrm{O}(1)-\mathrm{Zn}(1)-\mathrm{N}(4)$ & $98.04(12)$ & $\mathrm{O}(2)-\mathrm{Zn}(2)-\mathrm{N}(7)$ & $95.19(10)$ \\
\hline $\mathrm{O}(1)-\mathrm{Zn}(1)-\mathrm{N}(5)$ & $97.20(11)$ & $\mathrm{O}(2)-\mathrm{Zn}(2)-\mathrm{N}(8)$ & $98.91(10)$ \\
\hline $\mathrm{O}(1)-\mathrm{Zn}(1)-\mathrm{N}(3)$ & $178.50(10)$ & $\mathrm{O}(2)-\mathrm{Zn}(2)-\mathrm{N}(6)$ & $177.26(10)$ \\
\hline $\mathrm{N}(4)-\mathrm{Zn}(1)-\mathrm{N}(5)$ & $119.36(13)$ & $\mathrm{N}(7)-\mathrm{Zn}(2)-\mathrm{N}(8)$ & $119.49(11)$ \\
\hline $\mathrm{N}(4)-\mathrm{Zn}(1)-\mathrm{N}(3)$ & $81.78(12)$ & $\mathrm{N}(7)-\mathrm{Zn}(2)-\mathrm{N}(6)$ & $82.08(10)$ \\
\hline $\mathrm{N}(5)-\mathrm{Zn}(1)-\mathrm{N}(3)$ & $81.62(12)$ & $\mathrm{N}(8)-\mathrm{Zn}(2)-\mathrm{N}(6)$ & $82.28(10)$ \\
\hline $\mathrm{O}(2)-\mathrm{C}(30)-\mathrm{O}(1)$ & $126.0(3)$ & & \\
\hline
\end{tabular}

Im ESI-Massenspektrum aus einer Methanollösung von $\mathbf{4}$ beobachtet man bei $\mathrm{m} / \mathrm{z}=811$ und mit einer Intensität von $25 \%$ die Spezies $\left[\mathrm{L}^{7}{ }_{\mathrm{H}}\left(\mu-\mathrm{CH}_{3} \mathrm{COO}\right) \mathrm{Zn}_{2}\left(\mathrm{ClO}_{4}\right)\right]^{+}$. Die Signale bei $\mathrm{m} / \mathrm{z}=356$ mit der Intensität von $100 \%$ kann der Spezies $\left[\mathrm{L}^{7}{ }_{-\mathrm{H}}\left(\mu-\mathrm{CH}_{3} \mathrm{COO}\right) \mathrm{Zn}_{2}\right]^{2+}$ zugeordnet werden.

Im IR-Spektrum eines Einkristalls beobachtet man die für diese Komplexe typischen Acetatbanden. In diesem Fall kommen die erwarteten Signale bei 1577 und $1443 \mathrm{~cm}^{-1}$.

Beide Metallionen sind trigonal bipyramidal (Zn1: $\tau=0.99$; $Z n 2: \tau=0.91$ ) koordiniert und der Abstand zwischen beiden beträgt $4.22 \AA$. Dies ist der größte Abstand zwischen beiden Metallkernen in allen acetatverbrückten Dizinkkomplexen in dieser Arbeit. Die Verlängerung des $\mathrm{Zn} \cdots \mathrm{Zn}$-Abstands hängt mit der großen Beweglichkeit dieser Seitenarme zusammen. Beide Zinkkerne befinden sich deutlich außerhalb der Ebene, die der Pyrazolring bildet (Zn1: $0.4 \AA ; Z n 2: 0.58 \AA$ ).

Die Länge der $\mathrm{Zn}-\mathrm{N}$ Bindungen ist für alle $\mathrm{N}$-Donoratome unterschiedlich, obwohl pro Metallkern zwei davon gleich sind. Diese Längen sind auch größer als im Fall $\mathrm{sp}^{2}$-hybridisierter Stickstoffatome. Dieses Phänomen wurde schon bei anderen bimetallischen Pyrazolatokomplexen, die keine Acetatbrücke besitzen, beobachtet. ${ }^{[09,60]}$ Auch der Abstand zwischen dem Stickstoff, der an Pyrazol gebundenen - $\mathrm{CH}_{2} \mathrm{~N}$ - Gruppe, und dem entsprechenden Zinkatom ist kürzer als im Fall aller asymmetrischer Pyrazolliganden. Da die Seitenarme in diesem System keine große sterische Hinderung aufweisen, ist das Gerüst sehr flexibel. 
Eine ähnliche Struktur eines Zinkpyrazolatkomplexes mit einer Carbonatbrücke ist bereits bekannt. ${ }^{[64]}$ Die veränderte Zweitbrücke verursacht leichte Unterschiede in der Struktur und in den Abständen zwischen $\mathrm{Zn}$ und den Donoratomen. Auch der intermetallische Abstand ist etwas größer (4.22 vs. $4.18 \AA$ ). In beiden Fällen ist die Zweitbrücke stark zur Ebene der Pyrazoleinheit geneigt $\left(20.7^{\circ}\right)$.

Ein Dinickelkomplex ist mit demselben Aufbau bereits bekannt. ${ }^{[86]}$ Im Gegensatz zum Zinkkomplex ist im Nickelkomplex einer der Seitenarme nicht vollständig koordiniert. Die freie Koordinationsstelle wird von einem bidentaten Acetat besetzt. Diese Koordinationsart wurde für die Zinkkomplexe innerhalb dieser Arbeit nicht beobachtet. Die intermetallischen Abstände sind in beiden Fällen etwa gleich und die Acetatbrücke ist stärker gekippt $\left(20.7^{\circ}\right.$ vs. $\left.45.2^{\circ}\right)$.

\subsubsection{Zink(II)-Komplex des Liganden $\mathrm{L}^{6}$ - \\ Synthese von $\left[\mathrm{L}^{6} \cdot{ }_{\mathrm{H}}\left(\mu-\mathrm{CH}_{3} \mathrm{COO}\right) \mathrm{Zn}_{2}\right]\left(\mathrm{ClO}_{4}\right)_{2}(5)$}

Der Komplex 5 wurde durch die Reaktion von Zinkperchlorat Hexahydrat und Natriumacetat in Methanol mit dem deprotonierten Liganden $L^{6}$ erhalten (Abb. 35). Nach langsamer Diffusion von Diethylether wurden farblose Kristalle dieses Komplexes $\mathbf{5}$ gewonnen. Der Komplex kristallisiert in der Raumgruppe $P 2_{1} /$ c. Die monokline Zelle beeinhaltet vier Moleküle. In Abb. 36 sowie in Tab. 11 und 12 sind einige wichtige strukturelle Parameter des Kations des Komplexes $\left[\mathrm{L}^{6}{ }_{-\mathrm{H}}\left(\mu-\mathrm{CH}_{3} \mathrm{COO}\right) \mathrm{Zn}_{2}\right]\left(\mathrm{ClO}_{4}\right)_{2}(5)$ zusammengefasst.

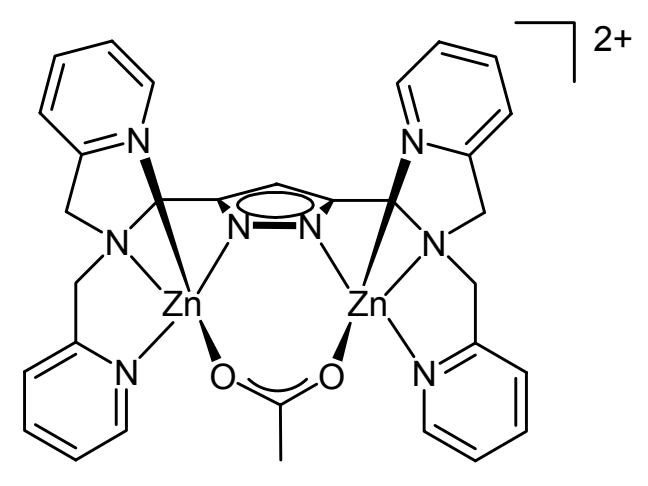

Abb. 35: Strukturformel des Kations von 5. 


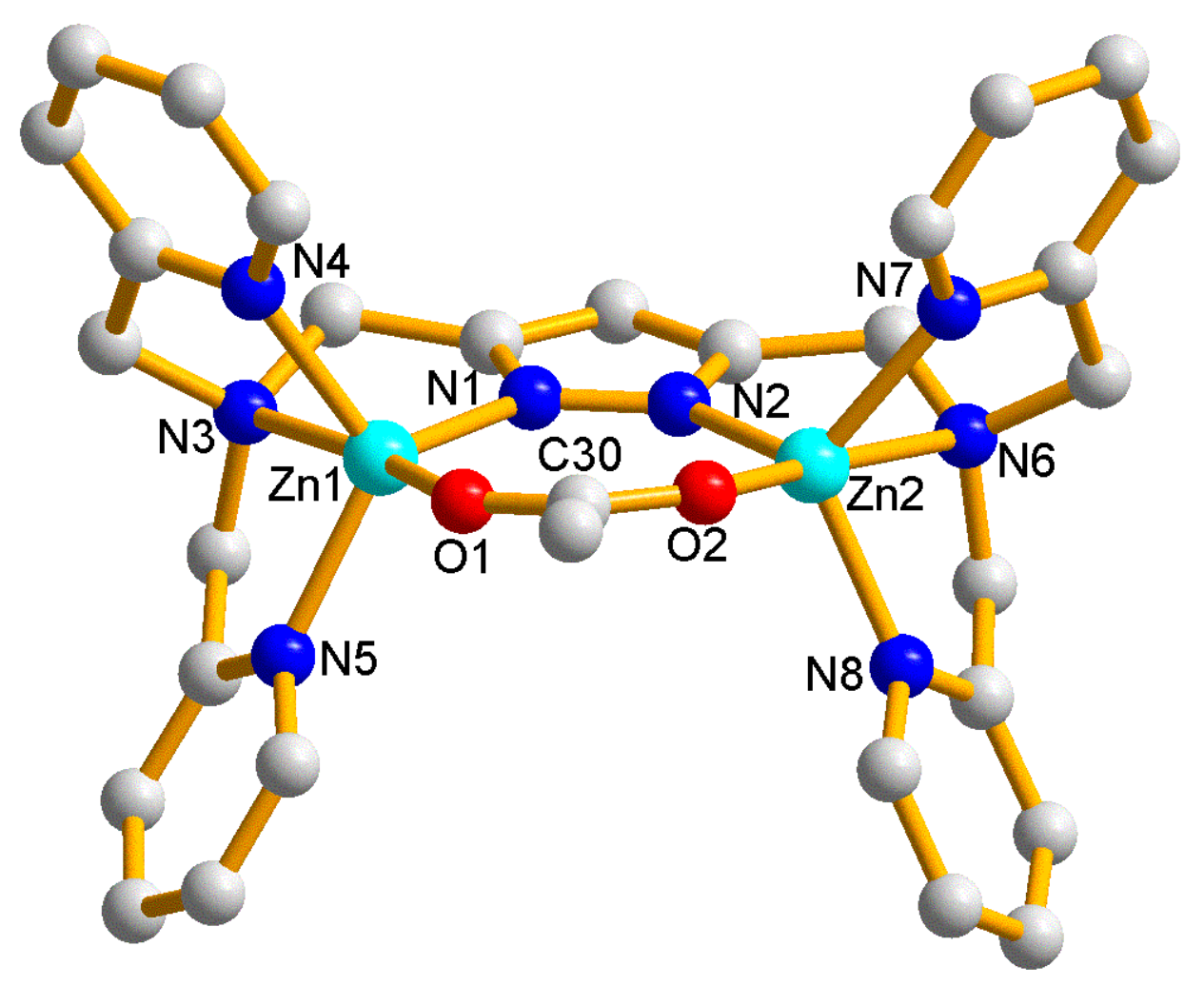

Abb. 36: Festkörperstruktur des Kations von 5.

Tab. 11: Ausgewählte Atomabstände $[\AA]]$ von 5.

\begin{tabular}{|l|l|l|l|}
\hline $\mathrm{Zn}(1)-\mathrm{O}(1)$ & $1.961(3)$ & $\mathrm{Zn}(2)-\mathrm{N}(2)$ & $1.982(4)$ \\
\hline $\mathrm{Zn}(1)-\mathrm{N}(1)$ & $1.979(3)$ & $\mathrm{Zn}(2)-\mathrm{N}(8)$ & $2.024(5)$ \\
\hline $\mathrm{Zn}(1)-\mathrm{N}(4)$ & $2.050(4)$ & $\mathrm{Zn}(2)-\mathrm{N}(7)$ & $2.040(4)$ \\
\hline $\mathrm{Zn}(1)-\mathrm{N}(5)$ & $2.054(4)$ & $\mathrm{Zn}(2)-\mathrm{N}(6)$ & $2.298(4)$ \\
\hline $\mathrm{Zn}(1)-\mathrm{N}(3)$ & $2.271(4)$ & $\mathrm{N}(1)-\mathrm{N}(2)$ & $1.366(5)$ \\
\hline $\mathrm{Zn}(1) \cdots \mathrm{Zn}(2)$ & $3.979(8)$ & $\mathrm{O}(1)-\mathrm{C}(30)$ & $1.237(5)$ \\
\hline $\mathrm{Zn}(2)-\mathrm{O}(2)$ & $1.978(3)$ & $\mathrm{O}(2)-\mathrm{C}(30)$ & $1.261(5)$ \\
\hline
\end{tabular}

Tab. 12: Ausgewählte Bindungswinkel ( $\left.{ }^{\circ}\right)$ von 5.

\begin{tabular}{|l|l|l|l|}
\hline $\mathrm{O}(1)-\mathrm{Zn}(1)-\mathrm{N}(1)$ & $112.23(14)$ & $\mathrm{O}(2)-\mathrm{Zn}(2)-\mathrm{N}(2)$ & $110.50(14)$ \\
\hline $\mathrm{O}(1)-\mathrm{Zn}(1)-\mathrm{N}(4)$ & $95.39(16)$ & $\mathrm{O}(2)-\mathrm{Zn}(2)-\mathrm{N}(8)$ & $98.02(16)$ \\
\hline
\end{tabular}




\begin{tabular}{|l|l|l|l|}
\hline $\mathrm{O}(1)-\mathrm{Zn}(1)-\mathrm{N}(5)$ & $96.95(16)$ & $\mathrm{O}(2)-\mathrm{Zn}(2)-\mathrm{N}(7)$ & $96.13(15)$ \\
\hline $\mathrm{O}(1)-\mathrm{Zn}(1)-\mathrm{N}(3)$ & $169.66(12)$ & $\mathrm{O}(2)-\mathrm{Zn}(2)-\mathrm{N}(6)$ & $172.35(14)$ \\
\hline $\mathrm{N}(1)-\mathrm{Zn}(1)-\mathrm{N}(4)$ & $113.21(15)$ & $\mathrm{N}(2)-\mathrm{Zn}(2)-\mathrm{N}(8)$ & $117.97(16)$ \\
\hline $\mathrm{N}(1)-\mathrm{Zn}(1)-\mathrm{N}(5)$ & $117.01(15)$ & $\mathrm{N}(2)-\mathrm{Zn}(2)-\mathrm{N}(7)$ & $115.46(16)$ \\
\hline $\mathrm{N}(1)-\mathrm{Zn}(1)-\mathrm{N}(3)$ & $78.03(14)$ & $\mathrm{N}(2)-\mathrm{Zn}(2)-\mathrm{N}(6)$ & $76.97(15)$ \\
\hline $\mathrm{N}(4)-\mathrm{Zn}(1)-\mathrm{N}(5)$ & $118.14(14)$ & $\mathrm{N}(8)-\mathrm{Zn}(2)-\mathrm{N}(7)$ & $114.57(17)$ \\
\hline $\mathrm{N}(4)-\mathrm{Zn}(1)-\mathrm{N}(3)$ & $78.74(14)$ & $\mathrm{N}(8)-\mathrm{Zn}(2)-\mathrm{N}(6)$ & $79.30(17)$ \\
\hline $\mathrm{N}(5)-\mathrm{Zn}(1)-\mathrm{N}(3)$ & $78.70(15)$ & $\mathrm{N}(7)-\mathrm{Zn}(2)-\mathrm{N}(6)$ & $78.69(15)$ \\
\hline $\mathrm{O}(1)-\mathrm{C}(30)-\mathrm{O}(2)$ & $126.0(5)$ & & \\
\hline
\end{tabular}

Im ESI-Massenspektrum findet man neben den Signalen für $\left[\mathrm{L}^{6}{ }_{\mathrm{H}}\left(\mu-\mathrm{CH}_{3} \mathrm{COO}\right) \mathrm{Zn}_{2}\left(\mathrm{ClO}_{4}\right)\right]^{+}$bei $\mathrm{m} / \mathrm{z}=779$ mit einer Intensität von $3 \%$ und für $\left(\left[\mathrm{L}^{6}{ }_{-\mathrm{H}}\left(\mu-\mathrm{CH}_{3} \mathrm{COO}\right) \mathrm{Zn}_{2}\right]^{2+}\right.$ bei $\mathrm{m} / \mathrm{z}=340$ mit einer Intensität von $22 \%$ weitere Signale, so dass in Lösung auf eine Mischung mehrerer Spezies geschlossen werden kann.

Der Abstand zwischen beiden Zink(II)-Ionen beträgt $3.98 \AA$, beide Atome sind trigonal bipyramidal (Zn1: $\tau=0.86$; Zn2: $\tau=0.91)$ koordiniert. Der $\tau$-Wert ist in derselben Größenordnung wie bei den anderen Strukturen, in denen $\mathrm{sp}^{2}$-hybridisierte Stickstoffatome beteiligt waren. Beide verbrückenden Einheiten sind mit den Zinkkernen fast in einer Ebene im Gegensatz zu anderen acetatverbrückten Komplexen wie $\mathbf{2}$ oder $\mathbf{4}$. Das hat eine nahezu symmetrische Struktur zur Folge. Wie bei $\mathbf{4}$ ist der Abstand zwischen dem Stickstoff der an das Pyrazol gebundenen - $\mathrm{CH}_{2} \mathrm{~N}$ - Gruppe und dem entsprechenden Zinkatom kürzer als bei den Strukturen mit ungleicher Substitution des N-Atoms der $-\mathrm{CH}_{2} \mathrm{~N}\left(\mathrm{R}_{1} \mathrm{R}_{2}\right)$-Gruppierung des Seitenarms.

Im IR-Spektrum sind zwei symmetrische und zwei asymmetrische Banden einer Carbonylverbindung zu sehen (1610 bzw. 1563 und 1483 bzw. $1440 \mathrm{~cm}^{-1}$ ), was durch die Anwesenheit von Aceton in der Kristallstruktur bedingt ist. 


\subsubsection{Schwingungen der Carbonylgruppe der Komplexe 1 bis 5}

In Abb. 37 sind zu Vergleichszwecken die asymmetrischen und die symmetrischen Schwingungen für die Carbonylgruppe der acetatverbrückten Komplexe dargestellt. Man erkennt, dass die gefundenen Werte für vasymm und $v_{\text {symm }}$ für $-\mathrm{COO}^{-}$für $\mathbf{1}$ bis $\mathbf{5}$ in ähnlichen Bereichen liegen.
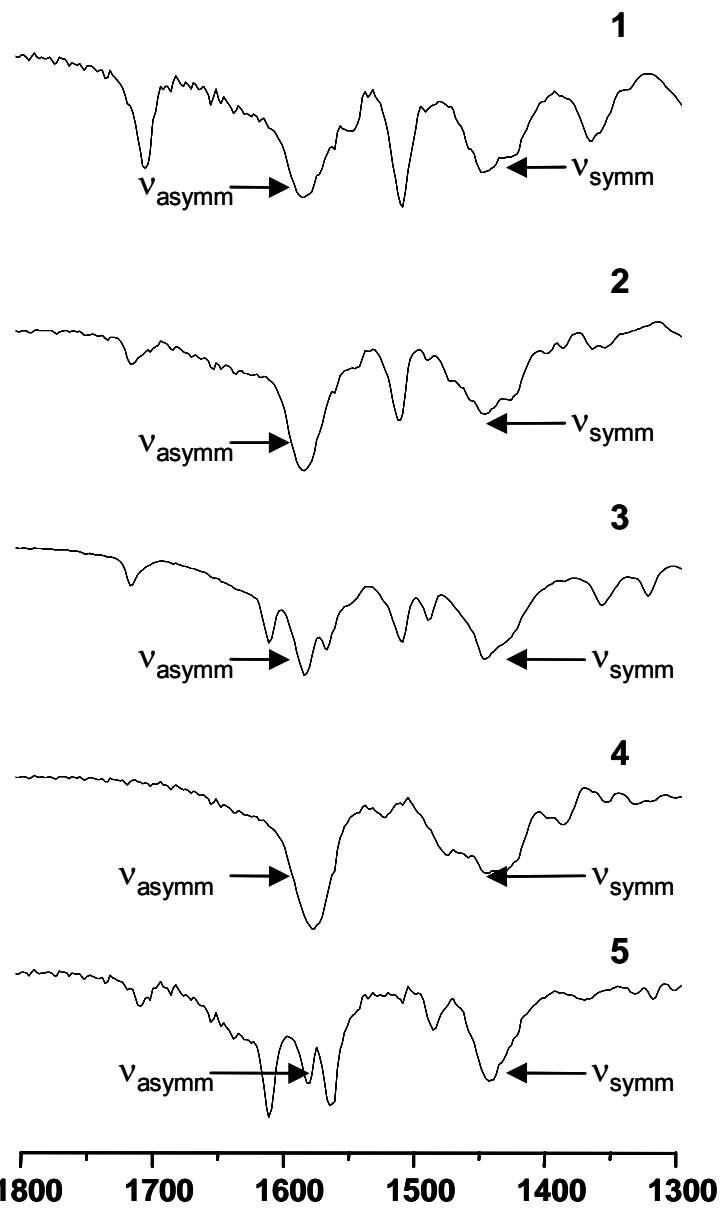

Abb. 37: Asymmetrische und symmetrische Carbonylschwingung in 1 bis 5.

Tab. 13: Zusammenstellung der Werte von $v_{\text {asymm }}$ und $v_{\text {symm }}$ in $\mathrm{cm}^{-1}$ für $\mathbf{1}$ bis $\mathbf{5}$.

\begin{tabular}{|c|c|c|}
\hline Verbindung & $v_{\text {asymm }}$ & $v_{\text {symm }}$ \\
\hline $\mathbf{1}$ & 1584 & 1440 \\
\hline $\mathbf{2}$ & 1584 & 1444 \\
\hline $\mathbf{3}$ & 1583 & 1442 \\
\hline $\mathbf{4}$ & 1577 & 1443 \\
\hline $\mathbf{5}$ & 1563 & 1440 \\
\hline
\end{tabular}




\subsection{Spektroskopische Untersuchungen}

In der vorliegenden Arbeit wurden durch Umsetzung verschiedener Liganden mit Zinkperchlorat Hexahydrat und Natriumacetat in einer Einstufensynthese die Dizinkkomplexe $\mathbf{1}$ bis $\mathbf{5}$ erhalten, welche neben der Pyrazolatbrücke über eine Acetatbrücke verfügen. Die Isolierung dieser Komplexe ist Voraussetzung für die Beobachtung eines stufenweisen Einbaus von Acetat als Zweitbrücke in den vorgebildeten Pyrazolkomplex mit nur einer Brücke, nämlich der Pyrazolatbrücke.

Als Acetatdonor für die Bildung der Zweitbrücke kommt dabei nicht nur Natriumacetat in Frage, sondern auch Substanzen, welche bei der Hydrolyse Acetat freisetzen. Dafür eignet sich in hervorragender Weise $p$-Nitrophenylacetat, welches bei Hydrolyse eine Acetateinheit freisetzt. Als Startkomplexe eignen sich dafür Methoxy- und Hydroxypyrazolatkomplexe. Dabei wurden die folgenden Verbindungen eingesetzt, welche in Lösung hergestellt, aber nicht gesondert isoliert wurden:

$\left[\mathrm{L}^{1}{ }_{-\mathrm{H}}(\mathrm{ROH})(\mathrm{OR}) \mathrm{Zn}_{2}\right]\left(\mathrm{ClO}_{4}\right)_{2}(\mathrm{XLV})$

$\left[\mathrm{L}^{3}{ }_{-H}(\mathrm{ROH})(\mathrm{OR}) \mathrm{Zn}_{2}\right]\left(\mathrm{ClO}_{4}\right)_{2}(\mathrm{XLIII})$

$\left[\mathrm{L}^{4}{ }_{-\mathrm{H}}(\mathrm{ROH})(\mathrm{OR}) \mathrm{Zn}_{2}\right]\left(\mathrm{ClO}_{4}\right)_{2}(\mathrm{XLIV}), \quad$ mit $\mathrm{R}=\mathrm{H}, \mathrm{Me}$

$\left[\mathrm{L}^{6}{ }_{-\mathrm{H}}(\mathrm{MeOH})(\mathrm{OH}) \mathrm{Zn}_{2}\right]\left(\mathrm{ClO}_{4}\right)_{2}{ }^{[65]}(\mathbf{X L I})$

$\left[\mathrm{L}^{7}{ }_{-H}(\mathrm{MeOH})(\mathrm{OH}) \mathrm{Zn}_{2}\right]\left(\mathrm{ClO}_{4}\right)_{2}{ }^{[65]}(\mathbf{X L I I})$

Die Vermutung liegt nahe, dass durch den Einbau der Acetatbrücke in diese Komplexe deren hydrolytische Aktivität gemindert oder aufgehoben wird.

\subsubsection{Aktivität der Pyrazolatodizinkkomplexe in der Esterhydrolyse}

\subsubsection{Metallverbindungen als Modelle für Esterhydrolasen}

Der Mechanismus vieler Hydrolysereaktionen durch Enzyme (z.B. Carboxypeptidase, Phosphatase, Carbonhydrase, etc.) ist von großem Interesse für die bioanorganische Chemie, da die Metallionen solcher Enzyme eine wichtige Rolle spielen. Verschiedene Metallkomplexe wurden entwickelt, 
um die Rolle der Zink(II)-Ionen in diesen Enzymen besser zu verstehen und zu modellieren. Die größten Erfolge wurden statt dessen mit anderen Metallzentren wie $\mathrm{Co}^{3+}$ oder $\mathrm{Cu}^{2+}$, die nicht typisch für diese Enzyme sind, erzielt. ${ }^{[90,91]}$ Zinkkomplexe, wie die in Abb. 38 dargestellten, wurden in letzter Zeit auch als Modellkomplexe für solche Enzymaktivitäten entwickelt und positiv getestet. $^{[92,93]}$

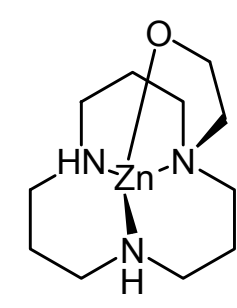

XXXVIII

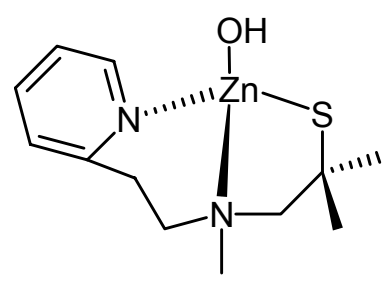

XXXIX

Abb 38: Zinkmodellkomplexe. ${ }^{[94,95]}$

Die Anwesenheit einer Hydroxid- oder einer Alkoxidgruppe in der Umgebung der Metallkerne spielt eine wichtige Rolle für die Eigenschaften dieser untersuchten Katalysatoren. Wie in den modellierten Enzymen wird das Wassermolekül oder die Alkoholgruppe durch die Wechselwirkung mit dem Metallkern aktiviert und damit der nukleophile Angriff ermöglicht. ${ }^{[94,96-99]}$ Es wurde postuliert, dass Alkoxide bessere Nukleophile sind. ${ }^{[93,100]}$ Theoretische Berechnungen mit dem aktiven Zentrum der Metalloproteine wurden auch angestellt, um ein besseres Verständnis der Deprotonierung zu bekommen. Sie zeigen, dass der $p K_{\mathrm{a}}$-Wert des koordinierten Wassermoleküls im Protein (bzw. Hydroxid) vom Metallion abhängt. ${ }^{[100,101]}$

In letzter Zeit wurden auch Dizinkkomplexe als Modellverbindungen für Metalloproteine, die zwei Metallkerne in inrem aktiven Zentrum besitzen (z.B. Aminopeptidasen), entwickelt (Abb. 39). ${ }^{[102,103]}$ Die unzureichende Flexibilität in vielen von diesen Verbindungen beschränkt die katalytische Aktivität und damit eine gute Modellierung des entsprechenden Enzyms. Wie bei den Monozinkkomplexen ist die Anwesenheit einer Hydroxid- bzw. Alkoxidgruppe unentbehrlich für einen nukleophilen Angriff. Verbrückende Hydroxid- oder 
Alkoxidgruppen in Dizinkkomplexen besitzen wohl deutlich geringere Nukleophilie als terminale Einheiten. ${ }^{[89,104,105]}$

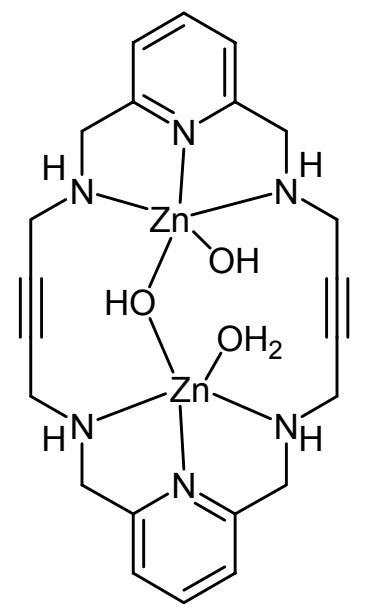

$\mathbf{X L}$

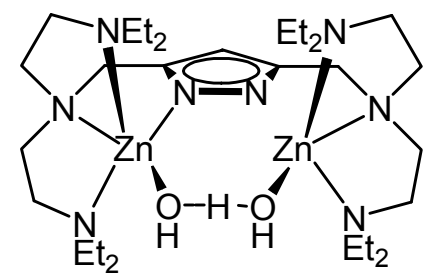

VII

Abb. 39: Dizinkmodellkomplexe. ${ }^{[102,103]}$

\subsubsection{Modellsubstrate für die Spaltung aktiver Ester}

Es ist bekannt, dass Zink(II)-Komplexe aktivierte Carboxyester hydrolysieren können. Verbindungen wie $p$-Nitrophenylacetat wurden in mehreren Arbeiten als Substrat für die Modellierung der hydrolytischen Aktivität von Metallverbindungen, besonders von Mono- und Dizinkkomplexen, gewählt. ${ }^{[106-108]}$ Obwohl das biologische Interesse nicht so groß ist wie bei anderen Enzymsubstraten, z.B. bei aktivierten Phosphoestern oder aktivierten Amiden, wird es wegen der schnellen Hydrolyse für viele katalytische Untersuchungen verwendet. ${ }^{[94]}$

Die Spaltung von $p$-Nitrophenylacetat, die in Schema 15 dargestellt ist, und die damit verbundene Freisetzung von $p$-Nitrophenolat kann sehr einfach anhand der starken Absorption bei $405 \mathrm{~nm}$ verfolgt werden.<smiles>C=C[CH+]Oc1ccc([N+](=O)[O-])cc1</smiles>

Schema 15: Hydrolyse von p-Nitrophenylacetat. 
Es ist auch bekannt, dass bei der Hydrolyse von $p$-Nitrophenylacetat Zwischenprodukte entstehen können, welche schnell weiter zu den Endprodukten reagieren. ${ }^{[93,108]}$ Die Isolierung dieser Zwischenprodukte hat aber ein besseres Verständnis der katalysierten Esterhydrolyse gebracht.

\subsubsection{Kinetische Untersuchung der Hydrolyse von p-Nitrophenylacetat}

In dieser Arbeit wurde die Hydrolyse von $p$-Nitrophenylacetat durch zwei Komplexe (XLI und XLII) verwendet, die in früheren Arbeiten für die Untersuchungen der Phosphatdiesterspaltung und der Öffnung von 3-Lactam-Substraten benutzt wurden. In Abb. 40 sind die Verbindungen XLI und XLII dargestellt.

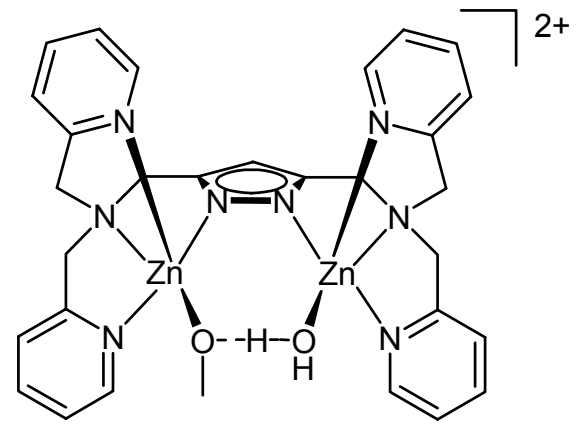

XLI

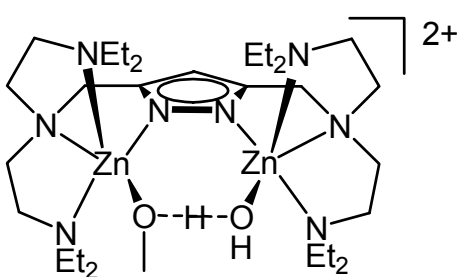

XLII

Abb. 40: Für die Hydrolyse verwendete Komplexe.

Für die Untersuchungen wurde, wie bei anderen Literaturvorschriften, ein 1:4 (v:v)-Lösungsmittelgemisch aus Acetonitril und Wasser verwendet. ${ }^{[93,94]}$ Der Acetonitril-Anteil sorgt für eine gute Löslichkeit der Komplexe und des Substrats, welches in Wasser unlöslich ist.

Als Puffer wurde ein Sulfonatpuffer wie HEPES oder BIS-TRIS eingesetzt, da sich damit ein großer pH-Bereich abdecken lässt und im Allgemeinen keine Koordination an Metallzentren erfolgt. Die Puffer wurden jeweils mit Perchlorsäure oder Natronlauge eingestellt. 
Die Reaktionsgeschwindigkeit bei $25{ }^{\circ} \mathrm{C}$ wurde durch den Anstieg der Nitrophenolatkonzentration anhand der Absorption bei $405 \mathrm{~nm}$ verfolgt und nur die Anfangsgeschwindigkeit zur weiteren Auswertung herangezogen. ${ }^{[09]}$ Ist eine Reaktion gegeben durch:

$$
x_{1} A+x_{2} B \rightarrow x_{3} C,
$$

so gilt für die Reaktionsgeschwindigkeit in Bezug auf das Produkt C:

(2) $\quad v=\frac{d(C)}{d(t)}=k[A]^{a}[B]^{b}$.

Um den Betrag des Geschwindigkeitskoeffizienten $k$ der Reaktion zu ermitteln, muss man die Exponenten $a$ und $b$ der Gleichung (2) kennen. Wenn die Reaktion kein Elementarprozess ist, sind diese Exponenten nicht die stöchiometrischen Koeffizienten $x_{1}$ und $x_{2}$. Zur Bestimmung von $a$ und $b$ muss man die Anfangskonzentration von $B$ konstant halten und die Konzentration von $A$ variieren, bzw. die Anfangskonzentration von $A$ konstant halten und die von $B$ variieren, woraus sich die Gleichungen (3) und (4) ergeben:

(4) $\quad v_{0}=k^{i}$ const $_{2}[\text { Subst }]_{0}=k_{\text {cat }}[\text { Subst }]_{0}$

Die Extinktionswerte wurden mit dem Lambert-Beer'schen Gesetz in Konzentrationswerte umgerechnet. Die Extinktionswerte des Nitrophenolats wurden dazu durch Messung der Extinktion von Nitrophenolat unter den gleichen Messbedingungen bestimmt. Dafür wurden vier Extinktionswerte in Abhängigkeit der Nitrophenolatkonzentration gemessen und durch lineare Regression der Kalibriergerade die pH-abhängigen effektiven Extinktionskoeffizienten $\varepsilon_{\text {eff }}$ nach dem Lambert-Beer'schen Gesetz bestimmt.

Die Hintergrundhydrolyse von $p$-Nitrophenolacetat muss ebenfalls betrachtet werden, da unter den gewählten Reaktionsbedingungen während des 
Zeitraums einer Messung Autohydrolyse von $p$-Nitrophenylacetat detektiert werden könnte.

\subsubsection{Abhängigkeit der $p$-Nitrophenylacetat-Hydrolyse von der Komplexkonzentration}

Um die hydrolytische Aktivität der Komplexe $\left[\mathrm{L}^{6}{ }_{-\mathrm{H}}(\mathrm{MeOH})(\mathrm{OH}) \mathrm{Zn}_{2}\right]\left(\mathrm{ClO}_{4}\right)_{2}(\mathbf{X L I})$ und $\left[\mathrm{L}^{7}{ }_{-\mathrm{H}}(\mathrm{MeOH})(\mathrm{OH}) \mathrm{Zn}_{2}\right]\left(\mathrm{ClO}_{4}\right)_{2}(\mathrm{XLI}) \mathrm{Zu}$ untersuchen wurden diese bei einem $\mathrm{pH}-$ Wert von 7.4 verglichen. Bei diesem $\mathrm{pH}$-Wert sind beide Komplexe in Lösung stabil und das abgespaltene 4-Nitrophenol liegt zu einem großen Teil in seiner deprotonierten Form vor. Bei größeren $\mathrm{pH}$-Werten ist die Autohydrolyse von $p$-Nitrophenylacetat sehr stark.

Die kinetischen Daten zeigen, dass die Hydrolyse von $p$-Nitrophenylacetat linear von der Komplexkonzentration abhängt. Die Geschwindigkeitskonstanten $k_{\exp }$ sind in beiden Fällen erster Ordnung mit einen Wert von $1.26 \mathrm{~h}^{-1}$ (für XLII) und $1.06 \mathrm{~h}^{-1}$ (für XLI). Die Werte von $k_{\exp }$ zeigen, dass diese beiden Komplexe sehr langsam als Promotoren für die Hydrolyse von $p$-Nitrophenylacetat wirken. Die Verbindung XLII, obwohl sie nicht besonders aktiv ist, wirkt eindeutig schneller als die Verbindung XLI. Ein Grund für die Inhibierung der Esterhydrolyse kann die Verbrückung beider Zink(II)-Ionen durch die abgespaltene Acetateinheit sein. Kristalle dieses Komplexes mit Acetateinheiten wurden in dieser Arbeit erhalten (Röntgenstrukturen 4 und 5). Die Koordination der Acetateinheit kann zur Folge haben, dass die Aktivität abgeschwächt oder ganz unterdrückt wird. 


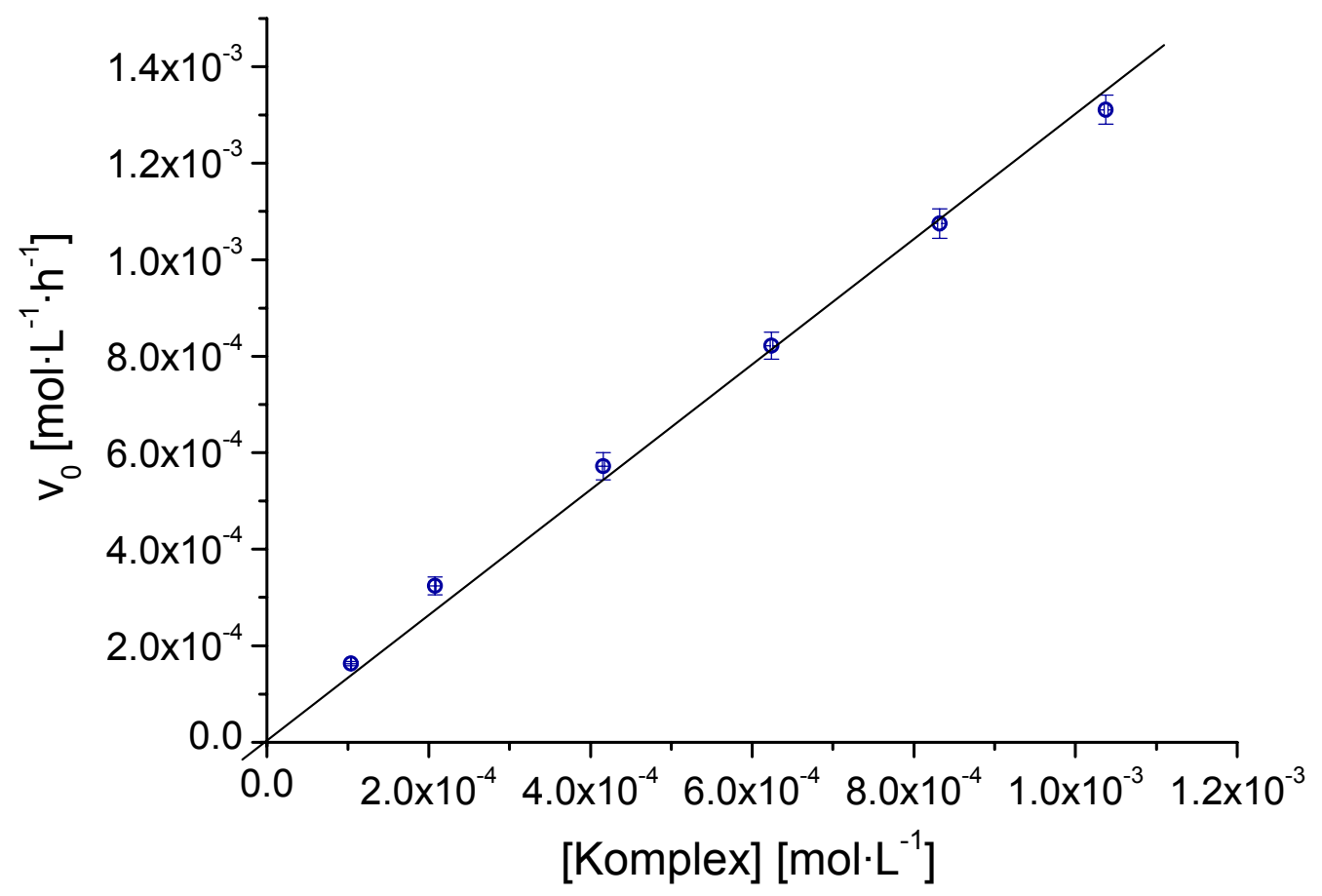

Abb. 41: Anfangsgeschwindigkeit der Hydrolyse von p-Nitrophenylacetat in Abhängigkeit von der Komplexkonzentration von XLII.

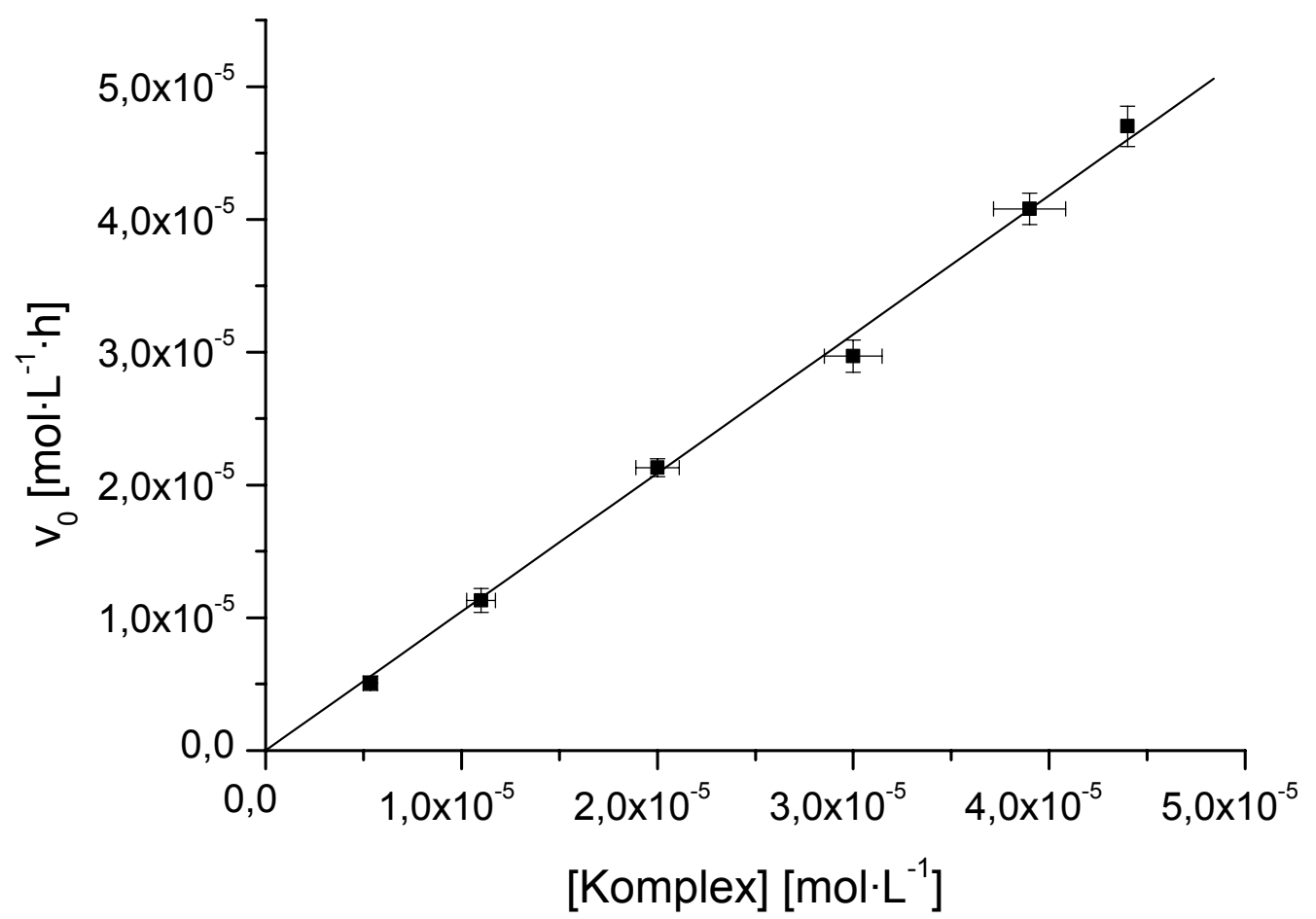

Abb. 42: Anfangsgeschwindigkeit der Hydrolyse von p-Nitrophenylacetat in Abhängigkeit von der Komplexkonzentration von XLI. 


\subsubsection{Abhängigkeit der $p$-Nitrophenylacetat-Hydrolyse von der Substratkonzentration und dem pH-Wert}

Weil die Messungen bei pH-Werten zwischen 6.6 und 7.9 nicht reproduzierbar waren, war die Ermittlung von $k_{\text {cat }}$ und des für die Hydrolyse optimalen pH-Werts, nicht möglich.

Ein Grund dafür könnte die Bildung des vierkernigen, carbonatverbrückten Zinkkomplexes $\left[\left(\mathrm{L}^{6}{ }_{-\mathrm{H}}\right)_{2}\left(\mu_{3}-\mathrm{CO}_{3}\right)\left(\mathrm{H}_{2} \mathrm{O}\right) \mathrm{Zn}_{4}\right]\left(\mathrm{ClO}_{4}\right)_{4}$ (8) sein, der während der Untersuchungen aus der Komplexlösung gewonnen wurde. Der Komplex in seiner kristallinen Form wurde bei allen untersuchten $\mathrm{pH}$-Werten gewonnen, aber seine Anwesenheit in Lösung konnte durch IR-Messungen nicht bestätigt werden.

\subsubsection{Untersuchungen mit Glycin-p-nitrophenylanilid}

Während dieser Arbeit wurde auch Glycin-p-nitrophenylanilid als Testsubstrat verwendet, das auch als Modellsubstrat für die Aminopeptidaseaktivität dient. Wegen der großen Stabilität der Amidbindung wurden bis jetzt sehr wenige Modellkomplexe für diese Zinkenzyme entwickelt. ${ }^{[110-112]}$

Die Messungen mit diesem Substrat erfolgten nur mit dem Komplex XLII. In den wasserhaltigen Lösungen, die eingesetzt wurden, konnte keine Aktivität beobachtet werden. Es wurden auch Tests unter wasserfreien Bedingungen, wie z.B. in DMSO oder DMF, gemacht. In diesen Tests konnte eine sofortige Spaltung des Substrats durch die Verstärkung der Signale von $p$-Nitroanilin bei $405 \mathrm{~nm}$ beobachtet werden.

\subsubsection{Massenspektrometrische Messungen}

In der vorliegenden Arbeit wurden Dizinkkomplexe auf Pyrazolatbasis hergestellt mit einer zusätzlichen Verbrückung durch Acetat. Die Massenspektren dieser Verbindungen belegen, dass diese verbrückende Einheit auch in Lösung stabil ist. Somit konnte man den Einbau einer solchen 
Zweitbrücke auch massenspektrometrisch verfolgen. Diese Untersuchungen wurden auch mit nicht in der vorliegenden Arbeit dargestellten Komplexen durchgeführt. Die Bildung der acetatverbrückten Komplexe wurde während der Hydrolyse von $p$-Nitrophenylacetat beobachtet. Dazu wurden Mischungen des jeweiligen Komplexes mit dem Substrat "in situ“ gemessen. Wie bei den UV-Vis Untersuchungen wurde dafür eine 1:4 Mischung aus Acetonitril und Wasser verwendet. Bei Verwendung von Acetonitril als Lösungsmittel kann dieses an die Metallzentren koordinieren. Das kann zu zusätzlichen Peaks in den Massenspektren führen. Um diesen Effekt zu vermeiden, wurde diese Untersuchung auch in methanolischer Lösung durchgeführt. Dadurch ist ein Vergleich der Massenspektren dieser Lösungen mit den Massenspektren bereits isolierter acetatverbrückter Pyrazolat-dizinkkomplexe möglich.

\subsubsection{Reaktion des Komplexes $\left[\mathrm{L}^{6}{ }_{-\mathrm{H}}(\mathrm{MeOH})(\mathrm{OH}) \mathrm{Zn}_{2}\right]\left(\mathrm{ClO}_{4}\right)_{2} \mathrm{zu} 5$}

$\mathrm{Zu}$ einer methanolischen Lösung des Komplexes wurden fünf Äquivalente $p$-Nitrophenylacetat in methanolischer Lösung zugegeben und aus der Mischung ein ESI-Massenspektrum gemessen. Die sofortige Gelbfärbung der Mischung nach Zugabe von $p$-Nitrophenylacetat weist auf die Spaltung der Esterbindung hin.

Im ESI-Spektrum zeigen sich zwei Signale, die auf die acetatverbrückten Komplexe hinweisen. Der Peak bei $\mathrm{m} / \mathrm{z}=779.2$ mit einer Intensität von $75 \%$ kann der Spezies mit Acetatverbrückung $\left[\mathrm{L}^{6}{ }_{-\mathrm{H}}\left(\mu-\mathrm{CH}_{3} \mathrm{COO}\right) \mathrm{Zn}_{2}\left(\mathrm{ClO}_{4}\right)\right]^{+}$ zugeordnet werden. Die zweifach geladene Spezies $\left[\mathrm{L}^{6}{ }_{-\mathrm{H}}\left(\mu-\mathrm{CH}_{3} \mathrm{COO}\right) \mathrm{Zn}_{2}\right]^{2+}$ bei $\mathrm{m} / \mathrm{z}=340.2$ bildet den Basispeak (Intensität $100 \%$ ). Beide Signale tretten auch im ESI-Massenspektrum der Verbindung 6 in methanolischer Lösung auf. Das ESI-Massenspektrum aus dem Reaktionsgemisch zeigt aber auch Signale, für die eine Zuordnung nicht möglich war. Der Einbau der Acetatbrücke in den Pyrazolatkomplex läuft nach folgender, in Schema 16 dargestellter, Reaktion ab. 

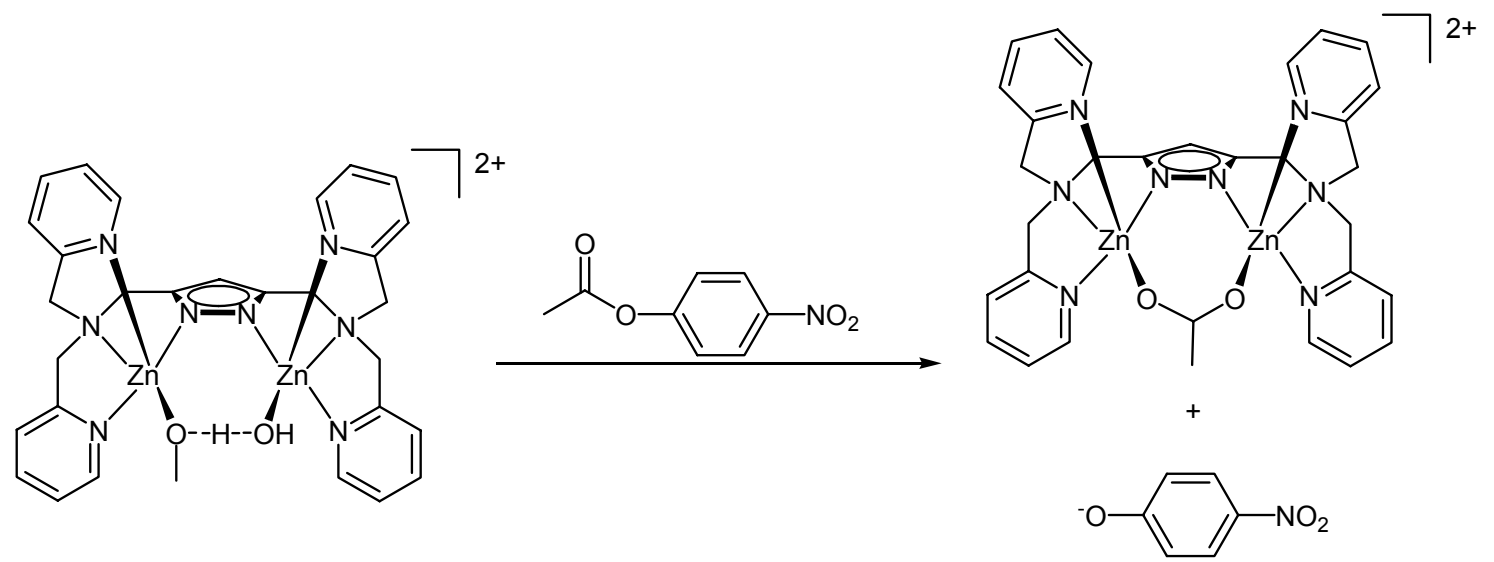

Schema 16: Reaktion des Komplexes $\left[L^{6}{ }_{-H}(\mathrm{MeOH})(\mathrm{OH}) \mathrm{Zn}_{2}\right]\left(\mathrm{ClO}_{4}\right)_{2}$ (XLI) mit p-Nitrophenylacetat.

Das ESI-Massenspektrum des Reaktionsgemisches ist in Abb. 43 als Teilausschnitt für den Bereich von $m / z=670$ bis $m / z=855$ dargestellt. Beigefügt ist dem auch die Isotopensimulation für den Peak bei $m / z=779.2$. Abb. 44 zeigt den Teilausschnitt für die doppelt geladene Spezies bei $\mathrm{m} / \mathrm{z}=340.2$ und das zugehörige simulierte Isotopenmuster.

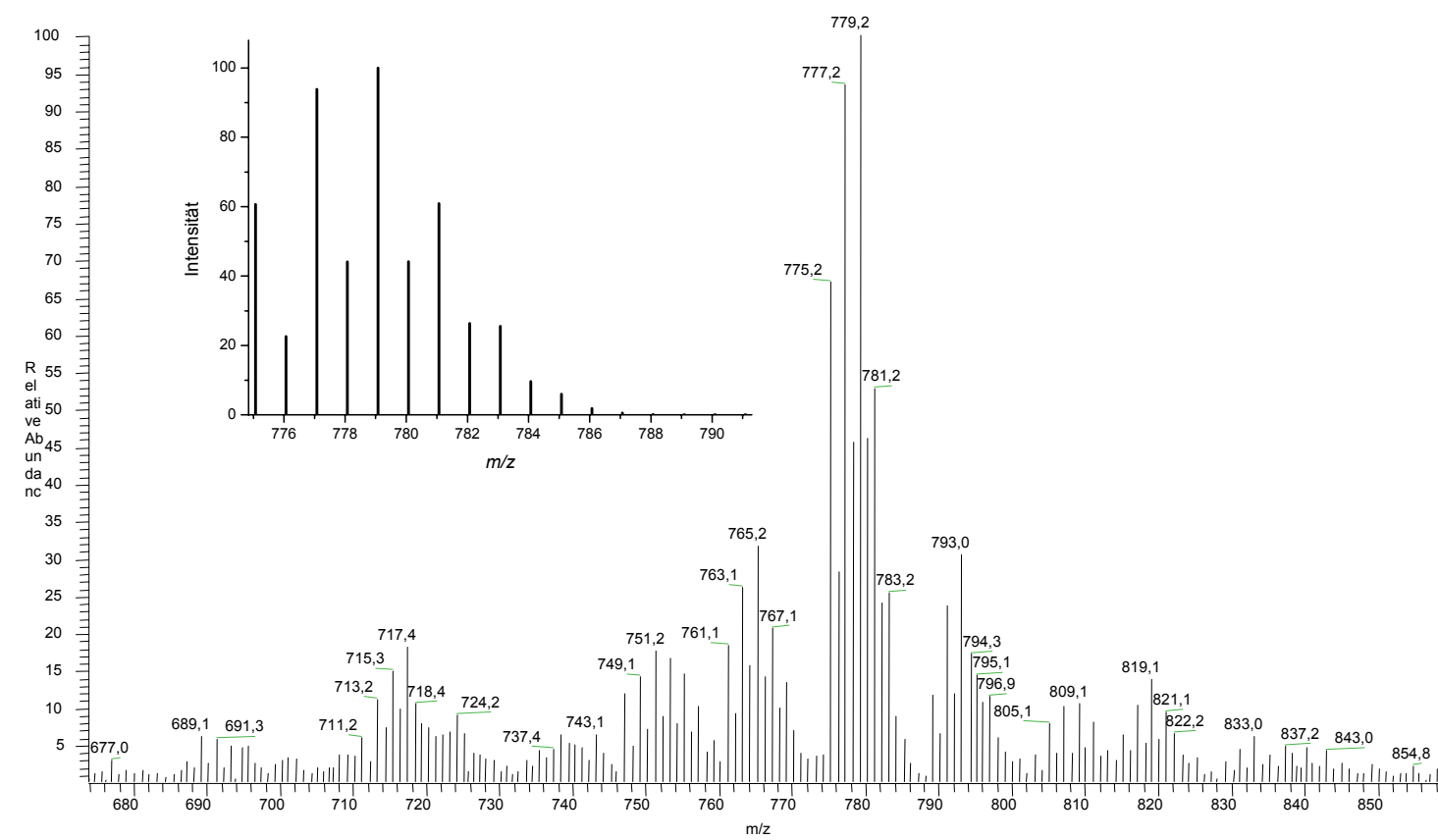

Abb. 43: Auflösung des Peaks bei $\mathrm{m} / \mathrm{z}=779.2$ und berechnete Isotopenverteilung für $\left[\mathrm{L}^{6}{ }_{-\mathrm{H}}\left(\mu-\mathrm{CH}_{3} \mathrm{COO}\right) \mathrm{Zn}_{2}\left(\mathrm{ClO}_{4}\right)\right]^{+}$. 


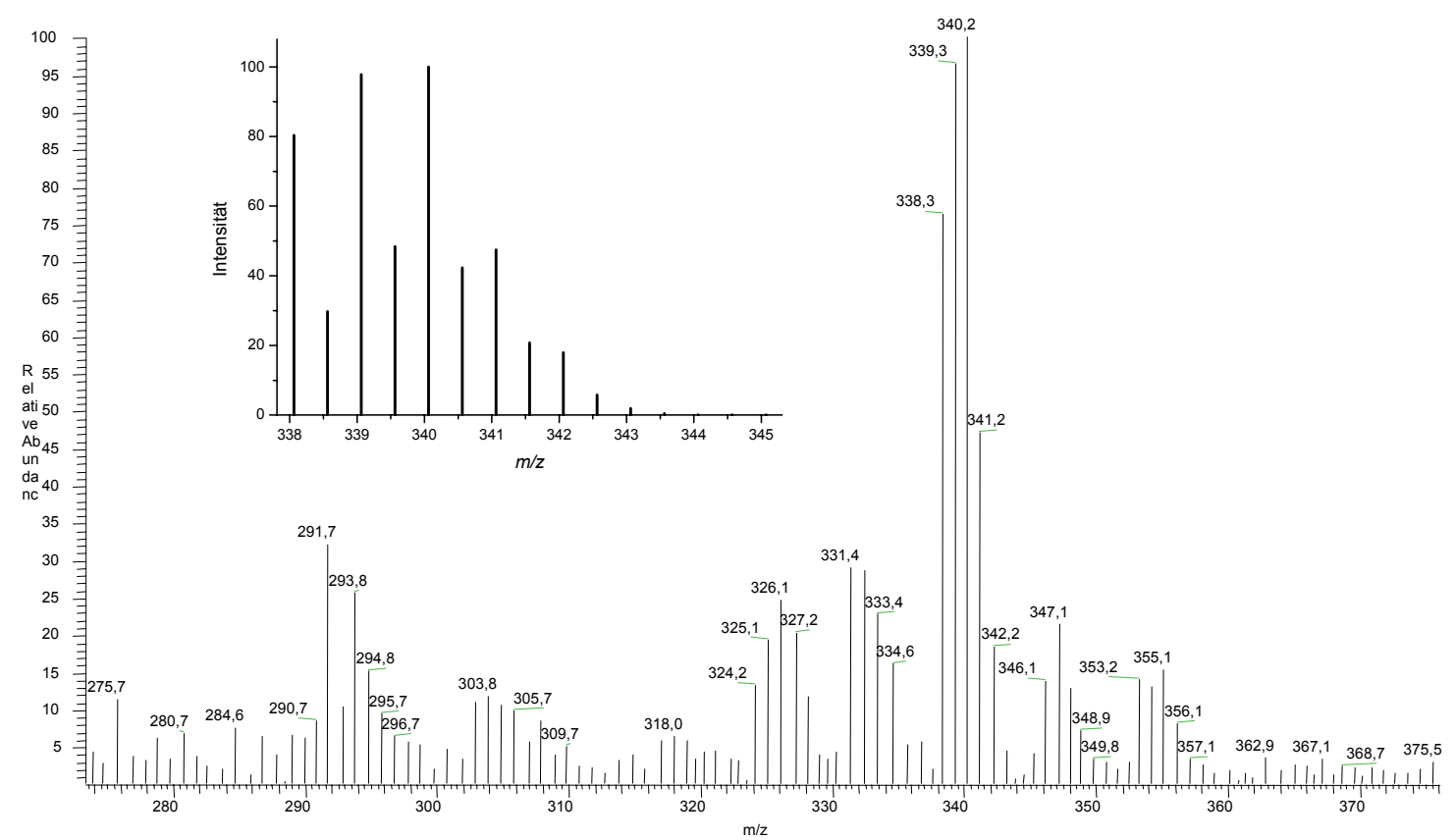

Abb. 44: Auflösung des Peaks bei $\mathrm{m} / \mathrm{z}=340.2$ und berechnete Isotopenverteilung für $\left[\mathrm{L}^{6}{ }_{-\mathrm{H}}\left(\mu-\mathrm{CH}_{3} \mathrm{COO}\right) \mathrm{Zn}_{2}\right]^{2+}$.

\subsubsection{Reaktion des Komplexes $\left[\mathrm{L}^{7}{ }_{-\mathrm{H}}(\mathrm{MeOH})(\mathrm{OH}) \mathrm{Zn}_{2}\right]\left(\mathrm{ClO}_{4}\right)_{2} \mathrm{zu} 4$}

Wie in 4.3.2.1. beschrieben, wurde auch mit $\left[\mathrm{L}^{7}{ }_{-\mathrm{H}}(\mathrm{MeOH})(\mathrm{OH}) \mathrm{Zn}_{2}\right]\left(\mathrm{ClO}_{4}\right)_{2}(\mathrm{XLII})$ verfahren. Der Ausgangskomplex wurde aus $\mathrm{L}^{7}$, Kalium-tert-butylat und Zinkperchlorat Hexahydrat in Methanol umgesetzt und im ESI-Massenspektrum aus dieser Lösung das Vorhandensein des angeführten Komplexes bestätigt. Danach erfolgte die Zugabe einer methanolischen Lösung von p-Nitrophenylacetat, welche mit sofortiger Gelbfärbung der Lösung verbunden war und damit die Zerstörung der Esterbindung anzeigte. Die Reaktion läuft demnach nach der in Schema 17 dargestellten Gleichung ab. 

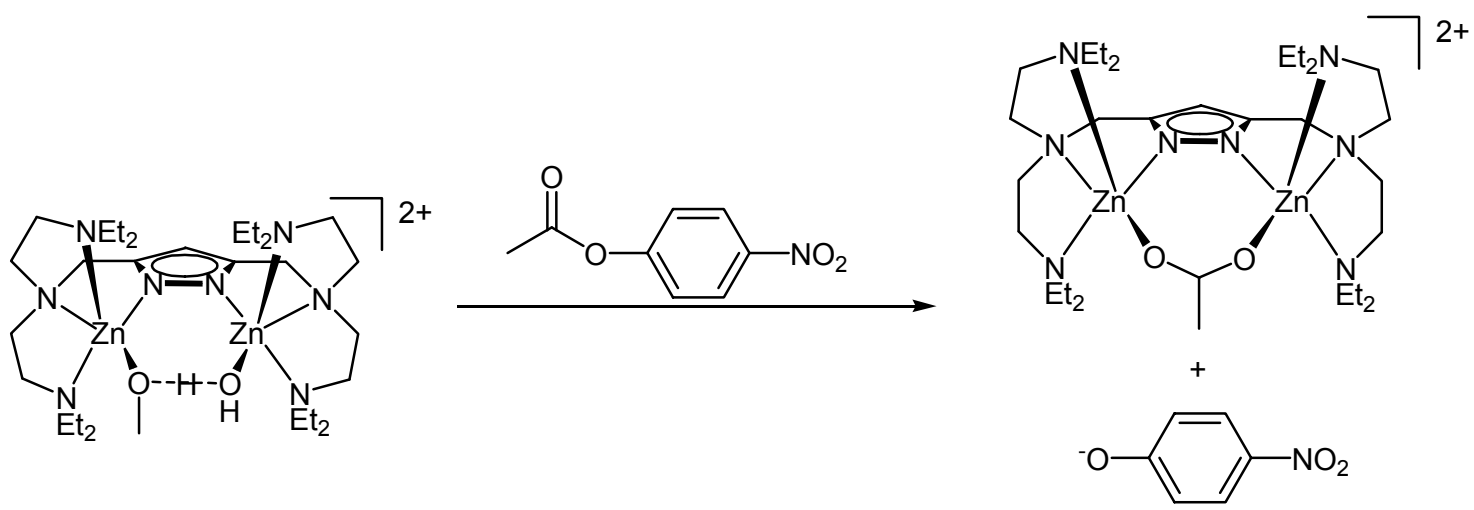

Schema 17: Reaktion des Komplexes $\left.\mathrm{L}^{7}{ }_{-H}(\mathrm{MeOH})(\mathrm{OH}) \mathrm{Zn}_{2}\right]\left(\mathrm{ClO}_{4}\right)_{2}$ (XLII) mit p-Nitrophenylacetat.

Das ESI-Massenspektrum lässt nur die Zuordnung eines Signals für den Basispeak bei $\mathrm{m} / \mathrm{z}=811.4 \mathrm{zu}$. Diese Masse entspricht der acetatverbrückten Spezies $\left[\mathrm{L}^{7}{ }_{\mathrm{H}}\left(\mu-\mathrm{CH}_{3} \mathrm{COO}\right) \mathrm{Zn}_{2}\left(\mathrm{ClO}_{4}\right)\right]^{+}$. Die zweifach geladene Spezies $\left[\mathrm{L}^{7}{ }_{-\mathrm{H}}\left(\mu-\mathrm{CH}_{3} \mathrm{COO}\right) \mathrm{Zn}_{2}\right]^{2+}$ wurde hier nicht festgestellt. Bei $\mathrm{m} / \mathrm{z}=787.3$ und mit einer Intensität von $50 \%$ beobachtet man das Signal der Spezies $\left[\mathrm{L}^{7}{ }_{-}\left(\mathrm{H}_{2} \mathrm{O}\right)(\mathrm{OH}) \mathrm{Zn}_{2}\left(\mathrm{ClO}_{4}\right)\right]^{+}$. Ein intensives Signal $(60 \%)$ bei $\mathrm{m} / \mathrm{z}=825.1$ konnte nicht zugeordnet werden.

Abb. 45 zeigt einen vergrösserten Teilausschnitt für den Peak bei $\mathrm{m} / \mathrm{z}=811.4$ und das für diesen Peak simulierte Isotopenmuster. 


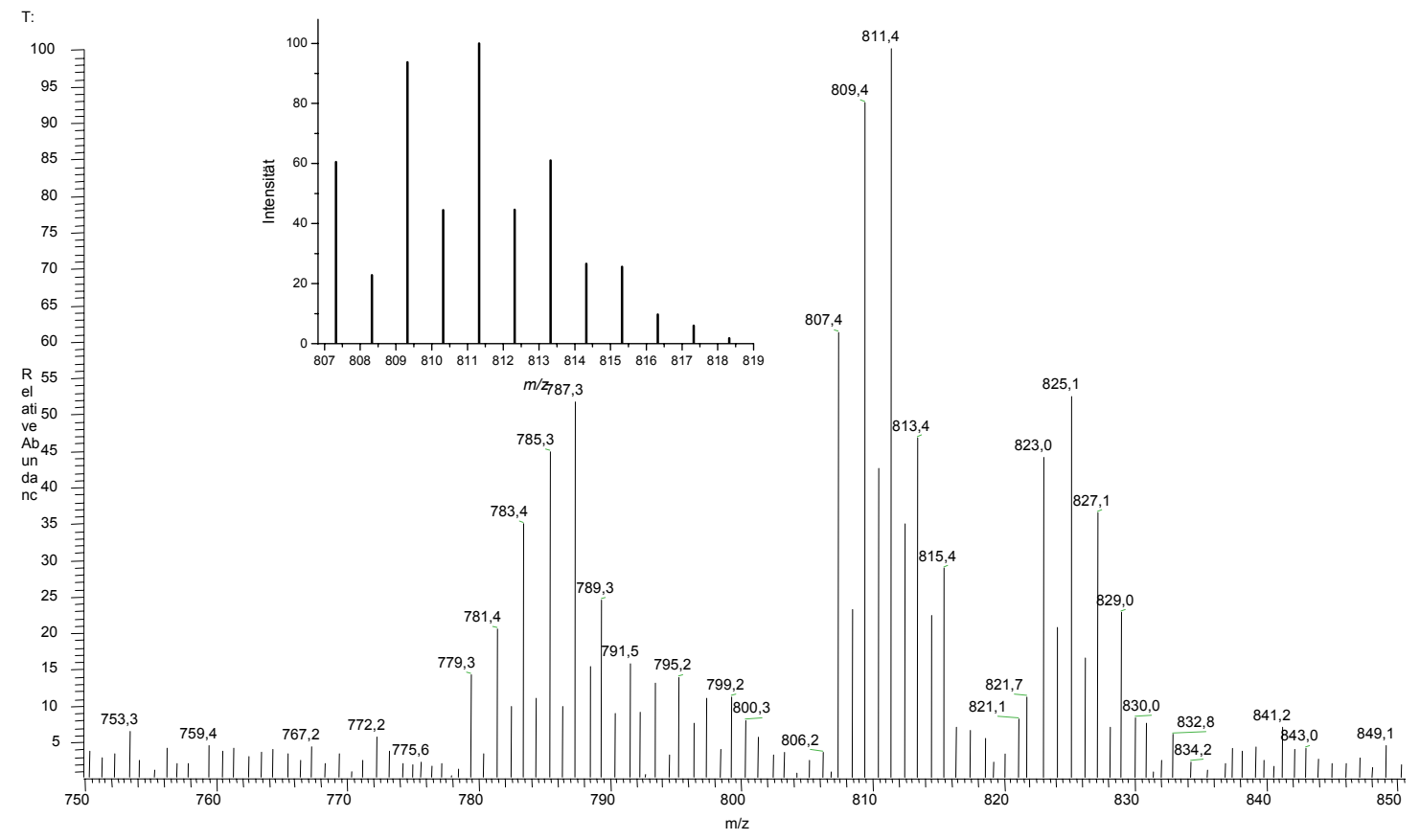

Abb. 45: Auflösung des Peaks bei $\mathrm{m} / \mathrm{z}=811.4$ und berechnete Isotopenverteilung für $\left[\mathrm{L}^{7}{ }_{-\mathrm{H}}\left(\mu-\mathrm{CH}_{3} \mathrm{COO}\right) \mathrm{Zn}_{2}\left(\mathrm{ClO}_{4}\right)\right]^{+}$.

\subsubsection{Reaktion von anderen Komplexen des Typs $\left[\mathrm{L}^{\mathrm{n}}{ }_{-\mathrm{H}}(\mathrm{ROH})(\mathrm{OR}) \mathrm{Zn}_{2}\right]\left(\mathrm{ClO}_{4}\right)_{2}$ mit $p$-Nitrophenylacetat}

Die Darstellung der Komplexe XLIII, XLIV und XLV erfolgt analog zu 4.3.2.2. aus $\mathrm{L}^{3}, \mathrm{~L}^{4}$ bzw. $\mathrm{L}^{1}$, Kalium-tert-butylat und Zinkperchlorat Hexahydrat. Die Bildung des Komplexes wird duch ESI-MS bestätigt. Nach Zugabe von fünf Äquivalenten p-Nitrophenylacetat wurde, wie bei 4.3.2.1 und 4.3.2.2, die Farbe der Lösung sofort gelb. Die drei Reaktionen laufen analog zu den beiden erwähnten Fällen ab.

In den ESI-Massenspektren der drei Reaktionen beobachtet man mit unterschiedlichen Intensitäten (von 100\% für der Komplex mit $L^{4}$ bis $35 \%$ für den Komplex mit $L^{1}$ bis $35 \%$ für das Signal der Spezies $\left[\mathrm{L}^{\mathrm{n}}{ }_{-\mathrm{H}}\left(\mu-\mathrm{CH}_{3} \mathrm{COO}\right) \mathrm{Zn}_{2}\left(\mathrm{ClO}_{4}\right)\right]^{+}$. Das Signal für die Spezies $\left[\mathrm{L}^{\mathrm{n}}{ }_{-\mathrm{H}}\left(\mu-\mathrm{CH}_{3} \mathrm{COO}\right) \mathrm{Zn}_{2}\right]^{2+}$ wurde nur für den Komplex aus $L^{1}$ gefunden (Intensität 100\%). 


\subsection{Zinkkomplexe mit anderen Zweitbrücken}

\subsubsection{Zink(II)-Komplex des Liganden $\mathrm{L}^{6}-$ Synthese von $\left[\mathrm{L}^{6}{ }_{-\mathrm{H}}(\mu-\mathrm{HCOO}) \mathrm{Zn}_{2}\right]\left(\mathrm{ClO}_{4}\right)_{2}(6)$}

Dieser Komplex (Abb. 46) wurde durch Reaktion des deprotonierten Liganden $\mathrm{L}^{6}$ mit Zinkperchlorat Hexahydrat in DMF erhalten. Ziel dieser Synthese war der Abbau der Amidbindung von L-Glycin-p-nitroanilid, das der Lösung ebenfalls beigefügt wurde. Statt dessen erfolgte offenbar eine Spaltung der Amidbindung des als Lösungsmittel verwendeten Dimethylformamids, sodass es zu einer Verbrückung zwischen den beiden Zink(II)-Ionen durch einen Formiatrest kam. Der Komplex kristallisiert in der Raumgruppe $P 2_{1} / a$ mit vier Molekülen in der monoklinen Zelle. In Abb. 47 sowie in Tab. 14 und 15 sind einige wichtige strukturelle Parameter des Kations des Komplexes $\left[\mathrm{L}^{6}{ }_{-\mathrm{H}}(\mu-\mathrm{COO}) \mathrm{Zn}_{2}\right]\left(\mathrm{ClO}_{4}\right)_{2}(6)$ zusammengefasst.

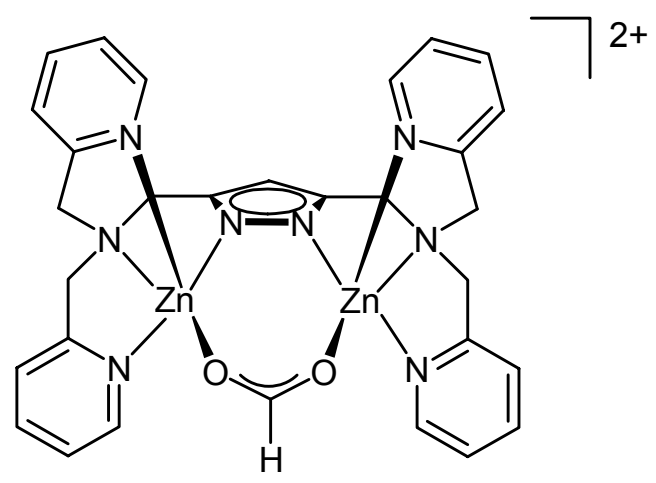

Abb. 46: Strukturformel des Kations von 6. 


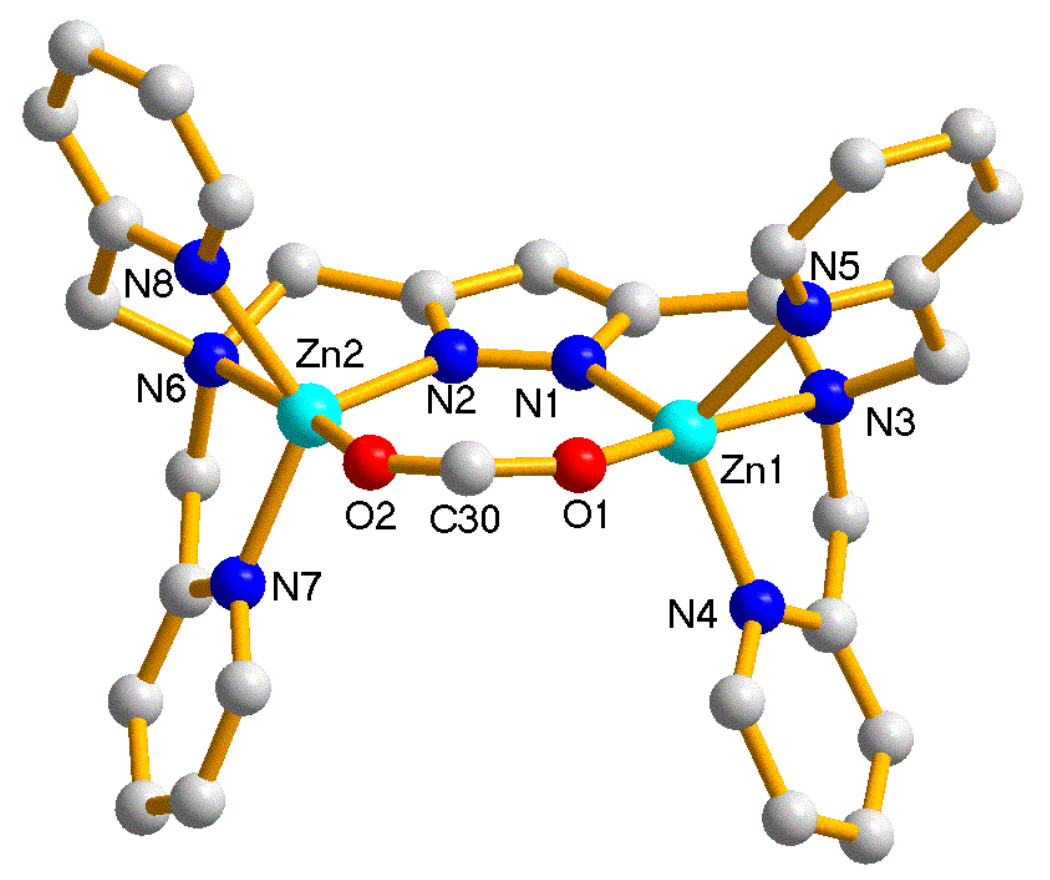

Abb. 47: Festkörperstruktur des Kations von 6.

Tab. 14: Ausgewählte Atomabstände [A] von 6.

\begin{tabular}{|l|l|l|l|}
\hline $\mathrm{Zn}(1)-\mathrm{N}(1)$ & $1.985(3)$ & $\mathrm{Zn}(2)-\mathrm{N}(2)$ & $1.988(3)$ \\
\hline $\mathrm{Zn}(1)-\mathrm{N}(3)$ & $2.276(3)$ & $\mathrm{Zn}(2)-\mathrm{N}(6)$ & $2.260(3)$ \\
\hline $\mathrm{Zn}(1)-\mathrm{N}(4)$ & $2.042(3)$ & $\mathrm{Zn}(2)-\mathrm{N}(7)$ & $2.038(3)$ \\
\hline $\mathrm{Zn}(1)-\mathrm{N}(5)$ & $2.052(3)$ & $\mathrm{Zn}(2)-\mathrm{N}(8)$ & $2.055(3)$ \\
\hline $\mathrm{Zn}(1)-\mathrm{O}(1)$ & $1.992(2)$ & $\mathrm{Zn}(2)-\mathrm{O}(2)$ & $2.003(2)$ \\
\hline $\mathrm{Zn}(1) \cdots \mathrm{Zn}(2)$ & $4.0490(6)$ & $\mathrm{O}(1)-\mathrm{C}(30)$ & $1.247(4)$ \\
\hline $\mathrm{O}(2)-\mathrm{C}(30)$ & $1.245(4)$ & & \\
\hline
\end{tabular}

Tab. 15: Ausgewählte Bindungswinkel () von 6.

\begin{tabular}{|l|l|l|l|}
\hline $\mathrm{N}(1)-\mathrm{Zn}(1)-\mathrm{O}(1)$ & $109.45(10)$ & $\mathrm{N}(2)-\mathrm{Zn}(2)-\mathrm{O}(2)$ & $109.36(10)$ \\
\hline $\mathrm{N}(1)-\mathrm{Zn}(1)-\mathrm{N}(4)$ & $117.53(11)$ & $\mathrm{N}(2)-\mathrm{Zn}(2)-\mathrm{N}(7)$ & $114.44(11)$ \\
\hline $\mathrm{N}(1)-\mathrm{Zn}(1)-\mathrm{N}(5)$ & $116.50(11)$ & $\mathrm{N}(2)-\mathrm{Zn}(2)-\mathrm{N}(6)$ & $78.74(10)$ \\
\hline $\mathrm{N}(1)-\mathrm{Zn}(1)-\mathrm{N}(3)$ & $77.75(11)$ & $\mathrm{N}(2)-\mathrm{Zn}(2)-\mathrm{N}(8)$ & $110.73(11)$ \\
\hline $\mathrm{O}(1)-\mathrm{Zn}(1)-\mathrm{N}(4)$ & $99.17(11)$ & $\mathrm{O}(2)-\mathrm{Zn}(2)-\mathrm{N}(7)$ & $99.06(11)$ \\
\hline
\end{tabular}




\begin{tabular}{|l|l|l|l|}
\hline $\mathrm{O}(1)-\mathrm{Zn}(1)-\mathrm{N}(5)$ & $96.22(11)$ & $\mathrm{O}(2)-\mathrm{Zn}(2)-\mathrm{N}(8)$ & $95.61(11)$ \\
\hline $\mathrm{O}(1)-\mathrm{Zn}(1)-\mathrm{N}(3)$ & $172.58(10)$ & $\mathrm{O}(2)-\mathrm{Zn}(2)-\mathrm{N}(6)$ & $171.38(11)$ \\
\hline $\mathrm{N}(4)-\mathrm{Zn}(1)-\mathrm{N}(5)$ & $113.84(11)$ & $\mathrm{N}(7)-\mathrm{Zn}(2)-\mathrm{N}(8)$ & $123.93(11)$ \\
\hline $\mathrm{N}(4)-\mathrm{Zn}(1)-\mathrm{N}(3)$ & $78.45(11)$ & $\mathrm{N}(7)-\mathrm{Zn}(2)-\mathrm{N}(6)$ & $79.62(11)$ \\
\hline $\mathrm{N}(5)-\mathrm{Zn}(1)-\mathrm{N}(3)$ & $78.55(11)$ & $\mathrm{N}(8)-\mathrm{Zn}(2)-\mathrm{N}(6)$ & $78.37(10)$ \\
\hline $\mathrm{O}(2)-\mathrm{C}(30)-\mathrm{O}(1)$ & $128.5(3)$ & & \\
\hline
\end{tabular}

Wie beim Komplex 5 beobachtet man im ESI-Massenspektrum aus einer methanolischen Lösung eine Mischung mehrerer Spezies. Das Signal mit einer Intensität von $100 \%$ bei $\mathrm{m} / \mathrm{z}=765$ gehört zu $\left[\mathrm{L}^{6}{ }_{-\mathrm{H}}(\mu-\mathrm{HCOO}) \mathrm{Zn}_{2}\left(\mathrm{ClO}_{4}\right)\right]^{+}$. Bei $\mathrm{m} / \mathrm{z}=333$ und mit einer Intensität von $15 \%$ kommt die Spezies $\left[\mathrm{L}^{6}{ }_{-\mathrm{H}}(\mu-\mathrm{COO}) \mathrm{Zn}_{2}\right]^{2+}$. Der Peak der Spezies $\left[\mathrm{L}^{6}{ }_{-\mathrm{H}}(\mathrm{MeOH})(\mathrm{MeO}) \mathrm{Zn}_{2}\right]^{+}$ist in diesem Fall vernachlässigbar, was für eine höhere Stabilität der Formiatbrücke spricht. Der Abstand zwischen den Metallzentren beträgt $4.05 \AA$. Diese Länge stimmt mit der in der acetatverbrückten Verbindung 5 überein. Beide Zink(II)-lonen sind trigonal bipyramidal $(\mathrm{Zn} 1: \tau=0.92 ; \mathrm{Zn} 2: \tau=0.79)$ koordiniert. Wie bei 5 liegen die verbrückenden Einheiten und die metallischen Atome fast in einer Ebene. Auch die Winkel, die in Tab. 15 zusammengefasst sind, stimmen mit den Winkeln aus Tab. 12 überein, was bedeutet, dass die $\mathrm{CH}_{3}$-Gruppe des Acetats keinen sterischen Einfluß auf die Koordination hat.

Im IR-Spektrum beobachtet man zwei Banden für die symmetrische Streckschwingung und zwei Banden für die asymmetrische Streckschwingung, was sich durch die Anwesenheit eines Moleküls DMF im Kristall erklären lässt (1668 und 1595 bzw. 1485 und $1439 \mathrm{~cm}^{-1}$ ).

\subsubsection{Zink(II)-Komplex des Liganden $\mathrm{L}^{1}-$ Synthese von $\left[\left(\mathrm{L}^{1}{ }_{-\mathrm{H}}\right)_{2} \mathrm{Zn}_{2}\right]\left(\mathrm{CF}_{3} \mathrm{SO}_{3}\right)_{2}(7)$}

Der Komplex 7 (Abb. 48) wurde erhalten durch die Reaktion des deprotonierten Liganden $\mathrm{L}^{1}$ mit Zinktriflat in Wasser und anschließende langsame Diffusion von Diethylether in eine konzentrierte methanolische Lösung des erhaltenen 
Komplexes. Der Komplex kristallisiert in der Raumgruppe P-1. Die trikline Zelle enthält ein Molekül.

In Abb. 49 sowie in Tab. 16 und 17 sind einige wichtige strukturelle Parameter des Kations des Komplexes $\left[\left(\mathrm{L}^{1}{ }_{-\mathrm{H}}\right)_{2} \mathrm{Zn}_{2}\right]\left(\mathrm{CF}_{3} \mathrm{SO}_{3}\right)_{2}$ (7) zusammengefasst.

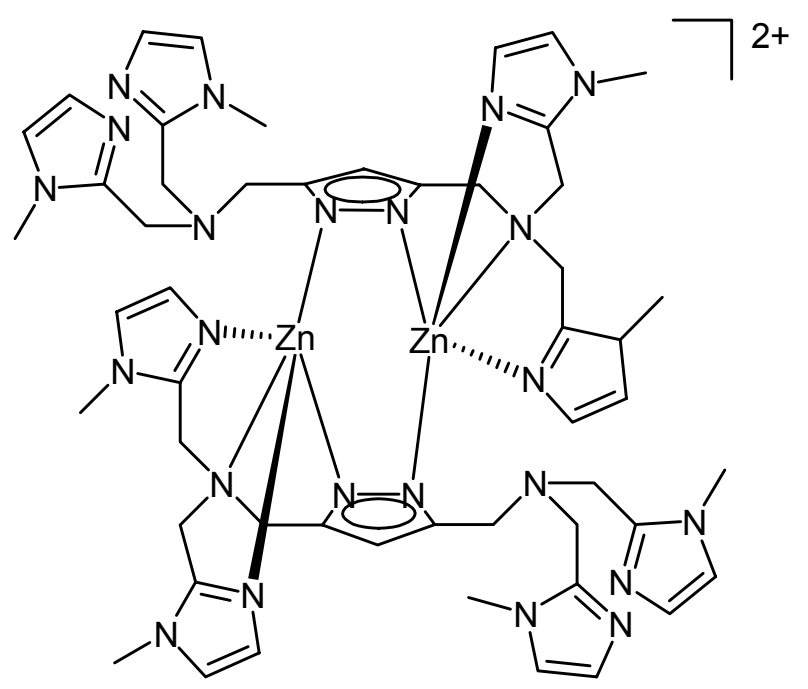

Abb. 48: Strukturformel des Kations von 7. 


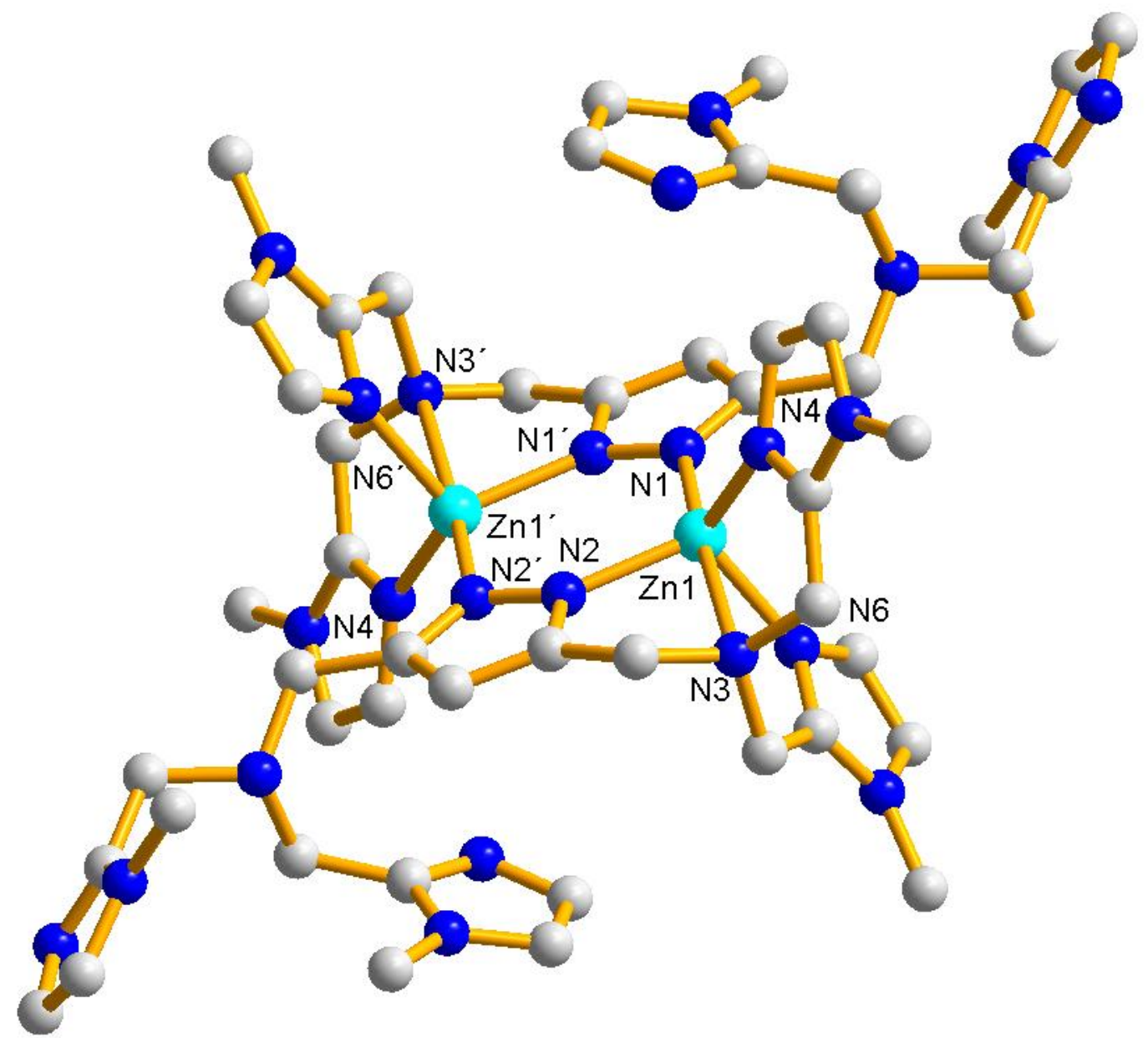

Abb. 49: Festkörperstruktur des Kations von 7.

Tab. 16: Ausgewählte Atomabstände $[\AA]$ von 7.

\begin{tabular}{|l|l|l|l|}
\hline $\mathrm{Zn}(1)-\mathrm{N}(1)$ & $2.002(3)$ & $\mathrm{Zn}(1)-\mathrm{N}(6)$ & $2.035(3)$ \\
\hline $\mathrm{Zn}(1)-\mathrm{N}(2)$ & $2.017(3)$ & $\mathrm{Zn}(1)-\mathrm{N}(3)$ & $2.531(3)$ \\
\hline $\mathrm{Zn}(1)-\mathrm{N}(4)$ & $2.032(3)$ & $\mathrm{Zn}(1) \cdots \mathrm{Zn}\left(1^{\prime}\right)$ & $3.7034(8)$ \\
\hline
\end{tabular}

Tab. 17: Ausgewählte Bindungswinkel ( $\left.{ }^{\circ}\right)$ von 7.

\begin{tabular}{|l|l|l|l|}
\hline $\mathrm{N}(1)-\mathrm{Zn}(1)-\mathrm{N}(2)$ & $108.81(12)$ & $\mathrm{N}(2)-\mathrm{Zn}(1)-\mathrm{N}(3)$ & $174.23(12)$ \\
\hline $\mathrm{N}(1)-\mathrm{Zn}(1)-\mathrm{N}(4)$ & $112.32(13)$ & $\mathrm{N}(4)-\mathrm{Zn}(1)-\mathrm{N}(3)$ & $73.16(12)$ \\
\hline $\mathrm{N}(2) 1-\mathrm{Zn}(1)-\mathrm{N}(4)$ & $109.39(12)$ & $\mathrm{N}(6)-\mathrm{Zn}(1)-\mathrm{N}(3)$ & $73.50(12)$ \\
\hline $\mathrm{N}(1)-\mathrm{Zn}(1)-\mathrm{N}(6)$ & $111.57(13)$ & $\mathrm{N}(4)-\mathrm{Zn}(1)-\mathrm{N}(6)$ & $113.30(12)$ \\
\hline $\mathrm{N}(2) 1-\mathrm{Zn}(1)-\mathrm{N}(6)$ & $100.75(13)$ & $\mathrm{N}(1)-\mathrm{Zn}(1)-\mathrm{N}(3)$ & $74.28(11)$ \\
\hline
\end{tabular}


Im ESI-Massenspektrum aus einer methanolischen Lösung beobachtet man mehrere Signale ohne eindeutige Zuordnung, die aber gemäß des Isotopenmusters zur Dizinkspezies gehören. Der einzige Peak, der zugeordnet werden konnte, kommt bei $\mathrm{m} / \mathrm{z}=345$ mit einer Intensität von $100 \%$ und gehört zu der Spezies $\left[\mathrm{L}^{1}{ }_{-\mathrm{H}}(\mathrm{MeOH})(\mathrm{MeO}) \mathrm{Zn}_{2}\right]^{2+}$.

Die Zinkatome sind trigonal bipyramidal $(\mathrm{Zn}: \tau=1.01)$ koordiniert, der Abstand zwischen ihnen beträgt 3.70 . Der Wert von $\tau$ ist in diesem Fall größer als 1, weil die Zinkatome über der trigonalen Ebene der Stickstoffatome liegen. Einer der Seitenarme jeder Pyrazoleinheit ist nicht ein Zinkatom koordiniert, und obwohl er eine größere Freiheit zur Drehung hat, bildet sich in diesem Fall im Festkörper eine symmetrische Struktur aus. Der Sechsring, der aus den pyrazolischen Stickstoffatomen und beiden Metallzentren entsteht, ist fast planar. Die Metallkerne sind leicht verschoben $(0.19 \AA)$. Der Pyrazolring wird durch einen an der Koordination unbeteiligten Seitenarm mit N-Methylimidazol überdeckt, sodass die Gesamtsymmetrie beeinflusst wird. In dieser Struktur zeigt sich der größte Unterschied in der Bindungslänge $\mathrm{sp}^{2}$ - und $\mathrm{sp}^{3}$ hybridisierter Stickstoffatome zum metallischen Zentrum ( 2.00 vs. $2.53 \AA$ ).

Über solche Komplextypen $\left[\mathrm{L}_{2} \mathrm{M}_{2}\right]^{2+}$, bei denen zwei Pyrazoleinheiten zwei Metallkerne überbrücken und Dimere ausbilden, wurde in der Literatur bereits berichtet. ${ }^{[57]}$ Dieser Typ entsteht durch die Tendenz des Pyrazols, Metallkerne zu überbrücken. Diese Tendenz verhindert die Koordination von anderen anwesenden Donoratomen.

\subsubsection{Zink(II)-Komplex des Liganden $\mathrm{L}^{6}$ - Synthese von $\left[\left(\mathrm{L}^{6}{ }_{-\mathrm{H}}\right)_{2}\left(\mu_{3}-\mathrm{CO}_{3}\right)\left(\mathrm{H}_{2} \mathrm{O}\right) \mathrm{Zn}_{4}\right]\left(\mathrm{ClO}_{4}\right)_{4}(8)$}

Dieser Komplex (Abb. 50) wurde durch die spontane Reaktion einer Lösung von $\left[\mathrm{L}^{6}{ }_{-\mathrm{H}}\left(\mathrm{CH}_{3} \mathrm{OH}\right)(\mathrm{OH}) \mathrm{Zn}_{2}\right]\left(\mathrm{ClO}_{4}\right)_{2}$ in einem Wasser/Acetonitril-Gemisch mit $\mathrm{CO}_{2}$ aus der Luft erhalten. Diese Art von Reaktion wurde schon bei anderen Pyrazolliganden, die mit Zink(II)-lonen umgesetzt wurden, beobachtet. ${ }^{[110]}$ Der Komplex kristallisiert in der Raumgruppe $P 2_{1} / \mathrm{n}$ mit vier Molekülen in der monoklinen Zelle. 
In Abb. 51 sowie in Tab. 18 und 19 sind einige wichtige strukturelle Parameter des Kations des Komplexes $\left[\left(\mathrm{L}^{6}{ }_{-H}\right)_{2}\left(\mu_{3}-\mathrm{CO}_{3}\right)\left(\mathrm{H}_{2} \mathrm{O}\right) \mathrm{Zn}_{4}\right]\left(\mathrm{ClO}_{4}\right)_{4}$ zusammengefasst.

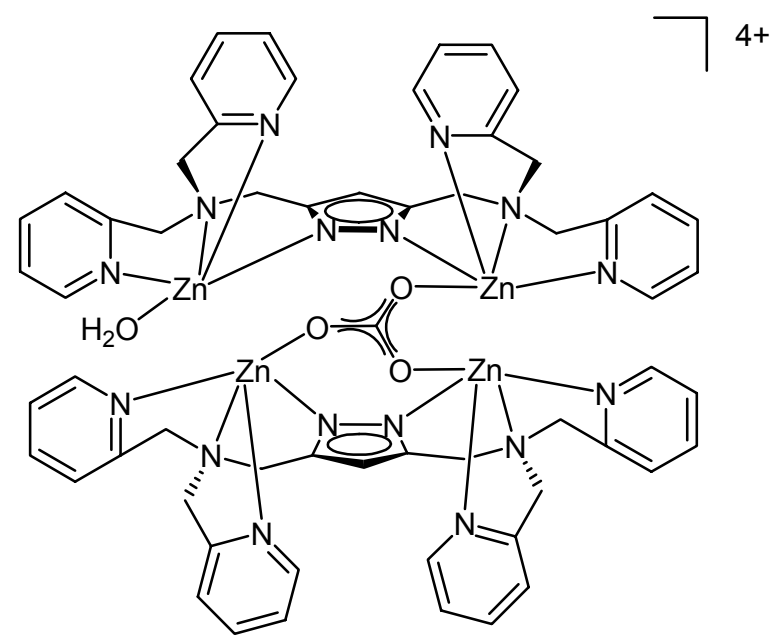

Abb. 50: Strukturformel des Kations von 8. 


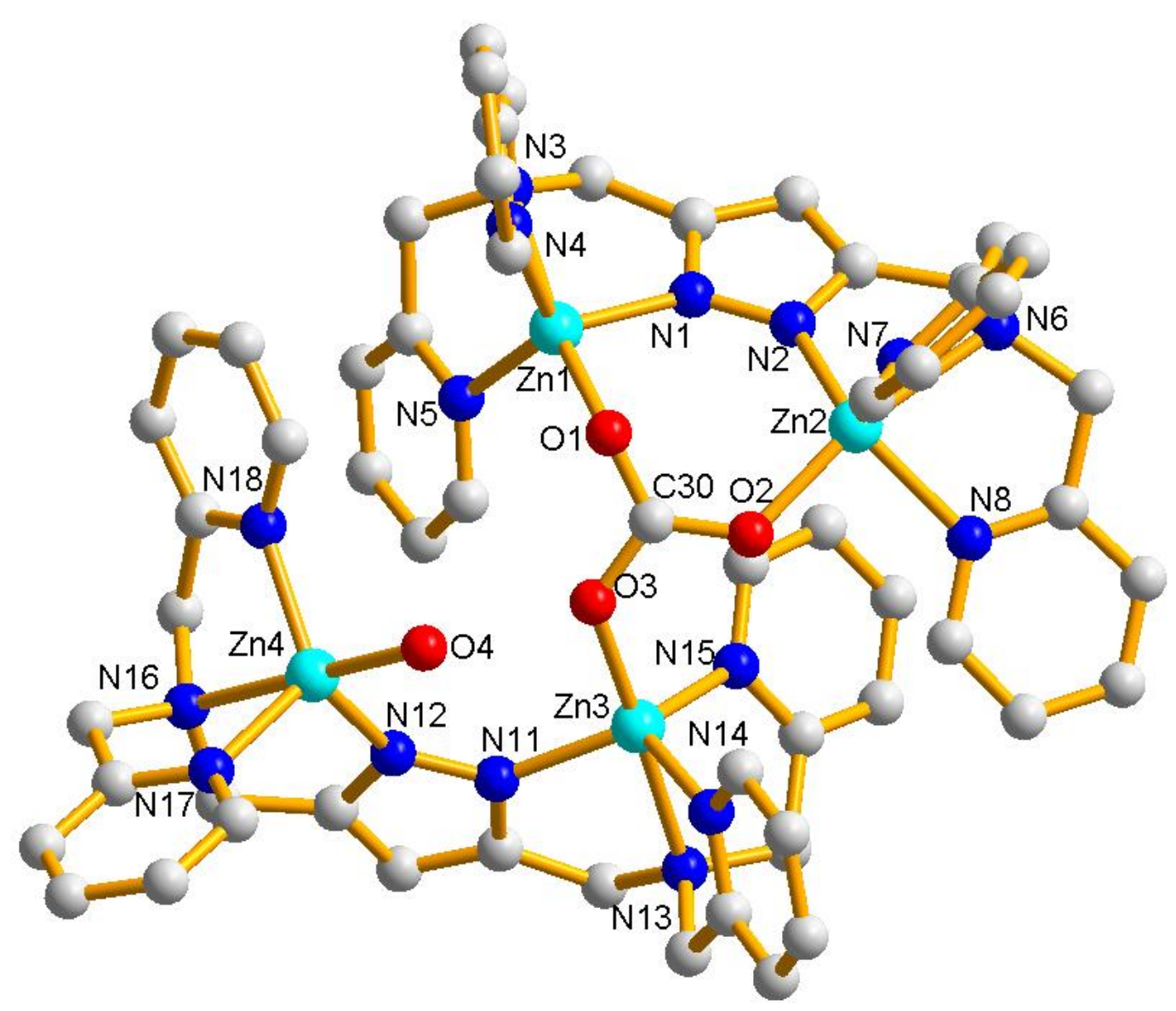

Abb. 51: Festkörperstruktur des Kations von 8.

Tab. 18: Ausgewählte Atomabstände $[\AA]$ von 8.

\begin{tabular}{|l|l|l|l|}
\hline $\mathrm{Zn}(1)-\mathrm{O}(1)$ & $1.983(2)$ & $\mathrm{Zn}(3)-\mathrm{O}(3)$ & $1.986(2)$ \\
\hline $\mathrm{Zn}(1)-\mathrm{N}(1)$ & $2.001(3)$ & $\mathrm{Zn}(3)-\mathrm{N}(11)$ & $2.029(3)$ \\
\hline $\mathrm{Zn}(1)-\mathrm{N}(4)$ & $2.039(3)$ & $\mathrm{Zn}(3)-\mathrm{N}(15)$ & $2.072(3)$ \\
\hline $\mathrm{Zn}(1)-\mathrm{N}(5)$ & $2.063(3)$ & $\mathrm{Zn}(3)-\mathrm{N}(14)$ & $2.074(3)$ \\
\hline $\mathrm{Zn}(1)-\mathrm{N}(3)$ & $2.274(3)$ & $\mathrm{Zn}(3)-\mathrm{N}(13)$ & $2.216(3)$ \\
\hline $\mathrm{Zn}(2)-\mathrm{O}(2)$ & $1.989(2)$ & $\mathrm{Zn}(4)-\mathrm{N}(12)$ & $2.013(3)$ \\
\hline $\mathrm{Zn}(2)-\mathrm{N}(2)$ & $2.010(3)$ & $\mathrm{Zn}(4)-\mathrm{O}(4)$ & $2.022(3)$ \\
\hline $\mathrm{Zn}(2)-\mathrm{N}(7)$ & $2.045(3)$ & $\mathrm{Zn}(4)-\mathrm{N}(18)$ & $2.057(3)$ \\
\hline $\mathrm{Zn}(2)-\mathrm{N}(8)$ & $2.096(3)$ & $\mathrm{Zn}(4)-\mathrm{N}(17)$ & $2.070(3)$ \\
\hline $\mathrm{Zn}(2)-\mathrm{N}(6)$ & $2.300(3)$ & $\mathrm{Zn}(4)-\mathrm{N}(16)$ & $2.240(3)$ \\
\hline
\end{tabular}




\begin{tabular}{|l|l|l|l|}
\hline$Z n(1) \cdots Z n(2)$ & $4.0922(5)$ & $Z n(3) \cdots Z n(4)$ & $4.3387(5)$ \\
\hline$Z n(1) \cdots Z n(3)$ & $5.2023(5)$ & $Z n(1) \cdots Z n(4)$ & $5.4847(5)$ \\
\hline$Z n(2) \cdots Z n(3)$ & $4.8321(5)$ & $Z n(2) \cdots Z n(4)$ & $7.6568(6)$ \\
\hline$O(1)-C(30)$ & $1.263(4)$ & $O(3)-C(30)$ & $1.309(4)$ \\
\hline$O(2)-C(30)$ & $1.280(4)$ & & \\
\hline
\end{tabular}

Tab. 19: Ausgewählte Bindungswinkel ( $\left.{ }^{\circ}\right)$ von 8.

\begin{tabular}{|l|l|l|l|}
\hline $\mathrm{O}(1)-\mathrm{Zn}(1)-\mathrm{N}(1)$ & $98.29(10)$ & $\mathrm{O}(3)-\mathrm{Zn}(3)-\mathrm{N}(11)$ & $99.61(10)$ \\
\hline $\mathrm{O}(1)-\mathrm{Zn}(1)-\mathrm{N}(4)$ & $94.36(11)$ & $\mathrm{O}(3)-\mathrm{Zn}(3)-\mathrm{N}(15)$ & $104.08(10)$ \\
\hline $\mathrm{O}(1)-\mathrm{Zn}(1)-\mathrm{N}(5)$ & $110.87(10)$ & $\mathrm{O}(3)-\mathrm{Zn}(3)-\mathrm{N}(14)$ & $100.36(10)$ \\
\hline $\mathrm{O}(1)-\mathrm{Zn}(1)-\mathrm{N}(3)$ & $170.34(10)$ & $\mathrm{O}(3)-\mathrm{Zn}(3)-\mathrm{N}(13)$ & $177.63(10)$ \\
\hline $\mathrm{N}(1)-\mathrm{Zn}(1)-\mathrm{N}(4)$ & $115.56(11)$ & $\mathrm{N}(11)-\mathrm{Zn}(3)-\mathrm{N}(15)$ & $116.71(10)$ \\
\hline $\mathrm{N}(1)-\mathrm{Zn}(1)-\mathrm{N}(5)$ & $107.39(11)$ & $\mathrm{N}(11)-\mathrm{Zn}(3)-\mathrm{N}(14)$ & $116.74(11)$ \\
\hline $\mathrm{N}(1)-\mathrm{Zn}(1)-\mathrm{N}(3)$ & $78.83(10)$ & $\mathrm{N}(11)-\mathrm{Zn}(3)-\mathrm{N}(13)$ & $79.35(10)$ \\
\hline $\mathrm{N}(4)-\mathrm{Zn}(1)-\mathrm{N}(5)$ & $125.84(11)$ & $\mathrm{N}(15)-\mathrm{Zn}(3)-\mathrm{N}(14)$ & $115.23(11)$ \\
\hline $\mathrm{N}(4)-\mathrm{Zn}(1)-\mathrm{N}(3)$ & $78.83(11)$ & $\mathrm{N}(15)-\mathrm{Zn}(3)-\mathrm{N}(13)$ & $78.28(10)$ \\
\hline $\mathrm{N}(5)-\mathrm{Zn}(1)-\mathrm{N}(3)$ & $78.76(10)$ & $\mathrm{N}(14)-\mathrm{Zn}(3)-\mathrm{N}(13)$ & $78.32(10)$ \\
\hline $\mathrm{O}(2)-\mathrm{Zn}(2)-\mathrm{N}(2)$ & $109.20(10)$ & $\mathrm{N}(12)-\mathrm{Zn}(4)-\mathrm{O}(4)$ & $101.85(11)$ \\
\hline $\mathrm{O}(2)-\mathrm{Zn}(2)-\mathrm{N}(7)$ & $105.67(10)$ & $\mathrm{N}(12)-\mathrm{Zn}(4)-\mathrm{N}(18)$ & $118.16(11)$ \\
\hline $\mathrm{O}(2)-\mathrm{Zn}(2)-\mathrm{N}(8)$ & $92.16(10)$ & $\mathrm{N}(12)-\mathrm{Zn}(4)-\mathrm{N}(17)$ & $112.67(11)$ \\
\hline $\mathrm{O}(2)-\mathrm{Zn}(2)-\mathrm{N}(6)$ & $168.77(10)$ & $\mathrm{N}(12)-\mathrm{Zn}(4)-\mathrm{N}(16)$ & $79.20(10)$ \\
\hline $\mathrm{N}(2)-\mathrm{Zn}(2)-\mathrm{N}(7)$ & $114.48(11)$ & $\mathrm{O}(4)-\mathrm{Zn}(4)-\mathrm{N}(18)$ & $101.67(11)$ \\
\hline $\mathrm{N}(2)-\mathrm{Zn}(2)-\mathrm{N}(8)$ & $126.17(11)$ & $\mathrm{O}(4)-\mathrm{Zn}(4)-\mathrm{N}(17)$ & $101.08(11)$ \\
\hline $\mathrm{N}(2)-\mathrm{Zn}(2)-\mathrm{N}(6)$ & $76.80(10)$ & $\mathrm{O}(4)-\mathrm{Zn}(4)-\mathrm{N}(16)$ & $178.56(12)$ \\
\hline $\mathrm{N}(7)-\mathrm{Zn}(2)-\mathrm{N}(8)$ & $105.46(11)$ & $\mathrm{N}(18)-\mathrm{Zn}(4)-\mathrm{N}(17)$ & $117.46(11)$ \\
\hline $\mathrm{N}(7)-\mathrm{Zn}(2)-\mathrm{N}(6)$ & $79.40(10)$ & $\mathrm{N}(18)-\mathrm{Zn}(4)-\mathrm{N}(16)$ & $78.60(11)$ \\
\hline $\mathrm{N}(8)-\mathrm{Zn}(2)-\mathrm{N}(6)$ & $76.75(10)$ & $\mathrm{N}(17)-\mathrm{Zn}(4)-\mathrm{N}(16)$ & $77.57(10)$ \\
\hline $\mathrm{O}(1)-\mathrm{C}(30)-\mathrm{O}(2)$ & $123.2(3)$ & $\mathrm{O}(2)-\mathrm{C}(30)-\mathrm{O}(3)$ & $117.7(3)$ \\
\hline $\mathrm{O}(1)-\mathrm{C}(30)-\mathrm{O}(3)$ & $119.1(3)$ & & \\
\hline & & & \\
\hline
\end{tabular}

Im ESI-Massenspektrum aus einer methanolischen Lösung des Komplexes beobachtet man eine Mischung mehrerer Spezies, wobei für viele keine 
eindeutige Zuordnung gefunden werden konnte. Eine dieser Spezies ist $\left[\left(\mathrm{L}^{6}{ }_{-\mathrm{H}}\right)(\mathrm{MeOH})(\mathrm{MeO}) \mathrm{Zn}_{2}\left(\mathrm{ClO}_{4}\right)\right]^{+}$, die bei $\mathrm{m} / \mathrm{z}=779$ mit einer Intensität von $10 \%$ zu sehen ist. Mit einer Intensität von $100 \%$ bei $\mathrm{m} / \mathrm{z}=339$ beobachtet man die Spezies $\left[\left(\mathrm{L}^{6}{ }_{-H}\right)(\mathrm{MeOH})(\mathrm{MeO}) \mathrm{Zn}_{2}\right]^{+}$. Die Anwesenheit beider Signale spricht für die Zersetzung des Komplexes $\left[\mathrm{L}^{6}{ }_{-}{ }_{\mathrm{H}}\left(\mu_{3}-\mathrm{CO}_{3}\right)\left(\mathrm{H}_{2} \mathrm{O}\right) \mathrm{Zn}_{4}\right]\left(\mathrm{ClO}_{4}\right)_{2}$ in einer methanolischen Lösung.

In Gegensatz zu der $\mu_{4}$-Carbonatbrücke in einem kürzlich gefundenen Komplex mit einem in Position 3 und 5 durch Ligandseitenarme substituierten Pyrazolring liegt in 8 ein $\mu_{3}-\mathrm{CO}_{3}{ }^{2-}$ vor. Die $\mu_{4}$-Koordination ist nur in seltenen Fällen gefunden worden. ${ }^{[113-115]}$ Das an der Carbonatbrücke nicht beteiligte Zink(II)-lon in 8 ist an ein Wassermolekül gebunden. Zwischen einem der Sauerstoffatome des Carbonations und dem Wassermolekül beobachtet man eine Wasserstoffbrückenbindung. Ein Grund für diese unterschiedlichen Verhältnisse zweier ähnlicher Pyrazoleinheiten könnte die unterschiedliche Zahl und Hybridisierung der Donoratome sein, die diese beiden Liganden aufweisen.

In der Struktur werden die beiden $\mathrm{LM}_{2}$ Subeinheiten durch das $\mu_{3}-\mathrm{CO}_{3}{ }^{2-}$ zusammengehalten. Die beiden Pyrazolringe beschreiben eine $V$-förmige Struktur, wobei die Carbonateinheit die Spitze dieses $V$ wäre. Zwei der Pyridinreste jeder Subeinheit überlappen miteinander.

Der Abstand zwischen den Zink(II)-lonen, die zu derselben Pyrazoleinheit gehören, ist kleiner in der Einheit, in der die beiden Metallkerne über Carbonat verbrückt sind (4.09 vs. $4.34 \AA$ ). Der intermetallische Abstand zwischen den carbonatverbrückten Zink(II)-Ionen hat eine Größenordnung wie die der acetatund formiatverbrückten Komplexe dieses Liganden, die während dieser Arbeit erhalten wurden. Die vier Zink(II)-lonen sind fünffach koordiniert und trigonal bipyramidal (Zn1: $\tau=0.74 ; \mathrm{Zn2}: \tau=0.71$; Zn3: $\tau=1.01 ; \mathrm{Zn} 4 \tau=1.01)$ umgeben. Hier befinden sich Zn3 und Zn4 außerhalb der trigonalen Ebene, die drei der $\mathrm{N}$ Donoratome bilden, was zu einem Wert von $\tau$ größer als 1 führt. Ähnliche Strukturen, wo zwei $\left[\mathrm{Zn}_{2} \mathrm{~L}\right]$ Einheiten durch eine $\mu_{3}-\mathrm{CO}_{3}{ }^{2-}$ Gruppe gebunden sind, sind bereits bekannt. ${ }^{[16]}$

Im IR-Spektrum beobachtet man zwei starke Signale bei 1489 bzw. $1396 \mathrm{~cm}^{-1}$, die zu der Carbonateinheit gehören. Diese Signale kommen im gleichen Bereich wie die für den aus der Literatur bekannten $\mu_{4}-\mathrm{CO}_{3}{ }^{2-}$-verbrückten tetrametallischen Pyrazolkomplex. ${ }^{[113]}$ 


\subsubsection{Zink(II)-Komplex des Liganden $\mathrm{L}^{1}-$ Synthese von $\left[\left(\mathrm{L}^{1}{ }_{-H}\right)_{2}\left(\mu_{4}-\mathrm{CO}_{3}\right) \mathrm{Zn}_{4}\right]\left(\mathrm{BPh}_{4}\right)_{4}(9)$}

Der Komplex 9 (Abb. 52) wurde durch Reaktion des deprotonierten Liganden $\mathrm{L}^{1}$ mit Zinkperchlorat Hexahydrat in Methanol und anschließende Zugabe von Natriumtetraphenylborat erhalten. Der Komplex fällt als farbloser Feststoff aus. Aus einer konzentrierten Lösung des Komplexes in einer Mischung aus Acetonitril und Wasser (1:4) wurden farblose Kristalle erhalten, die für die Röntgenstrukturanalyse geeignet waren. Der Komplex kristallisiert in der Raumgruppe C2/c mit vier Molekülen in der monoklinen Zelle.

In Abb. 53 sowie in Tab. 20 und 21 sind einige wichtige strukturelle Parameter des Kations des Komplexes $\left[\left(\mathrm{L}^{1}{ }_{-\mathrm{H}}\right)_{2}\left(\mu_{4}-\mathrm{CO}_{3}\right) \mathrm{Zn}_{4}\right]\left(\mathrm{BPh}_{4}\right)_{4}$ (9) zusammengefasst.

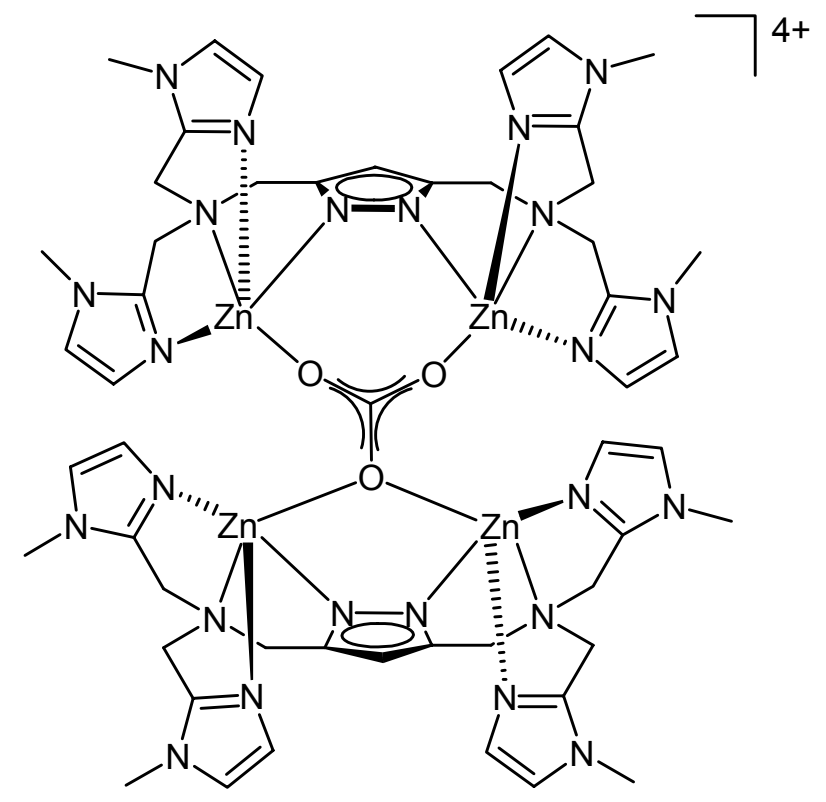

Abb. 52: Strukturformel des Kations von 9. 


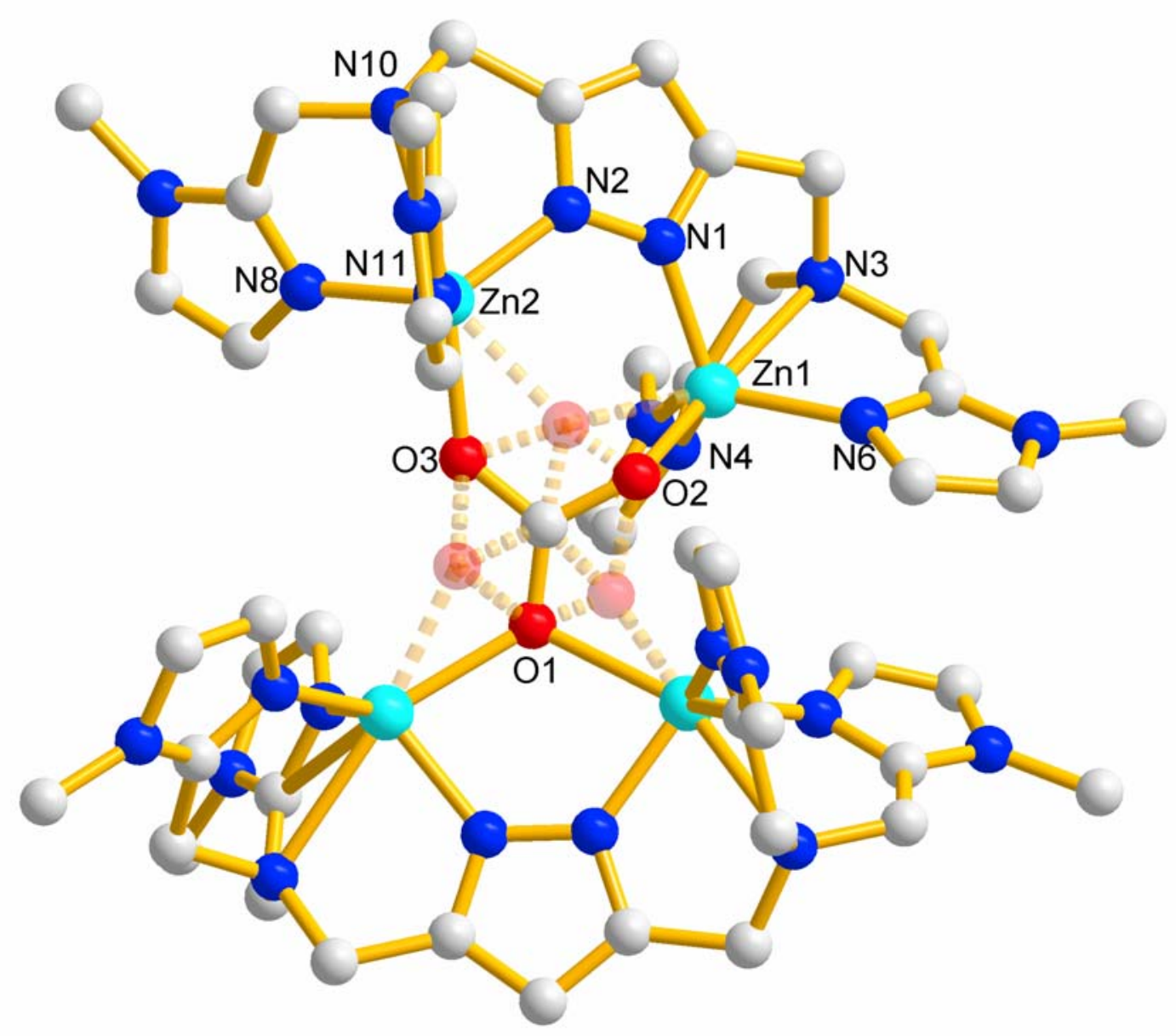

Abb. 53: Festkörperstruktur des Kations von 9.

Tab. 20: Ausgewählte Atomabstände $[\AA]$ von 9.

\begin{tabular}{|l|l|l|l|}
\hline $\mathrm{Zn}(1)-\mathrm{O}(2)$ & $1.862(7)$ & $\mathrm{O}(3)-\mathrm{Zn}(2)$ & $2.041(7)$ \\
\hline $\mathrm{Zn}(1)-\mathrm{N}(1)$ & $1.964(4)$ & $\mathrm{Zn}(2)-\mathrm{N}(11)$ & $1.992(10)$ \\
\hline $\mathrm{Zn}(1)-\mathrm{N}(4)$ & $2.003(5)$ & $\mathrm{Zn}(2-\mathrm{N}(10)$ & $2.467(8)$ \\
\hline $\mathrm{Zn}(1)-\mathrm{N}(6)$ & $2.004(5)$ & $\mathrm{Zn}(2)-\mathrm{N}(2)$ & $1.950(5)$ \\
\hline $\mathrm{Zn}(1)-\mathrm{N}(3)$ & $2.445(5)$ & $\mathrm{Zn}(2)-\mathrm{N}(8)$ & $1.968(9)$ \\
\hline $\mathrm{Zn}(1) \cdots \mathrm{Zn}(2)$ & $3.740(2)$ & $\mathrm{Zn}(1) \cdots \mathrm{Zn}(1)$ & $4.159(1)$ \\
\hline $\mathrm{Zn}(2) \cdots \mathrm{Zn}(2)$ & $5.181(5)$ & $\mathrm{Zn}(1) \cdots \mathrm{Zn}(2)$ & $5.832(3)$ \\
\hline $\mathrm{O}(1)-\mathrm{C}(26)$ & $1.265(5)$ & $\mathrm{O}(2)-\mathrm{C}(26)$ & $1.292(5)$ \\
\hline $\mathrm{O}(3)-\mathrm{C}(26)$ & $1.308(5)$ & $\mathrm{O}(1)-\mathrm{Zn}(2)$ & $2.154(8)$ \\
\hline $\mathrm{O}(1)-\mathrm{Zn}(1)$ & $2.224(9)$ & & \\
\hline
\end{tabular}


Tab. 21: Ausgewählte Bindungswinkel ( ${ }^{\circ}$ ) von 9.

\begin{tabular}{|l|l|l|l|}
\hline $\mathrm{O}(2)-\mathrm{Zn}(1)-\mathrm{N}(1)$ & $107.9(3)$ & $\mathrm{N}(2)-\mathrm{Zn}(2)-\mathrm{N}(8)$ & $121.6(4)$ \\
\hline $\mathrm{O}(2)-\mathrm{Zn}(1)-\mathrm{N}(4)$ & $106.2(3)$ & $\mathrm{N}(2)-\mathrm{Zn}(2)-\mathrm{N}(11)$ & $108.7(5)$ \\
\hline $\mathrm{O}(2)-\mathrm{Zn}(1)-\mathrm{N}(6)$ & $100.6(3)$ & $\mathrm{N}(2)-\mathrm{Zn}(2)-\mathrm{N}(10)$ & $73.3(3)$ \\
\hline $\mathrm{O}(2)-\mathrm{Zn}(1)-\mathrm{N}(3)$ & $176.8(3)$ & $\mathrm{N}(2)-\mathrm{Zn}(2 \mathrm{~A})-\mathrm{O}(3)$ & $114.4(5)$ \\
\hline $\mathrm{N}(1)-\mathrm{Zn}(1)-\mathrm{N}(4)$ & $111.18(19)$ & $\mathrm{N}(8)-\mathrm{Zn}(2)-\mathrm{N}(11)$ & $111.5(4)$ \\
\hline $\mathrm{N}(1)-\mathrm{Zn}(1)-\mathrm{N}(6)$ & $116.3(2)$ & $\mathrm{N}(8)-\mathrm{Zn}(2)-\mathrm{N}(10)$ & $76.7(4)$ \\
\hline $\mathrm{N}(1)-\mathrm{Zn}(1)-\mathrm{N}(3)$ & $73.15(17)$ & $\mathrm{N}(8)-\mathrm{Zn}(2)-\mathrm{O}(3)$ & $93.8(3)$ \\
\hline $\mathrm{N}(4)-\mathrm{Zn}(1)-\mathrm{N}(6)$ & $113.6(2)$ & $\mathrm{N}(11)-\mathrm{Zn}(2)-\mathrm{N}(10)$ & $76.9(4)$ \\
\hline $\mathrm{N}(4)-\mathrm{Zn}(1)-\mathrm{N}(3)$ & $76.00(19)$ & $\mathrm{N}(11)-\mathrm{Zn}(2)-\mathrm{O}(3)$ & $104.8(3)$ \\
\hline $\mathrm{N}(6)-\mathrm{Zn}(1)-\mathrm{N}(3)$ & $76.33(18)$ & $\mathrm{N}(10)-\mathrm{Zn}(2)-\mathrm{O}(3)$ & $170.2(4)$ \\
\hline $\mathrm{O}(1)-\mathrm{C}(26)-\mathrm{O}(2)$ & $124.4(7)$ & $\mathrm{O}(1)-\mathrm{C}(26)-\mathrm{O}(3)$ & $120.6(6)$ \\
\hline $\mathrm{O}(2)-\mathrm{C}(26)-\mathrm{O}(3)$ & $114.2(5)$ & & \\
\hline
\end{tabular}

Im ESI-Massenspektrum aus einer methanolischen Lösung des Komplexes beobachtet man eine Mischung mehrerer Spezies, wobei für manche keine eindeutige Zuordnung möglich war. Eine dieser Spezies entspricht $\left[\left(\mathrm{L}^{1}{ }_{-\mathrm{H}}\right)(\mathrm{MeOH})(\mathrm{MeO})\left(\mathrm{BPh}_{4}\right) \mathrm{Zn}_{2}\right]^{+}$, die bei $\mathrm{m} / \mathrm{z}=1011$ und mit einer Intensität von $35 \%$ beobachtet wurde. Mit einer Intensität von $100 \%$ bei $\mathrm{m} / \mathrm{z}=346$ beobachtet man die Spezies $\left[\left(\mathrm{L}^{1}{ }_{-H}\right)(\mathrm{MeOH})(\mathrm{MeO}) \mathrm{Zn}_{2}\right]^{2+}$. Die Anwesenheit beider Signale spricht für die Zerstörung des Komplexes $\left[\mathrm{L}^{1}{ }_{-\mathrm{H}}\left(\mu_{4}-\mathrm{CO}_{3}\right) \mathrm{Zn}_{4}\right]\left(\mathrm{BPh}_{4}\right)_{4}(9)$ in einer methanolischen Lösung.

Dieser Komplex enthält die seltene $\mu_{4}-\mathrm{CO}_{3}{ }^{2-}\left(\eta_{2}: \eta_{1}: \eta_{1}\right)$ Einheit, die in diesem Fall fehlgeordnet ist. Die $\mu_{4}-\mathrm{CO}_{3}{ }^{2-}$-Brücke wurde, wie schon erwähnt, bei anderen Pyrazolatodizinkkomplexen beobachtet. ${ }^{[113]}$ Der vierkernige Komplex hat zwei gleiche zweikernige Subeinheiten, die über Carbonat verbrückt sind. Der Abstand zwischen den Zinkkernen derselben Subeinheit beträgt $3.74 \AA$, beide sind trigonal bipyramidal koordiniert (Zn1: $\tau=1.01 ; \mathrm{Zn} 2: \tau=0.81)$. Die Pyrazolringe der beiden Subeinheiten sind stark zueinander gekippt $\left(34^{\circ}\right)$.

Der intermetallische Abstand ist in diesem Komplex eindeutig kleiner als der intermetallische Abstand in Komplex $8(\mathrm{Zn}-\mathrm{Zn}=4.09$ und $4.34 \AA)$. Die Abwesenheit des Wassermoleküls im Komplex verursacht eine große 
Annäherung beider Metallionen und ermöglicht den kleinsten Metall-MetallAbstand, der während dieser Arbeit erhalten wurde.

Die Abstände $\mathrm{Zn}-\mathrm{O}$ sind für jedes Sauerstoffatom des Carbonats unterschiedlich, wobei einer davon sehr kurz ist (größter Abstand $\mathrm{Zn}-\mathrm{O}=2.22 \AA$, kleinster Abstand $\mathrm{Zn}-\mathrm{O}=1.86 \AA$. Dieser kleinere Abstand kann durch die Fehlordnung verursacht sein. Solche kurzen $\mathrm{Zn}-\mathrm{O}$ Abstände wurden auch bei anderen Komplexen gefunden. ${ }^{[117,118]}$ Das verbrückende Sauerstoffatom verursacht einen langen Abstand zu den Zink(II)-Ionen.

Im Unterschied $\mathrm{zu}$ den anderen $\mu_{4}-\mathrm{CO}_{3}{ }^{2-}$-verbrückten tetrametallischen Pyrazolkomplexen, die bis heute bekannt sind, hat hier jeder Seitenarm drei statt zwei koordinierende Stickstoffatome. Wegen der großen Zahl der NDonoratome in den Seitenarmen scheidet die Bildung einer zusätzlichen Hydroxidbrücke aus. ${ }^{[113]}$

Im IR-Spektrum beobachtet man zwei starke Signale bei 1502 bzw. $1385 \mathrm{~cm}^{-1}$, die charakteristisch für die Carbonateinheit sind. Diese Signale kommen bei einer ähnlichen Wellenzahl, wie die für die aus der Literatur bekannten $\mu_{4}-\mathrm{CO}_{3}{ }^{2-}$-verbrückten tetrametallischen Pyrazolkomplexe. ${ }^{[113]}$

\subsection{Hydrolyse von $\gamma$-Butyrolacton durch einen Dizinkkomplex}

\subsubsection{Lactonhydrolyse}

Seit langer Zeit ist bekannt, dass die Hydrolyse von Lactonen (Abb. 54) durch unterschiedliche Prozesse in stark sauren oder basischen Medien stattfinden kann. ${ }^{[119,120]}$ Auch die Mechanismen für einige unterschiedliche Ringöffnungen mancher Lactone wurden erfolgreich untersucht. ${ }^{[121]}$

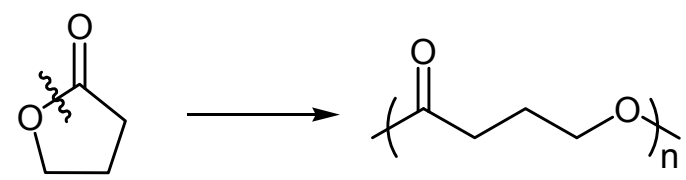

Abb. 54: Allgemeiner Ablauf der Hydrolyse und Polymerisation von $\gamma$-Butyrolacton. 
Polymere sind besonders interessant, wenn sie auch biologisch abbaubar sind. Deshalb wurden in letzter Zeit Untersuchungen zur Ringöffnung von Lactonen und Polymerisationen der Spaltprodukte untersucht. ${ }^{[122,123]}$ Hier werden enzymatische Katalysatoren wie Lipasen oder Polysaccharide wie Cyclodextrin für diese Ringöffnung benutzt. ${ }^{[124]}$ Die enantioselektive Hydrolyse von Lactonen als Zwischenstufe in der Synthese pharmazeutischer Produkte wie Antidepressiva war in der letzten Jahren von großem Interesse. ${ }^{[125]}$ Hier werden auch Biokatalysatoren wie Lipasen oder Esterasen eingesetzt.

Obwohl Katalysatoren für die Synthese von Lactonen aus unterschiedlichen Ausgangsstoffen eingesetzt wurden ${ }^{[126,127]}$, sind Koordinationskatalysatoren in der Lactonhydrolyse nicht so oft verwendet worden. Typische Katalysatoren für die Hydrolyse sind die Aluminoxane, wobei diese aber wegen ihrer schlechten Ausbeute und Enantioselektivität nur zweite Wahl nach den Biokatalysatoren sind. ${ }^{[128,129]}$ Es gibt nur ein Beispiel von Koordinationskomplexen, die diese Ringöffnung ermöglichen können, bei dem aber die katalytischen Eigenschaften wegen der Verbrückung beider Nickel(II)-lonen ausgeschlossen sind. ${ }^{[86]}$

Die Öffnung von $\gamma$-Butyrolacton besitzt seit einiger Zeit auch biologisches Interesse. Dieser Fünfring des Lactons ist ein Bestandteil von Homoserin Lacton (AHL), das in vielen Infektionsprozessen tätig ist. Das Dizinkmetalloprotein AHL-Lactonase kann die Esterbindung angreifen, den Ring öffnen und damit die Bindung dieser Moleküle an ihre Transkriptoren verhindern. ${ }^{[130,131]}$

\subsubsection{Nachweis der $\gamma$-Butyrolacton-Spaltung durch ${ }^{1} \mathrm{H}-\mathrm{NMR}$}

In der vorliegenden Arbeit ist die Öffnung des Lactonringes zur Hydroxypropancarbonsäure durch Reaktion von XLI mit $\gamma$-Butyrolacton unter mehrstündigem Temperieren auf $100^{\circ} \mathrm{C}$ gelungen. Dadurch wurden die beiden Zinkionen zusätzlich durch eine Hydroxypropylcarboxylatgruppe verbrückt.

XLI wurde in seiner kristallinen Form bereits erfolgreich als Katalysator und Promotor für hydrolytische Reaktionen in Bezug auf Phosphatase und $\beta$ Lactamase getestet. ${ }^{[103,104]}$ 
Die bei $100{ }^{\circ} \mathrm{C}$ zu 10 durchgeführte Reaktion von $\left[\mathrm{L}^{6}{ }_{-\mathrm{H}}(\mathrm{MeOH})(\mathrm{OH}) \mathrm{Zn}_{2}\right]\left(\mathrm{ClO}_{4}\right)_{2}$ (XLI) mit $\gamma$-Butyrolacton hat zur Öffnung der Lactonbindung geführt. Durch ${ }^{1} \mathrm{H}-\mathrm{NMR}-M e s s u n g e n$ konnte nachgewiesen werden, dass diese Ringöffnung bereits bei tieferen Temperaturen stattfindet. Die Reaktion läuft entsprechend der in Schema 18 angeführten Gleichung ab.

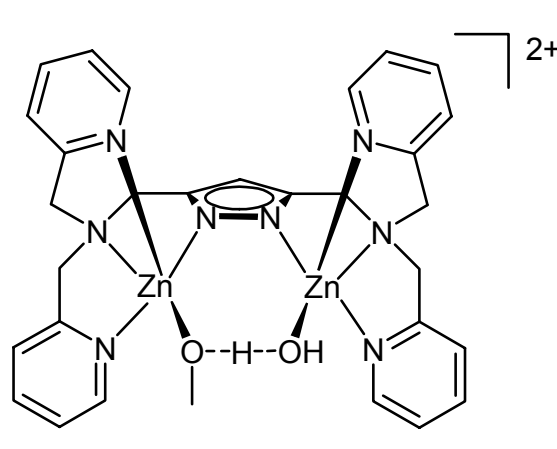

XLI
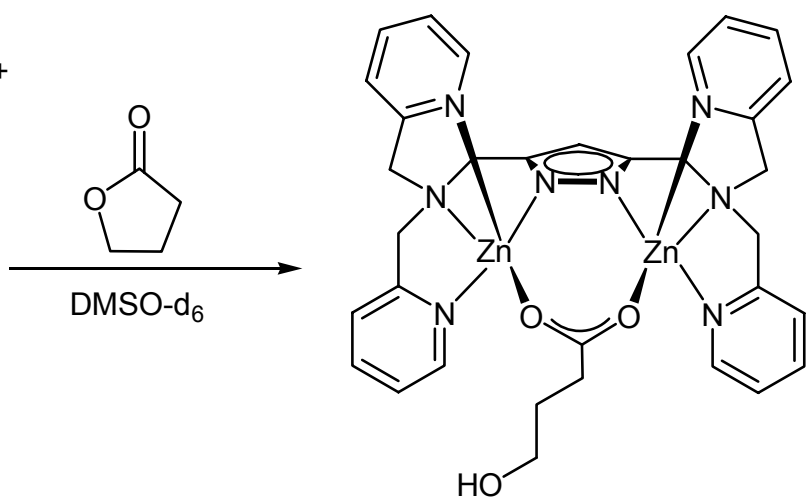

10

Schema 18: Untersuchte Ringöffnung von $\gamma$-Butyrolacton.

Um den Verlauf der Reaktion zu verfolgen, wurde der Reaktionsablauf für eine äquimolare Mischung ${ }^{1} \mathrm{H}-\mathrm{NMR}$-spektroskopisch verfolgt. Dazu wurde zu XLI, gelöst in DMSO- $\mathrm{d}_{6}$, ein Äquivalent $\gamma$-Butyrolacton zugesetzt und anschließend in Abständen von jeweils 15 Minuten eine ${ }^{1} \mathrm{H}-\mathrm{NMR}$-Messung bei $30{ }^{\circ} \mathrm{C}$ durchgeführt. Die stärksten Veränderungen im ${ }^{1} \mathrm{H}-\mathrm{NMR}$-Spektrum liegen im Bereich der Pyridinsignale. Man stellt einen starken Abfall der Signalintensität der $\mathrm{H}_{\mathrm{A}}$-Signale des Pyridins bei $8.8 \mathrm{ppm}$ und einen Anstieg neuer Signale (ebenfalls von $\mathrm{H}_{\mathrm{A}}$ des Pyridinrests) bei $8.6 \mathrm{ppm}$ fest. Diese Hochfeldverschiebung von 8.8 auf $8.6 \mathrm{ppm}$ ist durch die Koordination der Carboxylgruppe bedingt. Nach einer Reaktionszeit von 15 Minuten findet man für XLI nur noch ein schwaches, breites Signal für $\mathrm{H}_{\mathrm{A}}$, das nach 30 Minuten Reaktionszeit vollständig verschwunden ist. Damit ist die Reaktion beendet.

Das Signal $H_{D}$ des Pyridinrestes wird etwas schärfer und ist gegenüber XLI geringfügig nach höherem Feld verschoben. Nach beendeter Reaktion ist die Signallage für $H_{B}, H_{C}, H_{D}$ des Pyridinrestes wie in 10, nur $H_{A}$ von 10 ist geringfügig nach tieferem Feld verschoben. 
In Abb. 55 ist das ${ }^{1} \mathrm{H}$-NMR-Spektrum über den gesamten Bereich aus der Reaktionslösung in Abhängigkeit von der Reaktionszeit den NMR-Spektren von XLI und 10 gegenüber gestellt. Abb. 56 stellt den Teilausschnitt für den Pyridinbereich von 7.30 - 9.00 ppm, Abb. 57 den Teilausschnitt für den Pyrazolbereich von $5.50-6.50$ ppm dar.

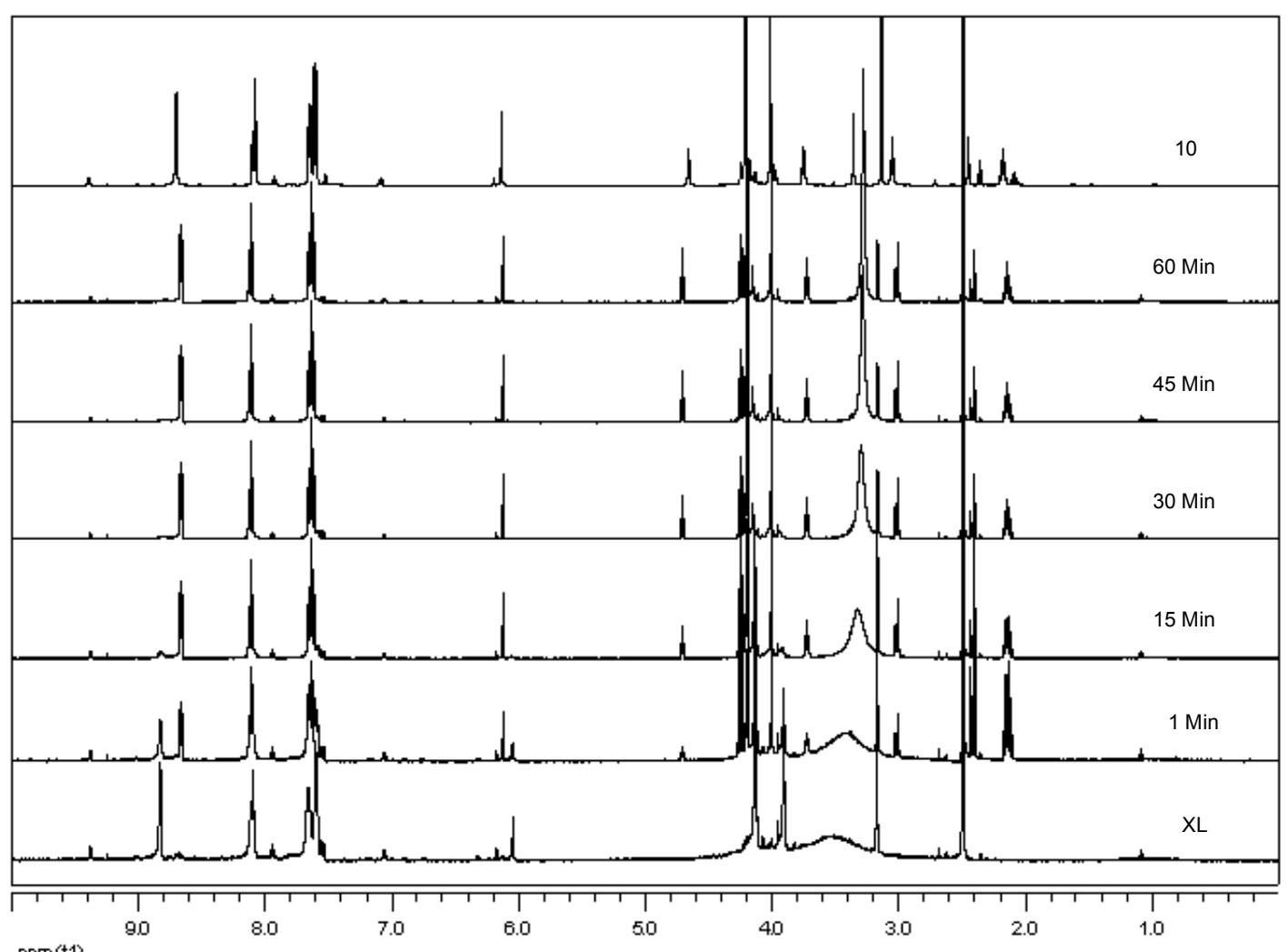

ppmo(t)

Abb. 55: ${ }^{1} H N M R$ Spektren in DMSO- $d_{6}$ während des Reaktionsverlaufs. 


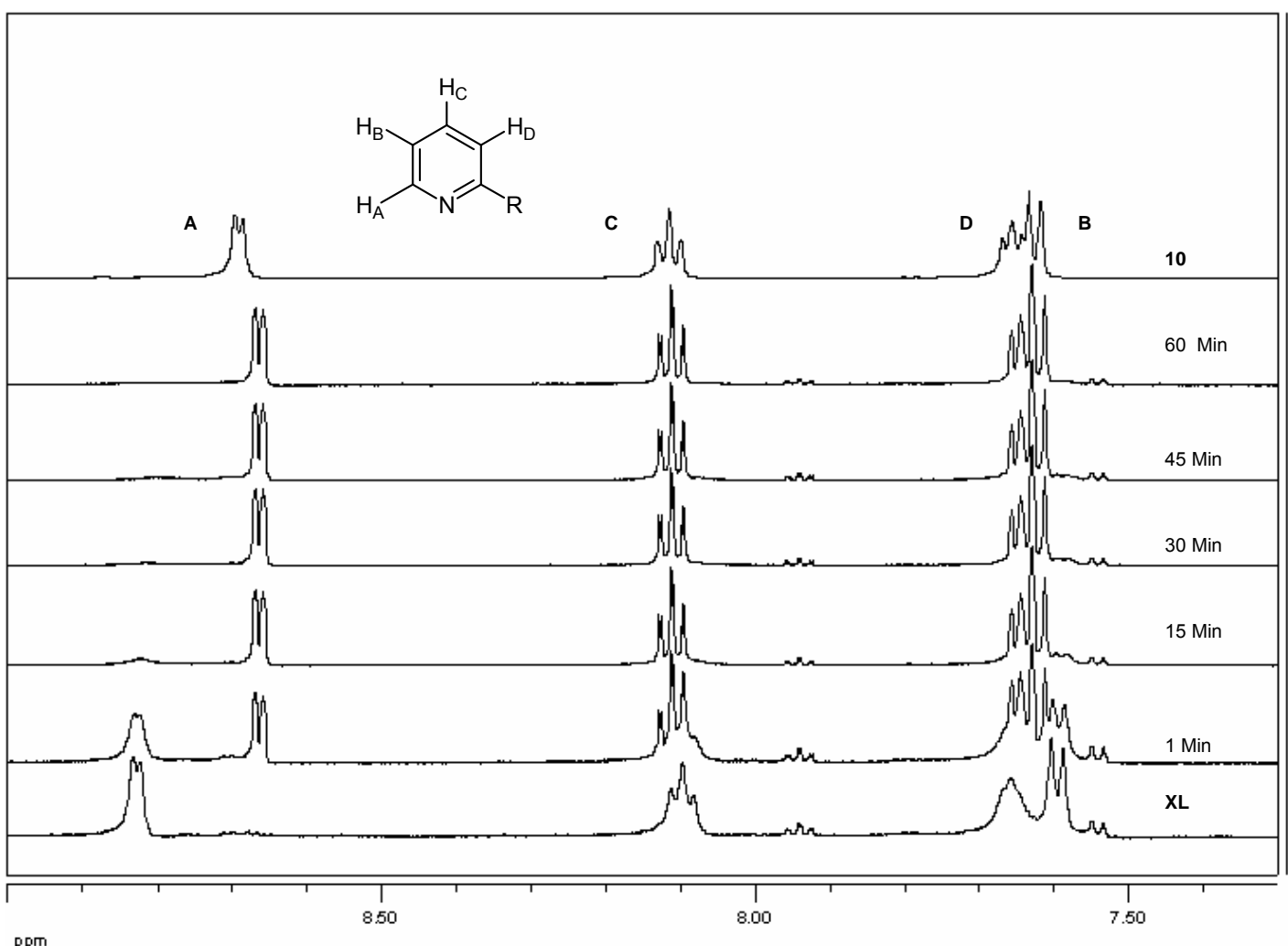

Abb. 56: Änderungen im Pyridinbereich während des Reaktionsverlaufs.

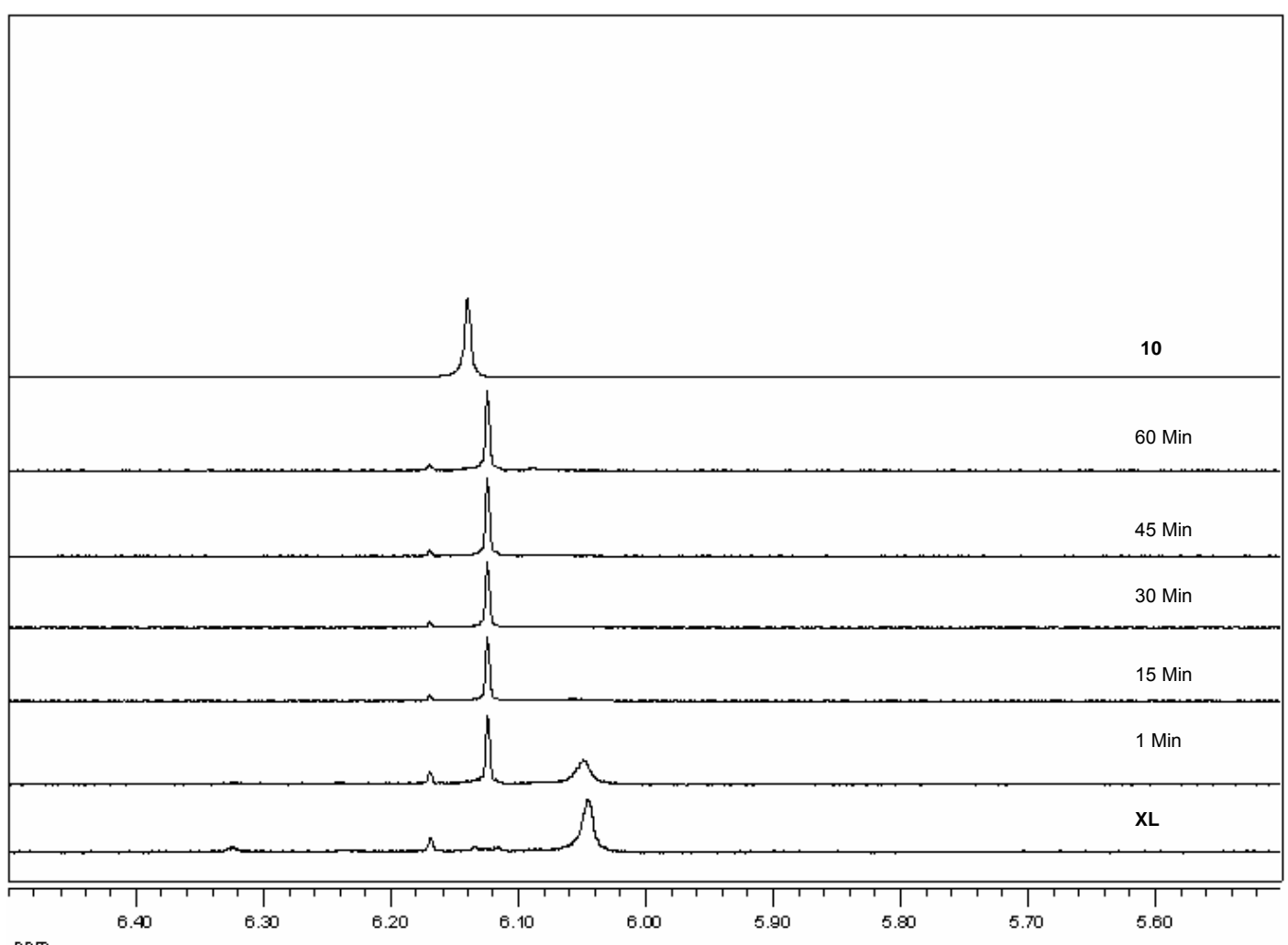

Abb. 57: Änderungen im Pyrazolbereich während des Reaktionsverlaufs. 
Das 4-H Signal des Pyrazols ist aus der Reaktionslösung gegenüber XLI leicht von etwa 6.04 ppm auf etwa 6.12 ppm nach tieferem Feld verschoben. Das 4-H Signal des Pyrazolrings in $\mathbf{1 0}$ liegt bei 6.14 ppm und ist, verglichen mit jenen von XLI, relativ scharf. Im Einklang mit den Ergebnissen des Reaktionsverlaufs im Bereich der Pyridinsignale zeigt auch Abb. 57 am 4-H Signal des Pyrazolrings, dass die Reaktion bereits nach 15 Minuten weitgehend beendet ist.

Bislang ist es noch nicht gelungen, die thermodynamische Konstante für die Ringöffnungsreaktion des Lactons durch den Komplex XLI zu berechnen.

Dadurch aber, dass die Ringöffnung durch den Komplex bereits bei Raumtemperatur abläuft, wie die NMR-Untersuchung zeigt, steht fest, dass dieser pyrazolbasierte Dizinkkomplex nicht nur ein Modell für eine $\beta$-Lactamase ist, sondern auch ein Beispiel für eine Lactonase.

\subsubsection{Zink(II)-Komplex des Liganden $\mathrm{L}^{6}-$ Synthese von $\left[\mathrm{L}^{6}{ }_{-\mathrm{H}}\left(\mu-\mathrm{HOCH}_{2} \mathrm{CH}_{2} \mathrm{CH}_{2} \mathrm{COO}\right) \mathrm{Zn}_{2}\right]\left(\mathrm{ClO}_{4}\right)_{2}(10)$}

Durch Reaktion des Komplexes $\left[\mathrm{L}^{6}{ }_{-\mathrm{H}}(\mathrm{MeOH})(\mathrm{OH}) \mathrm{Zn}_{2}\right]\left(\mathrm{ClO}_{4}\right)_{2}$ mit $\gamma$-Butyrolacton im Überschuss bei $100{ }^{\circ} \mathrm{C}$ und Entfernung des übrigen Lösungsmittels wurde der Komplex $\left[\mathrm{L}^{6}{ }_{-H}\left(\mu-\mathrm{HO}\left(\mathrm{CH}_{2}\right)_{3} \mathrm{COO}\right) \mathrm{Zn}_{2}\right]\left(\mathrm{ClO}_{4}\right)_{2}$ (10) (Abb. 58) erhalten. Durch langsame Diffusion von Diethylether in eine konzentrierte methanolische Lösung des gewonnenen Feststoffes wurden leicht beige Kristalle erhalten, die für die Röntgenstrukturanalyse geeignet waren. Der Komplex kristallisiert in der Raumgruppe $P-1$ mit zwei Molekülen in der triklinen Zelle.

In Abb. 59 sowie in Tab. 22 und 23 sind einige wichtige strukturelle Parameter des Kations des Komplexes $\left[\mathrm{L}^{6}{ }_{-\mathrm{H}}\left(\mu-\mathrm{HO}\left(\mathrm{CH}_{2}\right)_{3} \mathrm{COO}\right) \mathrm{Zn}_{2}\right]\left(\mathrm{ClO}_{4}\right)_{2}$ zusammengefasst. 


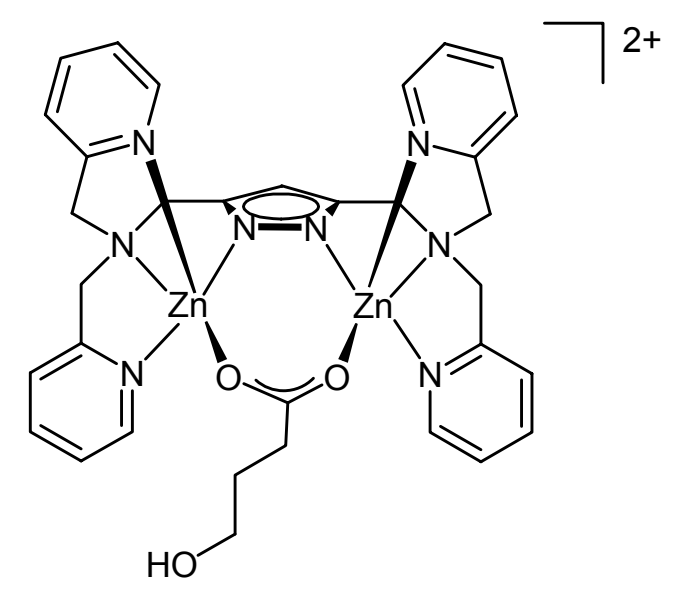

Abb. 58: Strukturformel des Kations von 10.

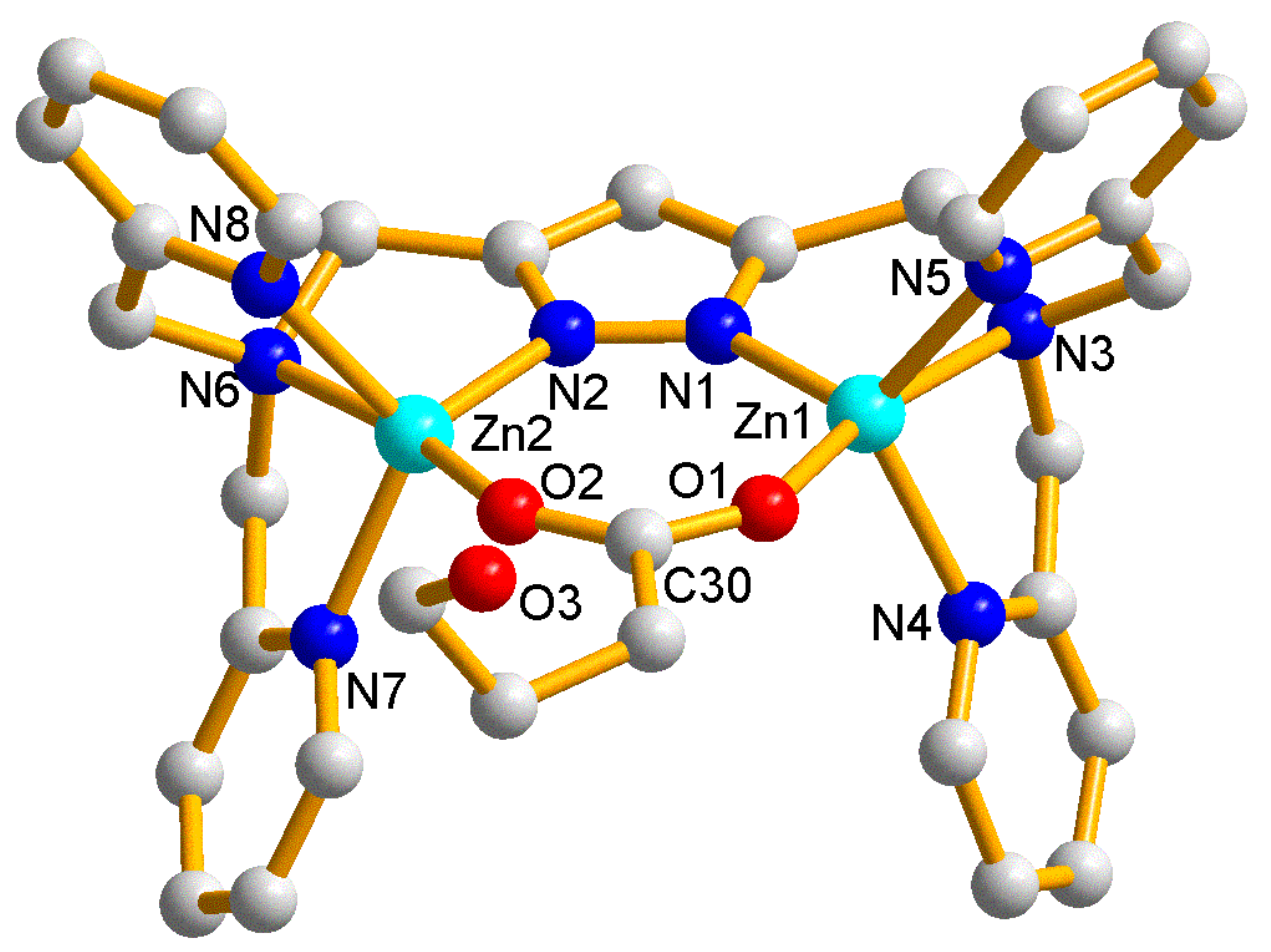

Abb. 59: Festkörperstruktur des Kations von 10.

Tab. 22: Ausgewählte Atomabstände $[\AA]]$ von 10.

\begin{tabular}{|l|l|l|l|}
\hline $\mathrm{Zn}(1)-\mathrm{N}(1)$ & $1.963(3)$ & $\mathrm{Zn}(2)-\mathrm{N}(2)$ & $1.985(3)$ \\
\hline $\mathrm{Zn}(1)-\mathrm{O}(1)$ & $1.978(2)$ & $\mathrm{Zn}(2)-\mathrm{O}(2)$ & $1.998(2)$ \\
\hline $\mathrm{Zn}(1)-\mathrm{N}(5)$ & $1.997(9)$ & $\mathrm{Zn}(2)-\mathrm{N}(8)$ & $2.057(3)$ \\
\hline
\end{tabular}




\begin{tabular}{|l|l|l|l|}
\hline $\mathrm{Zn}(1)-\mathrm{N}(4)$ & $2.133(10)$ & $\mathrm{Zn}(2)-\mathrm{N}(7)$ & $2.058(3)$ \\
\hline $\mathrm{Zn}(1)-\mathrm{N}(3)$ & $2.295(10)$ & $\mathrm{Zn}(2)-\mathrm{N}(6)$ & $2.287(3)$ \\
\hline $\mathrm{Zn}(1) \cdots \mathrm{Zn}(2)$ & $3.9838(6)$ & $\mathrm{O}(2)-\mathrm{C}(30)$ & $1.256(5)$ \\
\hline $\mathrm{O}(1)-\mathrm{C}(30)$ & $1.254(4)$ & & \\
\hline
\end{tabular}

Tab. 23: Ausgewählte Bindungswinkel ( $\left.{ }^{\circ}\right)$ von 10.

\begin{tabular}{|l|l|l|l|}
\hline $\mathrm{N}(1)-\mathrm{Zn}(1)-\mathrm{O}(1)$ & $111.49(11)$ & $\mathrm{N}(2)-\mathrm{Zn}(2)-\mathrm{O}(2)$ & $112.09(11)$ \\
\hline $\mathrm{N}(1)-\mathrm{Zn}(1)-\mathrm{N}(5)$ & $118.9(4)$ & $\mathrm{N}(2)-\mathrm{Zn}(2)-\mathrm{N}(8)$ & $113.19(13)$ \\
\hline $\mathrm{N}(1)-\mathrm{Zn}(1)-\mathrm{N}(3)$ & $78.4(2)$ & $\mathrm{N}(2)-\mathrm{Zn}(2)-\mathrm{N}(7)$ & $117.72(12)$ \\
\hline $\mathrm{N}(1)-\mathrm{Zn}(1)-\mathrm{N}(4)$ & $112.1(6)$ & $\mathrm{N}(2)-\mathrm{Zn}(2)-\mathrm{N}(6)$ & $77.46(11)$ \\
\hline $\mathrm{O}(1)-\mathrm{Zn}(1)-\mathrm{N}(4)$ & $96.7(3)$ & $\mathrm{O}(2)-\mathrm{Zn}(2)-\mathrm{N}(8)$ & $97.43(12)$ \\
\hline $\mathrm{O}(1)-\mathrm{Zn}(1)-\mathrm{N}(5)$ & $97.5(2)$ & $\mathrm{O}(2)-\mathrm{Zn}(2)-\mathrm{N}(7)$ & $96.83(12)$ \\
\hline $\mathrm{O}(1)-\mathrm{Zn}(1)-\mathrm{N}(3)$ & $169.7(2)$ & $\mathrm{O}(2)-\mathrm{Zn}(2)-\mathrm{N}(6)$ & $170.44(11)$ \\
\hline $\mathrm{N}(5)-\mathrm{Zn}(1)-\mathrm{N}(4)$ & $116.4(7)$ & $\mathrm{N}(8)-\mathrm{Zn}(2)-\mathrm{N}(7)$ & $116.11(13)$ \\
\hline $\mathrm{N}(5)-\mathrm{Zn}(1)-\mathrm{N}(3)$ & $79.1(3)$ & $\mathrm{N}(8)-\mathrm{Zn}(2)-\mathrm{N}(6)$ & $78.01(13)$ \\
\hline $\mathrm{N}(4)-\mathrm{Zn}(1)-\mathrm{N}(3)$ & $76.5(3)$ & $\mathrm{N}(7)-\mathrm{Zn}(2)-\mathrm{N}(6)$ & $78.01(12)$ \\
\hline $\mathrm{O}(1)-\mathrm{C}(30)-\mathrm{O}(2)$ & $126.2(3)$ & & \\
\hline
\end{tabular}

Der Abstand zwischen beiden Metallkernen beträgt $3.98 \AA$, beide Atome sind trigonal bipyramidal $(\mathrm{Zn} 1: \tau=0.85 ; \mathrm{Zn} 2: \tau=0.88)$ koordiniert. Dieser Abstand ist vergleichbar mit den Abständen in den Komplexen $\mathbf{5}$ und 6, wo ein Acetat bzw. ein Formiat als zweite Brücke beteiligt ist. Wie im Fall des Komplexes $\mathbf{5}$ spielt die aliphatische Kette der Zweitbrücke keine sterische Rolle. Auch die Winkel der formiatartigen Brücke sind mit denen anderer Komplexe vergleichbar. Beide Brücken liegen fast in der gleichen Ebene (Torsionswinkel: $0.56^{\circ}$ ), der alkoholische Rest steht im Festkörper fast senkrecht dazu (Torsionswinkel: $83.66^{\circ}$ ).

Die Länge der Bindungen der Zink(II)-lonen mit den N-Donoratomen ist im Fall von 10 für jeden Stickstoff unterschiedlich. Die $\mathrm{sp}^{2}$-hybridisierten Stickstoffatome der zwei Pyridineinheiten zeigen einen Unterschied von etwa $0.1 \AA$. Diese Unterschiede sind in den strukturanalogen Komplexen 5 und $\mathbf{6}$ nicht zu finden, wo die Bindungen der $\mathrm{sp}^{2}$-hybridisierten Stickstoffatome fast übereinstimmen. Die Länge der Bindungen der Zinkkerne zum pyrazolischen 
Stickstoff und zum Sauerstoff des Carboxylats ist für die drei Komplexe etwa gleich.

Auch durch die Ringöffnung beobachtet man die typischen IR-Signale für eine metallgebundene Carboxylverbindung bei 1562 und $1439 \mathrm{~cm}^{-1}$. Die IR Daten, die für eine symmetrische Bindung der 4-Hydroxybutyrate sprechen, stimmen mit der Kristallstruktur überein, in der die Abstände Zn1-O1 und Zn2-O2 etwa gleich sind (1.98 vs. $1.99 \AA$ ).

Durch die Öffnung des $\gamma$-Butyrolactons wird diese carboxylartige Brücke hergestellt, was durch eine bidentate Koordination an beide Zink(II)-lonen mit großer Annäherung der Metallkerne dem Edukt $\left(\left[\mathrm{L}^{6}{ }_{-\mathrm{H}}(\mathrm{MeOH})(\mathrm{OH}) \mathrm{Zn}_{2}\right]\left(\mathrm{ClO}_{4}\right)_{2}\right.$ entspricht, das an der hydrolytischen Öffnung beteiligt ist (3.98 vs. $4.15 \AA$ ). ${ }^{[65]}$

Diese hydrolytische Abspaltung wurde schon bei anderen Nickel(II)Pyrazolatokomplexen, bei denen eine Carboxylverbindung beide Metallkerne überbrückt, festgestellt. ${ }^{[86]}$ Der intermetallische Abstand ist in diesem Fall größer als beim Dizinkkomplex (4.30 vs. $3.98 \AA$ ). In der Nickelverbindung werden auch beide Nickelzentren näher zusammengerückt, aber dieser Unterschied beträgt nur $0.1 \AA$ im Vergleich zu fast $0.2 \AA$ für den Dizinkkomplex.

\subsection{Komplexe mit weiteren Übergangsmetallen}

In dieser Arbeit wurden außer mit Zink auch mit weiteren späten Übergangsmetallen wie z.B. Kupfer und Nickel bimetallische Komplexe dargestellt. Die Verwendung anderer Übergangsmetalle soll die Kentnisse über neue asymmetrische Pyrazolliganden verbessern. Mit farbigen Ionen wie $\mathrm{Cu}^{2+}$ oder $\mathrm{Ni}^{2+}$ ist eine Trennung unterschiedlicher Spezies über eine Sephadex lonenaustauschersäule möglich. Dies sollte zu einer einfachen und besseren Kristallisation führen. 


\subsubsection{Nickel(II)-Komplex des Liganden $\mathrm{L}^{2}-$ \\ Synthese von $\left[\mathrm{L}^{2}{ }_{-\mathrm{H}}\left(\mathrm{NO}_{3}\right)_{2} \mathrm{Ni}_{2}\right] \mathrm{NO}_{3}(11)$}

Der Komplex (Abb. 60) wurde durch die Reaktion des deprotonierten Liganden $\mathrm{L}^{2}$ mit Nickelperchlorat Hexahydrat in Methanol dargestellt. Der erhaltene Komplex wurde durch eine Sephadex Ionenaustauschersäule mit einer wäßrigen Lösung von $\mathrm{NaNO}_{3}(0.1 \mathrm{M}$ bis $1.0 \mathrm{M})$ gereinigt. Aus einer der gewonnenen Fraktionen, die vom Lösungsmittel befreit wurde, wurden durch langsame Diffusion von Diethylether in eine methanolische Lösung des Komplexes dunkelblaue Kristalle erhalten.

Der Komplex kristallisiert in der Raumgruppe Pcca mit vier Molekülen in der orthorhombischen Zelle. In Abb. 61 sowie in Tab. 24 und 25 sind einige wichtige strukturelle Parameter des Kations des Komplexes $\left[\mathrm{L}^{2}{ }_{\mathrm{H}}\left(\mathrm{NO}_{3}\right)_{2} \mathrm{Ni}_{2}\right]\left(\mathrm{NO}_{3}\right)$ (11) zusammengefasst.

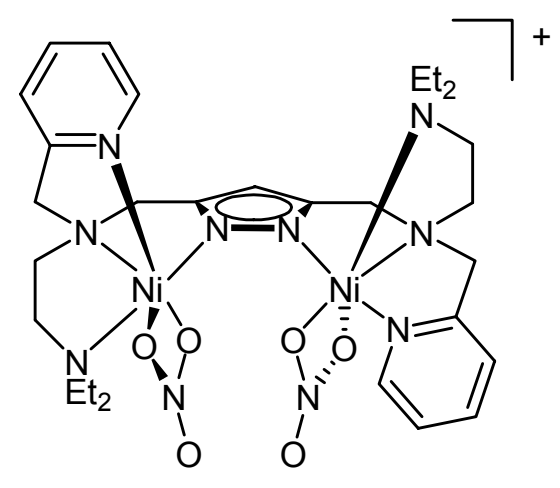

Abb. 60: Strukturformel des Kations von 11. 


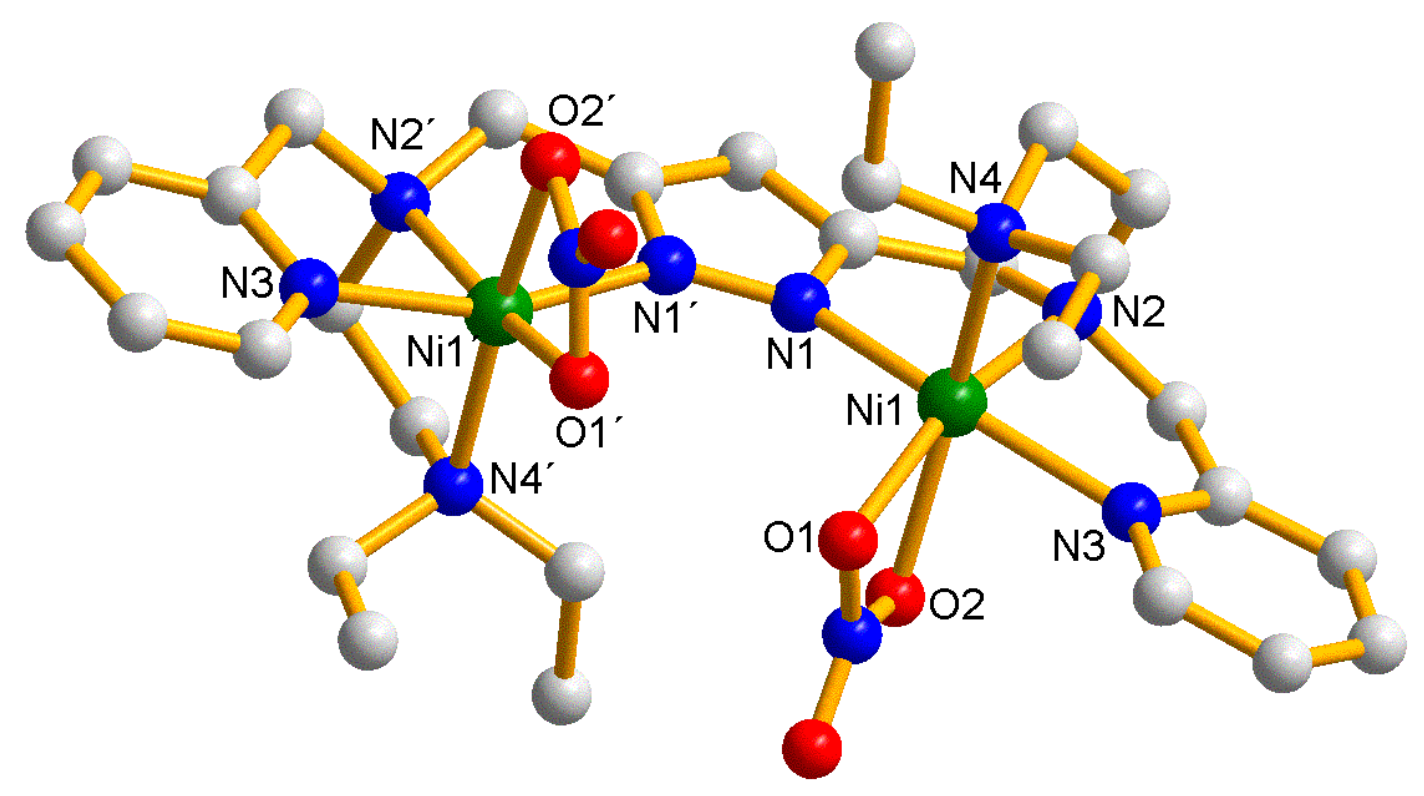

Abb. 61: Festkörperstruktur des Kations des Komplexes 11.

Tab. 24: Ausgewählte Atomabstände [Å] von 11.

\begin{tabular}{|l|l|l|l|}
\hline $\mathrm{Ni}(1)-\mathrm{N}(1)$ & $2.063(6)$ & $\mathrm{Ni}(1)-\mathrm{N}(4)$ & $2.142(7)$ \\
\hline $\mathrm{Ni}(1)-\mathrm{N}(2)$ & $2.067(6)$ & $\mathrm{Ni}(1)-\mathrm{O}(2)$ & $2.199(6)$ \\
\hline $\mathrm{Ni}(1)-\mathrm{O}(1)$ & $2.091(6)$ & $\mathrm{Ni}(1) \cdots \mathrm{Ni}\left(1^{\prime}\right)$ & $4.614(2)$ \\
\hline $\mathrm{Ni}(1)-\mathrm{N}(3)$ & $2.115(7)$ & & \\
\hline
\end{tabular}

Tab. 25: Ausgewählte Bindungswinkel ( ${ }^{\circ}$ ) von 11.

\begin{tabular}{|l|l|l|l|}
\hline $\mathrm{N}(1)-\mathrm{Ni}(1)-\mathrm{N}(2$ & $83.2(2)$ & $\mathrm{O}(1)-\mathrm{Ni}(1)-\mathrm{N}(3)$ & $89.7(2)$ \\
\hline $\mathrm{N}(1)-\mathrm{Ni}(1)-\mathrm{O}(1)$ & $103.1(2)$ & $\mathrm{N}(1)-\mathrm{Ni}(1)-\mathrm{N}(4)$ & $93.0(3)$ \\
\hline $\mathrm{N}(2)-\mathrm{Ni}(1)-\mathrm{O}(1)$ & $164.7(2)$ & $\mathrm{N}(2)-\mathrm{Ni}(1)-\mathrm{N}(4)$ & $86.5(2)$ \\
\hline $\mathrm{N}(1)-\mathrm{Ni}(1)-\mathrm{N}(3)$ & $159.8(2)$ & $\mathrm{O}(1)-\mathrm{Ni}(1)-\mathrm{N}(4)$ & $106.8(3)$ \\
\hline $\mathrm{N}(2)-\mathrm{Ni}(1)-\mathrm{N}(3)$ & $80.8(3)$ & $\mathrm{N}(3)-\mathrm{Ni}(1)-\mathrm{N}(4)$ & $98.3(3)$ \\
\hline $\mathrm{N}(1)-\mathrm{Ni}(1)-\mathrm{O}(2)$ & $92.2(2)$ & $\mathrm{O}(1)-\mathrm{Ni}(1)-\mathrm{O}(2)$ & $61.5(2)$ \\
\hline $\mathrm{N}(2)-\mathrm{Ni}(1)-\mathrm{O}(2)$ & $104.8(2)$ & $\mathrm{N}(3)-\mathrm{Ni}(1)-\mathrm{O}(2)$ & $80.0(2)$ \\
\hline $\mathrm{N}(4)-\mathrm{Ni}(1)-\mathrm{O}(2)$ & $168.0(2)$ & & \\
\hline
\end{tabular}


Im ESI-Spektrum einer methanolischen Lösung von 11 beobachtet man bei $m / z=745$ und mit einer Intensität von $100 \%$ die Spezies $\left[\left(\mathrm{L}^{2}{ }_{-\mathrm{H}}\right)\left(\mathrm{NO}_{3}\right)_{2} \mathrm{Ni}_{2}\right]^{+}$. Andere Signale ohne eindeutige Zuordnung sind auch zu beobachten.

Der Abstand zwischen beiden Nickel(II)-lonen beträgt 4.61 A. Dieser große Metall-Metall-Abstand kommt durch das Fehlen der zweiten Brücke zustande, die eine Annäherung der beiden Metallionen zueinander ermöglicht hätte. Die Zweitbrücke wird in diesem Fall durch den koordinierenden Charakter des Nitrations verhindert. Die beiden Nickel(II)-lonen sind leicht verzerrt oktaedrisch umgeben. Das Molekül besitzt kristallographische $\mathrm{C}_{2}$-Symmetrie, so dass der Komplex als Racemat vorliegt (rac Form). Der Kristall weist jedoch eine zentrosymmetrische Raumgruppe auf.

In dieser Struktur sind die Unterschiede der Bindungsabstände zwischen den Nickel(II)-Ionen und den Stickstoffatomen nicht so groß wie in den anderen Fällen, obwohl $\mathrm{sp}^{2}$ - und $\mathrm{sp}^{3}$-hybridisierte Stickstoffatome des Ligandgerüstes an Nickel(II)-lonen gebunden sind. Aufgrund des Fehlens der Zweitbrücke sind kürzere Ni1-N2 Abstände möglich.

Im IR-Spektrum beobachtet man die typischen drei Signale eines koordinierenden $\mathrm{NO}_{3}^{-}$-Ions bei 1467, 1301 und $1010 \mathrm{~cm}^{-1}$. Der Unterschied in den Wellenzahlen der beiden stärksten Signale liegt bei $166 \mathrm{~cm}^{-1}$. Dieser große Unterschied ist typisch für Nitrationen, die als bidentate Chelate koordiniert sind. ${ }^{[87]}$

\subsubsection{Nickel(II)-Komplex des Liganden $\mathrm{L}^{4}-$ Synthese von $\left[\mathrm{L}^{4}{ }_{\mathrm{H}}\left(\mu-\mathrm{CH}_{3} \mathrm{COO}\right) \mathrm{Ni}_{2}\right]\left(\mathrm{ClO}_{4}\right)_{2}(12)$}

Dieser Komplex (Abb. 62) wurde durch Reaktion von Nickelperchlorat Hexahydrat und Natriumacetat in Methanol mit dem deprotonierten Liganden $\mathrm{L}^{4}$ erhalten. Nach langsamer Diffusion von Diethylether und anschließendem Abdampfen der Lösung wurden grüne Kristalle des Komplexes 12 gewonnen. Der Komplex kristallisiert in der Raumgruppe $P 2_{1} / \mathrm{n}$. Die monokline Zelle enthält vier Moleküle.

In Abb. 63 sowie in Tab. 26 und 27 sind einige wichtige strukturelle Parameter vom Kation des Komplexes $\left[\mathrm{L}^{4}{ }_{-\mathrm{H}}\left(\mu-\mathrm{CH}_{3} \mathrm{COO}\right) \mathrm{Ni}_{2}\right]\left(\mathrm{ClO}_{4}\right)_{2}(\mathbf{1 2})$ zusammengefasst. 


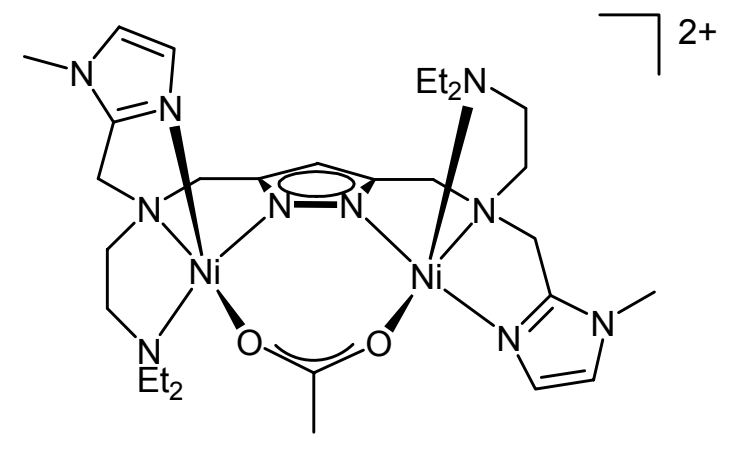

Abb. 62: Strukturformel des Kations von 12.

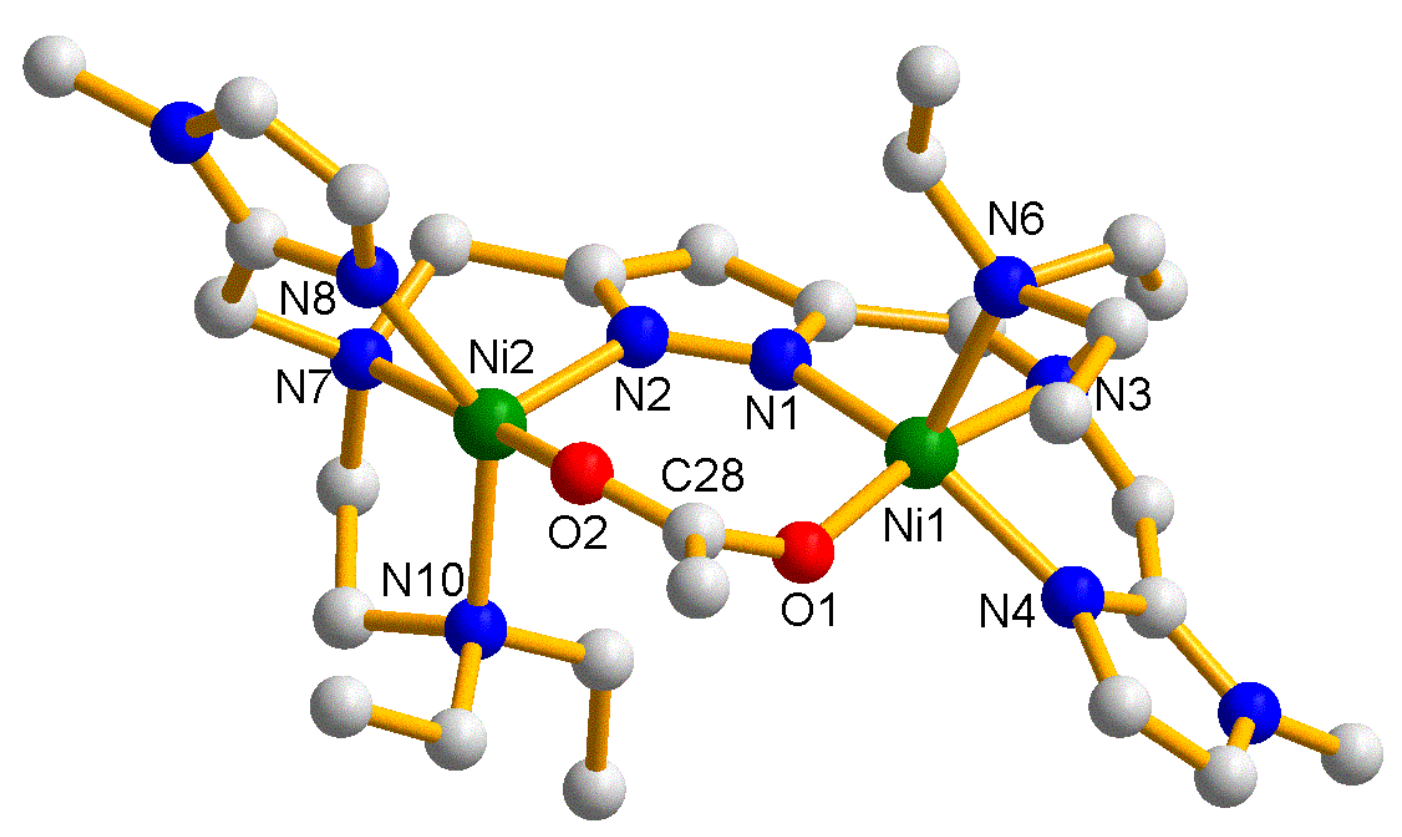

Abb. 63: Festkörperstruktur des Kations von 12.

Tab. 26: Ausgewählte Atomabstände [Å] von 12.

\begin{tabular}{|l|l|l|l|}
\hline $\mathrm{Ni}(1)-\mathrm{N}(1)$ & $1.968(5)$ & $\mathrm{Ni}(2)-\mathrm{N}(10)$ & $2.124(5)$ \\
\hline $\mathrm{Ni}(1)-\mathrm{N}(4)$ & $1.988(6)$ & $\mathrm{Ni}(2)-\mathrm{N}(7)$ & $2.169(5)$ \\
\hline $\mathrm{Ni}(1)-\mathrm{O}(1)$ & $2.013(4)$ & $\mathrm{Ni}(2)-\mathrm{O}(2)$ & $1.978(4)$ \\
\hline $\mathrm{Ni}(1)-\mathrm{N}(6)$ & $2.048(11)$ & $\mathrm{Ni}(2)-\mathrm{N}(8)$ & $2.017(6)$ \\
\hline $\mathrm{Ni}(1)-\mathrm{N}(3)$ & $2.166(5)$ & $\mathrm{Ni}(2)-\mathrm{N}(2)$ & $1.968(5)$ \\
\hline
\end{tabular}




\begin{tabular}{|l|l|l|l|}
\hline $\mathrm{Ni}(1) \cdots \mathrm{Ni}(2)$ & $4.096(1)$ & $\mathrm{C}(28)-\mathrm{O}(1)$ & $1.272(3)$ \\
\hline $\mathrm{C}(28)-\mathrm{O}(2)$ & $1.254(2)$ & & \\
\hline
\end{tabular}

Tabelle 27: Ausgewählte Bindungswinkel ( ${ }^{\circ}$ ) von 12.

\begin{tabular}{|l|l|l|l|}
\hline $\mathrm{N}(1)-\mathrm{Ni}(1)-\mathrm{N}(4)$ & $148.1(2)$ & $\mathrm{N}(2)-\mathrm{Ni}(2)-\mathrm{O}(2)$ & $105.9(2)$ \\
\hline $\mathrm{N}(1)-\mathrm{Ni}(1)-\mathrm{O}(1)$ & $103.2(2)$ & $\mathrm{N}(2)-\mathrm{Ni}(2)-\mathrm{N}(8)$ & $111.2(2)$ \\
\hline $\mathrm{N}(1)-\mathrm{Ni}(1)-\mathrm{N}(3)$ & $80.8(2)$ & $\mathrm{N}(2)-\mathrm{Ni}(2)-\mathrm{N}(7)$ & $80.9(2)$ \\
\hline $\mathrm{N}(1)-\mathrm{Ni}(1)-\mathrm{N}(6)$ & $102.5(3)$ & $\mathrm{N}(2)-\mathrm{Ni}(2)-\mathrm{N}(10)$ & $101.5(2)$ \\
\hline $\mathrm{N}(4)-\mathrm{Ni}(1)-\mathrm{O}(1)$ & $91.3(2)$ & $\mathrm{O}(2)-\mathrm{Ni}(2)-\mathrm{N}(10)$ & $99.57(19)$ \\
\hline $\mathrm{N}(4)-\mathrm{Ni}(1)-\mathrm{N}(6)$ & $101.7(3)$ & $\mathrm{O}(2)-\mathrm{Ni}(2)-\mathrm{N}(8)$ & $92.3(2)$ \\
\hline $\mathrm{N}(4)-\mathrm{Ni}(1)-\mathrm{N}(3)$ & $80.5(2)$ & $\mathrm{O}(2)-\mathrm{Ni}(2)-\mathrm{N}(7)$ & $170.8(2)$ \\
\hline $\mathrm{O}(1)-\mathrm{Ni}(1)-\mathrm{N}(6)$ & $103.0(3)$ & $\mathrm{N}(8)-\mathrm{Ni}(2)-\mathrm{N}(10)$ & $140.5(2)$ \\
\hline $\mathrm{O}(1)-\mathrm{Ni}(1)-\mathrm{N}(3)$ & $169.0(2)$ & $\mathrm{N}(8)-\mathrm{Ni}(2)-\mathrm{N}(7)$ & $79.3(2)$ \\
\hline $\mathrm{N}(6)-\mathrm{Ni}(1)-\mathrm{N}(3)$ & $85.9(3)$ & $\mathrm{N}(10)-\mathrm{Ni}(2)-\mathrm{N}(7)$ & $84.8(2)$ \\
\hline $\mathrm{O}(2)-\mathrm{C}(28)-\mathrm{O}(1)$ & $126.5(6)$ & & \\
\hline
\end{tabular}

Der Abstand zwischen beiden Nickel(II)-lonen beträgt 4.09 $\AA$. Die Besonderheit dieser Struktur ist, dass eines der Nickelatome tetragonal pyramidal koordiniert ist (Ni1: $\tau=0.35$ ) und der andere Metallkern an der Grenze beider Fälle liegt (Ni2: $\tau=0.5$ ). Das tetragonal pyramidale Nickelatom (Ni1) stellt noch Platz für eine zusätzliche Bindung zur Verfügung. Ni2 ist abgedeckter und bietet nicht diesen Raum, um ein zusätzliches Donoratom zu koordinieren. Eine ähnliche Struktur, in der zwei Nickelkerne durch eine Pyrazoleinheit und ein Acetation verbrückt sind, wurde schon in einer anderen Arbeit gefunden. ${ }^{[132]}$ Obwohl Nickel in dieser Struktur eine Koordinationszahl von sechs hat, ist der intermetallische Abstand in beiden Fällen fast derselbe (4.09 vs. $4.16 \AA$ ).

Im IR-Spektrum dieses Komplexes kommen die typischen asymmetrischen und symmetrischen Banden eines verbrückenden Acetats bei 1580 bzw. $1384 \mathrm{~cm}^{-1}$.

Die räumliche Struktur des Nickel(II)-Komplexes 12 entspricht der des zinkhaltigen Komplexes 2. Auch der Metall-Metall-Abstand ist in etwa gleich groß. Zink und Nickel zeigen allerdings in ihrem Koordinationsverhalten deutliche Unterschiede. Im Falle von Zink sind beide Zink(II)-lonen trigonal bipyramidal umgeben. Dagegen ist im Falle von Nickel ein Nickel(II)-lon 
tetragonal pyramidal, das andere in einem Grenzfall zwischen trigonal bipyramidaler und tetragonaler Symmetrie koordiniert. Die Bindungslängen von Zink(II)-Ionen zu den Donoratomen und von Nickel(II)-Ionen zu den Donoratomen sind sehr ähnlich. Sie liegen bei etwa $2.0 \AA$, wobei die Bindung mit dem tertiären Stickstoffatom am Methylpyrazolrest deutlich kürzer ist (2.17 vs. $2.41 \AA$ ). Die Zweitbrücke ist bei 12 nicht so stark gewinkelt $\left(8.89^{\circ}\right.$ vs. $\left.14.68^{\circ}\right)$. Auch zeigen sich deutliche Unterschiede in der räumlichen Anordnung der Metalle. Bei Komplex 2 befinden sich beide Zinkatome deutlich außerhalb der Ebene des Pyrazolrings. Dagegen liegt im Komplex 12 nur eines der Nickel(II)-Ionen (Ni2) $0.52 \AA$ außerhalb dieser Ebene. Wie im Fall des Zinkkomplexes 2 wurde hier die rac Form erhalten.

\subsubsection{Kupfer(II)-Komplex eines Restes des Liganden $\mathrm{L}^{4}-$ Synthese von $\left[\mathrm{DMelmDEtEtA}\left(\mathrm{NO}_{3}\right) \mathrm{Cu}\right]\left(\mathrm{NO}_{3}\right)(13)$}

Bei der Reaktion des deprotonierten Liganden $L^{4}$ mit Kupferperchlorat Hexahydrat in Methanol, gefolgt von einer Reinigung durch eine Sephadex lonenaustauschersäule, wurde der unerwartete Komplex [DMelmDEtEtA $\left.\left(\mathrm{NO}_{3}\right) \mathrm{Cu}\right]\left(\mathrm{NO}_{3}\right)$ (13) (Abb. 64) isoliert. Dies kommt zustande durch die Anwesenheit von Nebenprodukten der Synthese des Liganden $L^{4}$.

Der Komplex kristallisiert in der Raumgruppe $P 2_{1} / \mathrm{c}$ mit vier Molekülen in der monoklinen Zelle. In Abb. 65 sowie in Tab. 28 und 29 sind einige wichtige strukturelle Parameter des Kations des Komplexes [DMelmDEtEtA $\left.\left(\mathrm{NO}_{3}\right) \mathrm{Cu}\right]\left(\mathrm{NO}_{3}\right)$ (13) zusammengefasst. 


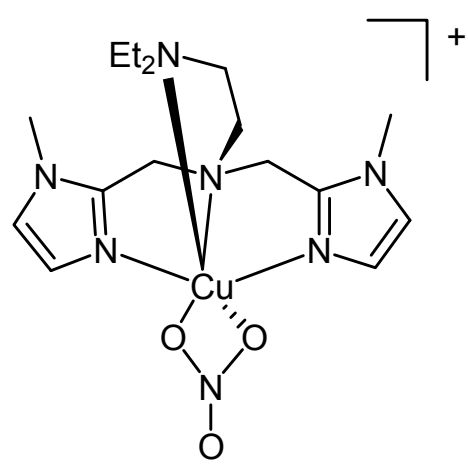

Abb. 64: Strukturformel des Kations von 13.

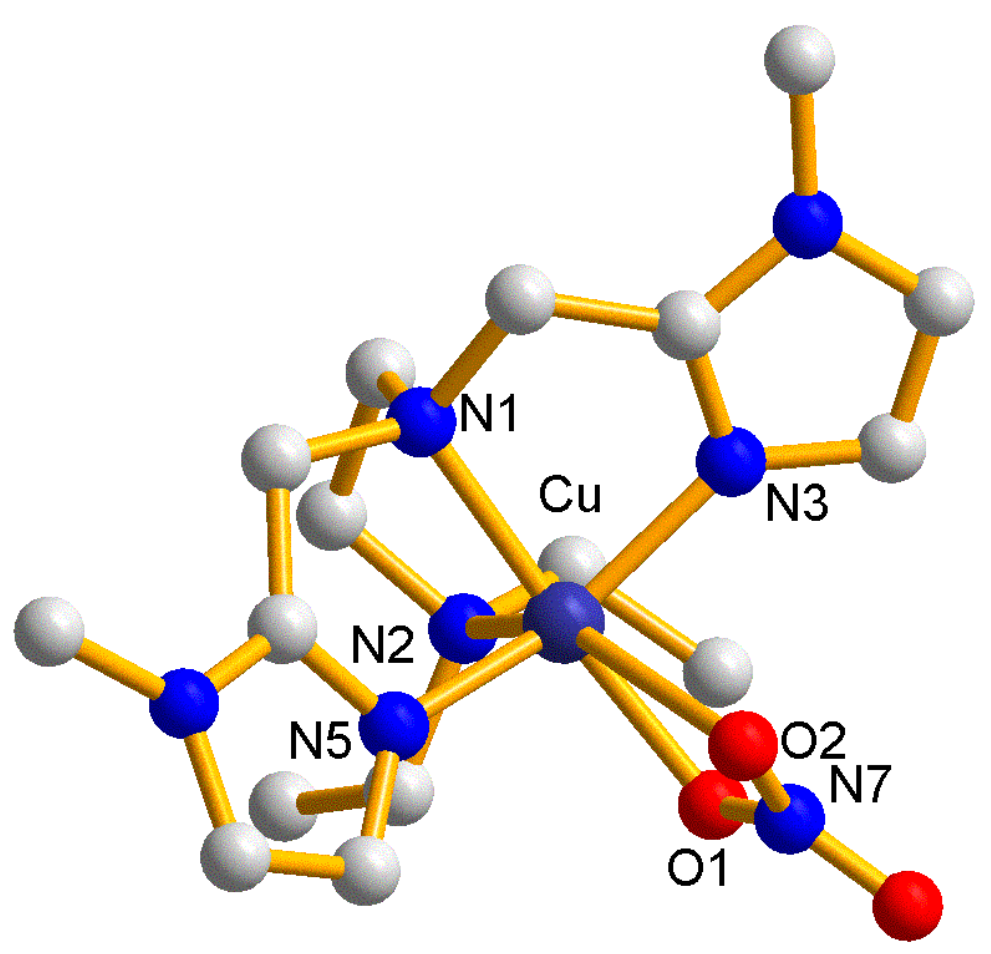

Abb. 65: Festkörperstruktur des Kations von 13.

Tab. 28: Ausgewählte Atomabstände [Å] von 13.

\begin{tabular}{|l|l|l|l|}
\hline $\mathrm{Cu}(1)-\mathrm{N}(1)$ & $2.096(2)$ & $\mathrm{Cu}(1)-\mathrm{O}(1)$ & $2.000(2)$ \\
\hline $\mathrm{Cu}(1)-\mathrm{N}(2)$ & $2.286(2)$ & $\mathrm{Cu}(1)-\mathrm{O}(2)$ & $2.704(2)$ \\
\hline $\mathrm{Cu}(1)-\mathrm{N}(3)$ & $1.968(2)$ & $\mathrm{N}(7)-\mathrm{O}(2)$ & $1.230(3)$ \\
\hline $\mathrm{Cu}(1)-\mathrm{N}(5)$ & $1.952(2)$ & $\mathrm{N}(7)-\mathrm{O}(1)$ & $1.299(3)$ \\
\hline
\end{tabular}


Tab. 29: Ausgewählte Bindungswinkel ( $\left.{ }^{\circ}\right)$ von 13.

\begin{tabular}{|l|l|l|l|}
\hline $\mathrm{N}(5)-\mathrm{Cu}(1)-\mathrm{N}(3)$ & $149.64(10)$ & $\mathrm{O}(1)-\mathrm{Cu}(1)-\mathrm{N}(1)$ & $175.28(8)$ \\
\hline $\mathrm{N}(5)-\mathrm{Cu}(1)-\mathrm{O}(1)$ & $98.62(9)$ & $\mathrm{N}(5)-\mathrm{Cu}(1)-\mathrm{N}(2)$ & $100.57(9)$ \\
\hline $\mathrm{N}(3)-\mathrm{Cu}(1)-\mathrm{O}(1)$ & $94.34(9)$ & $\mathrm{N}(3)-\mathrm{Cu}(1)-\mathrm{N}(2)$ & $104.33(9)$ \\
\hline $\mathrm{N}(5)-\mathrm{Cu}(1)-\mathrm{N}(1)$ & $83.33(9)$ & $\mathrm{O}(1)-\mathrm{Cu}(1)-\mathrm{N}(2)$ & $99.10(8)$ \\
\hline $\mathrm{N}(3)-\mathrm{Cu}(1)-\mathrm{N}(1)$ & $81.96(9)$ & $\mathrm{N}(1)-\mathrm{Cu}(1)-\mathrm{N}(2)$ & $84.71(8)$ \\
\hline $\mathrm{O}(2)-\mathrm{N}(7)-\mathrm{O}(1)$ & $118.9(2)$ & & \\
\hline
\end{tabular}

Im ESI-Massenspektrum aus einer methanolischen Lösung des Komplexes beobachtet man bei $m / z=429$ und mit einer Intensität von $90 \%$ das Signal der Spezies [DMelmDEtEtA $\left.\left(\mathrm{NO}_{3}\right) \mathrm{Cu}\right]^{+}$. Weitere Signale von möglichen Aggregaten dieses Komplexes ohne eindeutige Zuordnung kommen bei größeren $\mathrm{m} / \mathrm{z}$ Werten.

Das Kupfer(II)-Ion ist verzerrt oktaedrisch koordiniert. Die zwei $\mathrm{sp}^{2}$ hybridisierten, an das Kupfer(II)-Ion koordinierten, Stickstoffatome befinden sich in der äquatorialen Ebene und ihre Bindungslängen haben ähnliche Werte (1.95 vs. $1.97 \AA$ ). Für das andere, in der Äquatorebene liegende, Stickstoffatom ist die Bindungslänge zum Kupfer(II)-lon mit $2.09 \AA$ in der gleichen Größenordnung. Die Donoratome in den apikalen Stellen besitzen größere Bindungslängen, die auch etwas unterschiedlich sind ( 2.70 vs. $2.29 \AA$ ). Im IR-Spektrum beobachtet man die typischen drei Signale eines koordinierten $\mathrm{NO}_{3}{ }^{-}$-Ions bei 1469,1301 und $1010 \mathrm{~cm}^{-1}$. Der Unterschied in den Wellenzahlen der beiden stärksten Signale liegt bei $168 \mathrm{~cm}^{-1}$. Dieser große Unterschied ist typisch für Nitrationen, die als bidentate Chelate koordiniert sind. ${ }^{[87]}$

Viele Kupferkomplexe mit tripodalen Liganden des Typs $\mathrm{NL}_{3}$, in welchen $L$ ein Seitenarm mit koordinierenden Donoratomen ist, sind in der Literatur bekannt. ${ }^{[133-135]} \mathrm{Im}$ Gegensatz zur Struktur 13 sind auch fünffach koordinierte Kupferzentren mit Liganden dieser Art möglich. 


\section{Zusammenfassung}

In der vorliegenden Arbeit wurden bei der Synthese der Metallkomplexe die Liganden $L^{1}$ bis $L^{12}$ eingesetzt, wobei $L^{1}$ bis $L^{5}$ bislang noch nicht beschrieben waren. Die Synthese erfolgte nach der in Schema 19 dargestellten Gleichung. In Tab. 30 sind die unterschiedlichen Seitenarme dargestellt.

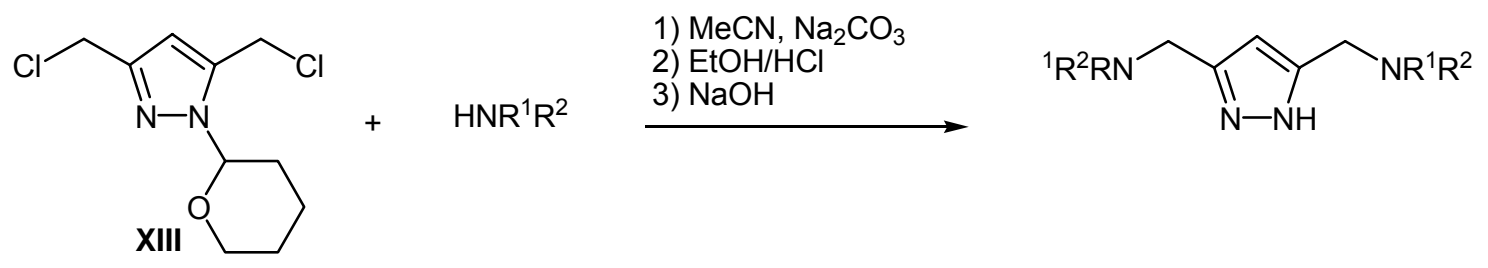

Schema 19: Synthese der Pyrazolliganden.

Tab. 30: Verwendete Seitenarme.
$\mathrm{L}^{\mathrm{n}}$
$\mathrm{R}^{1}$
$\mathrm{R}^{2}$
$\mathrm{L}^{1} \quad$ (N-methyl-imidazol-2-yl)methyl
(N-methyl-imidazol-2-yl)methyl
$\mathrm{L}^{2} \quad$ methylpyridin-2-yl
diethylaminoethyl
$\mathrm{L}^{3} \quad$ (N-methyl-imidazol-2-yl)methyl
ethylpyridin-2-yl
$\mathrm{L}^{4} \quad$ (N-methyl-imidazol-2-yl)methyl
diethylaminoethyl
$\mathrm{L}^{5} \quad$ 2,6-dimethylpyridin-6-yl
2,6-dimethylpyridin-6-yl

Die für die Synthese der Liganden $L^{n}(n=1-4)$ benötigten Amine $R_{1} R_{2} N H$ (XXIX, XXXIV, XXXV und XXXVI) wurden in der vorliegenden Arbeit erstmals dargestellt.

Durch diese insgesamt relativ große Zahl an Liganden war zum einen eine größere Variabilität hinsichtlich der Eigenschaften der Metallkomplexe gegeben. Andererseits mussten ebenfalls Liganden gefunden werden, welche die Kristallisation von Metallkomplexen begünstigen.

Die acetatverbrückten Komplexe $\left[\mathrm{L}^{\mathrm{n}}{ }_{-\mathrm{H}}\left(\mu-\mathrm{CH}_{3} \mathrm{COO}\right) \mathrm{Zn}_{2}\right]\left(\mathrm{ClO}_{4}\right)_{2} \mathbf{1}$ bis $\mathbf{5}$ ( $n=1,2,4,6,7)$ wurden durch die in Schema 20 dargestellte Reaktion der Liganden mit Kalium-tert-butylat, Zinkperchlorat Hexahydrat und Natriumacetat 
im Molverhältnis 1:1:2:1 in Methanol oder Aceton nach 24-stündiger Rührdauer bei Raumtemperatur erhalten.

$$
\mathrm{L}^{\mathrm{n}}+\mathrm{KO} \mathrm{Bu}+2 \mathrm{Zn}\left(\mathrm{ClO}_{4}\right)_{2} \cdot 6 \mathrm{H}_{2} \mathrm{O}+\mathrm{NaOAc} \underset{\begin{array}{c}
\text { Methanol } \\
\text { oder } \\
\text { Aceton }
\end{array}}{\stackrel{24^{\mathrm{h}} / \mathrm{RT}}{\mathrm{M}}}\left[\begin{array}{cc}
\left.\mathrm{L}^{\mathrm{n}} \cdot \mathrm{H}^{-}\left(\mu-\mathrm{CH}_{3} \mathrm{COO}\right) \mathrm{Zn}_{2}\right]\left(\mathrm{ClO}_{4}\right)_{2} \\
\mathbf{1}
\end{array}\right.
$$

Schema 20: Allgemeine Darstellung der Synthese der acetatverbrückten Komplexe.

Aus den erhaltenen Reaktionslösungen wurden nach Überschichten mit anderen Lösungsmitteln (z.B. Diethylether) farblose Kristalle isoliert, in welchen jedem Zink(II)-Ion als Koordinationspolyeder eine trigonale Bipyramide zukommt. Die Stabilität der Komplexe resultiert aus der Bildung energetisch sehr günstiger Chelat-5- oder 6-Ringe. Für 1, 2, 4 und 5 werden dabei aus jedem Zink(II)-lon drei Chelatringe mit Fünfringstruktur, für 3 zwei Chelatringe mit Fünfringstruktur und ein Chelatring mit Sechsringstruktur gebildet. Abb. 66 zeigt den schematischen Aufbau der acetatverbrückten Komplexe.

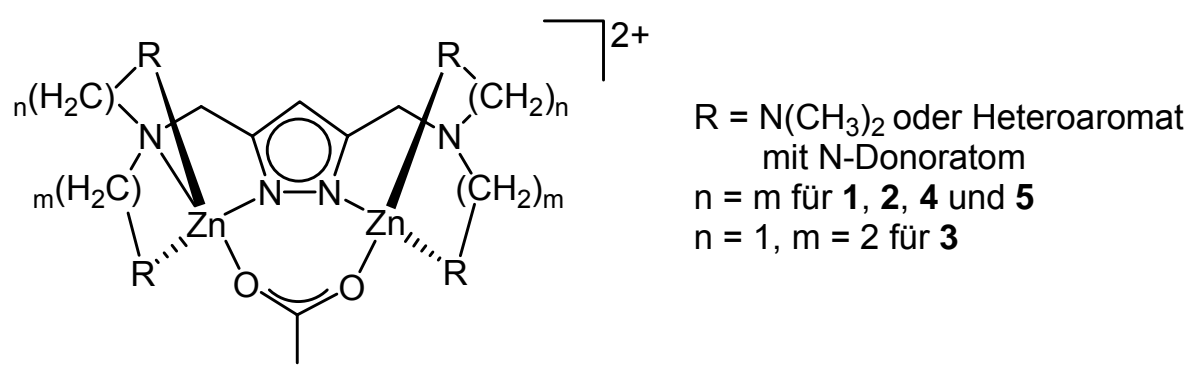

Abb. 66: Struktur der acetatverbrückten Komplexe 1 bis 5.

Der Abstand zwischen den beiden Zink(II)-lonen liegt für 1-3 und $\mathbf{5}$ in einem engen Rahmen zwischen $3.92 \AA$ und $4.01 \AA$. Lediglich in 4 stellt man mit $4.22 \AA$ einen größeren Abstand durch die erhöhte Beweglichkeit der aliphatischen Seitenarme fest.

Die ESI-Massenspektren zeigen neben dem Signal für $\left[\mathrm{L}^{\mathrm{n}}{ }_{-\mathrm{H}}\left(\mu-\mathrm{CH}_{3} \mathrm{COO}\right)\left(\mathrm{ClO}_{4}\right) \mathrm{Zn}_{2}\right]^{+}$auch eine zweifach geladene Spezies, nämlich $\left[\mathrm{L}^{\mathrm{n}}{ }_{\mathrm{H}}\left(\mu-\mathrm{CH}_{3} \mathrm{COO}\right) \mathrm{Zn}_{2}\right]^{2+}$. Die Werte für verbrückende Carboxylgruppen in den IRSpektren liegen im typischen Bereich, bei $1550-1600$ und $1440-1500 \mathrm{~cm}^{-1}$ für $v_{\text {as }}\left(\mathrm{CH}_{3} \mathrm{COO}^{-}\right)$und $v_{\mathrm{s}}\left(\mathrm{CH}_{3} \mathrm{COO}^{-}\right)$. 
Die Zwischenstufen $\left[\mathrm{L}^{\mathrm{n}}{ }_{\mathrm{H}}(\mathrm{MeOH})(\mathrm{OH}) \mathrm{Zn}_{2}\right]\left(\mathrm{ClO}_{4}\right)_{2}(\mathrm{n}=1,3,4,6,7)(\mathrm{XLI}$ bis XLV) auf dem Weg zur Bildung der acetatverbrückten Komplexe $\left[\mathrm{L}^{\mathrm{n}}{ }_{\mathrm{H}}\left(\mu-\mathrm{CH}_{3} \mathrm{COO}\right) \mathrm{Zn}_{2}\right]\left(\mathrm{ClO}_{4}\right)_{2}$ 1-5 sind als Modellsubstrate bei der Spaltung aktiver Ester von Interesse. Alle diese Komplexe wurden durch Umsetzung von $\mathrm{L}^{\mathrm{n}}$, Kalium-tert-butylat und Zinkperchlorat Hexahydrat in Methanol dargestellt. Die erfolgte Komplexbildung wurde durch ESI-MS nachgewiesen.

Als Substrat zur Modellierung der hydrolytischen Aktivität wurde $p$-Nitrophenylacetat gewählt, welches durch den Einfluss der Komplexe $\left[\mathrm{L}^{\mathrm{n}}{ }_{\mathrm{H}}(\mathrm{MeOH})(\mathrm{OH}) \mathrm{Zn}_{2}\right]\left(\mathrm{ClO}_{4}\right)_{2}(\mathrm{n}=1,3,4,6,7)$ (XLI bis XLV) unter Bildung von Acetat und $p$-Nitrophenolat gespalten wird. Die Reaktion läuft nach Schema 21 ab und wird durch eine starke Absorption des p-Nitrophenols bei $405 \mathrm{~nm}$ nachgewiesen.

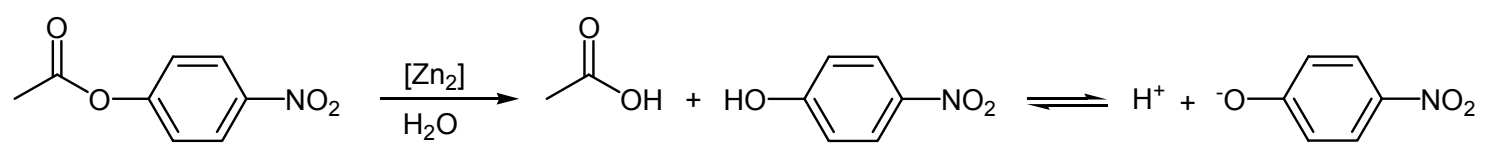

Schema 21: Hydrolyse von p-Nitrophenylacetat.

Das freigesetzte Acetation kann dann in XLI-XLV eine Acetatbrücke unter Bildung von 1-5 ergeben. Die Reaktionen laufen nach Schema 22 ab.

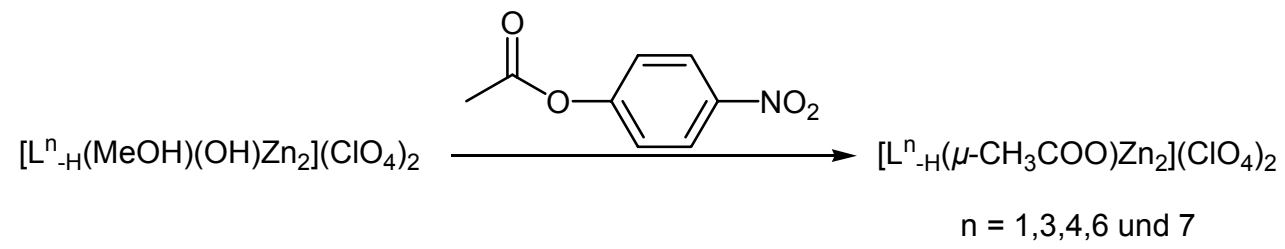

Schema 22: Bildung acetatverbrückter Komplexe.

$\mathrm{Zu}$ den Lösungen der Komplexe $\left[\mathrm{L}^{\mathrm{n}}{ }_{-\mathrm{H}}(\mathrm{MeOH})(\mathrm{OH}) \mathrm{Zn}_{2}\right]\left(\mathrm{ClO}_{4}\right)_{2}$ wurden fünf Äquivalente $p$-Nitrophenylacetat (in methanolischer Lösung) zugesetzt. Mittels ESI-MS aus den Reaktionslösungen wurde die Acetatverbrückung durch das Signal der Spezies $\left[\mathrm{L}^{\mathrm{n}}{ }_{-\mathrm{H}}\left(\mu-\mathrm{CH}_{3} \mathrm{COO}\right)\left(\mathrm{ClO}_{4}\right) \mathrm{Zn}_{2}\right]^{+}$nachgewiesen, das auch in den isolierten Komplexen 1-5 zu finden ist. 
Die hydrolytische Aktivität der Komplexe $\left[\mathrm{L}^{6}{ }_{\mathrm{H}}(\mathrm{MeOH})(\mathrm{OH}) \mathrm{Zn}_{2}\right]\left(\mathrm{ClO}_{4}\right)_{2} \mathbf{X L I}$ und $\left[\mathrm{L}^{7}{ }_{-\mathrm{H}}(\mathrm{MeOH})(\mathrm{OH}) \mathrm{Zn}_{2}\right]\left(\mathrm{ClO}_{4}\right)_{2}$ XLII wurde bei $\mathrm{pH}=7.4$ auch kinetisch untersucht. Die kinetischen Daten zeigen eine lineare Abhängigkeit der Hydrolyse von $p$-Nitrophenylacetat von den Komplexkonzentrationen. Es handelt sich in beiden Fällen um eine Reaktion 1. Ordnung. Die Geschwindigkeitskonstanten zeigen mit den Werten von $1.26 \mathrm{~h}^{-1}$ (für XLI) und $1.06 \mathrm{~h}^{-1}$ (für XLII), dass die Hydrolyse sehr langsam abläuft. Die geringe Aktivität lässt sich durch eine mögliche Blockadewirkung als Folge des Einbaus des Acetations in den Komplex erklären.

Für XLII wurden auch Aktivitätsmessungen in wasserhaltigen Lösungen mit einem anderen Substrat (Glycin-p-nitroanilid) durchgeführt. Eine Aktivität, die die Hydrolyse der Amidbindung induziert hatte, konnte dabei nicht festgestellt werden.

L-Glycin-p-nitroanilid wurde auch in einem zweiten Fall eingesetzt, bei dem das Ziel ebenfalls die Spaltung der Amidbindung war. Die Reaktion des deprotonierten Liganden $L^{6}$ mit Zinkperchlorat Hexahydrat in DMF führte nicht zur Amidspaltung des Substrats, sondern zur Spaltung der Amidbindung des eingesetzten Lösungsmittels unter Bildung des formiatverbrückten Komplexes 6 (Abb. 67).

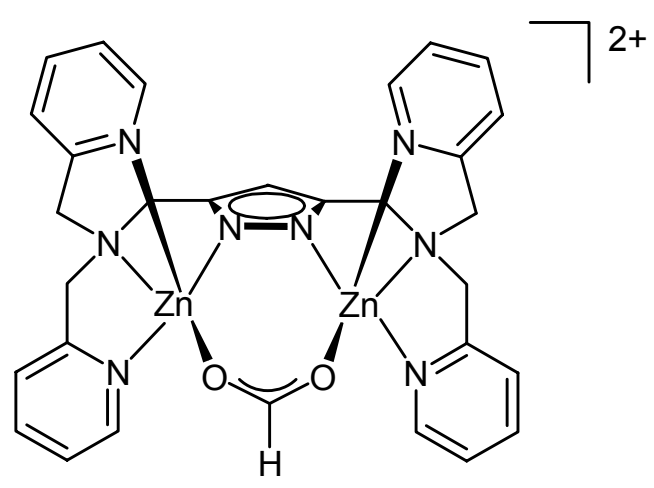

Abb. 67: Strukturformel des Kations von 6.

Der Abstand zwischen den beiden Zink(II)-lonen entspricht mit ca. $4.05 \AA$ jenem für acetatverbrückte Komplexe.

Durch die spontane Reaktion der Komplexe $\left[\mathrm{L}^{6}{ }_{-\mathrm{H}}(\mathrm{MeOH})(\mathrm{OH}) \mathrm{Zn}_{2}\right]\left(\mathrm{ClO}_{4}\right)_{2}$ und $\left[\mathrm{L}^{1}{ }_{-\mathrm{H}}(\mathrm{MeOH})(\mathrm{OH}) \mathrm{Zn}_{2}\right]\left(\mathrm{BPh}_{4}\right)_{2}$ mit $\mathrm{CO}_{2}$ aus der Luft wurden Kristalle der 
vierkernigen Zinkkomplexe mit Carbonatverbrückung, $\left[\left(\mathrm{L}^{6}{ }_{-\mathrm{H}}\right)_{2}\left(\mu_{3}-\mathrm{CO}_{3}\right)\left(\mathrm{H}_{2} \mathrm{O}\right) \mathrm{Zn}_{4}\right]\left(\mathrm{ClO}_{4}\right)_{4} \quad$ (8) und $\left[\left(\mathrm{L}^{1}{ }_{-\mathrm{H}}\right)_{2}\left(\mu_{4}-\mathrm{CO}_{3}\right) \mathrm{Zn}_{4}\right]\left(\mathrm{BPh}_{4}\right)_{4} \quad$ (13) erhalten.

Die Umsetzung des deprotonierten Liganden $\mathrm{L}^{1}$ in Methanol mit Zinkperchlorat Hexahydrat und anschließender Überschichtung der Reaktionslösung mit Diethylether führte zum Dizinkkomplex $\left[\left(\mathrm{L}^{1}{ }_{-\mathrm{H}}\right)_{2} \mathrm{Zn}_{2}\right]\left(\mathrm{CF}_{3} \mathrm{SO}_{3}\right)_{2}$ (7). In 7 sind beide Zink(II)-Ionen trigonal bipyramidal koordiniert und haben einen Abstand von 3.70 A zueinander.

Eine Reaktion, die ebenfalls zu carboxylatverbrückten Komplexen führt, ist die Umsetzung von $\left[\mathrm{L}^{6}{ }_{-} \mathrm{H}(\mathrm{MeOH})(\mathrm{OH}) \mathrm{Zn}_{2}\right]\left(\mathrm{ClO}_{4}\right)_{2}$ mit einem Überschuss von $\gamma$-Butyrolacton bei $100{ }^{\circ} \mathrm{C}(7 \mathrm{~h})$. Die Reaktion verläuft unter Spaltung des Lactonings nach Abb. 68.

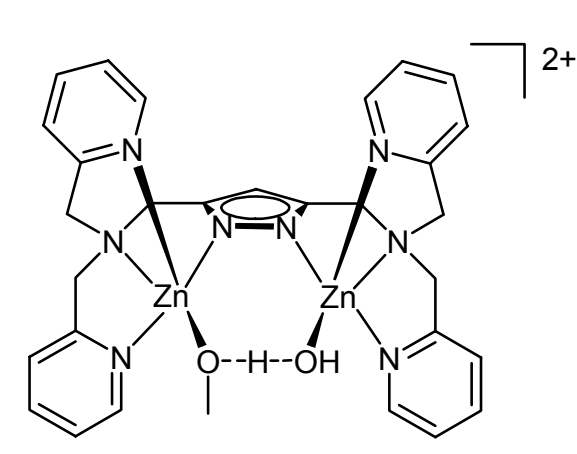

XLI

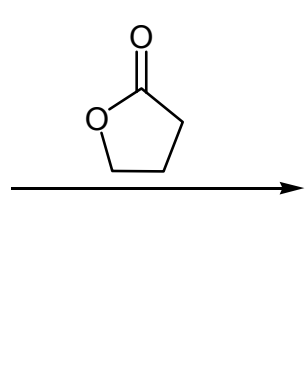

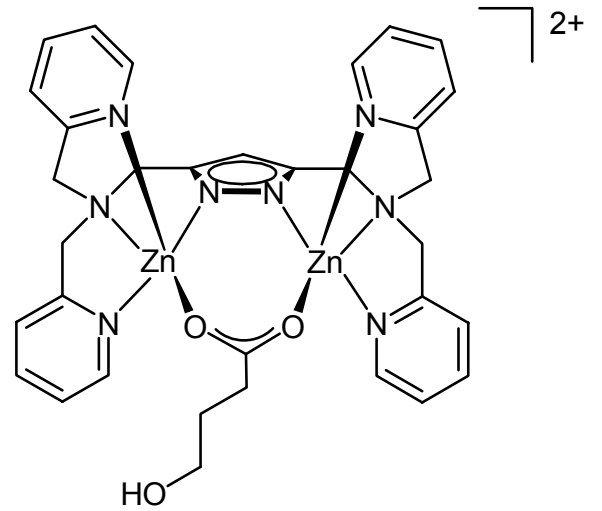

10

Abb. 68: Untersuchte Ringöffnung von $\gamma$-Butyrolacton.

Der Abstand zwischen den beiden Metallkernen liegt mit $3.98 \AA$ im gleichen Bereich wie für andere durch Carboxylationen verbrückte Komplexe. Beide Zink(II)-Ionen sind ebenfalls trigonal bipyramidal koordiniert. Durch die Carboxylatverbrückung rücken, verglichen mit XLI, die beiden Zink(II)-lonen etwa um $0.2 \AA$ zusammen.

Durch ${ }^{1} \mathrm{H}-\mathrm{NMR}$-Messungen konnte nachgewiesen werden, dass die Reaktion bereits bei $30^{\circ} \mathrm{C}$ abläuft. Um den Reaktionsablauf ${ }^{1} \mathrm{H}-\mathrm{NMR}$-spektroskopisch zu verfolgen, wurden von einer äquimolaren Mischung aus XLI und $\gamma$-Butyrolacton in DMSO- $\mathrm{d}_{6}{ }^{1} \mathrm{H}$-NMR-Messungen durchgeführt. Die $\mathrm{H}_{\mathrm{A}}$-Signale der Pyridinreste 
verschieben sich dabei von $8.8 \mathrm{ppm}$ in XLI nach $8.6 \mathrm{ppm}$ in $\mathbf{1 0}$, das $4-\mathrm{H}$ des Pyrazolrings verschiebt sich von $6.05 \mathrm{ppm}$ für XLI zu tieferem Feld nach 6.13 ppm für 10. Die ${ }^{1} \mathrm{H}-\mathrm{NMR}$-Daten belegen, dass die Reaktion spätestens nach 30 Minuten beendet ist.

Da die ${ }^{1} \mathrm{H}-\mathrm{NMR}$-Untersuchung zeigt, dass die Ringöffnung des Lactons bereits bei Raumtemperatur abläuft, kann der Dizinkkomplex XLI nicht nur als Modell für eine $\beta$-Lactamase, ${ }^{[103]}$ sondern auch als Modell für eine Lactonase angesehen werden.

Im Unterschied zu BTK-AiiA wirken Analoga der AHL-Lactonase auf etwas andere Art. Hier wird die Carboxylgruppe durch Wechselwirkung mit beiden Zinkkernen polarisiert und das Carboxyl-C-Atom vom Brückenligand des Dizinkkomplexes nucleophil angegriffen. Durch Einwirkung von Wasser auf das Zwischenprodukt im postulierten Mechanismus der BTK-AiiA wird auch hier der Lactonring zerstört. In diesem Zusammenhang wird angegeben, dass die Amidbindung wichtig für die korrekte Erkennung durch die AHL-Lactonase ist. Dies mag daran liegen, dass in diesem Fall durch den Angriff von Wasser auf das Zwischenprodukt ein Amid freigesetzt wird, welches den aufgespaltenen Lactonring am Stickstoff enthält. ${ }^{[2]}$

Zum Vergleich zwischen Zink(II)-lonen und Nickel(II)-lonen wurde der acetatverbrückte Komplex $\left[\mathrm{L}^{4}{ }_{-}\left(\mu-\mathrm{CH}_{3} \mathrm{COO}\right) \mathrm{Ni}_{2}\right]\left(\mathrm{ClO}_{4}\right)_{2}(12)$ auf analoge Weise dargestellt. Der Abstand zwischen beiden Nickel(II)-Ionen ist mit $4.09 \AA$ geringfügig größer als im Zinkkomplex 2, der bei $4.00 \AA$ liegt. Der wesentliche Unterschied zwischen den beiden Strukturen 2 und $\mathbf{1 2}$ besteht darin, dass in $\mathbf{1 2}$ eines der beiden Nickel(II)-lonen tetragonal pyramidal koordiniert ist, während das andere bezüglich seiner Koordination im Grenzbereich zwischen tetragonal pyramidaler und trigonal bipyramidaler Symmetrie liegt.

Ein weiterer Nickel(II)-Komplex wurde erhalten durch Reaktion des deprotonierten Liganden $\mathrm{L}^{2}$ mit Nickelperchlorat Hexahydrat in Methanol. Der erhaltene Komplex wurde über eine lonenaustauschersäule mit wässriger $\mathrm{NaNO}_{3}$-Lösung gereinigt und dabei der Komplex $\left[\mathrm{L}^{2}{ }_{-\mathrm{H}}\left(\mathrm{NO}_{3}\right)_{2} \mathrm{Ni}_{2}\right]\left(\mathrm{NO}_{3}\right)$ (11) isoliert. Durch das Fehlen der Zweitbrücke ist der Abstand zwischen den beiden Nickel(II)-lonen mit $4.61 \AA$ A ungewöhnlich groß.

Die Reaktion des deprotonierten Liganden $\mathrm{L}^{4}$ mit Kupferperchlorat unter gleichen Bedingungen wie bei der Darstellung von 11 ergibt den völlig 
unerwarteten Nitratkomplex des Kupfer(II)-lons mit N,N-Bis(1,2-dimethylimidazol-2-yl)- $\mathrm{N}^{\prime}, \mathrm{N}^{\prime}$-diethylethylendiamin $\left[(\mathrm{Dmelm})_{2} \operatorname{DetEtA}\left(\mathrm{NO}_{3}\right) \mathrm{Cu}\right]\left(\mathrm{NO}_{3}\right)$ (13), in welchem das Kupfer(II)-Ion oktaedrische Koordination einnimmt.

Die Pyrazolato-dizinkkomplexe (XLII-XLV) wurden erstmals dargestellt, aber nur durch ESI-Massenspektroskopie charakterisiert. Die Lösungen dieser Komplexe wurden direkt für spektroskopische Untersuchungen eingesetzt. 


\section{Experimenteller Teil}

\subsection{Allgemeines}

\section{Warnung}

Perchloratsalze von Übergangsmetallen sind potentiell explosiv. Obwohl während dieser Arbeit keine Probleme auftraten, sollten diese Verbindungen nur in kleinen Ansätzen dargestellt und mit entsprechender Vorsicht gehandhabt werden.

\section{Apparaturen}

Es wurden konventionelle Glasapparaturen oder Schlenkkolben verwendet. Sofern nötig, wurden die Apparaturen unter Verwendung eines Heißluftföns ausgeheizt, mehrmals im Ölpumpenvakuum evakuiert und mit Stickstoff (Trocknung durch Sicapent der Firma Merck) gespült.

\section{Lösungsmittel}

Alle Reaktionen wurden, sofern notwendig, in frisch absolutierten, desoxygenierten und destillierten Lösungsmitteln durchgeführt. Folgende Trocknungsmittel fanden Verwendung:

Aceton:

Calciumchlorid

Acetonitril:

Phosphorpentoxid und Calciumhydrid

DMF:

Benzol und Calciumhydrid

DMSO:

Calciumhydrid

Methanol:

Magnesiumspäne

Ethanol:

Calciumoxid und Magnesiumspäne

Petrolether 40/60:

Calciumhydrid 
Tetrahydrofuran: Kaliumhydroxid und Natrium/Kalium Legierung

Diethylether:

Kaliumhydroxid und Natrium/Kalium Legierung

Für die kinetischen Messungen mittels UV/Vis-Spektroskopie wurde Acetonitril $(99,5 \%)$ von der Firma Grüssing und destilliertes Wasser des Mikroanalytischen Labors des Instituts für Anorganische Chemie der Universität Göttingen verwendet.

Die Vorstufen zu den Liganden wurden destillativ je nach Menge der Substanz und deren Siedepunkt durch Destillation über eine Mikrodestille mit Vigreux-Kolonne oder durch Destillation aus einem rotierenden Dreikugelrohr (heizbares Luftbad) gereinigt. Die Liganden selbst wurden von Lösungsmittelresten im Dreikugelrohr bei $60{ }^{\circ} \mathrm{C} / 10^{-5} \mathrm{mbar}$ befreit.

$\mathrm{Na}_{2} \mathrm{CO}_{3}$ für die Ligandsynthese wurde in einer Hochvakuumanlage unter Stickstoffatmosphäre getrocknet.

\section{Schmelzpunkte}

Die Reinheit von Edukten, die als Feststoff vorlagen, wurde auch durch Messung des Schmelzpunktes überprüft. Dafür wurde ein Büchi Melting point B-540 Gerät verwendet, bei dem der Schmelzvorgang in einer Kapillare in einem beheizbaren Silikonbad beobachtet wurde.

\section{NMR-Spektroskopie}

Die NMR-Spektren wurden mit Geräten des Typs Bruker Avance $500\left({ }^{1} \mathrm{H}\right.$ : $\left.500.13 \mathrm{MHz},{ }^{13} \mathrm{C}: 125.77 \mathrm{MHz}\right), 300\left({ }^{1} \mathrm{H}: 300.13 \mathrm{MHz},{ }^{13} \mathrm{C}: 75.47 \mathrm{MHz}\right)$ und 200 $\left({ }^{1} \mathrm{H}: 200.13 \mathrm{MHz},{ }^{13} \mathrm{C}: 50.32 \mathrm{MHz}\right)$ aufgenommen. Die angegebenen Werte der Verschiebung $\delta$ beziehen sich auf den internen Standard durch die Lösungsmittel $\mathrm{CDCl}_{3}\left(\delta=7.24\right.$ für ${ }^{1} \mathrm{H}-\mathrm{NMR}$ bzw. $\delta=77.0$ für $\left.{ }^{13} \mathrm{C}-\mathrm{NMR}\right), \mathrm{d}_{6}$ Dimethylsulfoxid ( $\delta=2.49$ für ${ }^{1} \mathrm{H}-\mathrm{NMR}$ bzw. $\delta=39.5$ für ${ }^{13} \mathrm{C}-\mathrm{NMR}$ ) und $\mathrm{d}_{3^{-}}$ Acetonitril ( $\delta=1.94$ für ${ }^{1} \mathrm{H}-\mathrm{NMR}$ bzw. $\delta=1.32$ und 118.26 für ${ }^{13} \mathrm{C}-\mathrm{NMR}$ ) relativ zu externem Tetramethylsilan $(\delta=0)$. Die ${ }^{13} \mathrm{C}$ - Spektren wurden ${ }^{1} \mathrm{H}$-entkoppelt 
aufgenommen. Wenn nicht anders angegeben, wurden die Spektren bei $300 \mathrm{~K}$ gemessen.

Abkürzungen: $s=$ Singulett, $b s=$ breites Singulett, $d=$ Dublett, $t=$ Triplett, $q=$ Quartett, $m=$ Multiplett.

Zur Zuordnung der Signale wurden - soweit nötig - zusätzlich DEPT, H-HCOSY und $\mathrm{H}-\mathrm{C}-\mathrm{COSY}$ Experimente durchgeführt.

Die Atome in Verbindungen, die in ihrem Aufbau Pyridinreste enthalten, wurden wie folgt bezeichnet:<smiles>[R]c1nc(C)c(C)c(C)c1C</smiles>

\section{Massenspektrometrie}

Die Massenspektren wurden auf den Geräten Finnigan MAT 8200 für ElSpektren $(70 \mathrm{eV})$ und Finnigan MAT LCQ für ESI-Spektren (Lösungsmittel Methanol, wenn nicht anders angegeben) aufgenommen. Die Zuordnung der Signale in den Massenspektren wurde für besonders wichtige Peaks durch Isotopensimulation überprüft.

\section{Elementaranalytik}

Die CHN-Elementaranalysen erfolgten durch das Mikroanalytische Labor des Instituts für Anorganische Chemie der Universität Göttingen mit einem CHN-ORapid der Firma Elementar. 


\section{Infrarotspektroskopie}

Die Infrarotspektren wurden auf einem Digilab Excalibur Spektrometer aufgenommen. Feststoffe wurden als $\mathrm{KBr}$-Pressling gemessen. Die Lage der Banden ist in Wellenzahlen angegeben $\left(\tilde{v}\right.$ in $\left.\mathrm{cm}^{-1}\right)$. Die Intensitäten sind wie folgt abgekürzt:

$\mathrm{w}=$ schwach, $\mathrm{m}=$ mittel, $\mathrm{s}=$ stark, $\mathrm{vs}=$ sehr stark

\section{Reagentien}

Die ständig im Labor benötigten Chemikalien waren bei der Chemikalienausgabe des Anorganisch-chemischen Institutes der Universität Göttingen erhältlich. Folgende Reagentien wurden über die angegebenen Firmen bezogen:

BIS-TRIS

$n$-Buthyllithium

HEPES

Kalium-tert-butylat

Kaliumcarbonat

Lithiumhydroxid Monohydrat

N-Methylimidazol

Methanol

Natriumcarbonat

Natriumcyanoborhydrid

Natriumborhydrid

$\mathrm{Pd} / \mathrm{C}$

Pyridin-2-aldehyd

Zinkperchlorat Hexahydrat

Zinknitrat Hexahydrat

Zinkacetat

Zinksulfat Heptahydrat

Zinktrifluormethansulfonat

Zinkhexafluorophosphat
Aldrich

Fluka

Sigma

Aldrich

Merck

Fluka

Aldrich

CHROMASOLV

Merck

Aldrich

Aldrich

Aldrich

Aldrich

Aldrich

Aldrich

Aldrich

Maey

Fluka

Sigma 
Literaturhinweise zu den Ligandvorstufen sind in Kap. 3.2.1. und in Kap. 3.2.2. angegeben. Die Synthesen für die Liganden $L^{6}$ bis $L^{12}$ sind in der Literatur beschrieben. ${ }^{[51,61,63,77]} L^{1}$ bis $L^{5}$ wurden erstmals hergestellt. Ihre Darstellung ist in der Folge beschrieben.

Für spektroskopische Untersuchungen wurden die Komplexe $\left[\mathrm{L}^{\mathrm{n}}{ }_{-\mathrm{H}}(\mathrm{MeOH})(\mathrm{OH}) \mathrm{Zn}_{2}\right]\left(\mathrm{ClO}_{4}\right)_{2}{ }^{[65]}(\mathbf{X L I}-\mathbf{X L V})$ benutzt. Die Verbindungen (XLIIIXLV) wurden in dieser Arbeit erstmals dargestellt. Diese Darstellung erfolgte aus $L^{n}(n=1,3$ und 4), Kalium-tert-butylat und Zinkperchlorat Hexahydrat in Methanol. 


\subsection{Synthese von Ligandvorstufen}

\subsubsection{Synthese von Bis[2-(1-Methylimidazolyl)methyl]amin}

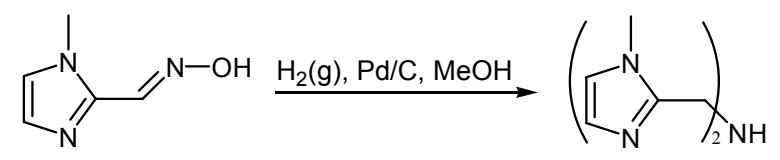

Zu $20 \mathrm{~g} \mathrm{Pd} / \mathrm{C}(10 \% \mathrm{Pd})$ und $41.9 \mathrm{~g}$ (0.34 mol) Methyl-2-imidazolcarboxaldoxim wurde $600 \mathrm{ml}$ trockenes Methanol gegeben und bei Atmosphärendruck und $65^{\circ} \mathrm{C} 3$ Tage hydriert. Dann wurde der Katalysator unter Stickstoffatmosphäre abfiltriert und das Lösungsmittel abgedampft. Es blieb ein leicht gelbes Öl zurück, welches bei Trocknung bei $10^{-3}$ mbar spontan kristallisiert.

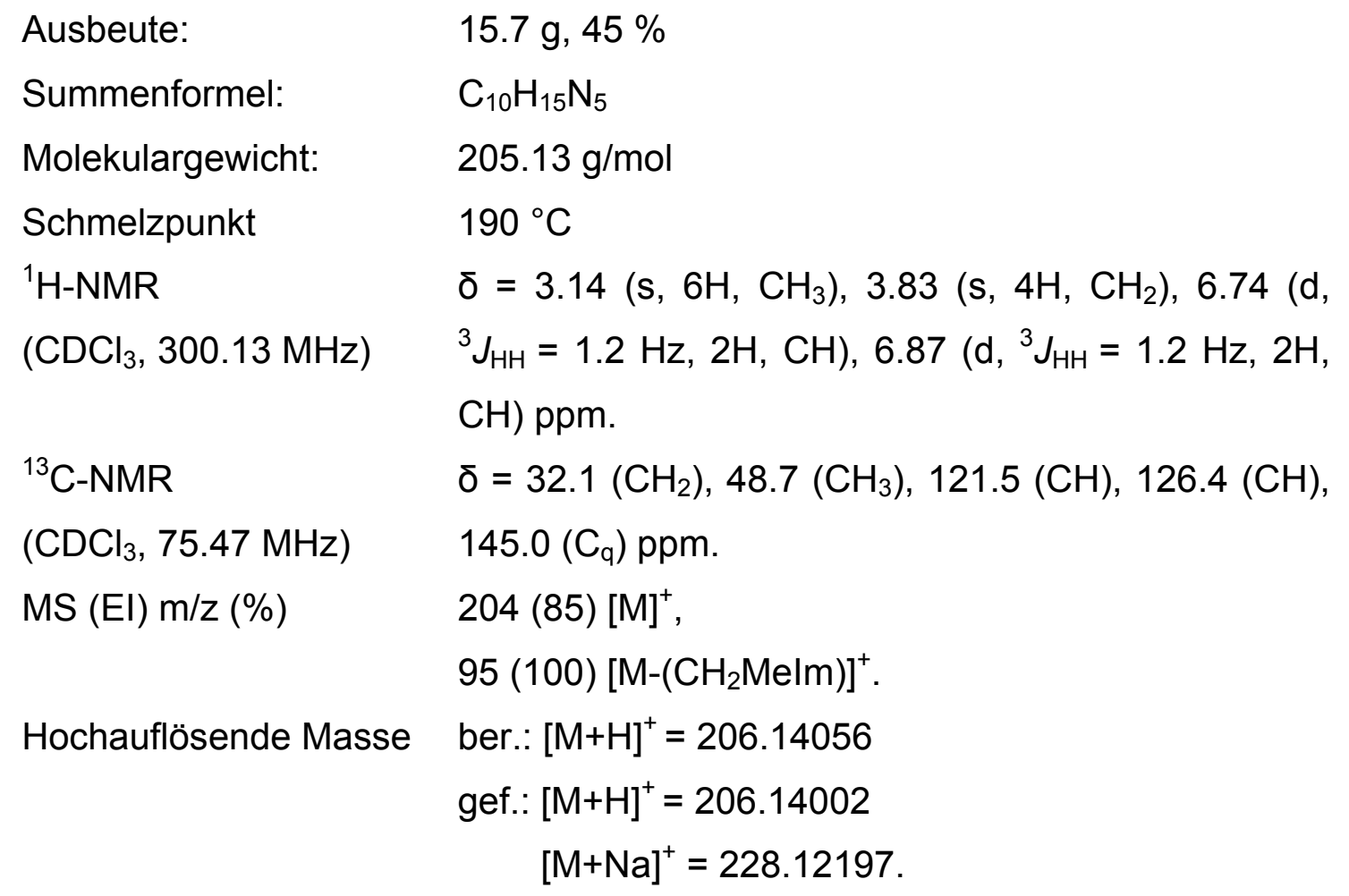

Elementaranalyse (\%) ber.: C 58.51, H 7.35, N 34.12

gef.: C 58.26, H 7.43, N 33.07 . 


\subsubsection{Synthese von (1-Methyl-imidazol-2-ylmethyl)(2-pyridin-2-ylethyl)amin}

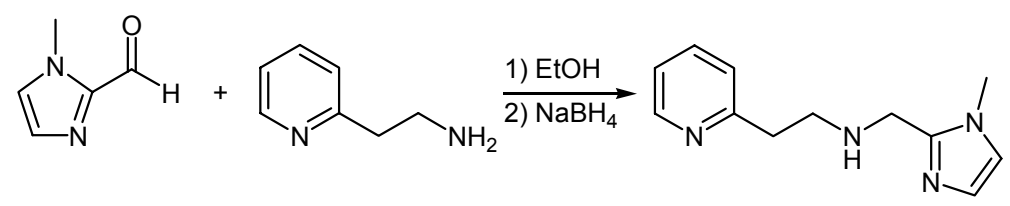

Methode A: $28.65 \mathrm{~g}(0.23 \mathrm{~mol})$ 2-(Pyridin-2-yl)ethylamin wurden in $300 \mathrm{ml}$ Ethanol gelöst und zu einer Lösung aus $25.25 \mathrm{~g}$ (0.23 mol) 1-Methyl-2imidazolcarboxaldehyd in $200 \mathrm{ml}$ Ethanol tropfenweise gegeben. Die Lösung wurde 20 Stunden gerührt und dann $18.20 \mathrm{~g}$ (0.48 mol, 2.04 Äq) $\mathrm{NaBH}_{4}$ portionsweise zugegeben. Dann wurde die Lösung 72 Stunden auf $70{ }^{\circ} \mathrm{C}$ erhitzt, und nach Abkühlung auf Raumtemperatur mit $12 \mathrm{M} \mathrm{HCl}$ bis $\mathrm{pH}=2$ angesäuert. Die dabei entstehende Suspension wurde abfiltriert, das Filtrat vom Lösungsmittel befreit, und mit $30 \mathrm{ml} 16.5 \mathrm{M} \mathrm{NaOH}$ versetzt. Die wässrige Lösung wurde mit $\mathrm{CHCl}_{3}$ extrahiert. Die organische Phase wurde über $\mathrm{MgSO}_{4}$ getrocknet und nach dem Entfernen des Lösungsmittels blieb ein dunkelbraunes Öl, das durch eine Kugelrohrdestillation $\left(10^{-5} \mathrm{mbar}\right.$ und $\left.70{ }^{\circ} \mathrm{C}\right)$ ein gelbes Öl ergibt.

Methode B: $\mathrm{NaBH}_{3} \mathrm{CN}$ wurde an Stelle von $\mathrm{NaBH}_{4}$ unter denselben Bedingungen eingesetzt. In diesem Fall wurde die Ausbeute geringfügig besser (62\%).

Ausbeute:

$28.25 \mathrm{~g}, 56.8 \%$

Summenformel:

$\mathrm{C}_{12} \mathrm{H}_{16} \mathrm{~N}_{4}$

Molekulargewicht:

$216.14 \mathrm{~g} / \mathrm{mol}$

${ }^{1} \mathrm{H}-\mathrm{NMR}$

$\delta=2.50(\mathrm{bs}, 1 \mathrm{H}, \mathrm{NH}) 2.92\left(\mathrm{t},{ }^{3} \mathrm{JHH}_{\mathrm{HH}}=6.8 \mathrm{~Hz}, 2 \mathrm{H}\right.$,

$\left(\mathrm{CDCl}_{3}, 500.13 \mathrm{MHz}\right)$

$\left.\mathrm{CH}_{2}\right), 3.00\left(\mathrm{td},{ }^{3} \mathrm{~J}_{\mathrm{HH}}=6.8 \mathrm{~Hz},{ }^{3} \mathrm{~J}_{\mathrm{HH}}=1.1 \mathrm{~Hz}, 2 \mathrm{H}\right.$,

$\mathrm{PyCH}_{2}$ ), 3.55 (s, $3 \mathrm{H}, \mathrm{CH}_{3}$ ), 3.81 (s, $\left.2 \mathrm{H}, \mathrm{CH}_{2}\right), 6.60$

$\left(\mathrm{d},{ }^{3} \mathrm{JHH}_{\mathrm{HH}}=1.2 \mathrm{~Hz}, 1 \mathrm{H}, \mathrm{CH}^{\mathrm{Melm}}\right), 6.70\left(\mathrm{~d},{ }^{3} \mathrm{~J}_{\mathrm{HH}}=1.2 \mathrm{~Hz}\right.$,

$\left.1 \mathrm{H}, \mathrm{CH}^{\mathrm{Melm}}\right), 7.04\left(\mathrm{qd}, 1 \mathrm{H},{ }^{3} \mathrm{JHH}_{\mathrm{HH}}=4.9 \mathrm{~Hz},{ }^{3} \mathrm{JHH}_{\mathrm{HH}}=7.5\right.$

$\left.\mathrm{Hz},{ }^{4} \mathrm{~J}_{\mathrm{HH}}=1.1 \mathrm{~Hz}, \mathrm{CH}_{\mathrm{B}}{ }^{\mathrm{Py}}\right), 7.09\left(\mathrm{dt}, 1 \mathrm{H},{ }^{3} \mathrm{~J}_{\mathrm{HH}}=7.7\right.$

$\left.\mathrm{Hz},{ }^{4} \mathrm{JHH}_{\mathrm{HH}}=1.0 \mathrm{~Hz}, \mathrm{CH}_{\mathrm{D}}{ }^{\mathrm{Py}}\right), 7.51\left(\mathrm{td},{ }^{3} \mathrm{~J}_{\mathrm{HH}}=7.7 \mathrm{~Hz}\right.$, 
${ }^{13} \mathrm{C}-\mathrm{NMR}$

$\left(\mathrm{CDCl}_{3}, 125.75 \mathrm{MHz}\right)$

MS (El) $\mathrm{m} / \mathrm{z}(\%)$

Hochauflösende Masse

Elementaranalyse (\%) $\left.{ }^{4} J_{\mathrm{HH}}=1.8 \mathrm{~Hz}, 1 \mathrm{H}, \mathrm{CH}_{\mathrm{C}}{ }^{\mathrm{Py}}\right), 8.44\left(\mathrm{dq},{ }^{3} \mathrm{~J}_{\mathrm{HH}}=4.9 \mathrm{~Hz}\right.$,

$\left.{ }^{4} J_{\mathrm{HH}}=1.8 \mathrm{~Hz}, 1 \mathrm{H}, \mathrm{CH}_{\mathrm{A}}{ }^{\mathrm{Py}}\right) \mathrm{ppm}$.

$\delta=32.6\left(\mathrm{CH}_{3}\right), 38.1\left(\mathrm{CH}_{2}\right), 45.5\left(\mathrm{CH}_{2}{ }^{\mathrm{Melm}}\right), 48.8$

$\left(\mathrm{CH}_{2}\right), 121.1\left(\mathrm{CH}^{\mathrm{Melm}}\right), 121.1\left(\mathrm{CH}_{\mathrm{B}}^{\mathrm{Py}}\right), 123.1\left(\mathrm{CH}_{\mathrm{D}}{ }^{\mathrm{Py}}\right)$,

$126.9\left(\mathrm{CH}^{\text {Melm }}\right), 136.2\left(\mathrm{CH}_{\mathrm{C}}{ }^{\mathrm{Py}}\right), 146.3\left(\mathrm{C}_{\mathrm{q}}^{\mathrm{Melm}}\right), 149.1$

$\left(\mathrm{CH}_{\mathrm{A}}^{\mathrm{Py}}\right), 160.1\left(\mathrm{C}_{\mathrm{q}}^{\mathrm{Py}}\right) \mathrm{ppm}$.

216 (16) [M] $]^{+}$,

$95(100)\left[\mathrm{M}-\left(\mathrm{PyCH}_{2} \mathrm{CH}_{2}\right)\right]^{+}$.

ber.: $[\mathrm{M}+\mathrm{H}]^{+}=217.14531$

gef.: $[\mathrm{M}+\mathrm{H}]^{+}=217.14477$.

ber.: C 66.63, H 7.46, N 25.90

gef.: C 66.08, H 7.36, N 25.55.

\subsubsection{Synthese von N,N-Diethyl-N' -(Pyridin-2-ylmethyl)ethylendiamin}

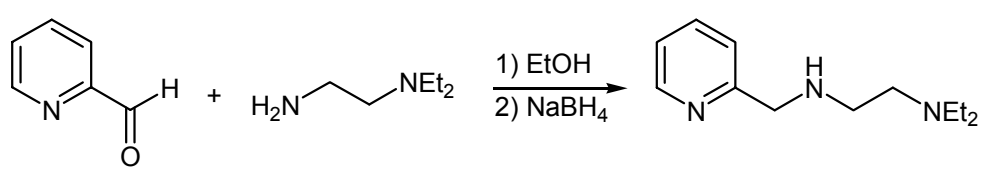

$13.30 \mathrm{~g}(0.11 \mathrm{~mol}, 1.02 \mathrm{Äq}) \mathrm{N}, \mathrm{N}$-Diethylethylendiamin, gelöst in $250 \mathrm{ml}$ trockenem Ethanol, wurden tropfenweise zu einer Lösung aus $12.04 \mathrm{~g}$ (0.11 mol) Pyridin-2-carboxaldehyd, gelöst in $100 \mathrm{ml}$ trockenem Ethanol, und $5 \mathrm{ml}$ Essigsäure zugegeben. Nach der vollständigen Zugabe wurde die Lösung für 2 Stunden zum Sieden erhitzt. Nach Abkühlung wurden portionsweise $8.51 \mathrm{~g}$ (0.22 mol, 1.96 Äq) $\mathrm{NaBH}_{4}$ zugegeben, die Lösung 3 Stunden weiter zum Rückfluss erhitzt und danach mit $50 \mathrm{ml} 12 \mathrm{M} \mathrm{HCl}$ versetzt. Die dabei entstehende Suspension wurde abfiltriert, vom Filtrat das Lösungsmittel entfernt und in $50 \mathrm{ml} 16.5 \mathrm{M} \mathrm{NaOH}$ gelöst. Die wässrige Phase wurde mit $\mathrm{CHCl}_{3}$ extrahiert. Die organische Phase wurde über $\mathrm{MgSO}_{4}$ getrocknet, abfiltriert und vom Lösungsmittel befreit. Aus dem verbliebenen braunen Öl wurde durch eine Kugelrohrdestillation ein leicht gelbes Öl bei $90{ }^{\circ} \mathrm{C}$ und $4.7 \cdot 10^{-3} \mathrm{mbar}$ abdestilliert. 
Ausbeute:

Summenformel:

Molekulargewicht:

${ }^{1} \mathrm{H}-\mathrm{NMR}$

$\left(\mathrm{CDCl}_{3}, 500 \mathrm{MHz}\right)$

${ }^{13} \mathrm{C}-\mathrm{NMR}$

$\left(\mathrm{CDCl}_{3}, 125.77 \mathrm{MHz}\right)$

MS (EI) $\mathrm{m} / \mathrm{z}(\%)$

Hochauflösende Masse

Elementaranalyse (\%)
$19.07 \mathrm{~g}, 80.7 \%$

$\mathrm{C}_{12} \mathrm{H}_{21} \mathrm{~N}_{3}$

$207.17 \mathrm{~g} / \mathrm{mol}$

$\delta=0.78\left(\mathrm{t},{ }^{3} \mathrm{~J}_{\mathrm{HH}}=7.2 \mathrm{~Hz}, 6 \mathrm{H}, \mathrm{CH}_{3}\right), 2.28(\mathrm{q}$,

$\left.{ }^{3} \mathrm{~J}_{\mathrm{HH}}=7.2 \mathrm{~Hz}, 4 \mathrm{H}, \mathrm{CH}_{2}\right), 2.37\left(\mathrm{t},{ }^{3} \mathrm{~J}_{\mathrm{HH}}=6.3 \mathrm{~Hz}, 2 \mathrm{H}\right.$, $\left.\mathrm{CH}_{2}\right), 2.49\left(\mathrm{t},{ }^{3} \mathrm{~J}_{\mathrm{HH}}=6.3 \mathrm{~Hz}, 2 \mathrm{H}, \mathrm{CH}_{2}\right), 3.71(\mathrm{~s}, 2 \mathrm{H}$, $\left.\mathrm{CH}_{2}\right), 6.90\left(\mathrm{qd}, 1 \mathrm{H},{ }^{3} \mathrm{~J}_{\mathrm{HH}}=7.5 \mathrm{~Hz},{ }^{3} \mathrm{~J}_{\mathrm{HH}}=4.8 \mathrm{~Hz}\right.$, $\left.{ }^{4} J_{\mathrm{HH}}=1.1 \mathrm{~Hz}, \mathrm{CH}_{\mathrm{B}}{ }^{\mathrm{Py}}\right), 7.10\left(\mathrm{~d}, 1 \mathrm{H},{ }^{3} \mathrm{~J}_{\mathrm{HH}}=7.8 \mathrm{~Hz}\right.$, $\left.\mathrm{CH}_{\mathrm{D}}{ }^{\mathrm{Py}}\right), 7.40\left(\mathrm{td}, 1 \mathrm{H},{ }^{3} \mathrm{~J}_{\mathrm{HH}}=7.6 \mathrm{~Hz},{ }^{4} \mathrm{~J}_{\mathrm{HH}}=1.8 \mathrm{~Hz}\right.$, $\mathrm{CH}_{\mathrm{C}}{ }^{\mathrm{Py}}$ ), $8.33\left(\mathrm{dq}, 1 \mathrm{H},{ }^{3} \mathrm{~J}_{\mathrm{HH}}=4.8 \mathrm{~Hz},{ }^{4} \mathrm{~J}_{\mathrm{HH}}=0.9 \mathrm{~Hz}\right.$, $\left.\mathrm{CH}_{\mathrm{A}}^{\mathrm{Py}}\right) \mathrm{ppm}$.

$\delta=11.6\left(\mathrm{CH}_{3}\right), 46.9\left(\mathrm{CH}_{2} \mathrm{CH}_{3}\right), 47.0\left(\mathrm{CH}_{2}\right), 52.5$ $\left(\mathrm{CH}_{2}\right), 55.2\left(\mathrm{PyCH}_{2}\right), 121.5\left(\mathrm{CH}_{\mathrm{B}}^{\mathrm{Py}}\right), 121.8\left(\mathrm{CH}_{\mathrm{D}}^{\mathrm{Py}}\right)$, $136.0\left(\mathrm{CH}_{\mathrm{C}}^{\mathrm{Py}}\right), 149.0\left(\mathrm{CH}_{\mathrm{A}}^{\mathrm{Py}}\right), 160.0\left(\mathrm{C}_{\mathrm{q}}\right) \mathrm{ppm}$.

$207(1)[\mathrm{M}]^{+}$,

$121(65)\left[\mathrm{M}-\left(\mathrm{CH}_{2} \mathrm{NEt}_{2}\right)\right]^{+}$,

$92(16)\left[\mathrm{PyCH}_{2}\right]^{+}$,

86 (100) $\left[\mathrm{CH}_{2} \mathrm{NEt}_{2}\right]^{+}$,

$72(12)\left[\mathrm{NEt}_{2}\right]^{+}$.

ber.: $[\mathrm{M}+\mathrm{H}]^{+}=208.18136$

gef.: $[\mathrm{M}+\mathrm{H}]^{+}=208.18082$.

ber.: C 69.52, H 10.21, N 20.27

gef.: C 69.05, H 10.04, N 20.25.

6.2.4 Synthese von N,N-Diethyl-N'-(1-methylimidazol-2ylmethyl)ethylendiamin

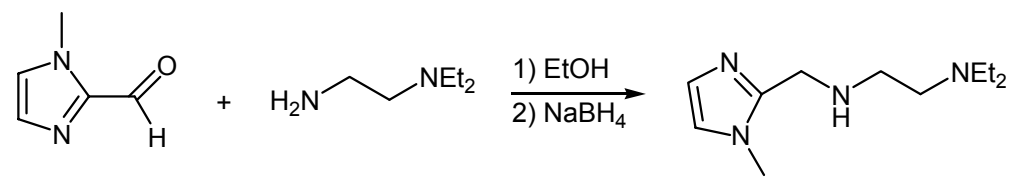


$\mathrm{Zu}$ einer Lösung von $10.10 \mathrm{~g}$ (0.092 mol) 1-Methyl-2-imidazolcarboxaldehyd und $5 \mathrm{ml}$ Essigsäure in $200 \mathrm{ml}$ Methanol wurde eine Lösung von $12.10 \mathrm{~g}(0.104$ mol) N,N-Diethylethylendiamin in $50 \mathrm{ml}$ Methanol zugetropft. Die Lösung wurde eine Stunde bei Raumtemperatur gerührt und anschließend portionsweise $\mathrm{NaBH}_{4}$ zugegeben. Die leicht trübe Lösung wurde 48 Stunden auf $65^{\circ} \mathrm{C}$ erhitzt und nach Abkühlung auf Raumtemperatur $12 \mathrm{M} \mathrm{HCl}$ bis $\mathrm{pH}=1$ zugetropft, danach mit $16.5 \mathrm{M} \mathrm{NaOH}$ auf $\mathrm{pH}=10$ eingestellt. Die Lösung wurde konzentriert und mit $\mathrm{CH}_{2} \mathrm{Cl}_{2}$ extrahiert. Die organische Phase wurde über $\mathrm{MgSO}_{4}$ getrocknet, abfiltriert und vom Lösungsmittel befreit. Man bekommt ein oranges Öl, das durch Destillation bei $85^{\circ} \mathrm{C}$ und $3.3 \cdot 10^{-2}$ mbar eine zähe gelbe Flüssigkeit ergibt.

Ausbeute:

Summenformel:

Molekulargewicht:

${ }^{1} \mathrm{H}-\mathrm{NMR}$

$\left(\mathrm{CDCl}_{3}, 500.13 \mathrm{MHz}\right)$

${ }^{13} \mathrm{C}-\mathrm{NMR}$

$\left(\mathrm{CDCl}_{3}, 125.77 \mathrm{MHz}\right)$

MS (El) $\mathrm{m} / \mathrm{z}(\%)$

Hochauflösende Masse

Elementaranalyse (\%)
$7.94 \mathrm{~g}, 41.3 \%$

$\mathrm{C}_{11} \mathrm{H}_{22} \mathrm{~N}_{4}$

$210.32 \mathrm{~g} / \mathrm{mol}$

$\delta=0.76\left(\mathrm{t},{ }^{3} \mathrm{~J}_{\mathrm{HH}}=7.1 \mathrm{~Hz}, 6 \mathrm{H}, \mathrm{CH}_{3}\right), 1.87(\mathrm{bs}, 1 \mathrm{H}$, $\mathrm{NH}), 2.27\left(\mathrm{q},{ }^{3} \mathrm{~J}_{\mathrm{HH}}=7.1 \mathrm{~Hz}, 4 \mathrm{H}, \mathrm{CH}_{2} \mathrm{CH}_{3}\right), 2.32(\mathrm{t}$, $\left.{ }^{3} J_{\mathrm{HH}}=6.0 \mathrm{~Hz},{ }^{3} \mathrm{JHH}_{\mathrm{HH}}=6.3 \mathrm{~Hz}, 2 \mathrm{H}, \mathrm{CH}_{2}\right), 2.45(\mathrm{t}$, $\left.{ }^{3} \mathrm{JHH}_{\mathrm{HH}}=6.0 \mathrm{~Hz},{ }^{3} \mathrm{~J}_{\mathrm{HH}}=6.3 \mathrm{~Hz}, 2 \mathrm{H}, \mathrm{CH}_{2}\right), 3.44(\mathrm{~s}, 3 \mathrm{H}$, $\left.\mathrm{NCH}_{3}\right), 3.62\left(\mathrm{~s}, 2 \mathrm{H}, \mathrm{CH}_{2}{ }^{\mathrm{Melm}}\right), 6.57\left(\mathrm{~d},{ }^{3} \mathrm{~J}_{\mathrm{HH}}=1.2 \mathrm{~Hz}\right.$, $\left.1 \mathrm{H}, \mathrm{CH}^{\mathrm{Melm}}\right), 6.67\left(\mathrm{~d},{ }^{3} \mathrm{~J}_{\mathrm{HH}}=1.2 \mathrm{~Hz}, 1 \mathrm{H}, \mathrm{CH}^{\mathrm{Melm}}\right)$ ppm.

$\delta=11.3\left(\mathrm{CH}_{3}\right), 32.2\left(\mathrm{NCH}_{3}\right), 45.3\left(\mathrm{CH}_{2}\right.$ Melm $), 46.4$ $\left(\mathrm{CH}_{2}\right), 46.5\left(\mathrm{CH}_{2}\right), 52.1\left(\mathrm{CH}_{2}\right), 120.6\left(\mathrm{CH}^{\mathrm{Melm}}\right), 126.5$ $\left(\mathrm{CH}^{\text {Melm }}\right), 145.9\left(\mathrm{C}_{\mathrm{q}}^{\text {Melm }}\right) \mathrm{ppm}$.

$210(5)[\mathrm{M}]^{+}$, 99 (32) [M-(MelmCH $\left.\left.{ }_{2} \mathrm{NH}\right)\right]^{+}$, 95 (25) $\left[\mathrm{MeImCH}_{2}\right]^{+}$, 86 (100) [M-(MelmCH $\left.\left.\mathrm{NHCH}_{2}\right)\right]^{+}$.

ber.: $[\mathrm{M}+\mathrm{H}]^{+}=211.19226$

gef.: $[\mathrm{M}+\mathrm{H}]^{+}=211.19172$.

ber.: C 62.82, H 10.54, N 26.70

gef.: C 61.15, H 9.87, N 25.72. 


\subsubsection{Synthese von Methyl-(1-methylimidazol-2-ylmethyl)amin}

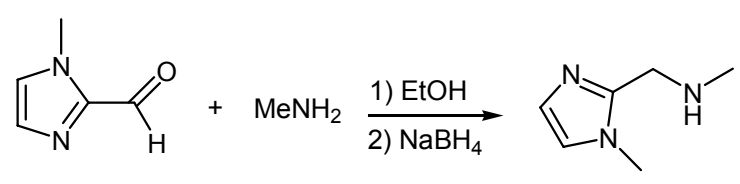

$22 \mathrm{ml}$ einer $8 \mathrm{M}$ Lösung von Methylamin in absolutem Ethanol wurden bei $0{ }^{\circ} \mathrm{C}$ zu einer Lösung von $9.70 \mathrm{~g}(0.088 \mathrm{~mol})$ 1-Methyl-2-imidazolcarboxaldehyd und $1 \mathrm{ml}$ Essigsäure in $50 \mathrm{ml}$ Ethanol zugetropft, über Nacht bei Raumtemperatur gerührt und anschließend portionsweise $4.20 \mathrm{~g}(0.11 \mathrm{~mol}, 1.25 \mathrm{Äq}) \mathrm{NaBH}_{4}$ zugegeben. Die weiße Suspension wurde 2 Stunden unter Rückfluss erhitzt und nach Abkühlung $12 \mathrm{M} \mathrm{HCl}$ bis $\mathrm{pH}=1$ zugetropft. Es fiel ein weißes Pulver aus. Nach Filtration wurde der Rückstand in $50 \mathrm{ml}$ einer $4.5 \mathrm{M} \mathrm{NaOH}$ gelöst. Die wässrige Phase wurde mit $\mathrm{CHCl}_{3}$ extrahiert. Nach Trocknung der organischen Phase über $\mathrm{MgSO}_{4}$ wurde die entstehende Suspension abfiltriert und das Lösungsmittel vom Filtrat abgedampft. Es wurde ein farbloses Öl erhalten, das nach einer Kugelrohrdestillation $\left(10^{-3}\right.$ mbar und $\left.45^{\circ} \mathrm{C}\right)$ bei Raumtemperatur spontan auskristallisiert.

$\begin{array}{ll}\text { Ausbeute: } & 4.5 \mathrm{~g}(0.036 \mathrm{~mol}), 43.2 \% \\ \text { Summenformel: } & \mathrm{C}_{6} \mathrm{H}_{11} \mathrm{~N}_{3} \\ \text { Schmelzpunkt } & 37{ }^{\circ} \mathrm{C} \\ \text { Molekulargewicht: } & 125.17 \mathrm{~g} / \mathrm{mol} \\ { }^{1} \mathrm{H}-\mathrm{NMR} & \delta=1.83(\mathrm{~s}, 1 \mathrm{H}, \mathrm{NH}), 2.35\left(\mathrm{~s}, 3 \mathrm{H}, \mathrm{NCH}_{3}\right), 3.56(\mathrm{~s}, 3 \mathrm{H}, \\ \left(\mathrm{CDCl}_{3}, 500.13 \mathrm{MHz}\right) & \left.\mathrm{N}^{\mathrm{Melm}} \mathrm{CH}_{3}\right), 3.67\left(\mathrm{~s}, 2 \mathrm{H}, \mathrm{CH}_{2}\right), 6.71\left(\mathrm{~d},{ }^{3} \mathrm{~J}_{\mathrm{HH}}=1.1 \mathrm{~Hz},\right. \\ & 1 \mathrm{H}, \mathrm{CH}), 6.81\left(\mathrm{~d},{ }^{3} \mathrm{JHH}_{\mathrm{HH}}=1.1 \mathrm{~Hz}, 1 \mathrm{H}, \mathrm{CH}\right) \mathrm{ppm} . \\ { }^{13} \mathrm{C}-\mathrm{NMR} & 32.4\left(\mathrm{CH}_{2}\right), 36.0\left(\mathrm{CH}_{2}\right), 47.4\left(\mathrm{NCH}_{3}\right), 120.9(\mathrm{CH}), \\ \left.(\mathrm{CDCl})_{3}, 125.75 \mathrm{MHz}\right) & 126.9(\mathrm{CH}), 146.3\left(\mathrm{C}_{\mathrm{q}}\right) \mathrm{ppm} . \\ \mathrm{MS}(\mathrm{El}) \mathrm{m} / \mathrm{z}(\%) & 125(2)[\mathrm{M}]^{+}, \\ & 124(8)[\mathrm{M}-\mathrm{H}]^{+}, \\ & 96(100)\left[\mathrm{M}-\left(\mathrm{NCH}_{3}\right)\right]^{+}, \\ & 95(85)\left[\mathrm{M}-\left(\mathrm{HNCH}_{3}\right)\right]^{+}, \\ & 81(15)\left[\mathrm{CH}_{2} \mathrm{Melm}^{+},\right. \\ & 44(15)\left[\mathrm{M}-\left(\mathrm{CH}_{2} \mathrm{Melm}^{+}\right]^{+} .\right.\end{array}$


Elementaranalyse (\%) ber.: C 57.57, H 8.86, N 33.57

gef.: C 57.06, H 8.62, N 31.53 .

\subsubsection{Synthese von $\mathrm{N}, \mathrm{N}, \mathrm{N}^{\prime}$-Trimethylethylendiamin}

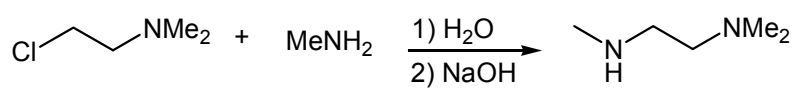

Zu einer Lösung von 2-Chlorethyl-N,N-dimethylamin Hydrochlorid $(88.6 \mathrm{~g}, 0.82$ mol) in $400 \mathrm{ml}$ Wasser wurden bei Raumtemperatur $387 \mathrm{~g}$ einer $40 \%$-igen wässrigen Methylaminlösung (154.6 mg, $4.98 \mathrm{~mol}, 6.1$ Äq) zugetropft. Die Mischung wurde $4 \mathrm{~h}$ bei Raumtemperatur gerührt und $15 \mathrm{~h}$ auf $80^{\circ} \mathrm{C}$ erhitzt. Die Lösung wurde dann auf $0{ }^{\circ} \mathrm{C}$ abgekühlt und mit $\mathrm{NaOH}$ gesättigt. Die gebildete Aminschicht wurde abgetrennt und die wässrige Phase mehrmals mit Diethylether extrahiert. Die vereinigten organischen Phasen wurden mit $16.5 \mathrm{M}$ $\mathrm{NaOH}$ Lösung gewaschen, über $\mathrm{Na}_{2} \mathrm{SO}_{4}$ getrocknet und vom Lösungsmittel befreit. Nach Destillation mit einer Vigreux-Kolonne wurde bei $63^{\circ} \mathrm{C}$ und $10^{-2}$ mbar eine farblose Flüssigkeit gewonnen.

Ausbeute:

$12.5 \mathrm{~g}(0.12 \mathrm{~mol}), 14.9 \%$

Summenformel:

$\mathrm{C}_{5} \mathrm{H}_{14} \mathrm{~N}_{2}$

Molekulargewicht:

$102.18 \mathrm{~g} / \mathrm{mol}$

${ }^{1} \mathrm{H}-\mathrm{NMR}$

$\delta=1.80(\mathrm{bs}, 1 \mathrm{H}, \mathrm{NH}), 1.98\left(\mathrm{~s}, 6 \mathrm{H}, \mathrm{CH}_{3}\right), 2.17(\mathrm{t}$,

$\left(\mathrm{CDCl}_{3}, 500.13 \mathrm{MHz}\right)$

$\left.{ }^{3} \mathrm{~J}_{\mathrm{HH}}=6.3 \mathrm{~Hz},{ }^{3} \mathrm{~J}_{\mathrm{HH}}=5.9 \mathrm{~Hz}, 2 \mathrm{H}, \mathrm{CH}_{2}\right), 2.20(\mathrm{~s}, 3 \mathrm{H}$,

$\left.\mathrm{CH}_{3}\right), 2.41\left(\mathrm{t},{ }^{3} \mathrm{JHH}_{\mathrm{HH}}=6.3 \mathrm{~Hz},{ }^{3} \mathrm{JHH}_{\mathrm{HH}}=5.9 \mathrm{~Hz}, 2 \mathrm{H}, \mathrm{CH}_{2}\right.$ ) ppm.

${ }^{13} \mathrm{C}-\mathrm{NMR}$

$\delta=36.0\left(\mathrm{NHCH}_{3}\right), 45.1\left(\mathrm{CH}_{3}\right), 49.1\left(\mathrm{CH}_{2}\right), 58.6$

$\left(\mathrm{CDCl}_{3}, 125.77 \mathrm{MHz}\right)$

$\left(\mathrm{CH}_{2}\right) \mathrm{ppm}$.

MS (El) $\mathrm{m} / \mathrm{z}(\%)$

$102(5)[\mathrm{M}]^{+}$,

$58(100)\left[\mathrm{M}-\mathrm{N}\left(\mathrm{CH}_{3}\right)_{2}\right]^{+}$.

Elementaranalyse (\%) ber.: C 58.76, H 13.81, N 27.43

gef.: C 56.28, H 13.58, N 26.54 . 


\subsection{Synthese der Liganden}

\subsubsection{Synthese von $L^{1}$}
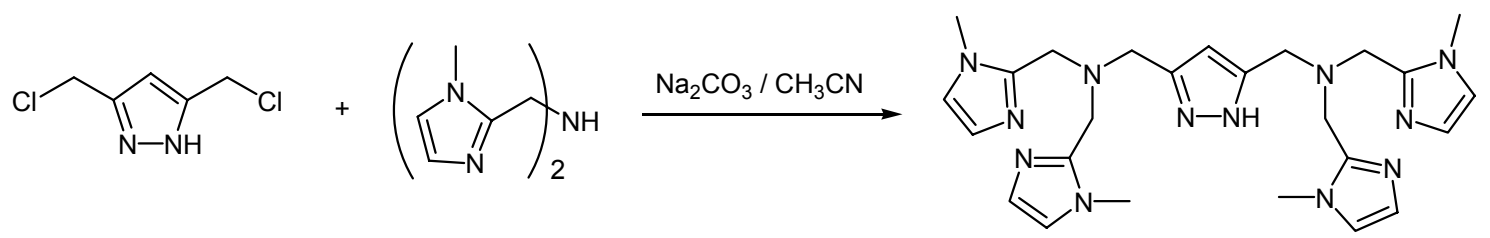

Methode A: $2.40 \mathrm{~g} \mathrm{(12} \mathrm{mmol,} 2.1 \mathrm{Äq})$ Bis[2-(1-methylimidazolyl)methyl]amin wurden zusammen mit $1.42 \mathrm{~g}$ (5.7 mmol) 3,5-Bis(chlormethyl)pyrazol und $7.0 \mathrm{~g}$ (66 mmol, $11.6 \mathrm{Äq}) \mathrm{Na}_{2} \mathrm{CO}_{3}$ in $250 \mathrm{ml}$ Acetonitril 24 Stunden unter $\mathrm{N}_{2}$-Atmosphäre bei $82{ }^{\circ} \mathrm{C}$ zum Ruckfluss erhitzt. Die Feststoffe wurden abfiltriert, das Lösungsmittel entfernt und der weiße Rückstand bei $10^{-5} \mathrm{mbar}$ getrocknet.

Methode B: Hier wurde als Ausgangsprodukt das THP-geschützte 3,5Bis(chlormethyl)pyrazol eingesetzt. Um die Schutzgruppe zu entfernen, wurde das Rohprodukt in $30 \mathrm{ml}$ Ethanol gelöst und $30 \mathrm{ml} 15 \%$-ige ethanolische $\mathrm{HCl}$ zugegeben. Die Suspension wurde 12 Stunden gerührt und dann mit Diethylether überschichtet. Der ausgefallene Feststoff wurde abfiltriert und getrocknet. Anschließend wurde der Feststoff in $30 \mathrm{ml} 16.5 \mathrm{M} \mathrm{NaOH}$ gelöst und mit $\mathrm{CH}_{2} \mathrm{Cl}_{2}$ extrahiert. Die organische Phase wurde abgetrennt, über $\mathrm{Na}_{2} \mathrm{SO}_{4}$ getrocknet und vom Lösungsmittel befreit. Der erhaltene gelbe Feststoff wurde bei $10^{-5}$ mbar getrocknet. Bei Methode B ist die Ausbeute niedriger (46\%) und das Produkt nicht so sauber wie bei Methode A.

Ausbeute:

$1.7 \mathrm{~g},(59.2 \%)$

Summenformel:

$\mathrm{C}_{25} \mathrm{H}_{34} \mathrm{~N}_{12}$

Molekulargewicht:

$502.3 \mathrm{~g} / \mathrm{mol}$

Schmelzpunkt

$168^{\circ} \mathrm{C}$

${ }^{1} \mathrm{H}-\mathrm{NMR}$

$\delta=3.45\left(\mathrm{~s}, 12 \mathrm{H}, \mathrm{CH}_{3}\right), 3.61\left(\mathrm{~s}, 4 \mathrm{H}, \mathrm{PzCH}_{2}\right), 3.65(\mathrm{~s}$,

$\left(\mathrm{CDCl}_{3}, 500.13 \mathrm{MHz}\right)$

$8 \mathrm{H}, \quad \mathrm{MelmCH}$ ),

$6.15\left(\mathrm{~s}, 1 \mathrm{H}, \mathrm{CH}^{\mathrm{Pz}}\right)$,

$6.79(d$, 
${ }^{13} \mathrm{C}-\mathrm{NMR}$

$\left(\mathrm{CDCl}_{3}, 125.77 \mathrm{MHz}\right)$

$\mathrm{IR}(\mathrm{KBr})$

MS (El) $\mathrm{m} / \mathrm{z}(\%)$

Hochauflösende Masse

gef.: $[\mathrm{M}+\mathrm{H}]^{+}=503.31022$

Elementaranalyse (\%) ber. (mit $\mathrm{H}_{2} \mathrm{O}$ ): C 57.65, H 6.97, N 32.29

gef.: C 56.99, H 6.99, N 30.51 .

\subsubsection{Synthese von $L^{2}$}
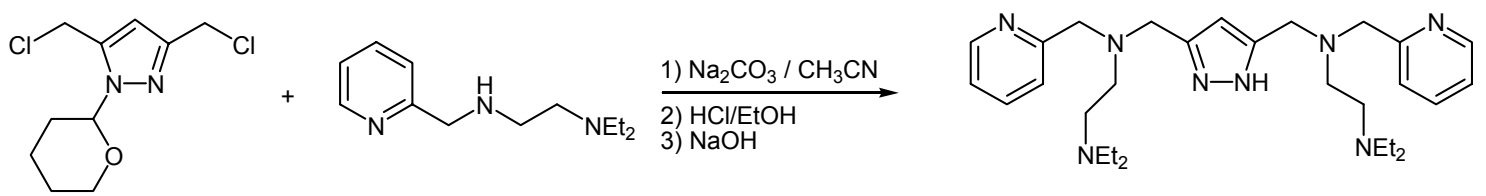

$7.0 \mathrm{~g}$ (0.028 mol) 3,5-Bis(chlormethyl)-1-(tetrahydropyran-2-yl)pyrazol wurden zusammen mit 11.7 g $(0.056$ mol, 2 Äq) N,N-Diethyl-N'-(Pyridin-2ylmethyl(ethylendiamin und $18.0 \mathrm{~g}(0.17 \mathrm{~mol}, 6.06 \mathrm{Äq}) \mathrm{Na}_{2} \mathrm{CO}_{3}$ in $250 \mathrm{ml}$ trockenem Acetonitril 60 Stunden zum Rückfluss erhitzt, wobei die Suspension eine gelbliche Farbe annahm. Die ausgefallenen Feststoffe wurden abfiltriert und das Filtrat zur Trockene eingeengt. Das verbliebene braune ÖI wurde in 50 ml 19.9 \%-iger ethanolischer $\mathrm{HCl}$ gelöst, 12 Stunden gerührt und nach Zugabe 
von Diethylether fiel ein beiger Feststoff aus. Dieser wurde abfiltriert, getrocknet und anschließend in $16.5 \mathrm{M} \mathrm{NaOH}$ gelöst. Die wässrige Lösung wurde mit $\mathrm{CH}_{2} \mathrm{Cl}_{2}$ extrahiert, die organische Phase über $\mathrm{MgSO}_{4}$ getrocknet und danach das Lösungsmittel am Rotationsverdampfer entfernt. Das erhaltene braune Öl wurde in $\mathrm{CH}_{2} \mathrm{Cl}_{2}$ gelöst und durch Zugabe von $\mathrm{PE}$ fällt $\mathrm{L}^{2}$ aus.

Ausbeute:

Summenformel:

Molekulargewicht:

${ }^{1} \mathrm{H}-\mathrm{NMR}$

$\left(\mathrm{CDCl}_{3}, 500.13 \mathrm{MHz}\right)$

${ }^{13} \mathrm{C}-\mathrm{NMR}$

$\left(\mathrm{CDCl}_{3}, 125.77 \mathrm{MHz}\right)$

MS (EI) $\mathrm{m} / \mathrm{z}(\%)$

Hochauflösende Masse

Elementaranalyse (\%)
$7.8 \mathrm{~g}, 53.6 \%$

$\mathrm{C}_{29} \mathrm{H}_{46} \mathrm{~N}_{8}$

$506.38 \mathrm{~g} / \mathrm{mol}$

$\delta=0.92\left(\mathrm{t},{ }^{3} \mathrm{JHH}_{\mathrm{HH}}=7.1 \mathrm{~Hz}, 12 \mathrm{H}, \mathrm{CH}_{3}\right), 2.43(\mathrm{q}$, $\left.{ }^{3} \mathrm{~J}_{\mathrm{HH}}=7.1 \mathrm{~Hz}, 8 \mathrm{H}, \mathrm{CH}_{2} \mathrm{CH}_{3}\right), 2.52\left(\mathrm{t},{ }^{3} \mathrm{~J}_{\mathrm{HH}}=6.1 \mathrm{~Hz}\right.$, $\left.4 \mathrm{H}, \mathrm{CH}_{2}\right), 2.58\left(\mathrm{t},{ }^{3} \mathrm{~J}_{\mathrm{HH}}=6.2 \mathrm{~Hz}, 4 \mathrm{H}, \mathrm{CH}_{2}\right), 3.65(\mathrm{~s}$, $\left.4 \mathrm{H}, \mathrm{CH}_{2}\right), 3.72\left(\mathrm{~s}, 4 \mathrm{H}, \mathrm{CH}_{2}\right), 5.96\left(\mathrm{~s}, 1 \mathrm{H}, \mathrm{CH}^{\mathrm{Pz}}\right), 7.05$ (qd, ${ }^{3} \mathrm{~J}_{\mathrm{HH}}=4.9 \mathrm{~Hz},{ }^{3} \mathrm{JHH}_{\mathrm{HH}}=7.4 \mathrm{~Hz},{ }^{4} \mathrm{JHH}_{\mathrm{HH}}=1.1 \mathrm{~Hz}, 2 \mathrm{H}$, $\left.\mathrm{CH}_{\mathrm{B}}{ }^{\mathrm{Py}}\right), 7.38\left(\mathrm{~d},{ }^{3} \mathrm{~J}_{\mathrm{HH}}=7.9 \mathrm{~Hz}, 2 \mathrm{H}, \mathrm{CH}_{\mathrm{D}}{ }^{\mathrm{Py}}\right), 7.54(\mathrm{td}$, $\left.{ }^{3} \mathrm{~J}_{\mathrm{HH}}=7.6 \mathrm{~Hz},{ }^{4} \mathrm{~J}_{\mathrm{HH}}=1.8 \mathrm{~Hz}, 2 \mathrm{H}, \mathrm{CH}_{\mathrm{C}}{ }^{\mathrm{Py}}\right), 8.44(\mathrm{dd}$, $\left.{ }^{3} J_{\mathrm{HH}}=4.9,{ }^{4} J_{\mathrm{HH}}=0.8 \mathrm{~Hz}, 2 \mathrm{H}, \mathrm{CH}_{\mathrm{A}}{ }^{\mathrm{Py}}\right) \mathrm{ppm}$.

$\delta=11.2\left(\mathrm{CH}_{3}\right), 47.1\left(\mathrm{CH}_{2} \mathrm{CH}_{3}\right), 50.5\left(\mathrm{CH}_{2}\right), 51.0$ $\left(\mathrm{CH}_{2} \mathrm{CH}_{2}\right), 52.0\left(\mathrm{CH}_{2} \mathrm{CH}_{2}\right), 60.4\left(\mathrm{CH}_{2}\right), 103.2\left(\mathrm{CH}^{\mathrm{Pz}}\right)$, $121.9\left(\mathrm{CH}_{\mathrm{B}}^{\mathrm{Py}}\right), 123.0\left(\mathrm{CH}_{\mathrm{D}}{ }^{\mathrm{Py}}\right), 136.4\left(\mathrm{CH}_{\mathrm{C}}{ }^{\mathrm{Py}}\right), 148.8$ $\left(\mathrm{CH}_{\mathrm{A}}^{\mathrm{Py}}\right), 159.5\left(\mathrm{C}_{\mathrm{q}}^{\mathrm{Py}}\right) \mathrm{ppm}$.

506 (10) [M] $]^{+}$,

420 (70) $\left[\mathrm{M}-\mathrm{CH}_{2} \mathrm{~N}\left(\mathrm{CH}_{2} \mathrm{CH}_{3}\right)_{2}\right]^{+}$,

414 (35) [M-PyCH$]^{+}$,

300 (100) $\left[\mathrm{M}-\mathrm{N}\left(\mathrm{CH}_{2} \mathrm{Py}\right)\left(\mathrm{CH}_{2} \mathrm{CH}_{2} \mathrm{NEt}_{2}\right)\right]^{+}$,

$100(65)\left[\mathrm{CH}_{2} \mathrm{CH}_{2} \mathrm{NEt}_{2}\right]^{+}$,

$86(90)\left[\mathrm{CH}_{2} \mathrm{NEt}_{2}\right]^{+}$.

ber.: $[\mathrm{M}+\mathrm{H}]^{+}=507.39235$

gef.: $[\mathrm{M}+\mathrm{H}]^{+}=507.39182$.

ber. (mit $\mathrm{H}_{2} \mathrm{O}$ ): $\mathrm{C}$ 66.36, H 9.22, N 21.36

gef.: C $65.98, \mathrm{H} 9.00, \mathrm{~N} 20.49$. 


\subsubsection{Synthese von $L^{3}$}
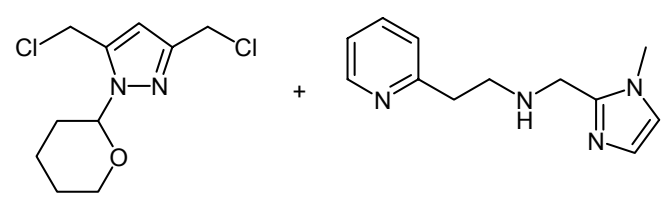

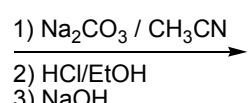

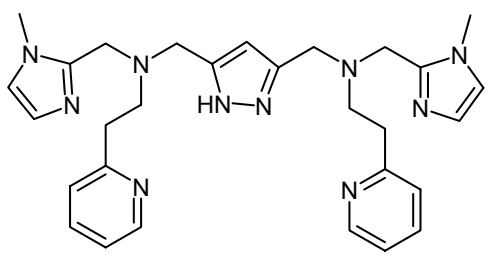

$4.0 \mathrm{~g}(0.016 \mathrm{~mol}) 3,5-\mathrm{Bis}$ (chlormethyl)-1-(tetrahydropyran-2-yl)pyrazol wurden zusammen mit $7.8 \mathrm{~g}$ (0.036 mol, 2.25 Äq) (1-Methylimidazol-2-ylmethyl)-(2pyridin-2-ylethyl)amin und $22.5 \mathrm{~g}(0.21 \mathrm{~mol}, 13.2 \mathrm{Äq}) \mathrm{Na}_{2} \mathrm{CO}_{3}$ in $150 \mathrm{ml}$ Acetonitril gelöst. Die gelbe Suspension wurde 60 Stunden am Rückfluss sieden gelassen. Nachdem der Feststoff abfiltriert und das Lösungsmittel im Vakuum entfernt wurde, ist das dabei entstandene dunkelbraune Öl in $50 \mathrm{ml}$ 19.9 \%-iger ethanolischer $\mathrm{HCl}$ gelöst und 12 Stunden gerührt worden. Nach der Zugabe von Diethylether fiel ein gelber Feststoff aus, der abfiltriert, getrocknet und anschließend in $16.5 \mathrm{M} \mathrm{NaOH}$ gelöst wurde. Die wässrige Lösung wurde mit $\mathrm{CH}_{2} \mathrm{Cl}_{2}$ extrahiert, die organische Phase über $\mathrm{MgSO}_{4}$ getrocknet, abfiltriert und vom Lösungsmittel befreit. Das erhaltene dunkelbraune Öl wurde zuerst in $\mathrm{CH}_{2} \mathrm{Cl}_{2}$ gelöst und mit PE überschichtet. Es wurde eine braune Öl ausgefallen, welches in Ethanol gelöst wurde und mit Diethylether überschichtet wurde. Das ölige Produkt fällt aus.

Ausbeute:

$5.42 \mathrm{~g}, 62.5 \%$

Summenformel:

$\mathrm{C}_{29} \mathrm{H}_{36} \mathrm{~N}_{10}$

Molekulargewicht:

$524.31 \mathrm{~g} / \mathrm{mol}$

${ }^{1} \mathrm{H}-\mathrm{NMR}$

$\delta=2.89\left(\mathrm{t},{ }^{3} \mathrm{~J}_{\mathrm{HH}}=5.6 \mathrm{~Hz}, 4 \mathrm{H}, \mathrm{CH}_{2}\right), 2.97(\mathrm{t}$, $\left(\mathrm{CDCl}_{3}, 500 \mathrm{MHz}\right)$

$\left.{ }^{3} \mathrm{~J}_{\mathrm{HH}}=5.6 \mathrm{~Hz}, 4 \mathrm{H}, \mathrm{CH}_{2}\right), 3.24\left(\mathrm{~s}, 6 \mathrm{H}, \mathrm{CH}_{3}\right), 3.63(\mathrm{~s}$, $\left.4 \mathrm{H}, \mathrm{CH}_{2}\right), 3.66\left(\mathrm{~s}, 4 \mathrm{H}, \mathrm{CH}_{2}\right), 6.00\left(\mathrm{~s}, 1 \mathrm{H}, \mathrm{CH}^{\mathrm{Pz}}\right), 6.69$ $\left(\mathrm{d},{ }^{3} \mathrm{~J}_{\mathrm{HH}}=1.2 \mathrm{~Hz}, 1 \mathrm{H}, \mathrm{CH}^{\mathrm{lm}}\right), 6.88\left(\mathrm{~d},{ }^{3} \mathrm{~J}_{\mathrm{HH}}=1.2 \mathrm{~Hz}\right.$, $\left.1 \mathrm{H}, \mathrm{CH}^{\mathrm{Im}}\right), 7.02\left(\mathrm{dd},{ }^{3} \mathrm{~J}_{\mathrm{HH}}=7.9 \mathrm{~Hz},{ }^{4} \mathrm{~J}_{\mathrm{HH}}=0.8 \mathrm{~Hz}\right.$, $\left.2 \mathrm{H}, \mathrm{CH}_{\mathrm{D}}{ }^{\mathrm{Py}}\right), 7.06\left(\mathrm{td},{ }^{3} J_{\mathrm{HH}}=4.9 \mathrm{~Hz},{ }^{4} J_{\mathrm{HH}}=1.1 \mathrm{~Hz}\right.$, $\left.2 \mathrm{H}, \mathrm{CH}_{\mathrm{B}}{ }^{\mathrm{Py}}\right), 7.50\left(\mathrm{td},{ }^{3} \mathrm{~J}_{\mathrm{HH}}=7.6 \mathrm{~Hz},{ }^{4} J_{\mathrm{HH}}=1.8 \mathrm{~Hz}\right.$, $\left.2 \mathrm{H}, \mathrm{CH}_{\mathrm{C}}{ }^{\mathrm{Py}}\right), 8.48\left(\mathrm{dq},{ }^{3} \mathrm{~J}_{\mathrm{HH}}=4.9 \mathrm{~Hz},{ }^{4} J_{\mathrm{HH}}=0.8 \mathrm{~Hz}\right.$, $\left.\mathrm{CH}_{\mathrm{A}}^{\mathrm{Py}}\right) \mathrm{ppm}$. 


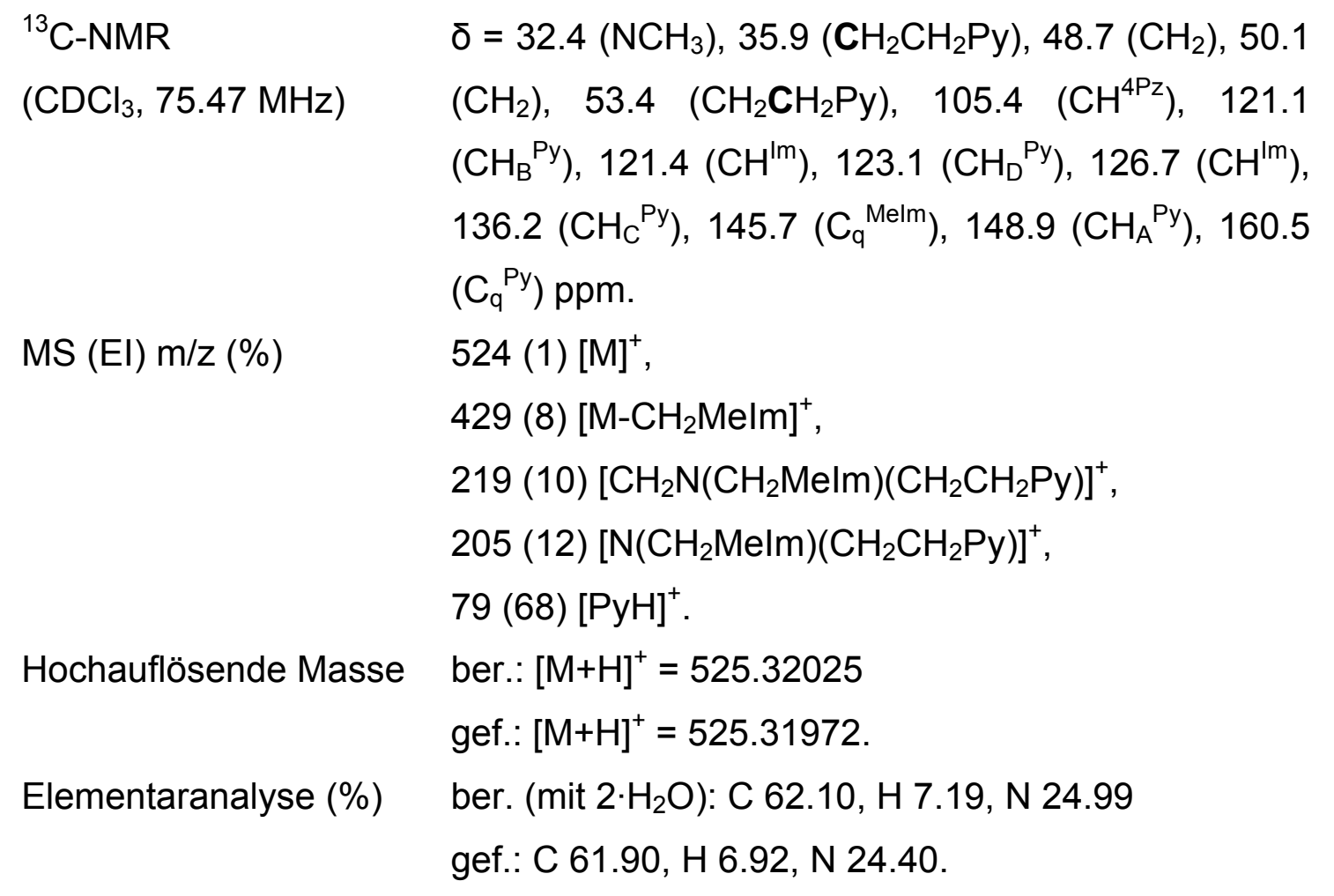

\subsubsection{Synthese von $L^{4}$}

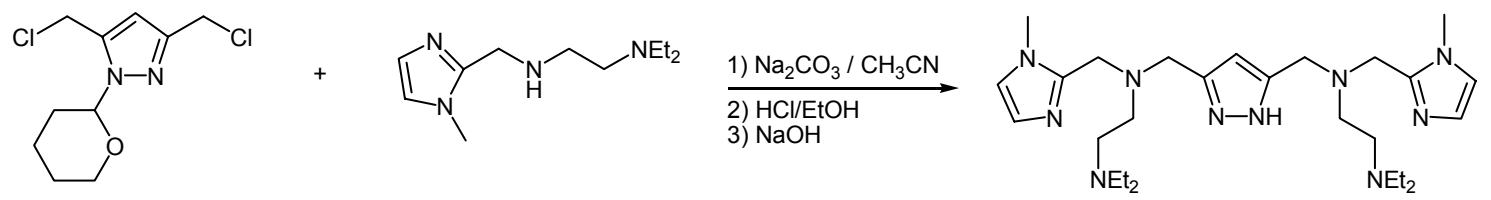

$4.6 \mathrm{~g}(0.018 \mathrm{~mol})$ 3,5-Bis(chlormethyl)-1-(tetrahydropyran-2-yl)pyrazol wurden

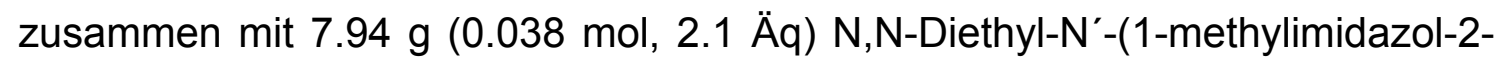
ylmethyl)ethylendiamin und $30 \mathrm{~g} \mathrm{Na}_{2} \mathrm{CO}_{3}(0.28 \mathrm{~mol}, 15.7 \mathrm{Äq})$ in $200 \mathrm{ml}$ trockenem Acetonitril 60 Stunden zum Rückfluss erhitzt. $\mathrm{Na}_{2} \mathrm{CO}_{3}$ wurde abfiltriert, das Filtrat vom Lösungsmittel befreit und das verbleibende leicht gelbe Öl in $50 \mathrm{ml} 19.9$ \%-iger ethanolischer $\mathrm{HCl}$ gelöst und 12 Stunden gerührt. Nach der Zugabe von Diethylether fiel ein weißer Feststoff aus, der abfiltriert, getrocknet und dann in $16.5 \mathrm{M} \mathrm{NaOH}$ gelöst wurde. Die wässrige Lösung wurde mit $\mathrm{CH}_{2} \mathrm{Cl}_{2}$ extrahiert, die organische Phase über $\mathrm{MgSO}_{4}$ getrocknet, abfiltriert 
und vom Lösungsmittel befreit. Das hellbraune Öl wurde in $\mathrm{CH}_{2} \mathrm{Cl}_{2}$ gelöst. Nach Zugabe von PE fällt das gereinigte ölige Produkt aus.

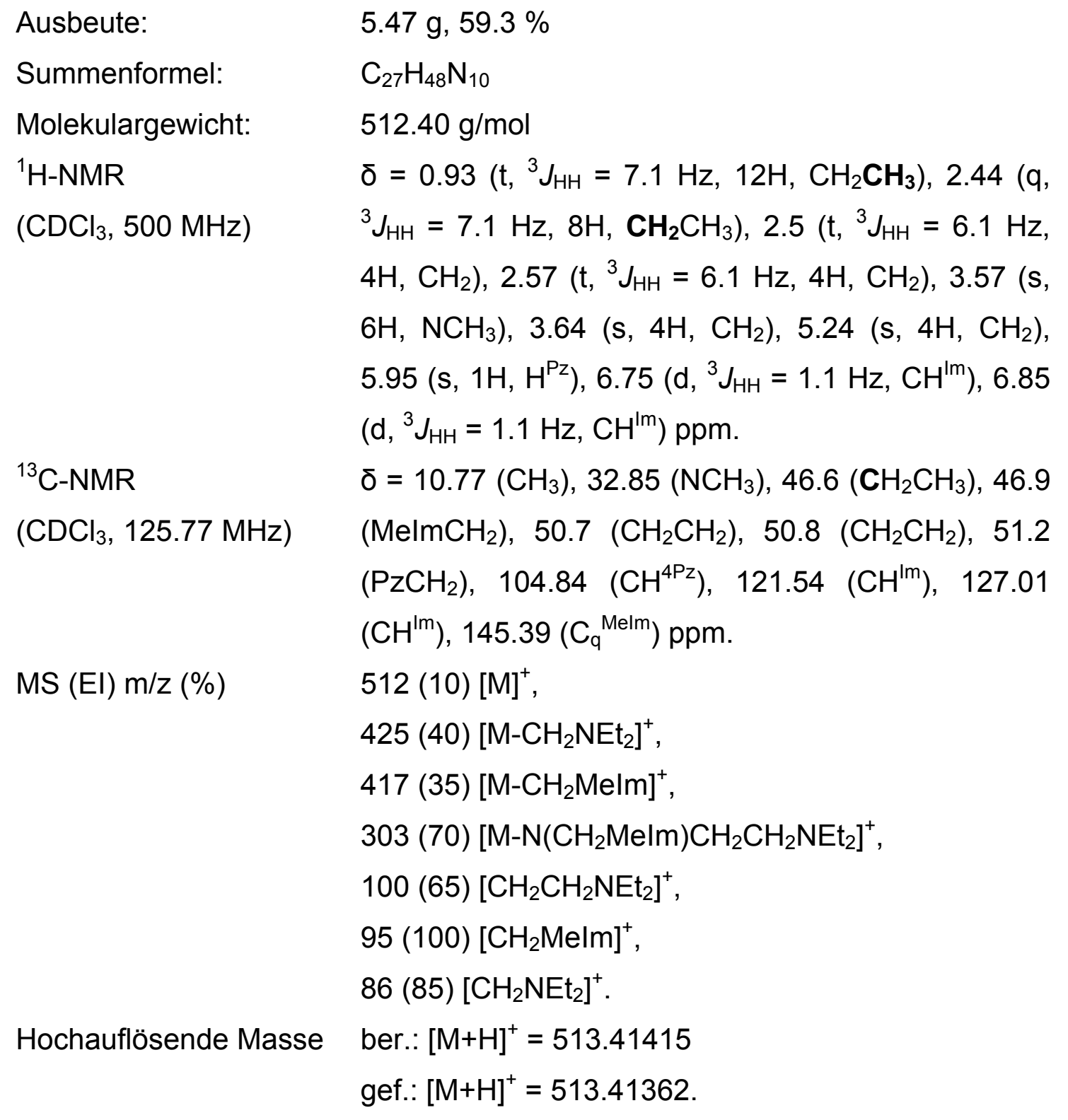




\subsection{Komplexsynthese}

Die Synthese acetatverbrückter Komplexe wurde nach einem allgemeinen Verfahren durchgeführt, bei welchem der jeweilige Ligand mit Kalium-tert-butylat, Zinkperchlorat Hexahydrat und Natriumacetat im Molverhältnis 1:1:2:1 entweder in Methanol oder in Aceton umgesetzt wurde. Die Rührdauer bei dieser Einstufensynthese eines Pyrazoldizinkkomplexes mit einer Zweitbrücke betrug 12 Stunden bei Raumtemperatur. Mit der erhaltenen Reaktionslösung wurden Kristallisationsversuche durchgeführt.

Für die Darstellung der Komplexe 6 bis 10, 12 und 13 wurden davon abweichende, in der Folge beschriebene Synthesemethoden verwendet.

Die für die speziellen spektroskopischen Untersuchungen benötigten einfach verbrückten Pyrazolat-dizink-hydroxykomplexe $\left[\mathrm{L}^{\mathrm{n}}{ }_{\mathrm{H}}(\mathrm{MeOH})(\mathrm{OH}) \mathrm{Zn}_{2}\right]\left(\mathrm{ClO}_{4}\right)_{2}$ $(n=1,2,3,6$ und 7 ) wurden aus dem jeweiligen Liganden, Kalium-tert-butylat und Zinkperchlorat Hexahydrat in Methanol nach 12-stündiger Rührdauer erhalten. Diese Komplexe wurden nicht isoliert, ihre Bildung aber durch das ESI-Massenspektrum überprüft.

Der Methoxykomplex XLI wurde nach Literaturangaben dargestellt. ${ }^{[6]}$

Um für die Röntgenstrukturanalyse brauchbare Einkristalle zu gewinnen, wurden verschiedene Methoden zur Kristallisation versucht. Die Versuche zur Kristallisation der Metallkomplexe wurden vor allem nach zwei Methoden probiert.

1) Langsames Abdunsten von Lösungsmittel aus einer Lösung des Metallkomplexes.

2) Überschichten der Lösung des Komplexes durch ein anderes Lösungsmittel. In vielen Fällen führte dabei die Diffusion an der Phasengrenzfläche zum Erfolg. Als Lösungsmittelpaare wurden u.a. verwendet: Aceton/Petrolether (Fraktion $40-60^{\circ} \mathrm{C}$ ), Acetonitril/Wasser, Methanol/Diethylether. 


\subsubsection{Synthese von $\left[\mathrm{L}^{1}{ }_{-\mathrm{H}}\left(\mu-\mathrm{CH}_{3} \mathrm{COO}\right) \mathrm{Zn}_{2}\right]\left(\mathrm{ClO}_{4}\right)_{2}(1)$}

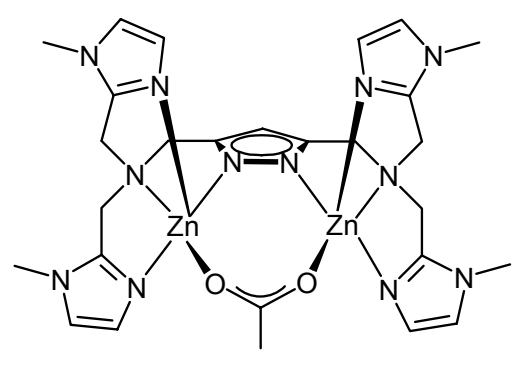

$\left(\mathrm{ClO}_{4}\right)_{2}$

Methode A: Zu einer Lösung von $L^{1}(158 \mathrm{mg}, 0.751 \mathrm{mmol})$ in $30 \mathrm{ml}$ Aceton wurden $88 \mathrm{mg} \quad \mathrm{KO}{ }^{\mathrm{t} B u}(0.788 \mathrm{mmol}, 1 \mathrm{Äq}), 569 \mathrm{mg} \mathrm{Zn}\left(\mathrm{ClO}_{4}\right)_{2} \cdot 6 \mathrm{H}_{2} \mathrm{O}$ (1.528 mmol, 2 Äq) und $70 \mathrm{mg}$ Natriumacetat $(0.76 \mathrm{mmol}, 1 \mathrm{Äq})$ zugefügt und bei Raumtemperatur $12 \mathrm{~h}$ gerührt. Nach Filtration wurde die Lösung mit $20 \mathrm{ml}$ Aceton verdünnt und anschließend mit PE (40-60-Fraktion) überschichtet. Die nach Kristallisation erhaltenen farblosen Kristalle waren für die Röntgenstrukturanalyse geeignet.

Methode B: Das für die Reaktion als Lösungsmittel verwendete Aceton wurde im Vakuum in einer Kühlfalle gesammelt. Das als Rückstand verbliebene Öl wurde in $30 \mathrm{ml}$ Acetonitril aufgenommen und ungelöste Anteile abfiltriert. Nach Überschichtung mit Diethylether bildeten sich durch langsame Diffusion farblose Kristalle, welche für die Röntgenstrukturanalyse geeignet waren.

Für 1a:

Ausbeute:

$6 \mathrm{mg}, 0.9 \%$

Summenformel:

$\mathrm{C}_{27} \mathrm{H}_{36} \mathrm{Cl}_{2} \mathrm{~N}_{12} \mathrm{O}_{10} \mathrm{Zn}_{2}$

Molekulargewicht:

$890.32 \mathrm{~g} / \mathrm{mol}$

${ }^{1} \mathrm{H}-\mathrm{NMR}$

$\delta=2.07\left(\mathrm{~s}, 3 \mathrm{H}, \mathrm{CH}_{3}\right), 3.57\left(\mathrm{~s}, 12 \mathrm{H}, \mathrm{NCH}_{3}\right), 4.16$ (q,

(DMSO, 500.13 MHz) $\left.{ }^{2} J_{\mathrm{HH}}=17.17 \mathrm{~Hz}, 8 \mathrm{H}, \mathrm{MelmCH}_{2}\right), 6.13\left(\mathrm{~s}, 1 \mathrm{H}, \mathrm{CH}^{\mathrm{Pz}}\right)$, $6.95\left(\mathrm{~d},{ }^{3} J_{\mathrm{HH}}=1.3 \mathrm{~Hz}, \mathrm{CH}^{\mathrm{Melm}}\right), 7.35\left(\mathrm{~d},{ }^{3} J_{\mathrm{HH}}=1.3\right.$

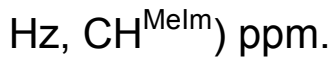

${ }^{13} \mathrm{C}-\mathrm{NMR}$ $\delta=30.6\left(\mathrm{CH}_{3}\right), 32.5\left(\mathrm{NCH}_{3}\right), 50.9\left(\mathrm{CH}_{2}\right), 53.2\left(\mathrm{CH}_{2}\right)$, (DMSO, 125.77 MHz) $100.3\left(\mathrm{C}^{4 \mathrm{Pz}}\right), 123.7\left(\mathrm{CH}^{\mathrm{Melm}}\right), 124.1\left(\mathrm{CH}^{\mathrm{Melm}}\right), 147.7$ $\left(\mathrm{C}_{\mathrm{q}}^{\text {Melm }}\right), 151.1\left(\mathrm{C}^{\text {Carbonyl }}\right) \mathrm{ppm}$. 


$\begin{array}{ll}\text { IR (KBr) } & \tilde{v}=3432(\mathrm{w}), 3127(\mathrm{w}), 2922(\mathrm{w}), 2012(\mathrm{w}), 1705(\mathrm{~s}), \\ & 1583(\mathrm{~s}), 1508(\mathrm{~s}), 1444(\mathrm{~s}), 1361(\mathrm{~m}), 1286(\mathrm{~m}), \\ & 1228(\mathrm{~m}), 1094(\mathrm{vs}), 960(\mathrm{~m}), 875(\mathrm{w}), 765(\mathrm{~s}), 653 \\ & (\mathrm{w}), 623(\mathrm{~s}) \mathrm{cm}^{-1} . \\ \mathrm{MS}(\mathrm{ESI}) \mathrm{m} / \mathrm{z}(\%) & 791.1(100)\left[\mathrm{L}^{1} \cdot{ }_{-\mathrm{H}}\left(\mu-\mathrm{CH}_{3} \mathrm{COO}\right)\left(\mathrm{ClO}_{4}\right) \mathrm{Zn}_{2}\right]^{+}, \\ \text {(in MeOH) } & 777.1(20)\left[\mathrm{L}^{1}{ }_{-\mathrm{H}}(\mathrm{MeOH})(\mathrm{OH})\left(\mathrm{ClO}_{4}\right) \mathrm{Zn}_{2}\right]^{+}, \\ & 346.3(5)\left[\mathrm{L}^{1}{ }_{-\mathrm{H}}\left(\mu-\mathrm{CH}_{3} \mathrm{COO}\right) \mathrm{Zn}_{2}\right]^{2+} .\end{array}$

\subsubsection{Synthese von $\left[\mathrm{L}^{4}{ }_{-\mathrm{H}}\left(\mu-\mathrm{CH}_{3} \mathrm{COO}\right) \mathrm{Zn}_{2}\right]\left(\mathrm{ClO}_{4}\right)_{2}(2)$}

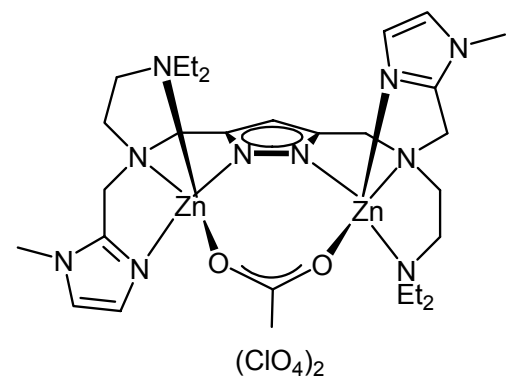

Zu einer Lösung von $\mathrm{L}^{4}(94 \mathrm{mg}, 0.18 \mathrm{mmol})$ in $30 \mathrm{ml}$ Aceton wurden $41 \mathrm{mg}$ $\mathrm{KO}{ }^{\mathrm{t}} \mathrm{Bu}(0.36 \mathrm{mmol}, 2 \mathrm{Äq}), 140 \mathrm{mg} \mathrm{Zn}\left(\mathrm{ClO}_{4}\right)_{2} \cdot 6 \mathrm{H}_{2} \mathrm{O}(0.37 \mathrm{mmol}, 2 \mathrm{Äq})$ und $22 \mathrm{mg}$ Natriumacetat $(0.27 \mathrm{mmol}, 1.5 \mathrm{Äq})$ zugefügt und bei Raumtemperatur $12 \mathrm{~h}$ gerührt. Nach Filtration wurde die Lösung mit $20 \mathrm{ml}$ Aceton verdünnt und anschließend mit PE (40-60-Fraktion) überschichtet. Die erhaltenen farblosen Kristalle waren für die Röntgenstrukturanalyse geeignet.
Ausbeute:
$9 \mathrm{mg}, 5.5 \%$
Summenformel:
$\mathrm{C}_{29} \mathrm{H}_{50} \mathrm{Cl}_{2} \mathrm{~N}_{10} \mathrm{O}_{10} \mathrm{Zn}_{2}$
Molekulargewicht:
$896.17 \mathrm{~g} / \mathrm{mol}$
$\mathrm{IR}(\mathrm{KBr})$
$\tilde{v}=3435(\mathrm{~m}), 2980(\mathrm{w}), 1710(\mathrm{w}), 1584(\mathrm{~s}), 1511$
(m), 1444 (m), 1354 (w), 1286 (w), 1091 (vs), 966
(w), $806(w), 766(w), 624(s) \mathrm{cm}^{-1}$.
MS (ESI) $\mathrm{m} / \mathrm{z}(\%)$
$801.3(25)\left[\mathrm{L}^{4} \cdot \mathrm{H}\left(\mu-\mathrm{CH}_{3} \mathrm{COO}\right)\left(\mathrm{ClO}_{4}\right) \mathrm{Zn}_{2}\right]^{+}$, 
(in Aceton)

Hochauflösende Masse (ESI) (in $\mathrm{MeCN}$ )
$350.4(100)\left[\mathrm{L}^{4}{ }_{-\mathrm{H}}\left(\mu-\mathrm{CH}_{3} \mathrm{COO}\right) \mathrm{Zn}_{2}\right]^{2+}$.

ber.: $\left[\mathrm{L}^{4}{ }_{-\mathrm{H}}\left(\mu-\mathrm{CH}_{3} \mathrm{COO}\right) \mathrm{Zn}_{2}\right]^{2+} 349.13504$

gef.: 349.13451 .

\subsubsection{Synthese von $\left[\mathrm{L}^{3}{ }_{-\mathrm{H}}\left(\mu-\mathrm{CH}_{3} \mathrm{COO}\right) \mathrm{Zn}_{2}\right]\left(\mathrm{ClO}_{4}\right)_{2}(3)$}

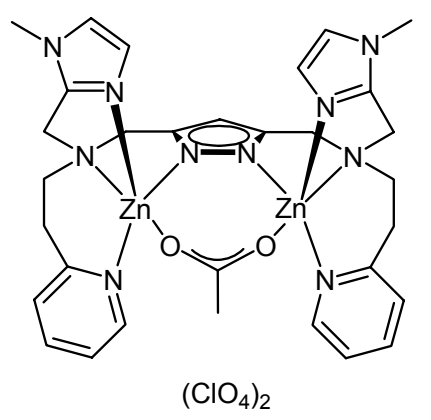

Zu einer Lösung von $\mathrm{L}^{3}(125 \mathrm{mg}, 0.24 \mathrm{mmol})$ in $30 \mathrm{ml}$ Aceton wurden $60 \mathrm{mg}$ $\mathrm{KO}{ }^{\mathrm{t}} \mathrm{Bu}(0.53 \mathrm{mmol}, 2 \mathrm{Äq}), 200 \mathrm{mg} \mathrm{Zn}\left(\mathrm{ClO}_{4}\right)_{2} \cdot 6 \mathrm{H}_{2} \mathrm{O}(0.53 \mathrm{mmol}, 2 \mathrm{Äq})$ und $24 \mathrm{mg}$ Natriumacetat $(0.29 \mathrm{mmol}, 1 \mathrm{Äq})$ zugefügt und bei Raumtemperatur $12 \mathrm{~h}$ gerührt. Nach Filtration wurde die Lösung mit $20 \mathrm{ml}$ Aceton verdünnt und anschließend mit PE (40-60-Fraktion) überschichtet. Die nach Kristallisation erhaltenen farblosen Kristalle waren für die Röntgenstrukturanalyse geeignet.

Ausbeute:

Summenformel:

Molekulargewicht:

$\mathrm{IR}(\mathrm{KBr})$
$15 \mathrm{mg}, 6.8 \%$

$$
\mathrm{C}_{31} \mathrm{H}_{38} \mathrm{Cl}_{2} \mathrm{~N}_{10} \mathrm{O}_{10} \mathrm{Zn}_{2}
$$

$912.38 \mathrm{~g} / \mathrm{mol}$

$\tilde{v}=3435(\mathrm{~m}), 3137(\mathrm{w}), 2962(\mathrm{w}), 2923(\mathrm{w}), 2856$

(w), $2019(w), 1712(w), 1583(s), 1509(m), 1442$

(s), $1354(w), 1320(w), 1261(s), 1095$ (vs), $869(w)$, $801(\mathrm{~s}), 650(\mathrm{w}), 623(\mathrm{~s}), 523(\mathrm{w}), 482(\mathrm{w}) \mathrm{cm}^{-1}$.

MS (ESI) $\mathrm{m} / \mathrm{z}(\%)$

(in Aceton)

Hochauflösende Masse (ESI) (in $\mathrm{MeCN}$ )
$813.2(15)\left[\mathrm{L}^{3}{ }_{-\mathrm{H}}\left(\mu-\mathrm{CH}_{3} \mathrm{COO}\right)\left(\mathrm{ClO}_{4}\right) \mathrm{Zn}_{2}\right]^{+}$,

$771.3(100)\left[\mathrm{L}^{3}{ }_{-\mathrm{H}}(\mathrm{OH})\left(\mathrm{ClO}_{4}\right) \mathrm{Zn}_{2}\right]^{+}$.

ber.: $\left[\mathrm{L}^{3}{ }_{-\mathrm{H}}\left(\mu-\mathrm{CH}_{3} \mathrm{COO}\right) \mathrm{Zn}_{2}\right]^{2+} 355.08809$

gef.: 355.08756 . 


\subsubsection{Synthese von $\left[\mathrm{L}^{7}{ }_{\mathrm{H}}\left(\mu-\mathrm{CH}_{3} \mathrm{COO}\right) \mathrm{Zn}_{2}\right]\left(\mathrm{ClO}_{4}\right)_{2}(4)$}

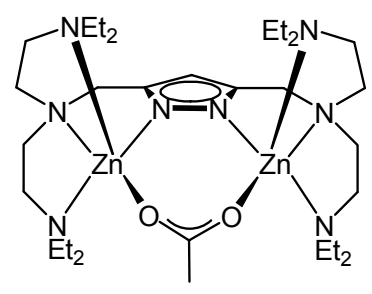

$\left(\mathrm{ClO}_{4}\right)_{2}$

Zu einer Lösung von $\mathrm{L}^{7}(94 \mathrm{mg}, 0.18 \mathrm{mmol})$ in $30 \mathrm{ml}$ Methanol wurden $41 \mathrm{mg}$ $\mathrm{KO} \mathrm{t}^{\mathrm{Bu}}(0.36 \mathrm{mmol}, 2 \mathrm{Äq}), 140 \mathrm{mg} \mathrm{Zn}\left(\mathrm{ClO}_{4}\right)_{2} \cdot 6 \mathrm{H}_{2} \mathrm{O}(0.37 \mathrm{mmol}, 2 \mathrm{Äq})$ und $22 \mathrm{mg}$ Natriumacetat $(0.27 \mathrm{mmol}, 1.5 \mathrm{Äq})$ zugefügt und bei Raumtemperatur $12 \mathrm{~h}$ gerührt. Nach Filtration wurde die Lösung mit $20 \mathrm{ml}$ Methanol verdünnt und anschließend mit Diethylether überschichtet. Die nach der Kristallisation erhaltenen farblosen Kristalle waren für die Röntgenstrukturanalyse geeignet.

Ausbeute:

$34 \mathrm{mg}, 20.7 \%$

Summenformel:

$\mathrm{C}_{31} \mathrm{H}_{64} \mathrm{Cl}_{2} \mathrm{~N}_{8} \mathrm{O}_{10} \mathrm{Zn}_{2}$

Molekulargewicht:

$910.57 \mathrm{~g} / \mathrm{mol}$

$\mathrm{IR}(\mathrm{KBr})$

$\tilde{v}=3436(\mathrm{~m}), 2979(\mathrm{~m}), 2943(\mathrm{~m}), 2879(\mathrm{~m}), 1576$

(s), $1439(\mathrm{~m}), 1385$ (m), 1267 (w), 1095 (vs), 912

(w), $793(w), 737(w), 623(s) \mathrm{cm}^{-1}$.

MS (ESI) $\mathrm{m} / \mathrm{z}(\%)$

$811.3(25)\left[\mathrm{L}^{7}{ }_{-\mathrm{H}}\left(\mu-\mathrm{CH}_{3} \mathrm{COO}\right)\left(\mathrm{ClO}_{4}\right) \mathrm{Zn}_{2}\right]^{+}$,

(in $\mathrm{MeOH}$ )

$356.4(100)\left[\mathrm{L}^{7}{ }_{-\mathrm{H}}\left(\mu-\mathrm{CH}_{3} \mathrm{COO}\right) \mathrm{Zn}_{2}\right]^{2+}$.

Elementaranalyse (\%) ber.: C 41.05, H 7.12, N 12.36

gef.: C 40.74, H 6.99, N 12.06 . 


\subsubsection{Synthese von $\left[\mathrm{L}^{6}{ }_{-\mathrm{H}}\left(\mu-\mathrm{CH}_{3} \mathrm{COO}\right) \mathrm{Zn}_{2}\right]\left(\mathrm{ClO}_{4}\right)_{2}(5)$}

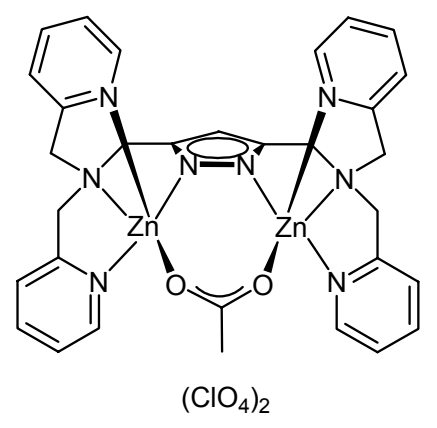

Zu einer Lösung von $L^{6}(170 \mathrm{mg}, 0.35 \mathrm{mmol})$ in $30 \mathrm{ml}$ Aceton wurden $39 \mathrm{mg}$ $\mathrm{KO}{ }^{\mathrm{t}} \mathrm{Bu}(0.35 \mathrm{mmol}, 1 \mathrm{Äq}), 260 \mathrm{mg} \mathrm{Zn}\left(\mathrm{ClO}_{4}\right)_{2} \cdot 6 \mathrm{H}_{2} \mathrm{O}(0.70 \mathrm{mmol}, 2 \mathrm{Äq})$ und $33 \mathrm{mg}$ Natriumacetat $(0.40 \mathrm{mmol}, 1 \mathrm{Äq})$ zugefügt und bei Raumtemperatur $12 \mathrm{~h}$ gerührt. Nach Filtration wurde die Lösung mit Diethylether überschichtet. Die erhaltenen farblosen Kristalle waren für die Röntgenstrukturanalyse geeignet.

Ausbeute:

Summenformel:

Molekulargewicht:

${ }^{1} \mathrm{H}-\mathrm{NMR}$

(DMSO, $500.13 \mathrm{MHz}$ )

$\mathrm{IR}(\mathrm{KBr})$

MS (ESI) $\mathrm{m} / \mathrm{z}(\%)$

(in $\mathrm{MeOH}$ )

Hochauflösende Masse (ESI) (in MeCN)
$3 \mathrm{mg}, 1 \%$

$\mathrm{C}_{31} \mathrm{H}_{32} \mathrm{Cl}_{2} \mathrm{~N}_{8} \mathrm{O}_{10} \mathrm{Zn}_{2}$

$878.32 \mathrm{~g} / \mathrm{mol}$

$\delta=3.99\left(\mathrm{~s}, 4 \mathrm{H}, \mathrm{PzCH}_{2}\right), 4.19\left(\mathrm{~d},{ }^{2} \mathrm{JHH}_{\mathrm{HH}}=6.2 \mathrm{~Hz}, 8 \mathrm{H}\right.$, $\left.\mathrm{PyCH}_{2}\right), 6.11\left(\mathrm{~s}, 1 \mathrm{H}, \mathrm{CH}^{\mathrm{Pz}}\right), 7.60-7.65(\mathrm{~m}, 8 \mathrm{H}$, $\mathrm{CH}_{\mathrm{B}}{ }^{\mathrm{Py}}$ und $\left.\mathrm{CH}_{\mathrm{D}}{ }^{\mathrm{Py}}\right), 8.09-8.11\left(\mathrm{~m}, 4 \mathrm{H}, \mathrm{CH}_{\mathrm{C}}{ }^{\mathrm{Py}}\right)$, 8.66 - $8.67\left(\mathrm{~m}, 4 \mathrm{H}, \mathrm{CH}_{\mathrm{D}}^{\mathrm{Py}}\right) \mathrm{ppm}$.

$\tilde{v}=3436$ (vs), $2923(\mathrm{w}), 1706(\mathrm{w}), 1610(\mathrm{~m}), 1563$ (m), $1483(w), 1440(m), 1262$ (w), 1093 (vs), 801 (w), $768(\mathrm{w}), 623(\mathrm{~m}) \mathrm{cm}^{-1}$.

$779.0(5)\left[\mathrm{L}^{6}{ }_{-\mathrm{H}}\left(\mu-\mathrm{CH}_{3} \mathrm{COO}\right)\left(\mathrm{ClO}_{4}\right) \mathrm{Zn}_{2}\right]^{+}$ $339.3(25)\left[\mathrm{L}^{6}{ }_{-\mathrm{H}}\left(\mu-\mathrm{CH}_{3} \mathrm{COO}\right) \mathrm{Zn}_{2}\right]^{2+}$ $332.2(100)\left[\mathrm{L}^{6}{ }_{-\mathrm{H}}(\mu-\mathrm{HCOO}) \mathrm{Zn}_{2}\right]^{2+}$.

ber.: $\left[\mathrm{L}^{6}{ }_{\mathrm{H}} \mathrm{H}\left(\mu-\mathrm{CH}_{3} \mathrm{COO}\right) \mathrm{Zn}_{2}\right]^{2+} 338.06155$ gef.: 338.06101. 


\subsubsection{Synthese von $\left[\mathrm{L}^{6}{ }_{-\mathrm{H}}(\mu-\mathrm{HCOO}) \mathrm{Zn}_{2}\right]\left(\mathrm{ClO}_{4}\right)_{2}(6)$}

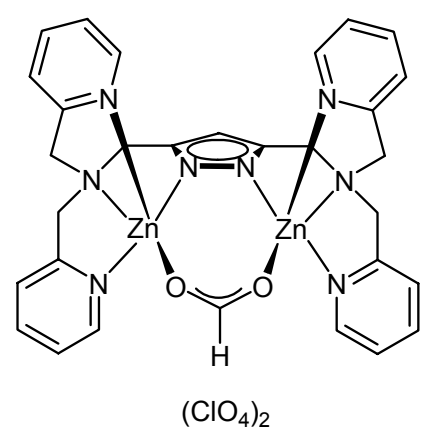

Zu einer Lösung von $\mathrm{L}^{6}$ (155 mg, $\left.0.316 \mathrm{mmol}\right)$ in $30 \mathrm{ml}$ trockenem DMF wurden unter $\mathrm{N}_{2}$-Atmosphäre $71.4 \mathrm{mg} \quad \mathrm{KO} \mathrm{Bu} \quad(0.636 \mathrm{mmol}, 2$ Äq), 240mg $\mathrm{Zn}\left(\mathrm{ClO}_{4}\right)_{2} \cdot 6 \mathrm{H}_{2} \mathrm{O}(0.634 \mathrm{mmol}, 2 \mathrm{Äq})$ und $62.5 \mathrm{mg}$ Glycin-p-nitroanilide ( $0.320 \mathrm{mmol}, 1 \mathrm{Äq}$ ) zugefügt und bei Raumtemperatur $12 \mathrm{~h}$ gerührt. Die leicht gelbe Suspension wurde unter $\mathrm{N}_{2}$-Atmosphäre abfiltriert und mit $20 \mathrm{ml}$ trockenem DMF verdünnt. Um die Anwesenheit von Wasser zu vermeiden, wurde zu der Mutterlösung Molsieb $4 \AA$ zugefügt. Die Lösung wurde mit trockenem Diethylether überschichtet. Die nach Kristallisation erhaltenen hellgelben Kristalle waren für die Röntgenstrukturanalyse geeignet.

Ausbeute:

$22 \mathrm{mg}, 8.1 \%$

Summenformel:

$\mathrm{C}_{30} \mathrm{H}_{30} \mathrm{Cl}_{2} \mathrm{~N}_{8} \mathrm{O}_{10} \mathrm{Zn}_{2}$

Molekulargewicht:

$864.29 \mathrm{~g} / \mathrm{mol}$

${ }^{1} \mathrm{H}-\mathrm{NMR}$

$\delta=4.04\left(\mathrm{~s}, 4 \mathrm{H}, \mathrm{CH}_{2} \mathrm{Pz}\right), 4.24\left(\mathrm{q},{ }^{2} \mathrm{~J}_{\mathrm{HH}}=16.6 \mathrm{~Hz} 8 \mathrm{H}\right.$,

(DMSO, $500.13 \mathrm{MHz}$ )

$\left.\mathrm{CH}_{2} \mathrm{Py}\right), 6.15\left(\mathrm{~s}, 1 \mathrm{H}, \mathrm{H}^{\mathrm{Pz}}\right), 7.64\left(\mathrm{~m}, 8 \mathrm{H}, \mathrm{CH}_{\mathrm{D}}{ }^{\mathrm{Py}}\right.$ und $\mathrm{CH}_{\mathrm{B}}^{\mathrm{Py}}$ ), $8.12\left(\mathrm{td},{ }^{3} \mathrm{~J}_{\mathrm{HH}}=7.7 \mathrm{~Hz},{ }^{4} \mathrm{~J}_{\mathrm{HH}}=1.3 \mathrm{~Hz}\right.$, $\left.\mathrm{CH}_{\mathrm{C}}{ }^{\mathrm{Py}}\right), 8.74\left(\mathrm{~d},{ }^{3} \mathrm{~J}_{\mathrm{HH}}=4.9 \mathrm{~Hz}, \mathrm{CH}_{\mathrm{A}}{ }^{\mathrm{Py}}\right), 9.24(\mathrm{~s}, 1 \mathrm{H}$, $\mathrm{CH}^{\text {Form }) ~ p p m . ~}$

${ }^{13} \mathrm{C}-\mathrm{NMR}$ $\delta=52.3\left(\mathrm{CH}_{2} \mathrm{Pz}\right), 57.5\left(\mathrm{CH}_{2} \mathrm{Py}\right), 100.3\left(\mathrm{C}^{4 \mathrm{Pz}}\right), 124.9$

(DMSO, $125.77 \mathrm{~Hz}$ )

$\left(\mathrm{CH}_{\mathrm{B}}{ }^{\mathrm{Py}}\right), \quad 125.0\left(\mathrm{CH}_{\mathrm{B}}^{\mathrm{Py}}\right), \quad 141.3 \quad\left(\mathrm{CH}_{\mathrm{D}}^{\mathrm{Py}}\right), \quad 147.8$ $\left(\mathrm{CH}_{\mathrm{C}}^{\mathrm{Py}}\right), 150.9\left(\mathrm{CH}_{\mathrm{A}}^{\mathrm{Py}}\right), 155.9\left(\mathrm{C}_{\mathrm{q}}\right), 170.6\left(\mathrm{C}^{\mathrm{Form}}\right)$ ppm.

$\mathrm{IR}(\mathrm{KBr})$

$\tilde{v}=3437(w), 2920(w), 2261(w), 1668(w), 1595(s)$, $1485(w), 1439(w), 1381(w), 1259(w), 1155(w)$, 
1095 (vs), $804(w), 769(w), 623(m), 504(w), 418$ (w) $\mathrm{cm}^{-1}$.

MS (ESI) $\mathrm{m} / \mathrm{z}(\%) \quad 779.1(30)\left[\mathrm{L}^{6}{ }_{-\mathrm{H}}(\mathrm{MeOH})(\mathrm{MeO})\left(\mathrm{ClO}_{4}\right) \mathrm{Zn}_{2}\right]^{+}$, (in $\mathrm{MeOH}$ ) $765.0(100)\left[\mathrm{L}^{6}{ }_{-\mathrm{H}}(\mu-\mathrm{HCOO})\left(\mathrm{ClO}_{4}\right) \mathrm{Zn}_{2}\right]^{+}$, $333.2(15)\left[\mathrm{L}^{6}{ }_{-\mathrm{H}}(\mu-\mathrm{HCOO}) \mathrm{Zn}_{2}\right]^{2+}$.

\subsubsection{Synthese von $\left[\left(\mathrm{L}^{1}{ }_{-\mathrm{H}}\right)_{2} \mathrm{Zn}_{2}\right]\left(\mathrm{CF}_{3} \mathrm{SO}_{3}\right)_{2}(7)$}

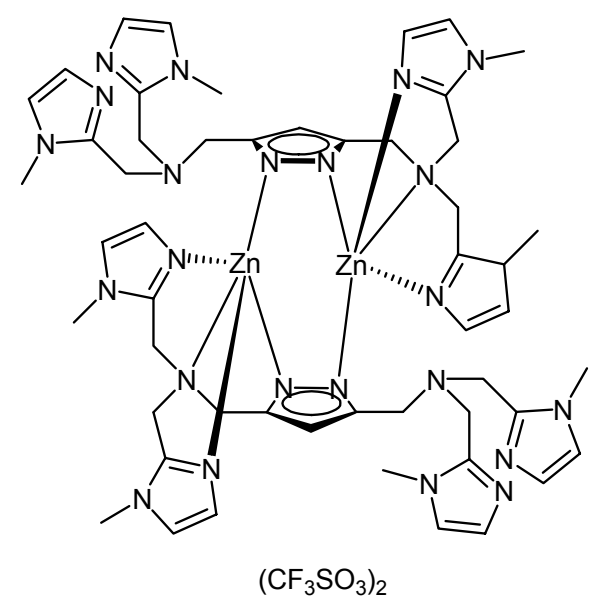

Eine Suspension von $\mathrm{L}^{1}(420 \mathrm{mg}, 0.84 \mathrm{mmol})$ in $50 \mathrm{ml}$ Wasser wurde bis zur vollständigen Auflösung der Substanz erwärmt. Anschließend wurden $94 \mathrm{mg}$ $\mathrm{KO}{ }^{\mathrm{t}} \mathrm{Bu}(84 \mathrm{mmol}, 1 \mathrm{Äq})$ und $630 \mathrm{mg} \mathrm{Zn}\left(\mathrm{CF}_{3} \mathrm{SO}_{3}\right)_{2} \cdot 6 \mathrm{H}_{2} \mathrm{O}$ (169 mmol, $\left.2 \mathrm{Äq}\right)$ zugefügt. Die Suspension wurde $30 \mathrm{~min}$ auf $50{ }^{\circ} \mathrm{C}$ erwärmt und dann $12 \mathrm{~h}$ bei Raumtemperatur gerührt. Nach Filtration wurde der Niederschlag in $30 \mathrm{ml}$ siedendem Methanol gelöst und wieder abfiltriert. Die Lösung wurde mit Diethylether überschichtet. Die nach Kristallisation erhaltenen farblosen Kristalle waren für die Röntgenstrukturanalyse geeignet.

Ausbeute: $2 \mathrm{mg}, 0.8 \%$

Summenformel: $\mathrm{C}_{52} \mathrm{H}_{66} \mathrm{~F}_{6} \mathrm{~N}_{24} \mathrm{O}_{6} \mathrm{~S}_{2} \mathrm{Zn}_{2}$

Molekulargewicht: $1432.14 \mathrm{~g} / \mathrm{mol}$ IR (KBr) $\tilde{v}=3436(\mathrm{~m}), 2924(\mathrm{w}), 2362(\mathrm{~m}), 1508(\mathrm{~m}), 1438$ 
(w), $1286(w), 1099(v s), 959(w), 875(w), 792(w)$, $759(\mathrm{w}), 623(\mathrm{w}) \mathrm{cm}^{-1}$.

MS (ESI) $\mathrm{m} / \mathrm{z}(\%)$

$345.3(100)\left[\mathrm{L}^{1}{ }_{-H}(\mathrm{MeOH})(\mathrm{MeO}) \mathrm{Zn}_{2}\right]^{2+}$.

(in $\mathrm{MeOH}$ )

\subsubsection{Synthese von $\left[\left(\mathrm{L}^{6}{ }_{-\mathrm{H}}\right)_{2}\left(\mathrm{OH}_{2}\right)\left(\mu_{3}-\mathrm{CO}_{3}\right) \mathrm{Zn}_{4}\right]\left(\mathrm{ClO}_{4}\right)_{4}(8)$}

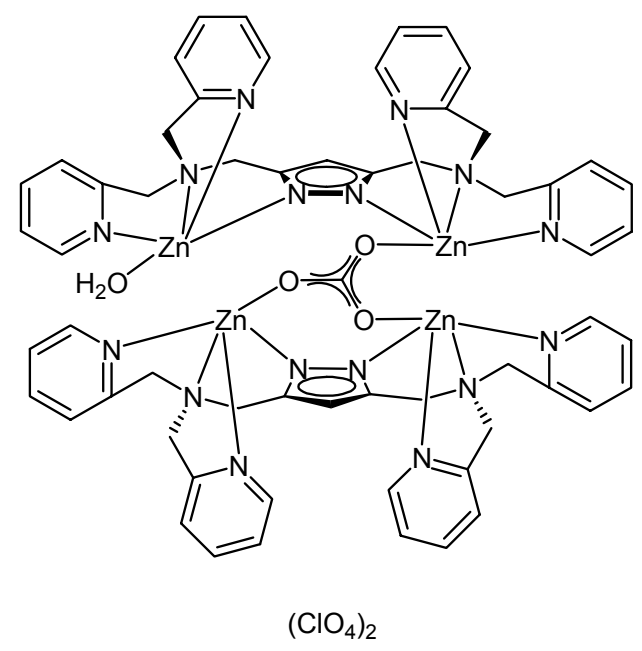

$44 \mathrm{mg}(0.05 \mathrm{mmol})\left[\mathrm{L}^{6}{ }_{-\mathrm{H}}(\mathrm{MeOH})(\mathrm{OH}) \mathrm{Zn}_{2}\right]\left(\mathrm{ClO}_{4}\right)_{2}$ wurden in $5 \mathrm{ml}$ einer bei $\mathrm{pH}=7.9$ mit HEPES $(0.05 \mathrm{M})$ gepufferten Lösung aus Acetonitril und Wasser (1:4) gelöst. Nach langsamer Abdampfung der Lösungsmittel wurden farblose Kristalle erhalten, die für die Röntgenstrukturanalyse geeignet waren.

Ausbeute:

$16 \mathrm{mg}, 9.3 \%$

Summenformel:

$\mathrm{C}_{59} \mathrm{H}_{60} \mathrm{Cl}_{4} \mathrm{~N}_{16} \mathrm{O}_{20} \mathrm{Zn}_{4}$

Molekulargewicht:

$1708.01 \mathrm{~g} / \mathrm{mol}$

${ }^{1} \mathrm{H}-\mathrm{NMR}$

$\delta=3.95\left(\mathrm{~s}, 8 \mathrm{H}, \mathrm{CH}_{2} \mathrm{Pz}\right), 4.11\left(\mathrm{q},{ }^{2} \mathrm{~J}_{\mathrm{HH}}=16.6 \mathrm{~Hz}\right.$,

$\left(\mathrm{CD}_{3} \mathrm{CN}, 500.13 \mathrm{MHz}\right)$ $\left.16 \mathrm{H}, \mathrm{CH}_{2} \mathrm{Py}\right), 6.16\left(\mathrm{~s}, 2 \mathrm{H}, \mathrm{H}^{\mathrm{Pz}}\right), 7.17$ (bs, 8H, $\mathrm{CH}_{\mathrm{D}}{ }^{\mathrm{Py}}$ ), $7.48\left(\mathrm{~d},{ }^{3} \mathrm{~J}_{\mathrm{HH}}=7.8 \mathrm{~Hz}, 8 \mathrm{H}, \mathrm{CH}_{\mathrm{B}}{ }^{\mathrm{Py}}\right), 7.89\left(\mathrm{t},{ }^{3} \mathrm{~J}_{\mathrm{HH}}=7.6\right.$ $\left.\mathrm{Hz}, 8 \mathrm{H}, \mathrm{CH}_{\mathrm{C}}^{\mathrm{Py}}\right), 8.71\left(\mathrm{~d},{ }^{3} \mathrm{JHH}_{\mathrm{HH}}=4.6 \mathrm{~Hz}, 8 \mathrm{H}, \mathrm{CH}_{\mathrm{A}}^{\mathrm{Py}}\right)$ ppm.

${ }^{13} \mathrm{C}-\mathrm{NMR}$ $\delta=52.4\left(\mathrm{PzCH}_{2}\right), 57.6\left(\mathrm{CH}_{2} \mathrm{Py}\right), 102.0\left(\mathrm{C}^{4 \mathrm{Pz}}\right), 125.8$ 


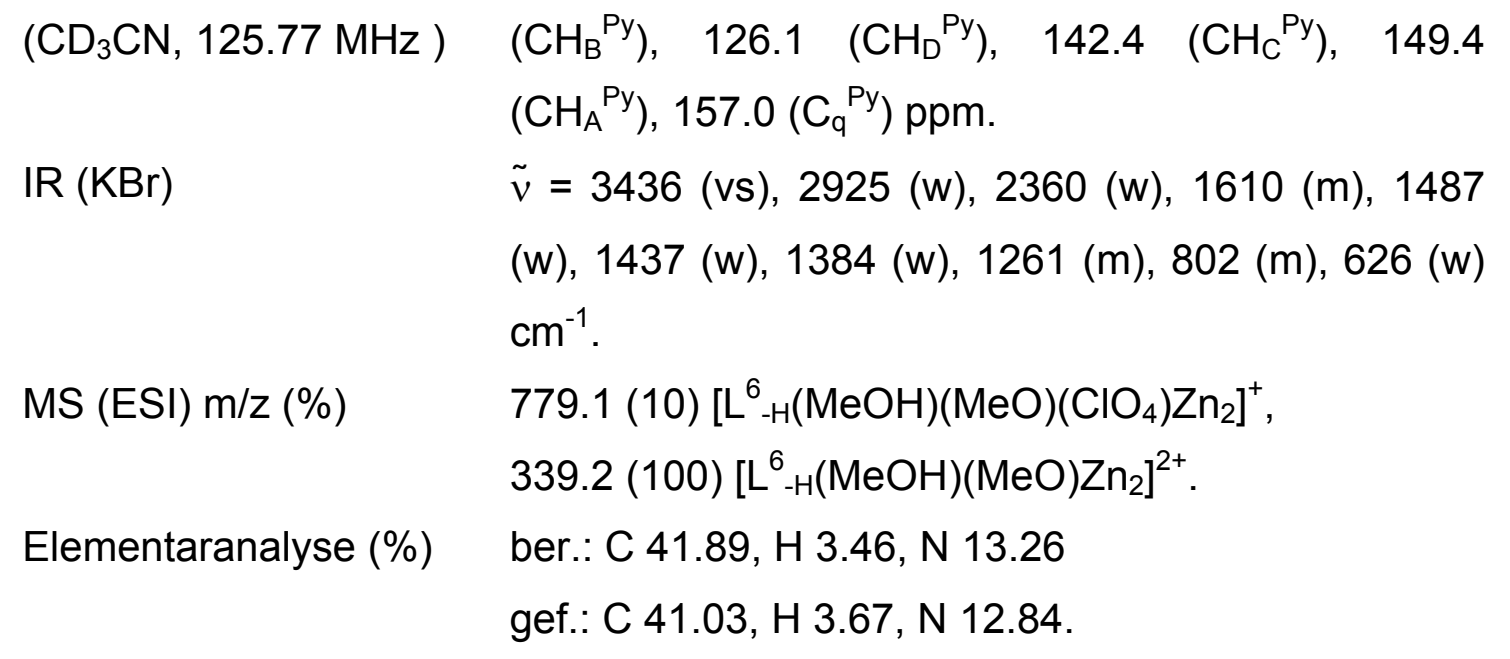

\subsubsection{Synthese von $\left[\mathrm{L}^{1}{ }_{\mathrm{H}}\left(\mu_{4}-\mathrm{CO}_{3}\right) \mathrm{Zn}_{4}\right]\left(\mathrm{BPh}_{4}\right)_{4}(9)$}

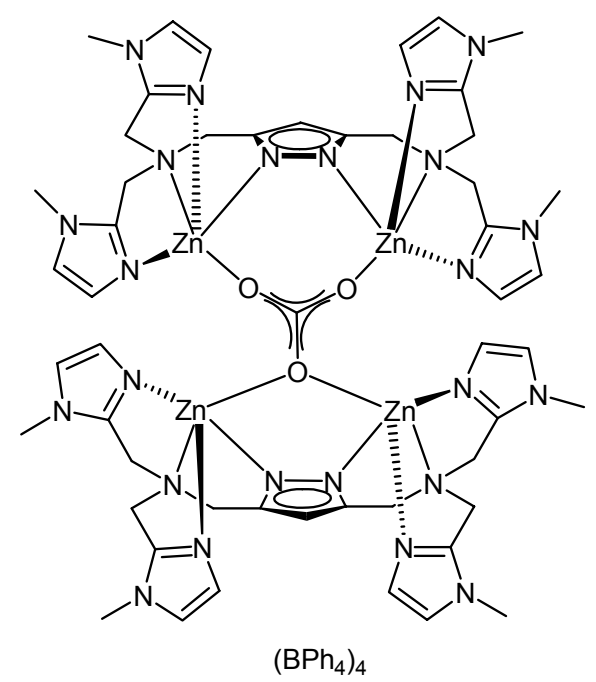

$82 \mathrm{mg}(0.16 \mathrm{mmol})$ von $\mathrm{L}^{1}$ wurden mit $40(0.35 \mathrm{mmol}, 2.2 \mathrm{Äq}) \mathrm{KO}{ }^{\mathrm{t}} \mathrm{Bu}$ und mit $0.1 \mathrm{~g}(0.34 \mathrm{mmol}, 2.1 \mathrm{Äq}) \mathrm{Zn}\left(\mathrm{ClO}_{4}\right)_{2} \cdot 6 \mathrm{H}_{2} \mathrm{O}$ in $50 \mathrm{ml}$ Methanol 12 Stunden gerührt. Die Suspension wurde abfiltriert und vom Lösungsmittel befreit. Der Rückstand wurde in $50 \mathrm{ml}$ Methanol wieder gelöst und $120 \mathrm{mg}(0.34 \mathrm{mmol}, 2.1$ Äq) Natriumtetraphenylborat zugegeben. Die weiße Suspension wurde 12 Stunden gerührt und dann erneut das Lösungsmittel im Vakuum entfernt. Das entstandene weiße Pulver wurde in einer Mischung von Acetonitril und Wasser 
gelöst. Nach langsamem Abdampfen des Lösungsmittels wurden farblose Kristalle erhalten, die für die Röntgenstrukturanalyse geeignet waren.

Ausbeute:

$14 \mathrm{mg}, 3.4 \%$

Summenformel:

$\mathrm{C}_{147} \mathrm{H}_{146} \mathrm{~B}_{4} \mathrm{~N}_{24} \mathrm{O}_{3} \mathrm{Zn}_{4}$

Molekulargewicht:

$2601.69 \mathrm{~g} / \mathrm{mol}$

IR ( $\mathrm{KBr})$

$\tilde{v}=2924(w), 2363(w), 2092(w), 1655$ (vs), 1629

(vs), $1579(\mathrm{~m}), 1502(\mathrm{~s}), 1479(\mathrm{~s}), 1426(\mathrm{~m}), 1385$

$(\mathrm{s}), 1163(\mathrm{~m}), 1130(\mathrm{~m}), 1087(\mathrm{w}), 1032(\mathrm{w}), 958$

$(\mathrm{m}), 869(\mathrm{w}), 847(\mathrm{w}) \mathrm{cm}^{-1}$.

MS (ESI) $\mathrm{m} / \mathrm{z}(\%)$

$1011.2\left[\left(\mathrm{~L}^{1}{ }_{-\mathrm{H}}\right)(\mathrm{MeOH})(\mathrm{MeO})\left(\mathrm{BPh}_{4}\right) \mathrm{Zn}_{2}\right]^{+}$,

(in $\mathrm{MeOH}$ )

$346.3(100)\left[\left(\mathrm{L}^{1}{ }_{-H}\right)(\mathrm{MeOH})(\mathrm{MeO}) \mathrm{Zn}_{2}\right]^{2+}$.

\subsubsection{Synthese von $\left[\mathrm{L}^{6}{ }_{-\mathrm{H}}\left(\mu-\mathrm{HOCH}_{2} \mathrm{CH}_{2} \mathrm{CH}_{2} \mathrm{COO}\right) \mathrm{Zn}_{2}\right]\left(\mathrm{ClO}_{4}\right)_{2}(10)$}

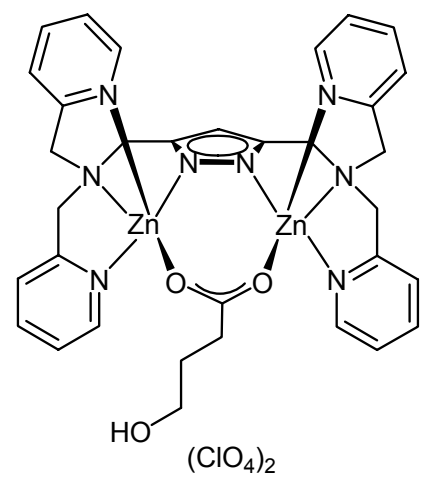

$400 \mathrm{mg}(0.46 \mathrm{mmol})$ von $\left[\mathrm{L}^{6}{ }_{-\mathrm{H}}(\mathrm{MeOH})(\mathrm{OH}) \mathrm{Zn}_{2}\right]\left(\mathrm{ClO}_{4}\right)_{2}$ wurden in $3 \mathrm{ml}$ $\gamma$-Butyrolacton gelöst und 7 Stunden bei $100{ }^{\circ} \mathrm{C}$ unter Rückfluss erhitzt. Anschließend wurde das Lösungsmittel in einer Hochvakuumanlage entfernt und das entstandende beigefarbene Pulver in $25 \mathrm{ml}$ einer Lösung aus Methanol und Acetonitril (4:1) gelöst und mit Diethylether überschichtet. Durch langsame Diffusion von Diethylether wurden leicht beigefarbene Kristalle erhalten, die für die Röntgenstrukturanalyse geeignet waren. 
Ausbeute:

Summenformel:

Molekulargewicht:

${ }^{1} \mathrm{H}-\mathrm{NMR}$

(DMSO, 500.13 MHz)

${ }^{13} \mathrm{C}-\mathrm{NMR}$

(DMSO, 125.75 MHz)

IR (KBr)

MS (ESI) m/z (\%)

Elementaranalyse (\%)
$19 \mathrm{mg}, 4.2 \%$

$\mathrm{C}_{33} \mathrm{H}_{36} \mathrm{Cl}_{2} \mathrm{~N}_{8} \mathrm{O}_{11} \mathrm{Zn}_{2}$

$992.37 \mathrm{~g} / \mathrm{mol}$

$\delta=2.17\left(\mathrm{q},{ }^{3} \mathrm{~J}_{\mathrm{HH}}=6.2 \mathrm{~Hz},{ }^{3} \mathrm{~J}_{\mathrm{HH}}=7.4 \mathrm{~Hz}, 2 \mathrm{H}\right.$, $\left.\mathrm{CH}_{2} \mathrm{CH}_{2} \mathrm{OH}\right), \quad 3.03\left(\mathrm{t},{ }^{3} \mathrm{~J}_{\mathrm{HH}}=7.4 \mathrm{~Hz}, 2 \mathrm{H}\right.$, $\left.\mathrm{CH}_{2} \mathrm{CH}_{2} \mathrm{CH}_{2} \mathrm{OH}\right), \quad 3.75\left(\mathrm{q},{ }^{3} \mathrm{~J}_{\mathrm{HH}}=6.2 \mathrm{~Hz}\right.$, $\left.{ }^{3} \mathrm{~J}_{\mathrm{HH}}=4.9 \mathrm{~Hz}, 2 \mathrm{H}, \mathrm{CH}_{2} \mathrm{OH}\right), 4.02$ (s, 4H, $\mathrm{PzCH}_{2}$ ), $4.22\left(\mathrm{q},{ }^{2} J_{\mathrm{HH}}=16.5 \mathrm{~Hz}, 8 \mathrm{H}, \mathrm{CH}_{2} \mathrm{Py}\right), 4.68\left(\mathrm{t},{ }^{3} J_{\mathrm{HH}}=\right.$ $4.9 \mathrm{~Hz}, 1 \mathrm{H}, \mathrm{OH}), 6.14\left(\mathrm{~s}, 1 \mathrm{H}, \mathrm{H}^{\mathrm{Pz}}\right), 7.63\left(\mathrm{~d},{ }^{3} \mathrm{~J}_{\mathrm{HH}}=7.9\right.$ $\left.\mathrm{Hz}, 4 \mathrm{H}, \mathrm{CH}_{\mathrm{D}}^{\mathrm{Py}}\right), 7.66\left(\mathrm{t},{ }^{3} \mathrm{~J}_{\mathrm{HH}}=4 \mathrm{H}, \mathrm{CH}_{\mathrm{B}}^{\mathrm{Py}}\right), 8.11$ (td, $\left.{ }^{3} J_{\mathrm{HH}}=7.6 \mathrm{~Hz},{ }^{4} J_{\mathrm{HH}}=1.0 \mathrm{~Hz}, 4 \mathrm{H}, \mathrm{CH}_{\mathrm{C}}{ }^{\mathrm{Py}}\right), 8.69\left(\mathrm{~d},{ }^{3} J_{\mathrm{HH}}\right.$ $=4.8 \mathrm{~Hz}, 4 \mathrm{H}, \mathrm{CH}_{\mathrm{A}}^{\mathrm{Py}}$ ) ppm.

$\delta=29.1\left(\mathrm{CH}_{2} \mathrm{CH}_{2} \mathrm{OH}\right), 34.4\left(\mathrm{CH}_{2} \mathrm{CH}_{2} \mathrm{CH}_{2} \mathrm{OH}\right), 52.3$

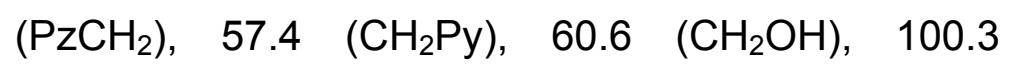
$(\mathrm{CHPz}), 125.0\left(\mathrm{CH}_{\mathrm{B}}^{\mathrm{Py}}\right), 125.1\left(\mathrm{CH}_{\mathrm{D}}^{\mathrm{Py}}\right), 141.3\left(\mathrm{CH}_{\mathrm{C}}^{\mathrm{Py}}\right)$, $147.8\left(\mathrm{CH}_{\mathrm{A}}{ }^{\mathrm{Py}}\right), 156.0\left(\mathrm{C}_{\mathrm{q}}{ }^{\mathrm{Py}}\right), 182.7\left(\mathrm{C}^{\text {Carbonyl }}\right) \mathrm{ppm}$.

$\tilde{v}=3433(\mathrm{~s}), 2929(\mathrm{w}), 2018(\mathrm{w}), 1610$ (s), 1562 (s), 1483 (w), 1439 (s), 1367 (w), 1267 (w), 1093 (vs), $1026(w), 958(w), 818(w), 765(m), 623(s) \mathrm{cm}^{-1}$.

$821.1(5)\left[\mathrm{L}^{6}{ }_{-\mathrm{H}}\left(\mu-\mathrm{HOCH}_{2} \mathrm{CH}_{2} \mathrm{CH}_{2} \mathrm{CHCOO}\right)\left(\mathrm{ClO}_{4}\right) \mathrm{Zn}_{2}\right]^{+}$, $777.1(12)\left[\mathrm{L}^{6}{ }_{-\mathrm{H}}(\mathrm{MeOH})(\mathrm{MeO})\left(\mathrm{ClO}_{4}\right) \mathrm{Zn}_{2}\right]^{+}$, $362.1(28)\left[\mathrm{L}^{6}{ }_{-H}\left(\mu-\mathrm{HOCH}_{2} \mathrm{CH}_{2} \mathrm{CH}_{2} \mathrm{CHCOO}\right) \mathrm{Zn}_{2}\right]^{2+}$, $339.3(100)\left[\mathrm{L}^{6}{ }_{-\mathrm{H}}(\mathrm{MeOH})(\mathrm{MeO}) \mathrm{Zn}_{2}\right]^{2+}$.

ber.: C 43.13, H 3.95, N 12.20 gef.: C 42.50, H 4.06, N 11.75. 


\subsubsection{Synthese von $\left[\mathrm{L}^{2}{ }_{\mathrm{H}} \mathrm{Ni}_{2}\left(\mathrm{NO}_{3}\right)_{2}\right]\left(\mathrm{NO}_{3}\right)(11)$}

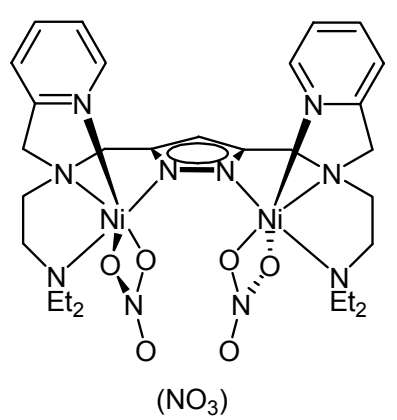

Zu einer Lösung von $\mathrm{L}^{2}$ (484 mg, $0.96 \mathrm{mmol}$ ) in $30 \mathrm{ml}$ Methanol wurden $126 \mathrm{mg}$ $\mathrm{KO}^{\mathrm{t}} \mathrm{Bu}(1.10 \mathrm{mmol}, 1.1 \mathrm{Äq})$ und $550 \mathrm{mg} \mathrm{Ni}\left(\mathrm{ClO}_{4}\right)_{2} \cdot 6 \mathrm{H}_{2} \mathrm{O}(2.20 \mathrm{mmol}, 2.1 \mathrm{Äq})$ zugefügt und bei Raumtemperatur $12 \mathrm{~h}$ gerührt. Anschließend wurden die Lösungsmittel entfernt und der Rückstand in $500 \mathrm{ml}$ demineralisiertem Wasser wieder gelöst und in einer SP Sephadex-Säule mit wäßriger $\mathrm{NaNO}_{3}$-Lösung als Eluent gereinigt. Von den gewonnenen Fraktionen mit unterschiedlichen Konzentrationen an $\mathrm{NaNO}_{3}$-Lösung wurde das Wasser im Vakuum entfernt, in $\mathrm{MeOH}$ gelöst, abfiltriert und mit Diethylether überschichtet. Aus der Fraktion, die bei Verwendung von $0.4 \mathrm{M} \mathrm{NaNO}_{3}$ gewonnen wurde, bildeten sich nach Überschichtung der methanolischen Lösung des Komplexes mit Diethylether blaue, für die Röntgenstrukturanalyse geeignete Kristalle.

Ausbeute: $\quad 8 \mathrm{mg}, 1 \%$

Summenformel: $\quad \mathrm{C}_{29} \mathrm{H}_{45} \mathrm{~N}_{11} \mathrm{O}_{9} \mathrm{Ni}_{2}$

Molekulargewicht: $\quad 807.21 \mathrm{~g} / \mathrm{mol}$

$\mathrm{IR}(\mathrm{KBr}) \quad \tilde{v}=2972(\mathrm{w}), 2926(\mathrm{w}), 1629(\mathrm{w}), 1551(\mathrm{w}), 1512$

(m), 1467 (s), 1381 (vs), 1301 (s), $1166(\mathrm{~m}), 1097$

(m), $1057(\mathrm{w}), 1010(\mathrm{~m}), 831(\mathrm{~m}) \mathrm{cm}^{-1}$.

MS (ESI) $\mathrm{m} / \mathrm{z}(\%) \quad 745.2(100)\left[\mathrm{L}^{2}{ }_{-} \mathrm{Ni}_{2}\left(\mathrm{NO}_{3}\right)_{2}\right]^{+}$. 


\subsubsection{Synthese von $\left[\mathrm{L}^{4}{ }_{-\mathrm{H}}\left(\mu-\mathrm{CH}_{3} \mathrm{COO}\right) \mathrm{Ni}_{2}\right]\left(\mathrm{ClO}_{4}\right)_{2}(12)$}

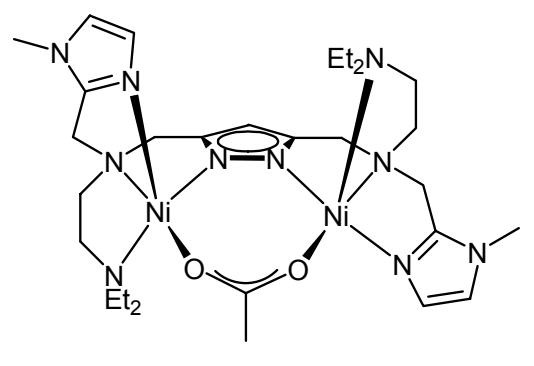

$\left(\mathrm{ClO}_{4}\right)_{2}$

Zu einer Lösung von $\mathrm{L}^{4}(172 \mathrm{mg}, 0.33 \mathrm{mmol})$ in $50 \mathrm{ml}$ Methanol wurden $31 \mathrm{mg}$ $\mathrm{KO} \mathrm{B} \mathrm{Bu}(0.34 \mathrm{mmol}, 1 \mathrm{Äq}), 250 \mathrm{mg} \mathrm{Ni}\left(\mathrm{ClO}_{4}\right)_{2} \cdot 6 \mathrm{H}_{2} \mathrm{O}(0.68 \mathrm{mmol}, 2 \mathrm{Äq})$ und $29 \mathrm{mg}$ Natriumacetat $(0.35 \mathrm{mmol}, 1 \mathrm{Äq})$ zugefügt und bei Raumtemperatur $12 \mathrm{~h}$ gerührt. Nachdem das Lösungsmittel entfernt und der Rückstand erneut in $30 \mathrm{ml}$ Methanol gelöst wurde, ist die grüne Lösung mit Diethylether überschichtet worden. Die dabei erhaltenen grünen Kristalle waren für die Röntgenstrukturanalyse geeignet.

Ausbeute:

Summenformel:

Molekulargewicht:

$\mathrm{IR}(\mathrm{KBr})$

MS (ESI) $\mathrm{m} / \mathrm{z}(\%)$

(in $\mathrm{MeOH}$ )

Hochauflösende Masse (ESI) (in MeCN)
$1.4 \mathrm{mg}, 0.5 \%$

$\mathrm{C}_{29} \mathrm{H}_{50} \mathrm{Cl}_{2} \mathrm{~N}_{10} \mathrm{O}_{10} \mathrm{Ni}_{2}$

$887.11 \mathrm{~g} / \mathrm{mol}$

$\tilde{v}=3428(\mathrm{~s}), 2965(\mathrm{~m}), 2016(\mathrm{w}), 1580(\mathrm{~s}), 1506(\mathrm{~m})$,

$1415(\mathrm{~m}), 1384$ (w), 1097 (vs), 623 (s), 570 (s) cm $\mathrm{cm}^{-1}$.

$787.2(25)\left[\mathrm{L}^{4}{ }_{-\mathrm{H}}\left(\mu-\mathrm{CH}_{3} \mathrm{COO}\right)\left(\mathrm{ClO}_{4}\right) \mathrm{Ni}_{2}\right]^{+}$, $336.2(100)\left[\mathrm{L}^{4}{ }_{-\mathrm{H}}(\mu-\mathrm{HCOO}) \mathrm{Ni}_{2}\right]^{2+}$.

ber.: $\left[\mathrm{L}^{4}{ }_{-\mathrm{H}}(\mu-\mathrm{COO}) \mathrm{Ni}_{2}\right]^{2+} 343.14124$

gef.: 343.14071

ber.: $\left[\mathrm{L}^{4}{ }_{\mathrm{H}}(\mu-\mathrm{HCOO}) \mathrm{Ni}_{2}\right]^{2+} 336.13342$

gef.: 336.13288. 


\subsubsection{Synthese von [DMelmDEtEtA $\left.\left(\mathrm{NO}_{3}\right) \mathrm{Cu}\right]\left(\mathrm{NO}_{3}\right)(13)$}

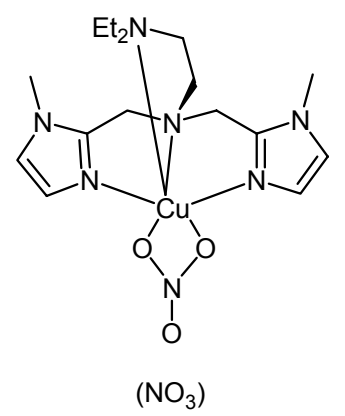

Methode A: Zu einer Lösung von $\mathrm{L}^{4}(300 \mathrm{mg}, 0.58 \mathrm{mmol})$ in $30 \mathrm{ml}$ Methanol wurden $72 \mathrm{mg} \mathrm{KO}{ }^{\mathrm{t}} \mathrm{Bu}(1.1 \mathrm{mmol}, 1.1 \mathrm{Äq})$ und $477 \mathrm{mg} \mathrm{Zn}\left(\mathrm{ClO}_{4}\right)_{2} \cdot 6 \mathrm{H} 2 \mathrm{O}$ (2.20 mmol, 2.1 Äq) zugefügt und bei Raumtemperatur $12 \mathrm{~h}$ gerührt. Danach wurde das Lösungsmittel entfernt, der Rückstand in $500 \mathrm{ml}$ demineralisiertem Wasser gelöst und mittels einer SP Sephadex Säule mit wässriger $\mathrm{NaNO}_{3}$ Lösung als Eluent gereinigt. Von den mit unterschiedlichen Konzentrationen der $\mathrm{NaNO}_{3}$-Lösung gewonnenen Fraktionen wurde das Wasser im Vakuum entfernt und in $\mathrm{MeOH}$ gelöst, abfiltriert und mit Diethylether überschichtet. Aus der Fraktion, die mit $0.2 \mathrm{M} \mathrm{NaNO} 3$ erhalten wurde, zeigten sich nach Überschichtung einer methanolischen Lösung des Komplexes mit Diethylether blaue, für die Röntgenstrukturanalyse geeignete Kristalle.

Methode B: Dieselben Kristalle wurden aus einer acetonischen Lösung des Komplexes, die mit PE überschichtet wurde, erhalten.

Ausbeute: $25 \mathrm{mg}, 8.7 \%$

Summenformel: $\mathrm{C}_{16} \mathrm{H}_{28} \mathrm{~N}_{8} \mathrm{O}_{6} \mathrm{Cu}$

Molekulargewicht: $492.0 \mathrm{~g} / \mathrm{mol}$ IR ( $\mathrm{KBr})$ $\tilde{v}=3433(s), 3111(w), 2974(w), 1627(w), 1550(w)$, 1512 (w), 1512 (w), 1469 (m), 1381 (vs), 1343 (vs), 1301 (s), 1166 (w), 1097 (w), 1010 (w), 832 (w), 761 (w), $664(\mathrm{w}) \mathrm{cm}^{-1}$.

MS (ESI) m/z (\%) $429.0(90)\left[\text { DmelmDEtEtA }\left(\mathrm{NO}_{3}\right) \mathrm{Cu}\right]^{+}$. (in $\mathrm{MeOH}$ )

Elementaranalyse (\%) ber.: C 39.09, H 5.74, N 22.81 gef.: C 38.68, H 5.68, N 22.10. 


\subsection{Untersuchungen mit $p$-Nitrophenylacetat}

\subsubsection{Kinetische Messungen der $p$-Nitrophenylacetathydrolyse mittels UVIVis-Spektroskopie}

Die kinetischen Messungen wurden auf einem Specord S 100 Spektrometer der Firma Analytik Jena unter Verwendung eines thermostatisierten 10-fach Küvettenwechslers für Quarzküvetten der Dicke $1.0 \mathrm{~cm}$ (Suprasil QS Firma Hellma) aufgenommen.

Die kinetischen Messungen zur $p$-Nitrophenylacetat-Hydrolyse wurden bei $25^{\circ} \mathrm{C}$ in gepufferten Lösungen von Acetonitril und Wasser (1:4) durchgeführt. HEPES (N-(2-Hydroxyethyl)piperazin-N'-2-propansulfonsäure) und BIS-TRIS $0.05 \mathrm{M}$ wurden als Puffer benutzt. Die Konzentrationen der Standardlösungen der Komplexe in Acetonitril/Wasser (1:4) betrugen von $0.04 \mathrm{mM}$ bis $0.8 \mathrm{mM}$ für den Komplex XLI (100- bis 5- facher Unterschuss) und von $0.4 \mathrm{mM}$ bis 4.8 mMol (36- bis 4- facher Unterschuss) für den Komplex XLII.

In einem typischen Experiment wurden $0.3 \mathrm{ml}$ der Pufferlösung zu $0.2 \mathrm{ml}$ (2 $\mu \mathrm{mol})$ der Komplexlösung in einer thermostatisierten Küvette gegeben. Nach 5 min Äquilibrierung wurden $2.0 \mathrm{ml}(20 \mu \mathrm{mol})$ der p-Nitrophenylacetat-Lösung zugefügt und die Datensammlung sofort gestartet. Die Hydrolyse von p-Nitrophenylacetat wurde durch den Anstieg der Extinktion von 4-Nitrophenolat bei $405 \mathrm{~nm}$ verfolgt. Die Umrechnung von Extinktion in Konzentration wurde mit Hilfe des Lambert-Beer'schen Gesetzes $A=\varepsilon_{\text {eff }} \cdot C \cdot d$ vorgenommen. Zur Bestimmung von Eeff wurden unter identischen Bedingungen die Extinktionen von 4-Nitrophenolat bestimmt, indem eine Eichgerade mit jeweils vier Messpunkten aufgestellt wurde.

Die Aktivität der Komplexe wurde nach der Methode der Anfangsgeschwindigkeiten bestimmt. Für jeden Messpunkt wurden mindestens zwei unabhängige Messungen durchgeführt. 


\subsubsection{ESI-MS Untersuchungen}

Die untersuchten Komplexe wurden in Lösung hergestellt. Zu dem entsprechenden, in Methanol oder Acetonitril/Wasser gelösten, Ligand wurden zwei Äquivalente Kalium-tert-butylat und zwei Äquivalente Zinkperchlorat Hexahydrat zugegeben. Die Mischung wurde 12 Stunden gerührt und anschließend abfiltriert. Aus der methanolischen Lösung wurde ein ESIMassenspektrum gemessen.

$\mathrm{Zu}$ einer Lösung des entsprechenden Komplexes in Methanol oder Acetonitril/Wasser (1:4) wurden fünf Äquivalente $p$-Nitrophenylacetat zugegeben und nach 5 Minuten das Reaktionsgemisch im ESI-Massenspektrometer gemessen.

\section{$6.6{ }^{1} \mathrm{H}-N M R$ Untersuchungen}

Für die Verfolgung der Öffnung des $\gamma$-Butyrolactons mittels ${ }^{1} \mathrm{H}-\mathrm{NMR}$ wurde zuerst der Komplex $\left[\mathrm{L}_{(-\mathrm{H})}^{6}(\mathrm{MeO})(\mathrm{OH}) \mathrm{Zn}_{2}\right]$ in DMSO- $\mathrm{d}_{6}$ gelöst und bei $30{ }^{\circ} \mathrm{C}$ ein NMR-Spektrum aufgenommen. Anschließend wurde ein Äquivalent $\gamma$-Butyrolacton zugegeben und alle 15 Minuten ${ }^{1} \mathrm{H}$-NMR-Spektren aufgenommen bis die Reaktion beendet war.

\subsection{Röntgenstrukturanalyse}

\subsubsection{Allgemeines}

Die Bestimmung der Elementarzelle und die Sammlung der Messdaten erfolgte an einem STOE IPDS II Gerät, einem Vierkreisdiffraktometer mit OffsetEulerwiege der Firma Huber mit einem Bruker SMART 6K CCD-Zähler mit graphitmonochromatisierter Mo-K $\mathrm{K}_{\alpha}$-Strahlung $(\lambda=0.711 \AA)$.

Die Messwerte wurden bezüglich Lorentz- und Polarisationseffekten korrigiert. Zusätzlich erfolgten Absorptionskorrekturen. Die Lösung und Verfeinerung 
wurde mit den Programmen SHELXS-97und SHELXL-97 durchgeführt. ${ }^{[136,137]}$ Bei den angegebenen Kristalldaten und den folgenden Gitterkonstanten sind in Klammern hinter den jeweiligen Werten die Standardabweichungen in Einheiten der letzten Dezimale angegeben.

Die Röntgenstrukturanalysen wurden von Dr. Sebastian Dechert an der GeorgAugust-Universität Göttingen durchgeführt. 


\subsubsection{Röntgenographischer Anhang}

\begin{tabular}{|c|c|c|}
\hline Verbindung & $1 a$ & 1b \\
\hline Formel & $\mathrm{C}_{33} \mathrm{H}_{48} \mathrm{Cl}_{2} \mathrm{~N}_{12} \mathrm{O}_{12} \mathrm{Zn}_{2}$ & $\mathrm{C}_{31} \mathrm{H}_{42} \mathrm{Cl}_{2} \mathrm{~N}_{14} \mathrm{O}_{10} \mathrm{Zn}_{2}$ \\
\hline$M\left[\mathrm{~g} \cdot \mathrm{mol}^{-1}\right]$ & 1006.47 & 972.43 \\
\hline Kristallgröße [mm] & $0.42 \times 0.39 \times 0.12$ & $0.26 \times 0.22 \times 0.16$ \\
\hline Kristallsystem & Triklin & Monoklin \\
\hline Raumgruppe & $P-1$ & $C 2_{1} / \mathrm{c}$ \\
\hline$a[\AA]$ & $12.9694(6)$ & $26.741(2)$ \\
\hline$b[\AA]$ & $13.0764(6)$ & $11.0821(8)$ \\
\hline$c[\AA]$ & $14.3683(5)$ & $17.5492(14)$ \\
\hline$\alpha\left[^{\circ}\right]$ & $93.360(2)$ & 90 \\
\hline$\beta\left[^{\circ}\right]$ & $113.841(2)$ & $127.472(4)$ \\
\hline$\gamma\left[{ }^{\circ}\right]$ & $98.791(2)$ & 90 \\
\hline$V\left[\AA^{3}\right]$ & $2183.03(16)$ & $4127.4(5)$ \\
\hline$Z$ & 2 & 4 \\
\hline$\rho_{\text {ber. }}\left[\mathrm{g} \cdot \mathrm{cm}^{-3}\right]$ & 1.531 & 1.565 \\
\hline$\mu\left(\mathrm{Mo}-\mathrm{K}_{\alpha}\right)\left[\mathrm{mm}^{-1}\right]$ & 1.293 & 1.362 \\
\hline$F(000)$ & 1040 & 2000 \\
\hline$\theta$ Bereich $\left[^{\circ}\right]$ & $1.79-26.00$ & $1.92-24.85$ \\
\hline$h k l$ Bereich & $\pm 15, \pm 16,-17$ bis 12 & $\pm 31,-13$ bis $12, \pm 20$ \\
\hline Gemessene Reflexe & 26206 & 10448 \\
\hline Unabhängige Reflexe $\left[R_{\text {int }}\right]$ & $8349[0.0569]$ & $3440[0.0376]$ \\
\hline Verfeinerte Parameter & 635 & 269 \\
\hline Goodness-of-Fit & 1.060 & 1.039 \\
\hline$R 1(I>2 \sigma(I))$ & 0.0581 & 0.0555 \\
\hline wR2 (alle Daten) & 0.1791 & 0.1577 \\
\hline Restelektronendichte $\left[\mathrm{e} \AA^{-3}\right]$ & $0.881 /-0.799$ & $0.763 /-0.618$ \\
\hline
\end{tabular}




\begin{tabular}{|c|c|c|}
\hline Verbindung & 2 & 3 \\
\hline Formel & $\mathrm{C}_{32} \mathrm{H}_{56} \mathrm{Cl}_{2} \mathrm{~N}_{10} \mathrm{O}_{11} \mathrm{Zn}_{2}$ & $\mathrm{C}_{32.5} \mathrm{H}_{41} \mathrm{Cl}_{2} \mathrm{~N}_{10} \mathrm{O}_{10.5} \mathrm{Zn}_{2}$ \\
\hline$M\left[\mathrm{~g} \cdot \mathrm{mol}^{-1}\right]$ & 958.51 & 941.39 \\
\hline Kristallgröße [mm] & $0.48 \times 0.46 \times 0.38$ & $0.38 \times 0.36 \times 0.31$ \\
\hline Kristallsystem & Monoklin & Monoklin \\
\hline Raumgruppe & $C 2_{1} / \mathrm{c}$ & $P 2_{1} / \mathrm{C}$ \\
\hline$a[\AA]$ & $14.4323(7)$ & $18.8375(9)$ \\
\hline$b[\AA]$ & $23.4883(11)$ & $13.8401(8)$ \\
\hline$c[\AA]$ & $25.8756(11)$ & $16.1020(8)$ \\
\hline$\alpha\left[^{\circ}\right]$ & 90 & 90 \\
\hline$\beta\left[^{\circ}\right]$ & $100.449(3)$ & $112.346(3)$ \\
\hline$\gamma\left[{ }^{\circ}\right]$ & 90 & 90 \\
\hline$V\left[\AA^{3}\right]$ & $8626.1(7)$ & $3882.7(3)$ \\
\hline Z & 8 & 4 \\
\hline$\rho_{\text {ber. }}\left[\mathrm{g} \cdot \mathrm{cm}^{-3}\right]$ & 1.476 & 1.610 \\
\hline$\mu\left(\mathrm{Mo}-\mathrm{K}_{\alpha}\right)\left[\mathrm{mm}^{-1}\right]$ & 1.301 & 1.444 \\
\hline$F(000)$ & 4000 & 1936 \\
\hline$\theta$ Bereich $\left[{ }^{\circ}\right]$ & $1.60-24.77$ & $1.88-24.82$ \\
\hline$h k l$ Bereich & $\pm 16, \pm 27, \pm 30$ & -21 bis $22, \pm 16, \pm 18$ \\
\hline Gemessene Reflexe & 23184 & 24325 \\
\hline Unabhängige Reflexe $\left[R_{\text {int }}\right]$ & $13703[0.0283]$ & $6648[0.0367]$ \\
\hline Verfeinerte Parameter & 1023 & 511 \\
\hline Goodness-of-Fit & 1.007 & 1.045 \\
\hline$R 1(I>2 \sigma(I))$ & 0.0519 & 0.0403 \\
\hline wR2 (alle Daten) & 0.1376 & 0.1095 \\
\hline Restelektronendichte $\left[\mathrm{e} \AA^{-3}\right]$ & $1.094 /-0.420$ & $0.942 /-1.061$ \\
\hline
\end{tabular}




\begin{tabular}{|c|c|c|}
\hline Verbindung & 4 & 5 \\
\hline Formel & $\mathrm{C}_{32} \mathrm{H}_{68} \mathrm{Cl}_{2} \mathrm{~N}_{8} \mathrm{O}_{11} \mathrm{Zn}_{2}$ & $\mathrm{C}_{34} \mathrm{H}_{38} \mathrm{Cl}_{2} \mathrm{~N}_{8} \mathrm{O}_{11} \mathrm{Zn}_{2}$ \\
\hline$M\left[\mathrm{~g} \cdot \mathrm{mol}^{-1}\right]$ & 942.58 & 936.36 \\
\hline Kristallgröße [mm] & $0.47 \times 0.34 \times 0.29$ & $0.31 \times 0.18 \times 0.11$ \\
\hline Kristallsystem & Monoklin & Monoklin \\
\hline Raumgruppe & $P 2_{1} / \mathrm{c}$ & $P 2_{1} / \mathrm{c}$ \\
\hline$a[\AA \AA]$ & $18.6857(11)$ & $17.8409(13)$ \\
\hline$b[\AA]]$ & $14.7866(8)$ & $15.4721(8)$ \\
\hline$c[\AA]$ & $15.8634(8)$ & $14.9536(12)$ \\
\hline$\alpha\left[^{\circ}\right]$ & 90 & 90 \\
\hline$\beta\left[^{\circ}\right]$ & $103.557(5)$ & $106.446(6)$ \\
\hline$\gamma\left[{ }^{\circ}\right]$ & 90 & 90 \\
\hline$V\left[\AA^{3}\right]$ & $4260.9(4)$ & $3958.9(5)$ \\
\hline$Z$ & 4 & 4 \\
\hline$\rho_{\text {ber. }}\left[\mathrm{g} \cdot \mathrm{cm}^{-3}\right]$ & 1.469 & 1.571 \\
\hline$\mu\left(\mathrm{Mo}-\mathrm{K}_{\alpha}\right)\left[\mathrm{mm}^{-1}\right]$ & 1.314 & 1.415 \\
\hline$F(000)$ & 1992 & 1920 \\
\hline$\theta$ Bereich $\left[{ }^{\circ}\right]$ & $1.78-24.84$ & $1.77-24.70$ \\
\hline$h k l$ Bereich & -22 bis $21, \pm 17, \pm 18$ & $\pm 20, \pm 18, \pm 17$ \\
\hline Gemessene Reflexe & 25291 & 62504 \\
\hline Unabhängige Reflexe $\left[R_{\text {int }}\right]$ & $7254[R($ int $)=0.0509]$ & $6697[\mathrm{R}(\mathrm{int})=0.1510]$ \\
\hline Verfeinerte Parameter & 525 & 533 \\
\hline Goodness-of-Fit & 1.041 & 1.013 \\
\hline$R 1(I>2 \sigma(I))$ & 0.0420 & 0.0516 \\
\hline wR2 (alle Daten) & 0.1093 & 0.0811 \\
\hline Restelektronendichte $\left[\mathrm{e} \AA^{-3}\right]$ & $0.896 /-0.596$ & $0.409 /-0.413$ \\
\hline
\end{tabular}




\begin{tabular}{|c|c|c|}
\hline Verbindung & 6 & 7 \\
\hline Formel & $\mathrm{C}_{33} \mathrm{H}_{37} \mathrm{~N}_{9} \mathrm{Cl}_{2} \mathrm{O}_{11} \mathrm{Zn}_{2}$ & $\mathrm{C}_{52} \mathrm{H}_{66} \mathrm{~F}_{6} \mathrm{~N}_{24} \mathrm{O}_{6} \mathrm{~S}_{2} \mathrm{Zn}_{2}$ \\
\hline$M\left[\mathrm{~g} \cdot \mathrm{mol}^{-1}\right]$ & 937.36 & 1432.15 \\
\hline Kristallgröße [mm] & $0.21 \times 0.16 \times 0.11$ & $0.49 \times 0.42 \times 0.38$ \\
\hline Kristallsystem & Monoklin & Triklin \\
\hline Raumgruppe & $P 2_{1} / \mathrm{a}$ & $P-1$ \\
\hline$a[\AA]$ & $15.5386(7)$ & $9.5356(7)$ \\
\hline$b[\AA]$ & $14.7277(10)$ & $13.6989(11)$ \\
\hline$c[\AA]$ & $16.8313(8)$ & $13.7795(10)$ \\
\hline$\alpha\left[{ }^{\circ}\right]$ & 90 & $108.794(6)$ \\
\hline$\beta\left[^{\circ}\right]$ & $99.442(4)$ & $94.775(6)$ \\
\hline$\gamma\left[^{\circ}\right]$ & 90 & $108.977(6)$ \\
\hline$V\left[\AA^{3}\right]$ & $3799.6(4)$ & $1575.5(2)$ \\
\hline$Z$ & 4 & 1 \\
\hline$\rho_{\text {ber. }}\left[\mathrm{g} \cdot \mathrm{cm}^{-3}\right]$ & 1.639 & 1.509 \\
\hline$\mu\left(\mathrm{Mo}-\mathrm{K}_{\alpha}\right)\left[\mathrm{mm}^{-1}\right]$ & 1.475 & 0.914 \\
\hline$F(000)$ & 1920 & 740 \\
\hline$\theta$ Bereich $\left[^{\circ}\right]$ & $1.85-24.84$ & $1.60-24.79$ \\
\hline$h k l$ Bereich & -18 bis $16, \pm 17, \pm 19$ & $\pm 11,-16$ bis $14, \pm 16$ \\
\hline Gemessene Reflexe & 22133 & 16181 \\
\hline Unabhängige Reflexe $\left[R_{\text {int }}\right]$ & $6490[0.0618]$ & $5381[0.0410]$ \\
\hline Verfeinerte Parameter & 526 & 411 \\
\hline Goodness-of-Fit & 1.013 & 1.043 \\
\hline$R 1(I>2 \sigma(I))$ & 0.0378 & 0.0530 \\
\hline wR2 (alle Daten) & 0.0883 & 0.1460 \\
\hline Restelektronendichte $\left[\mathrm{e}^{-3}\right]$ & $0.349 /-0.469$ & $1.393 /-1.023$ \\
\hline
\end{tabular}




\begin{tabular}{|c|c|c|}
\hline Verbindung & 8 & 9 \\
\hline Formel & $\mathrm{C}_{60} \mathrm{H}_{65.5} \mathrm{Cl}_{4} \mathrm{~N}_{16.5} \mathrm{O}_{22} \mathrm{Zn}_{4}$ & $\mathrm{C}_{147} \mathrm{H}_{146} \mathrm{~B}_{4} \mathrm{~N}_{24} \mathrm{O}_{3} \mathrm{Zn}_{4}$ \\
\hline$M\left[\mathrm{~g} \cdot \mathrm{mol}^{-1}\right]$ & 1773.07 & 2601.60 \\
\hline Kristallgröße [mm] & $0.31 \times 0.24 \times 0.13$ & $0.47 \times 0.34 \times 0.22$ \\
\hline Kristallsystem & Monoklin & Monoklin \\
\hline Raumgruppe & $P 2_{1} / \mathrm{n}$ & $\mathrm{C} 2 / \mathrm{c}$ \\
\hline$a[\AA]$ & $16.4263(5)$ & $30.0579(18)$ \\
\hline$b[\AA]$ & $24.2280(9)$ & $17.4577(8)$ \\
\hline$c[\AA]$ & $17.9869(5)$ & $31.610(2)$ \\
\hline$\alpha\left[^{\circ}\right]$ & 90 & 90 \\
\hline$\beta\left[^{\circ}\right]$ & $100.529(2)$ & $99.216(6)$ \\
\hline$\gamma\left[^{\circ}\right]$ & 90 & 90 \\
\hline$V\left[\AA^{3}\right]$ & $7037.8(4)$ & $16372.8(18)$ \\
\hline$Z$ & 4 & 4 \\
\hline$\rho_{\text {ber. }}\left[\mathrm{g} \cdot \mathrm{cm}^{-3}\right]$ & 1.673 & 1.055 \\
\hline$\mu\left(\mathrm{Mo}-\mathrm{K}_{\alpha}\right)\left[\mathrm{mm}^{-1}\right]$ & 1.587 & 0.631 \\
\hline$F(000)$ & 3620 & 5440 \\
\hline$\theta$ Bereich $\left[^{\circ}\right]$ & $1.43-24.89$ & $1.31-24.79$ \\
\hline$h k l$ Bereich & $\pm 19, \pm 28,-20$ bis 21 & -34 bis $35, \pm 20, \pm 37$ \\
\hline Gemessene Reflexe & 78149 & 44737 \\
\hline Unabhängige Reflexe $\left[R_{\text {int }}\right]$ & $11946[0.0726]$ & $13383[0714]$ \\
\hline Verfeinerte Parameter & 1026 & 1026 \\
\hline Goodness-of-Fit & 1.009 & 1.004 \\
\hline$R 1(I>2 \sigma(I))$ & 0.0351 & 0.0666 \\
\hline wR2 (alle Daten) & 0.0754 & 0.1798 \\
\hline Restelektronendichte $\left[\mathrm{e}^{-3}\right]$ & $0.619 /-0.486$ & $1.106 /-0.389$ \\
\hline
\end{tabular}




\begin{tabular}{|c|c|c|}
\hline Verbindung & 10 & 11 \\
\hline Formel & $\mathrm{C}_{34} \mathrm{H}_{40} \mathrm{Cl}_{2} \mathrm{~N}_{8} \mathrm{O}_{12} \mathrm{Zn}_{2}$ & $\mathrm{C}_{30} \mathrm{H}_{49} \mathrm{~N}_{11} \mathrm{O}_{10} \mathrm{Ni}_{2}$ \\
\hline$M\left[\mathrm{~g} \cdot \mathrm{mol}^{-1}\right]$ & 954.38 & 841.22 \\
\hline Kristallgröße [mm] & $0.50 \times 0.43 \times 0.34$ & $0.31 \times 0.22 \times 0.11$ \\
\hline Kristallsystem & Triklin & Orthorhombisch \\
\hline Raumgruppe & $P-1$ & Pcca \\
\hline$a[\AA]$ & $12.0745(6)$ & $19.3063(10)$ \\
\hline$b[\AA]$ & $12.3501(6)$ & $16.6032(12)$ \\
\hline$c[\AA]$ & $13.8555(7)$ & $12.5946(8)$ \\
\hline$\alpha\left[^{\circ}\right]$ & $99.760(4)$ & 90 \\
\hline$\beta\left[^{\circ}\right]$ & $95.553(4)$ & 90 \\
\hline$\gamma\left[^{\circ}\right]$ & $102.798(4)$ & 90 \\
\hline$V\left[\AA^{3}\right]$ & 1966.17(17) & $4037.2(4)$ \\
\hline$Z$ & 2 & 4 \\
\hline$\rho_{\text {ber. }}\left[\mathrm{g} \cdot \mathrm{cm}^{-3}\right]$ & 1.612 & 1.384 \\
\hline$\mu\left(\mathrm{Mo}-\mathrm{K}_{\alpha}\right)\left[\mathrm{mm}^{-1}\right]$ & 1.428 & 0.996 \\
\hline$F(000)$ & 980 & 1768 \\
\hline$\theta$ Bereich $\left[^{\circ}\right]$ & $1.72-24.69$ & $2.11-24.72$ \\
\hline$h k l$ Bereich & $\pm 14, \pm 14,-14$ bis 16 & $\pm 22, \pm 19, \pm 14$ \\
\hline Gemessene Reflexe & 37310 & 38121 \\
\hline Unabhängige Reflexe $\left[R_{\text {int }}\right]$ & $6649[0.0388]$ & $3456[0.1298]$ \\
\hline Verfeinerte Parameter & 730 & 263 \\
\hline Goodness-of-Fit & 1.034 & 1.06 \\
\hline$R 1(I>2 \sigma(I))$ & 0.0395 & 0.0815 \\
\hline wR2 (alle Daten) & 0.1038 & 0.2361 \\
\hline Restelektronendichte $\left[\mathrm{e} \AA^{-3}\right]$ & $0.694 /-0.592$ & $1.252 /-0.623$ \\
\hline
\end{tabular}




\begin{tabular}{|c|c|c|}
\hline Verbindung & 12 & 13 \\
\hline Formel & $\mathrm{C}_{29} \mathrm{H}_{50} \mathrm{Cl}_{2} \mathrm{~N}_{10} \mathrm{O}_{10} \mathrm{Ni}_{2}$ & $\mathrm{C}_{16} \mathrm{H}_{28} \mathrm{~N}_{8} \mathrm{O}_{6} \mathrm{Cu}$ \\
\hline$M\left[\mathrm{~g} \cdot \mathrm{mol}^{-1}\right]$ & 887.11 & 492.00 \\
\hline Kristallgröße [mm] & $0.21 \times 0.17 \times 0.06$ & $0.27 \times 0.22 \times 0.15$ \\
\hline Kristallsystem & Monoklin & Monoklin \\
\hline Raumgruppe & $P 2_{1} / \mathrm{n}$ & $P 2_{1} / \mathrm{c}$ \\
\hline$a[\AA]$ & $16.0770(14)$ & $7.8600(6)$ \\
\hline$b[\AA]]$ & $9.9659(9)$ & $21.629(2)$ \\
\hline$c[\AA]]$ & $24.1194(17)$ & $13.1694(12)$ \\
\hline$\alpha\left[^{\circ}\right]$ & 90 & 90 \\
\hline$\beta\left[^{\circ}\right]$ & $96.686(6)$ & $98.189(7)$ \\
\hline$\gamma\left[^{\circ}\right]$ & 90 & 90 \\
\hline$V\left[\AA^{3}\right]$ & $3838.2(6)$ & $2216.0(3)$ \\
\hline$Z$ & 4 & 4 \\
\hline$\rho_{\text {ber. }}\left[\mathrm{g} \cdot \mathrm{cm}^{-3}\right]$ & 1.535 & 1.475 \\
\hline$\mu\left(\mathrm{Mo}-\mathrm{K}_{\alpha}\right)\left[\mathrm{mm}^{-1}\right]$ & 1.186 & 1.035 \\
\hline$F(000)$ & 1856 & 1028 \\
\hline$\theta$ Bereich $\left[^{\circ}\right]$ & $1.45-24.81$ & $1.82-24.78$ \\
\hline$h k l$ Bereich & $\pm 18, \pm 11,-28$ bis 25 & -9 bis $8, \pm 25,-15$ bis 13 \\
\hline Gemessene Reflexe & 22109 & 9007 \\
\hline Unabhängige Reflexe $\left[R_{\text {int }}\right]$ & $6457[0.1168]$ & $3610[0.0477]$ \\
\hline Verfeinerte Parameter & 478 & 284 \\
\hline Goodness-of-Fit & 1.002 & 1.006 \\
\hline$R 1(I>2 \sigma(I))$ & 0.0609 & 0.0348 \\
\hline wR2 (alle Daten) & 0.1051 & 0.0906 \\
\hline Restelektronendichte $\left[\mathrm{e} \AA^{-3}\right]$ & $0.676 /-0.452$ & $0.502 /-0.386$ \\
\hline
\end{tabular}




\section{Literaturverzeichnis}

[1] Römmp Chemie Lexikon, 9. Auflage, J. Falbe, M. Regitz, Georg Thieme Verlag, 1992.

[2] Advanced Organic Chemistry, Part B, Fourth Edition, F. A. Carey, R. J. Sundberg, Kluwer Academic/Plenum Publishers, 2000.

[3] M. W. Rathke, Org. React. 1975, 22, 423-458.

[4] L. Lombardo, Org. Synth. 1987, 65, 81-85.

[5] W. Kaim, B. Schwederski, Bioanorganische Chemie, 1. Aufl., VCH, Weinheim, 1994.

[6] B. Chevrier, C. Schalk, H. D'Orchymont, J. M. Rondeau, D. Moras, C. Tarnus, Structure, 1994, 2, 283-291.

[7] B. L. Vallee, D. S Auld, Matrix Metalloproteinases Inhib., Proc. Matrix Metalloproteinase Conf. 1992, 5-19.

[8] G. Parkin, Chem. Rev. 2004, 104, 699-767.

[9] B. L. Vallee, D. S. Auld, Acc. Chem. Res. 1993, 26, 543-551.

[10] J. M. Berg, Y. Shi, Science 1996, 271, 1081-1085.

[11] B. L. Vallee, D. S. Auld, Proc. Natl. Acad. Sci. USA 1993, 90, 27152718.

[12] D. S. Auld, Methods Enzymol. 1995, 248, 228-242.

[13] C. W. Bock, A. K. Katz, J. P. Glusker, J. Am. Chem. Soc. 1995, 117, 3754-3765.

[14] R. Krämer, Coord. Chem. Rev. 1999, 182, 243-261.

[15] W. N. Lipscomb, N. Sträter, Chem. Rev. 1996, 96, 2375-2433.

[16] D. W. Christianson, W. N. Lipscomb, Acc. Chem. Res. 1989, 22, 62-69.

[17] W. L. Mock, D. J. Stanford, Biochemistry 1996, 35, 7369-7377.

[18] S. Rowsell, R. A. Paupit, A. D. Tucker, R. G. Melton, D. M. Blow, P. Brick, Structure 1996, 4, 823-836.

[19] J. E. Coleman, Curr. Opin. Chem. Biol. 1998, 2, 222-234.

[20] B. L. Vallee, K. H. Falchuk, Physiol. Rev. 1993, 73, 79-118.

[21] Y. H. Dong, L. H. Zhang, J. Microbiol. 2005, 43, 101-109.

[22] Y. H. Dong, J. L. Xu, X. Z. Li, L. H. Zhang, Proc. Natl. Acad. Sci. USA 2000, 97, 3526-3531. 
[23] L. Molina, F. Rezzonico, G. Defago, B. Duffy, J. Bacteriol. 2005, 187, 3206-3213.

[24] M. H. Kim, W. C. Choi, H. O. Kang, J. S. Lee, B. S. Kang, K. J. Kim, Z. S. Derewenda, T. K. Oh, C. H. Lee, J. K. Lee, Proc. Natl. Acad. Sci. USA 2005, 102, 17606-17611.

[25] S. J. Lee, S. Y. Park, J. J. Lee, D. Y. Yum, B. T. Koo, J. K. Lee, Appl. Environ. Microbiol. 2002, 68, 3919-3924.

[26] I. L. de la Sierra-Gallay, O. Pellegrini, C. Condon, Nature 2005, 433, 657-661.

[27] D. E. Wilcox, Chem. Rev. 1996, 96, 2435- 2458.

[28] J. Weston, Chem. Rev. 2005, 105, 2151-2174.

[29] C. C. De Paola, B. Bennett, R. C. Holz, D. Ringen, G. A. Petsko, Biochemistry 1999, 38, 9048-9053.

[30] R. Gilboa, H. M. Greenblatt, M. Perach, A. Spungin-Bialik, U. Lessel, G. Wohlfahrt, D. Schomburg, S. Blumberg, G. Shoham, Acta Crystallogr. 2000, D56, 551-558.

[31] W. T. Lowther, B. W. Matthews, Chem. Rev. 2002, 102, 4581-4607.

[32] A. Turzynski, R. Mentlein, Eur. J. Biochem. 1990, 190, 509-515.

[33] E. L Smith, D. J. Spackman, J. Biol. Chem. 1955, 212, 271-299.

[34] H. Kim, W. N. Lipscomb, Proc. Nat. Acad. Sci. USA 1993, 90, 5006-5010.

[35] S. K. Burley, P. R. David, A. Taylor, W. N. Lipscomb, Proc. Natl. Acad. Sci. USA 1990, 87, 6878-6882.

[36] S. R. Himmelhoch, Arch. Biochem. Biophys. 1969, 134, 597-602.

[37] G. A. Thompson, F. H. Carpenter, J. Biol. Chem. 1976, 251, 16181624.

[38] W. Y. Lin, S. H. Lin, H. E. Van Wart, Biochemistry 1988, 27, 5062-5068.

[39] V. K. Antonov, L. M. Ginodman, L. D. Rumsh, Y. V. Kapitannikov, T. N. Barshevskaya, L. P. Yavashev, A. G. Gurova, L. I. Volkova, Eur. J. Biochem. 1981, 117, 195-200.

[40] N. Sträter, W. N. Lipscomb, T. Klabunde, B. Krebs, Angew. Chem. 1996, 108, 2158-2191.

[41] P. J. Steel, Coord. Chem. Rev. 1990, 106, 247-265. 
[42] A. P. Sadimenko, S. S. Basson, Coord. Chem. Rev. 1996, 147, 247297

[43] N. Masciocchi, M. Moret, P. Cairati, A. Sironi, G. A. Ardizzoia, G. La Monica, J. Am. Chem. Soc. 1994, 116, 7668-7676.

[44] G. La Monica, G. A. Ardizzoia, Prog. Inorg. Chem. 1997, 46, 151-238.

[45] F. Meyer, I. Hyla-Kryspin, E. Kaifer, P. Kircher, Eur. J. Inorg. Chem. 2000, 771-781.

[46] F. Meyer, K. Heinze, B. Nuber, L. Zsolnai, J. Chem. Soc., Dalton Trans. 1998, 207-213.

[47] J. C. Bayon, P. Esteban, G. Net, P. G. Rasmussen, K. N. Baker, C. W. Hahn, M. M. Gumz, Inorg. Chem. 1991, 30, 2572-2574.

[48] M. Nakahanada, K. Ino, S. Kaizaki, J. Chem. Soc., Dalton Trans. 1993, 3681-3684.

[49] C. Acerete, J. M. Bueno, L. Campayo, P. Navarro, M. I. RodriguezFranco, A. Samat, Tetrahedron 1994, 50, 4765-4774.

[50] T. G. Schenck, J. M. Downes, C. R. C. Milne, P. B. MacKenzie, H. Boucher, J. Whelan, B. Bosnich, Inorg. Chem. 1985, 24, 2334-2337.

[51] F. Meyer, S. Beyreuther, K. Heinze, L. Zsolnai, Chem. Ber. / Recueil 1997, 130, 605-613.

[52] F. Meyer, P. Kircher, H. Pritzkow, Chem. Commun. 2003, 774-775.

[53] M. Konrad, S. Wuthe, F. Meyer, E. Kaifer, Eur. J. Inorg. Chem. 2001, 2233-2240.

[54] F. Meyer, M. Konrad, E. Kaifer, Eur. J. Inorg. Chem. 1999, 1851-1855.

[55] J. C. Röder, F. Meyer, I. Hyla-Kryspin, R. F. Winter, E. Kaifer, Chem. Eur. J. 2003, 9, 2636-2648.

[56] J. C. Röder, F. Meyer, R. F. Winter, E. Kaifer, J. Organomet. Chem. 2002, 641, 113-120.

[57] L. Siegfred, T. Kaden, F. Meyer, P. Kircher, H. Pritzkow, J. Chem. Soc., Dalton Trans. 2001, 2310-2315.

[58] F. Meyer, S. Demeshko, G. Leibeling, B. Kersting, E. Kaifer, H. Pritzkow, Chem. Eur. J. 2005, 11, 1518-1526.

[59] S. Demeshko, G. Leibeling, W. Maringgele, F. Meyer, C. Mennerich, H. H. Klauss, H. Pritzkow, Inorg. Chem. 2005, 44, 519-528. 
[60] J. Ackermann, F. Meyer, E. Kaifer, H. Pritzkow, Chem. Eur. J. 2002, 8, 247-258.

[61] S. Buchler, F. Meyer, E. Kaifer, H. Pritzkow, Inorg. Chim. Acta 2002, 337, 371-386.

[62] S. Buchler, Dissertation, Universität Heidelberg 2002.

[63] J. Ackermann, Dissertation, Universität Göttingen 2003.

[64] F. Meyer, P. Rutsch, Chem. Commun. 1998, 1037-1038.

[65] B. Bauer-Siebenlist, Dissertation, Universität Göttingen 2004.

[66] L. H. Gade, Koordinationschemie, Wiley-VCH, Weinheim, 1998.

[67] J. S. Bradshaw, R. B. Nielsen, P. Tse, G. Arena, B. E. Wilson, N. K. Dalley, J. D. Lamb, J. C. Christensen, R. M. Izatt, J. Heterocyclic Chem. 1986, 23, 361-368.

[68] J. C. Röder, F. Meyer, H. Pritzkow, Organomet. 2001, 20, 811-817.

[69] A. Sami, A. S. Shawali, S. S. Biechler, J. Am. Chem. Soc. 1967, 89, 3020-3026.

[70] J. Krapcho, C. F. Turk, J. Med. Chem. 1966, 9, 191-195.

[71] L. E. Brady, M. Freifelder, G. R. Stone, J. Org. Chem. 1961, 26, 47574758.

[72] H. J. Hoorn, P. de Joode, W. L. Driessen, J. Reedijk, Recl. Trav. Chim. Pays-Bas 1996, 115, 191-197.

[73] G. Gelbard, P. Rumpf, Bull. Soc. Chim. Fr. 1969, 4, 1161-1170.

[74] H. Nagao, N. Komeda, M. Mukaida, M. Suzuki, K. Tanaka Inorg. Chem. 1996, 35, 6809-6815.

[75] M. C. Rodríguez, I. Morgenstern-Badarau, M. Cesario, J. Guilhem, B. Keita, L. Nadjo, Inorg. Chem. 1996, 35, 7804-7810.

[76] K. J. Oberhausen, J. F. Richardson, R. M. Buchanan, Polyhedron, 1989, 659-668.

[77] F. Meyer, U. Ruschewitz, P. Schober, B. Antelmann, L. Zsolnai, J. Chem. Soc., Dalton Trans. 1998, 1181-1186.

[78] C. Acerete, Tetrahedron 1994, 50, 4765-4774.

[79] J. Ackermann, F. Meyer, H. Pritzkow, Inorg. Chim. Acta, 2004, 357, 3703-3711.

[80] T. Sheng, S. Dechert, I. Hyla-Kryspin, R. F. Winter, F. Meyer, Inorg. 
Chem. 2005, 44, 3863-3874.

[81] S. V. Kryatov, E. V. Rybak-Akimova, F. Meyer, H. Pritzkow, Eur. J. Inorg. Chem. 2003, 1581-1590.

[82] A. W. Addison, T. Negeswara Rao, J. Reedijk, J. van Rijn, G. C. Verschoor, J. Chem. Soc., Dalton Trans. 1984, 1349-1356.

[83] C. Sens, I. Romero, A. Llobet, T. Parella, J. Benet-Bucholz, J. Am. Chem. Soc. 2004, 126, 7798-7799.

[84] A. M. Barrios, S. J. Lippard, Inorg. Chem. 2001, 40, 1060-1064.

[85] C. Incarvito, A. Rheingold, C. Jin Qin, A. L. Gavrilova, B. Bosnich, Inorg. Chem. 2001, 40, 1386-1390.

[86] F. Meyer, E. Kaifer, P. Kircher, K. Heinze, H. Pritzkow, Chem. Eur. J. 1999, 5, 1617-1630.

[87] K. Nakamoto, Infrared and Raman Spectra of Inorganic and Coordination Compounds, Part B, Wiley-Interscience, 1997.

[88] G. B. Deacon, R. J. Phillips, Coord. Chem. Rev. 1980, 33, 227-251.

[89] B. Bauer-Siebenlist, F. Meyer, E. Farkas, D. Vidovic, J. A. CuestaSeijo, R. Herbst-Irmer, H. Pritzkow, Inorg. Chem. 2004, 43, 4189-4202.

[90] J. T. Groves, L. A. Baron, J. Am. Chem. Soc. 1989, 111, 5442-5448.

[91] J. Chin, V. J. Juvian, Chem. Commun. 1989, 839-841.

[92] E. Kimura, T. Shiota, T. Koike, M. Shiro, M. Kodama, J. Am. Chem. Soc. 1990, 112, 5805-5811.

[93] T. Koike, S. Kajitani, I. Nakamura, E. Kimura, M. Shiro, J. Am. Chem. Soc. $1995,117,1210-1219$.

[94] E. Kimura, I. Nakamura, T. Koike, M. Shionoya, Y. Kodama, T. Ikeda, M. Shiro, J. Am. Chem. Soc. 1994, 116, 4754-4771.

[95] R. C. di Targiani, S. C. Chang, M. H. Salter Jr., R. D. Hancock, D. P. Goldberg, Inorg. Chem. 2003, 42, 5825-5836.

[96] J. E. Coleman, Annu. Rev. Biophys. Biomol. Struct. 1992, 21, 441-483.

[97] E. E. Kim, H. W. Wyckoff, J. Mol. Biol. 1991, 218, 449-464.

[98] S. H. Gellman, R. Petter, R. J. Breslow, J. Am. Chem. Soc. 1986, 108, 2388-2394.

[99] D. Herschlag, W. P. Jenks, J. Am. Chem. Soc. 1987, 109, 4665-4674.

[100] J. Xia, Y. B. Shi, Y. Zhang, Q. Miao, W. X. Tang, Inorg Chem. 2003, 42, 
70-77.

[101] I. Bertini, C. Luchinat, M. Rosi, A. Sgamellotti, F. Tarantelli, Inorg. Chem. 1990, 29, 1460-1463.

[102] C. Wendelsdorf, S. Warzeska, E. Kovari, R. Krämer, J. Chem. Soc., Dalton Trans. 1996, 3087-3092.

[103] B. Bauer-Siebenlist, S. Dechert, F. Meyer, Chem. Eur. J. 2005, 11, $5342-5352$.

[104] B. Bauer-Siebenlist, F. Meyer, E. Farkas, D. Vidovic, S. Dechert, Chem. Eur. J. 2005, 11, 4349-4360.

[105] S. Uhlenbrock, B. Krebs, Angew. Chem. Int. Ed. Engl. 1992, 31, 16471648.

[106] J. Chin, X. Zou, J. Am. Chem. Soc. 1984, 106, 3687-3688.

[107] J. Suh, D. Koh, J. Org. Chem. 1987, 52, 3446-3448.

[108] S. A. Li, D. X. Yang, D. F. Li, J. Huang, W. X. Tang, New J. Chem. 2002, 26, 1831-1837.

[109] H. Bisswanger, Enzymkinetik: Theorie und Methoden, VCH, Weinheim; New York, Basel, 1994.

[110] H. Sakiyama, R. Mochizuki, A. Sugawara, M. Sakamoto, Y. Nishida, M. Yamasaki, J. Chem. Soc., Dalton Trans. 1999, 997-1000.

[111] H. Sakiyama, Y. Iragashi, Y. Nakayama, J. Hossain, K. Unoura, Y. Nishida, Inorg. Chim. Acta 2003, 351, 256-260.

[112] H. Sakiyama, K. Ono, T. Suzuki, K. Tone, T. Ueno, Y. Nishida, Inorganic Chem. Commun., 2005, 8, 372-374.

[113] B. Bauer-Siebenlist, F. Meyer, D. Vidovic, H. Pritzkow, Z. Anorg. Allg. Chem. 2003, 629, 2152-2156.

[114] M. Döring, M Ciesielski, O. Walter, H. Görls, Eur. J. Inorg. Chem. 2002, 1615-1621.

[115] M. Fondo, A. M. García-Deibe, M. R. Bermejo, J. Sanmartín, A. L. Llamas-Saiz, J. Chem. Soc., Dalton Trans. 2002, 4746-4750.

[116] H. Adams, D. Bradshaw, D. E. Fenton, J. Chem. Soc., Dalton Trans. 2001, 3407-3409.

[117] R. Alsfasser, M. Ruf, S. Trofimenko, H. Vahrenkamp, Chem. Ber. 1993, 126, 703-710. 
[118] H. Brombacher, H. Vahrenkamp, Inorg. Chem. 2004, 43, 6042-6049.

[119] A. R. Olson, R. J. Miller, J. Am. Chem. Soc. 1938, 60, 2687-2692.

[120] A. R. Olson, J. L. Hyde, J. Am. Chem. Soc. 1941, 63, 2459-2461.

[121] J. A. Moore, J. M. Schwab, Tetrahedron Lett. 1991, 32, 2331-2334.

[122] W. Tsuzuki, T. Sasaki, T. J. Suzuki, J. Chem. Soc. Perkin Trans. 1991, 2, 1851-1854.

[123] F. He, S. Li, H. Garreau, M. Vert, R. Zhuo, Polymer 2005, 46, $12682-$ 12688.

[124] Y. Takashima, Y. Kawaguchi, S. Nakagawa, A. Harada, Chemistry Letters 2003, 32, 1122-1123.

[125] P. Viazzo, V. Alphand, R. Furstoss, Tetrahedron Lett. 1996, 37, 45194522.

[126] N. J. Kerrigan, T. Upadhyay, D. J. Procter, Tetrahedron Lett. 2004, 45, 9087-9090.

[127] J. Zhao, J. F. Hartwig, Organometallics 2005, 24, 2441-2446.

[128] D. E. Agostini, J. B. Lando, J. R. Shelton, J. Polym. Sci., Part A-1 1971, 9, 2775-2787.

[129] G. A. R. Nobes, R. J. Kazlauskas, R. H. Marchessault, Macromolecules 1996, 29, 4829-4833.

[130] Y. H. Dong, L. H. Zhang, J. Microbiol. 2005, 43, 101-109.

[131] Y. H. Dong, J. L. Xu, X. Z. Li, L. H. Zhang, Proc. Natl. Acad. Sci. USA 2000, 97, 3526-3531.

[132] M. Konrad, F. Meyer, A. Jacobi, P. Kircher, P. Rutsch, L. Zsolnai, Inorg. Chem. 1999, 38, 4559-4566.

[133] I. Sanyal, P. Ghosh, K. D. Karlin, Inorg. Chem. 1995, 34, 3050-3056.

[134] Z. Tyeklar, R. R. Jacobson, N. Wei, N. N. Murthy, J. Zubieta, K. D. Karlin J. Am. Chem. Soc. 1993, 115, 2677-2689.

[135] G. J. Anthony, A. Koolhaas, W. L. Driessen, J. Reedijk, H. Kooijman, A. L. Spek, J. Chem. Soc., Chem. Commun. 1995, 517-518.

[136] G. M. Sheldrick, SHELXS-97, Program for Crystal Structure Solution, Universität Göttingen, 1997.

[137] G. M. Sheldrick, SHELXL-97, Program for Crystal Structure Refinement, Universität Göttingen, 1997. 


\section{Formelverzeichnis}<smiles>Cn1ccnc1CN(Cc1cc(CN(Cc2nccn2C)Cc2nccn2C)[nH]n1)Cc1nccn1C</smiles>

$\mathrm{L}^{1}$<smiles>Cn1ccnc1CN(CCc1ccccn1)Cc1cc(CN(CCc2ccccn2)Cc2nccn2C)[nH]n1</smiles>

$\mathrm{L}^{3}$<smiles>Cc1cccc(CN(Cc2cc(CN(Cc3cccc(C)n3)Cc3cccc(C)n3)[nH]n2)Cc2cccc(C)n2)n1</smiles>

$\mathrm{L}^{5}$<smiles>CCNCCN(CCNCC)Cc1cc(CN(CCNCC)CCNCC)[nH]n1</smiles>

$\mathrm{L}^{7}$<smiles>c1ccc(CCN(Cc2ccccn2)Cc2cc(CN(CCc3ccccn3)Cc3ccccn3)[nH]n2)nc1</smiles>

$L^{9}$<smiles>CNCCN(C)Cc1cc(CN(C)CCNC)[nH]n1</smiles><smiles>CCNCCN(Cc1ccccn1)Cc1cc(CN(CCNCC)Cc2ccccn2)[nH]n1</smiles>

$\mathbf{L}^{2}$<smiles>CCNCCN(Cc1cc(CN(CCNCC)Cc2nccn2C)[nH]n1)Cc1nccn1C</smiles>

$L^{4}$<smiles>c1ccc(CN(Cc2ccccn2)Cc2cc(CN(Cc3ccccn3)Cc3ccccn3)[nH]n2)nc1</smiles>

$L^{6}$<smiles>c1ccc(CCN(CCc2ccccn2)Cc2cc(CN(CCc3ccccn3)CCc3ccccn3)[nH]n2)nc1</smiles><smiles>CNCCCN(CCCN(C)C)Cc1cc(CN(CCCNC)CCCN(C)C)[nH]n1</smiles>

$\mathrm{L}^{10}$<smiles>CNCCCN(C)Cc1cc(CN(C)CCCN(C)C)[nH]n1</smiles>

$\mathrm{L}^{12}$ 


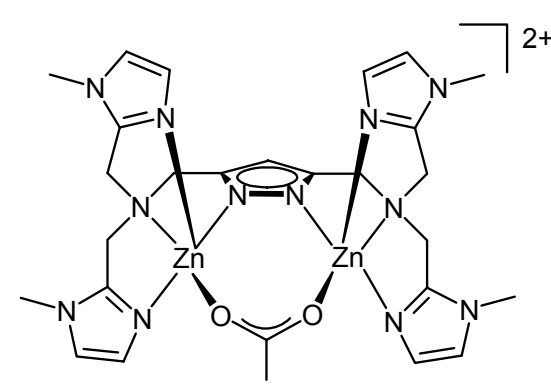

1a und 1b
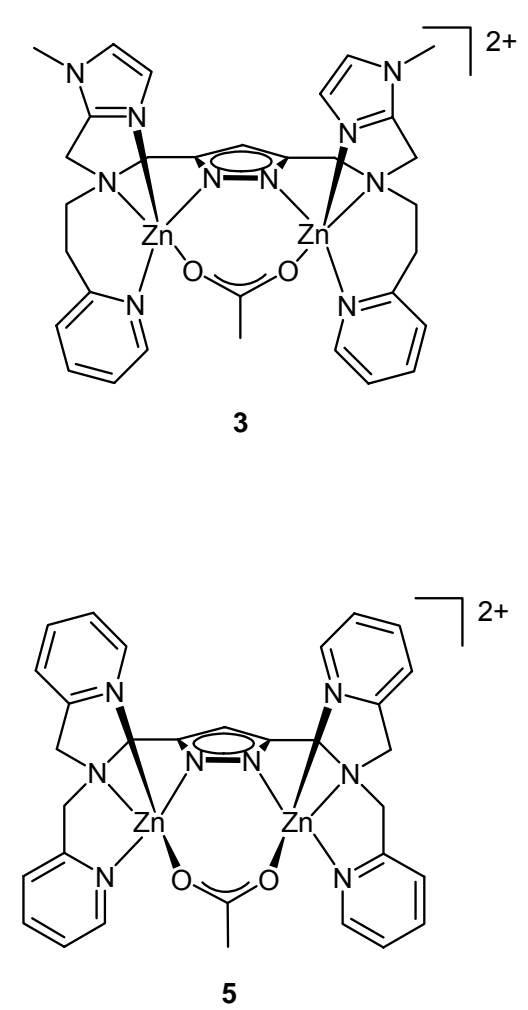
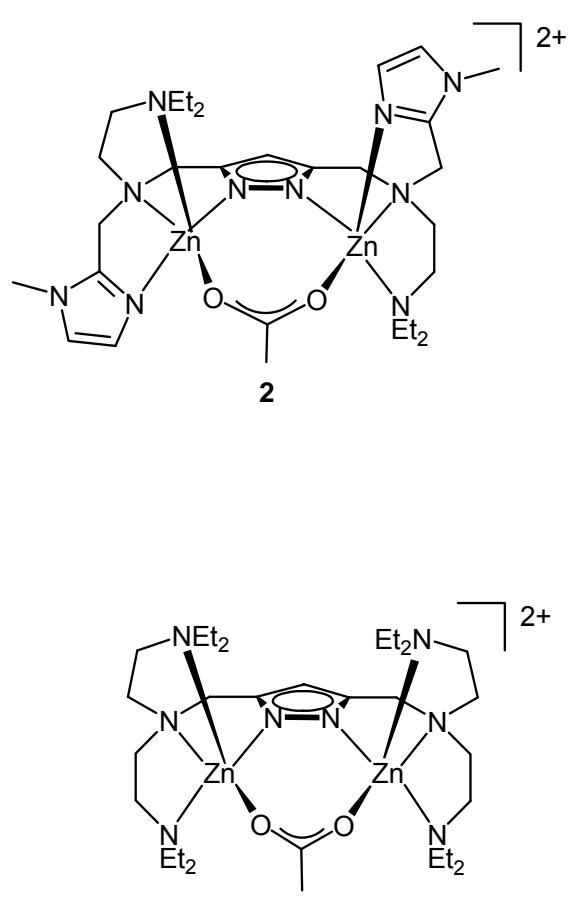

4

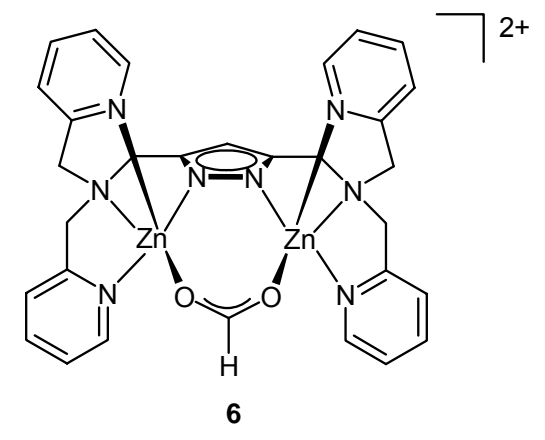

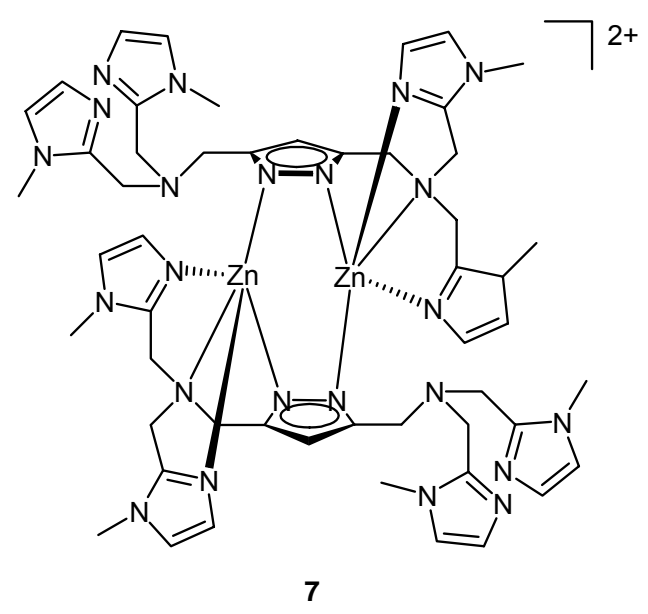



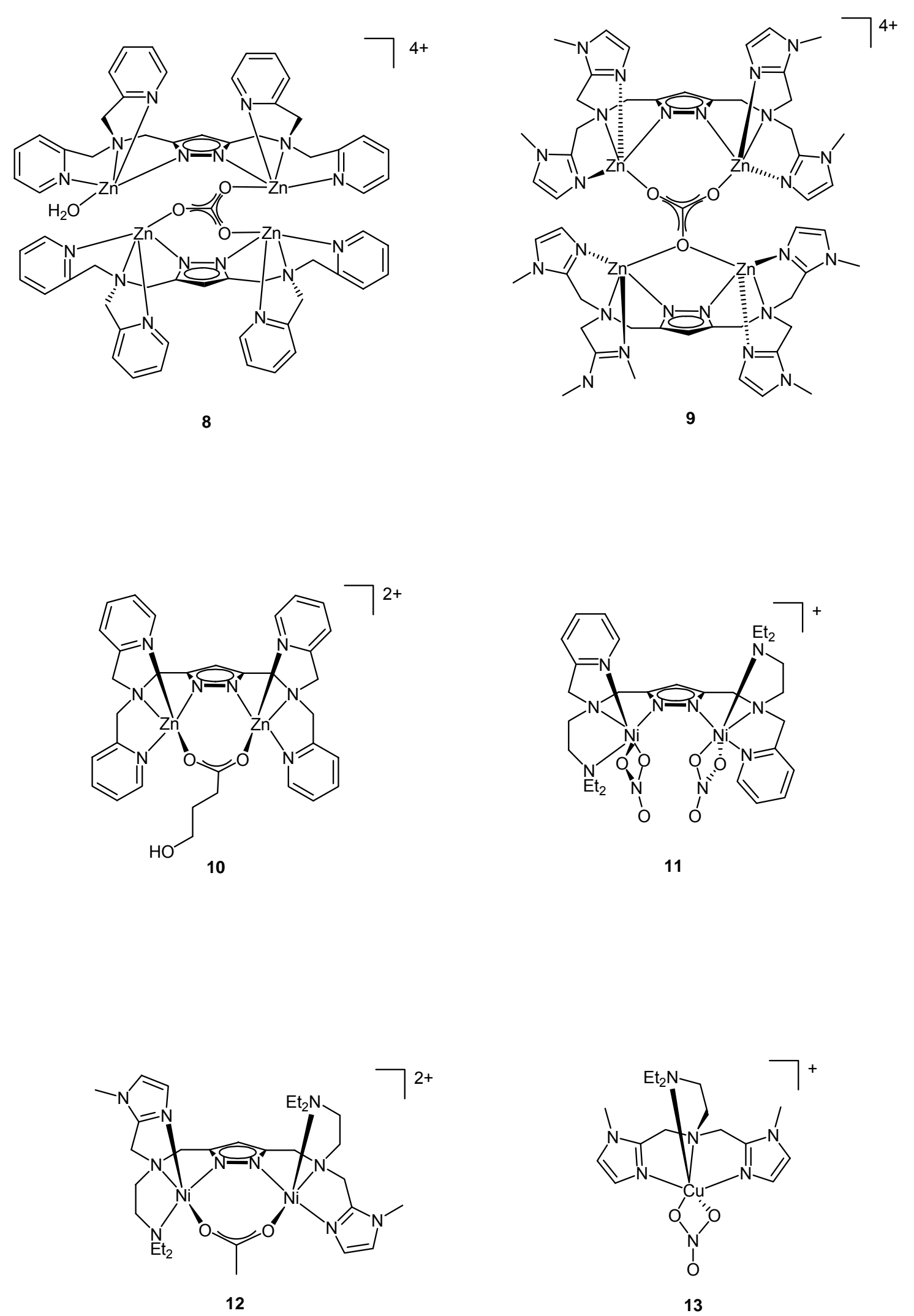

13 


\section{DANK}

Zuerst möchte ich Prof. Meyer für die Möglichkeit danken, diese Arbeit in einer hervorragend ausgestatteten Arbeitsumgebung zu erstellen. Danke auch für die ständige Diskussionsbereitschaft.

Ein Sonderdank geht an Dr. Walter Maringgele, Jörg Teichgräber und Dr. Nie Feng Mei, die eine hervorragende Arbeitsatmosphäre im Labor 208 ermöglicht haben. Es gab zahlreiche Witze, die wir miteinander gemacht haben. Jungs, es hat Spaß gemacht!!!!

Ich danke allen anderen Mitgliedern des AK Meyer für das gute und freundschaftliche Arbeitsklima. Insbesondere möchte ich Stamatia Katsiaouni, Dr. Gilles Noël, Dr. Julia Klingele, Dr. Marco Klingele und Holger Müller danken. Dr Sebastian Dechert danke ich für seine unerschöpfliche Hilfsbereitschaft bei meinen „technischen“ Problemen und für die unbezahlbare kristallographische Arbeit mit meinen „Nanokristallen“.

Der NMR-Abteilung, dem analytischen Labor sowie der Abteilung für Massenspektroskopie möchte ich für ihre Hilfsbereitschaft danken. Insbesondere möchte ich Herrn Zolke, den ich in letzter Zeit immer belastet habe, danken.

Ich möchte auch allen Assistenten des Praktikums für Physiker und Geowissenschaftler danken, insbesondere Kathrin Meindl. Der Leiterin des Praktikums, Dr. Claudia Stückl, möchte ich für ihre Hilfsbereitschaft und ihren unerschöpflichen Optimismus danken.

Frau Unger und Dr. Claudia Stückl danke ich für die Hilfe mit den administrativen Themen.

Den Praktikanten Tina, Esteban, Norman und Ole danke ich für die gute Zusammenarbeit während der Praktikumszeit.

Dr. Andrea Küsel und Dr. Björn Dietrich danke ich für die gute Zusammenarbeit in der Organischen Chemie. Björn Dietrich danke ich auch für die schönen Fußballabende und für die interessanten Gespräche über die deutsche Kultur und Politik. 
Dr. Walter Maringgele, Dr. Gilles Noël, Kathrin Meindl, Holger Müller, Stamatia Katsiaouni und Prof. Meyer danke ich für das schnelle Korrekturlesen dieser Arbeit. Es tut mir leid, dass "meine Deutsch nicht so gut ist" :-).

Holger Müller möchte ich auch danken, weil er verstanden hat, dass die spanischen Sportler echt klasse sind (Auf Spanien!! Auf „matador“ Alonso!!). Stamatia Katsiaouni für ihr dickes Fell gegenüber meinen „frechen“ Bemerkungen. Den Doktoren Klingele danke ich für vieles und für die schönen Abende in Göttingen und in Freiburg.

Den Jungs des AK Tietze: Dr. Gordon Brasche, Dr. Kersten Gericke und Dr. Christian Stadler danke ich für ihre Freundschaft. Irgendwann wird Spanien Fußballweltmeister und irgendwann wird Werder Bremen Champions League Sieger. Demnächst gibt es auch in Spanien eine grüne Seele.

Kathrin Meindl und den Mädels des AK Stalke (Kathrin und Ulli) danke ich für die sehr witzigen Gespräche über alles außer Chemie. Sie haben die Grundstufe für „spanische Philosophie des Lebens“ bestanden.

Den Jungs des MTV Geismar danke ich für die Ablenkung, die Basketball gebracht hat. Ich werde die „katastrophalen“ Trainings und Spiele nie vergessen.

Karla, Hannah, Halil, Halvard, Christine, Jenny und Georg danke ich für die schönen Tage in Göttingen.

También quiero agradecer a la comunidad científica española de Göttingen los buenos tiempos que pasé con ellos. Muchas gracias a Dra. Nuria García, Dr. Victor Pedregal, Dr. Álvaro Gil, Dr. Roberto Roda, Dr. Jose Cuesta, Dr. Santi Martín, Dra. Paula Vázquez, Dr. Greco Hernández y José García. Paula, José y Greco, las ex-colonias también son España.

A Alfredo, Aarón, Alberto, Alberte, Concha, Raquel y Dácil muchísimas gracias por ese año divertidísimo. $\mathrm{Y}$ a alguno de ellos también por los siguientes y por los que vendrán.

A toda esa xente de Galicia, tanto de Landrove e alrededores, como da RUMC, como da Carreira agradecervos os ánimos neses momentos duros que pasei en Alemania. Serían moitos os nomes e pouco o espacio, pero ben sabedes quenes sodes. Gracias de todo corazón por non ter fallado nunca.

I'm very thankful to all the people that have helped to make all of this possible. 
E por último, pero no lugar máis importante, moitas gracias á miña familia, en especial a mamá e a papá, por todo e por animarme nos peores momentos. Perdoade por térvolo feito pasar tan mal. 


\section{Publikationen}

A. Küsel, J. Zhang, M. Alvariño Gil, A.C. Stückl, W. Meyer-Klaucke, F. Meyer,

U. Diederichsen, Eur. J. Inorg. Chem. 2005, 4317-4324.

„Metal Binding Within a Peptide-Based Nucleobase Stack with Tuneable

Double-Strand Topology“

\section{Poster}

7th European Biological Inorganic Chemistry Conference EUROBIC 7, Garmisch-Partenkirchen 2004

"Dizinc complexes of multidentate pyrazolate ligands as promotors of carboxyester hydrolysis" 


\section{LEBENSLAUF}

NAME

GEBOREN

STAATSANGEHÖRIGKEIT

FAMILIENSTAND

SHULAUSBILDUNG

September 1983 -

Juni 1987

September 1987-

Juni 1993

September 1993 -

Juni 1997

HOCHSHULSTUDIUM

Oktober 1997-

Juli 2002

Februar 2002 -

Juli 2002

\section{PROMOTION}

November 2002 -

Juni 2006

STIPENDIEN

Oktober 1997 -

Juli 2002
C. P. Unitario de Landrove

Miguel Alvariño Gil

Am 27. April 1979 in Viveiro (Spanien)

spanisch

ledig

C.P. „A. Noriega Varela” de Viveiro

I.E.S. „Irmáns Vilar Ponte” de Viveiro

Licenciatura en Química (Diplom-Chem.), an der Universidade de Santiago de Compostela (Spanien)

Proxecto fin de Carreira (Diplomarbeit) bei Prof.

J. Sordo Rodríguez an der Universidade de Santiago de Compostela

„Mercaptocarboxilatos metálicos: síntese e estudio estructural"

Doktorarbeit bei Prof. Dr. Franc Meyer an der Universität Göttingen

Stipendiat der „Ministerio de Educación y Ciencia" (Bildungsministerium) (Spanien) 